\title{
Characterization of Low Thermal Conductivity $P-125$ PAN-Based Carbon Fibers
}

Prepared by

H. A. KATZMAN, P. M. ADAMS, T. D. LE, and C. S. HEMMINGER Mechanics and Materials Technology Center

Technology Operations

15 March 1992

Prepared for

National Aeronautics and Space Administration

Marshall Space Flight Center

Huntsville, AL 35812

Engineering and Technology Group

El Segundo, California 


\section{TECHNOLOGY OPERATIONS}

The Aerospace Corporation functions as an "architect-engineer" for national security programs, specializing in advanced military space systems. The Corporation's Technology Operations supports the effective and timely development and operation of national security systems through scientific research and the application of advanced technology. Vital to the success of the Corporation is the technical staff's wide-ranging expertise and its ability to stay abreast of new technological developments and program support issues associated with rapidly evolving space systems. Contributing capabilities are provided by these individual Technology Centers:

Electronics Technology Center: Microelectronics, solid-state device physics, VLSI reliability, compound semiconductors, radiation hardening, data storage technologies, infrared detector devices and testing; electro-optics, quantum electronics, solid-state lasers, optical propagation and communications; $\mathrm{cw}$ and pulsed chemical laser development, optical resonators, beam control, atmospheric propagation, and laser effects and countermeasures; atomic frequency standards, applied laser spectroscopy, laser chemistry, laser optoelectronics, phase conjugation and coherent imaging, solar cell physics, battery electrochemistry, battery testing and evaluation.

Mechanics and Materials Technology Center: Evaluation and characterization of new materials: metals, alloys, ceramics, polymers and their composites, and new forms of carbon; development and analysis of thin films and deposition techniques; nondestructive evaluation, component failure analysis and reliability; fracture mechanics and stress corrosion; development and evaluation of hardened components; analysis and evaluation of materials at cryogenic and elevated temperatures; launch vehicle and reentry fluid mechanics, heat transfer and flight dynamics; chemical and electric propulsion; spacecraft structural mechanics, spacecraft survivability and vulnerability assessment; contamination, thermal and structural control; high temperature thermomechanics, gas kinetics and radiation; lubrication and surface phenomena.

Space and Environment Technology Center: Magnetospheric, auroral and cosmic ray physics, wave-particle interactions, magnetospheric plasma waves; atmospheric and jonospheric physics, density and composition of the upper atmosphere, remote sensing using atmospheric radiation; solar physics, infrared astronomy, infrared signature analysis; effects of solar activity, magnetic storms and nuclear explosions on the earth's atmosphere, ionosphere and magnetosphere; effects of electromagnetic and particulate radiations on space systems; space instrumentation; propellant chemistry, chemical dynamics, environmental chemistry, trace detection; atmospheric chemical reactions, atmospheric optics, light scattering, state-specific chemical reactions and radiative signatures of missile plumes, and sensor out-of-field-of-view rejection. 
Aerospace Report No.

ATR-91(6819)-1

\title{
CHARACTERIZATION OF LOW THERMAL CONDUCTIVITY PAN-BASED CARBON FIBERS
}

\author{
Prepared by \\ H. A. Katzman, P. M. Adams, T. D. Le, and C. S. Hemminger \\ Mechanics and Materials Technology Center \\ Technology Operations
}

15 March 1992

Engineering and Technology Group
THE AEROSPACE CORPORATION
El Segundo, CA $90245-4691$

Prepared for

National Aeronautics and Space Administration

Marshall Space Flight Center

Huntsville, AL 35812

PUBLIC RELEASE IS AUTHORIZED 
Aerospace Report No.

ATR-91(6819)-1

\section{CHARACTERIZATION OF LOW THERMAL CONDUCTIVITY PAN-BASED CARBON FIBERS}

Prepared
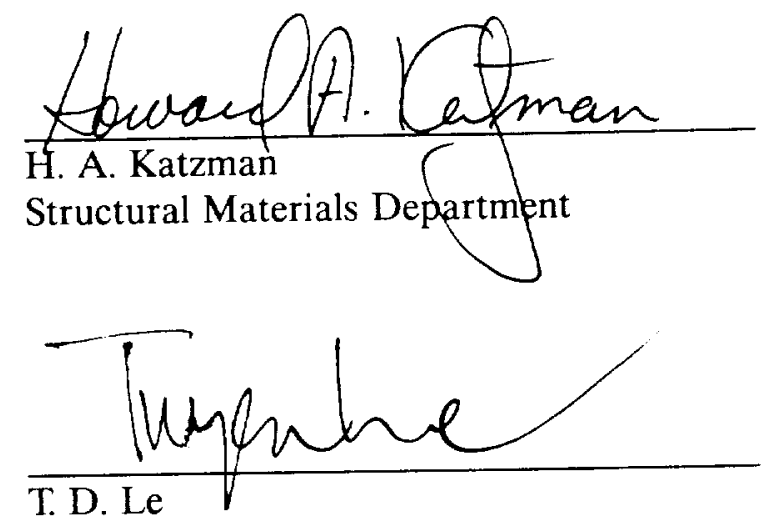

Structural Materials Department

Approved

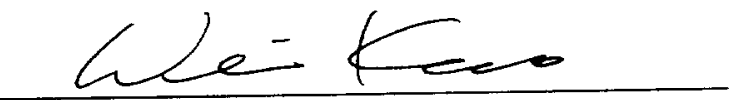

W. H. Kao, Director

Structural Materials Department

Mechanics and Materials Technology Center

S) S Suth

D. G. Sutton, Director

Materials Evaluation and Survivability

Department

Mechanics and Materials Technology Center

\section{Malasus}

P. M. Adams

Materials Evaluation and Survivability

Department

\section{Cants Stemencien}

C. S. Hemminger

Materials Evaluation and Survivability

Department
R. W. Fillers, Principal Director Mechanics and Materials Technology Center Technology Operations 


\section{ABSTRACT}

The microstructure and surface chemistry of eight low thermal conductivity (LTC) PAN-based carbon fibers were determined and compared with PAN-based fibers heat treated to higher temperatures.

Based on wide-angle X-ray diffraction, the LTC PAN fibers all appear to have a similar turbostratic structure with large $002 \mathrm{~d}$-spacings, small crystallite sizes, and moderate preferred orientation. All the LTC fibers are slightly less ordered than T300 fibers, which are much less ordered than T50 fibers. This observation is consistent with the relative heat-treatment temperatures (HTTs) of the fibers.

Limited small-angle X-ray scattering (SAXS) results indicate that, with the exception of LTC fibers made by BASF, the LTC fibers do not have well developed pores. This suggests that they have not been subjected to a high enough HTT to drive off all of their volatile constituents (mainly nitrogen). The BASF fibers produce SAXS patterns intermediate between T300 and the other LTC fibers.

Transmission electron microscopy shows that the texture of the two LTC PAN-based fibers studied (Amoco T350/23X and /25X) consists of multiple sets of parallel, wavy, bent layers that interweave with each other forming a complex three-dimensional network oriented randomly around the fiber axis. In the cases of higher HTT fibers (T300 and T50), the texture consists of two distinct regions with the core's texture being similar to that of the LTC fibers, whereas the outer region is better ordered and oriented. No differences between the textures of the outer and inner regions of the LTC fibers were observed. Crystallite size and the extent of graphitization, the latter based on lattice d-spacing, were both observed to increase with increased HTT. These results are consistent with those from X-ray diffraction.

X-ray photoelectron spectroscopy (XPS) analysis finds correlations between the HTT and the surface composition and chemistry of the carbon fiber samples. The concentration of surface oxygen and nitrogen for PAN-based fibers decreases with increasing HTT, which is consistent with increased volatilization of nitrogen and greater extent of graphitization. The XPS data did not have adequate resolution to distinguish differences in the extent of graphitization of the LTC fibers. Comparative analyses were also hindered by significant variability in surface contamination levels, particularly of silica, and by variability in surface composition between different samples taken from the same batch of fibers. 


\section{ACKNOWLEDGMENTS}

The authors would like to thank NASA Marshall Space Flight Center (Ms. Ann Puckett and Dr. R. G. Clinton) and USAF Ballistic Missile Office (Lt. R. Einhorn) for funding this program. Ms. Gloria To performed the $\mathrm{pH}$ and fiber sizing level measurements. Mr. Joe Uht was responsible for the scanning electron microscopy. Drs. W. T. Barry and J. J. Mallon provided many helpful suggestions. Dr. G. S. Rellick reviewed the manuscript, and Ms. J. Naiditch and Mr. J. Shaffer edited the manuscript.

Funding for this effort was processed through SSD contract No. F04701-88-C-0089 under an Interagency Agreement from NASA. 
-

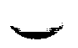




\section{CONTENTS}

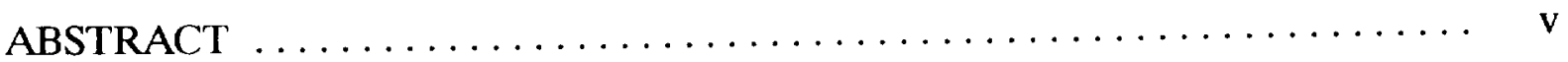

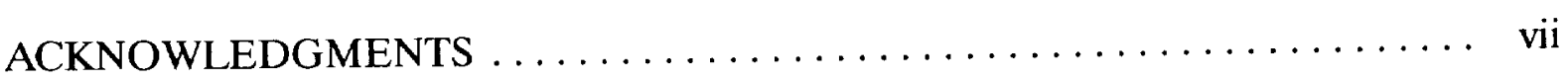

I. INTRODUCTION $\ldots \ldots \ldots \ldots \ldots \ldots \ldots \ldots \ldots \ldots \ldots \ldots \ldots \ldots \ldots \ldots \ldots$

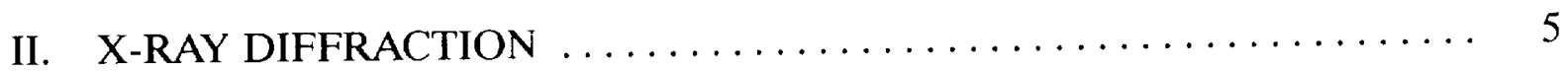

A. Wide-Angle X-Ray Diffraction $\ldots \ldots \ldots \ldots \ldots \ldots \ldots \ldots \ldots \ldots$

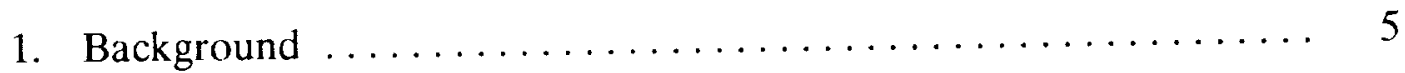

2. Experimental ............................ 7

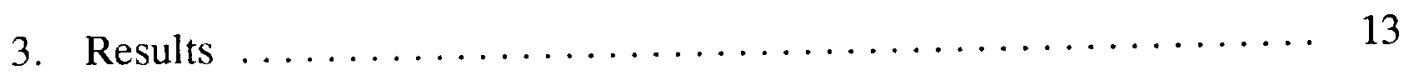

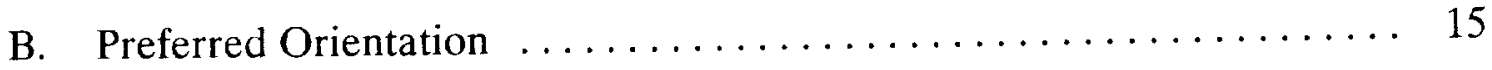

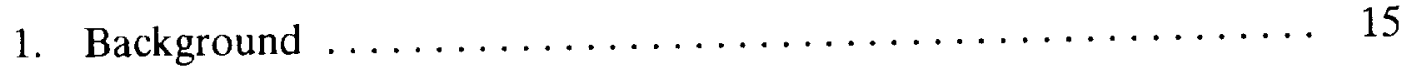

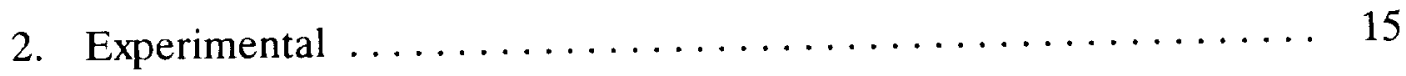

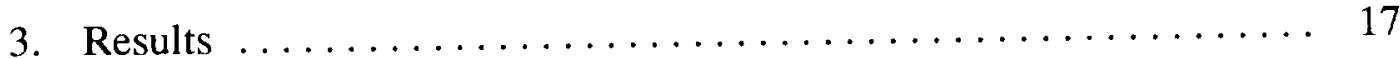

C. Small-Angle X-Ray Scattering $\ldots \ldots \ldots \ldots \ldots \ldots \ldots \ldots \ldots \ldots$

1 Background $\ldots \ldots \ldots \ldots \ldots \ldots \ldots \ldots \ldots \ldots \ldots \ldots \ldots \ldots \ldots \ldots \ldots \ldots \ldots$

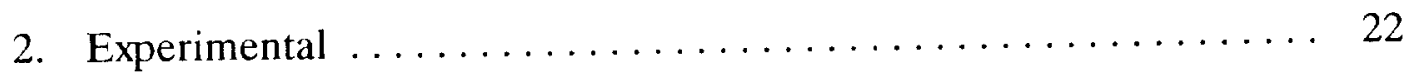

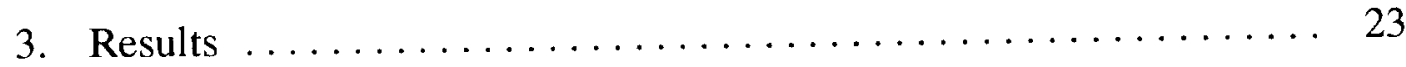

a. Qualitative Observations ................... 23

b. Quantiative Measurements $\ldots \ldots \ldots \ldots \ldots \ldots \ldots \ldots \ldots \ldots \ldots \ldots$

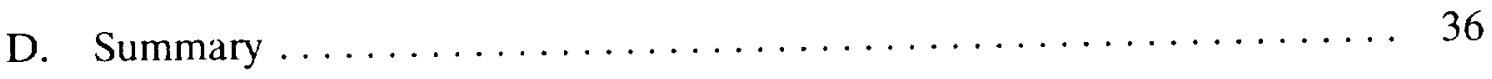

III. TRANSMISSION ELECTRON MICROSCOPY .............. 37

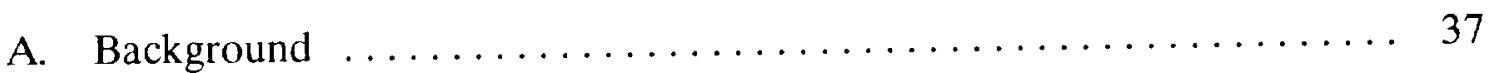

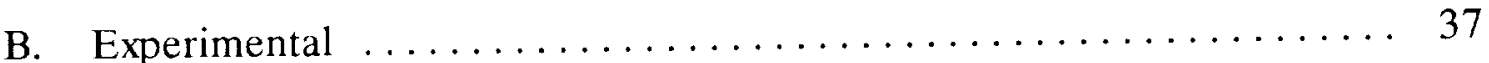

C. Results and Discussion ....................... 40

1. Macroscopic Texture $\ldots \ldots \ldots \ldots \ldots \ldots \ldots \ldots \ldots \ldots, 41$

a. Longitudinal .......................... 41

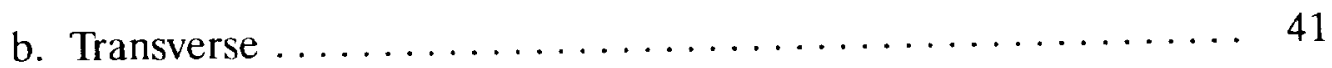

ix 


\section{CONTENTS (Continued)}

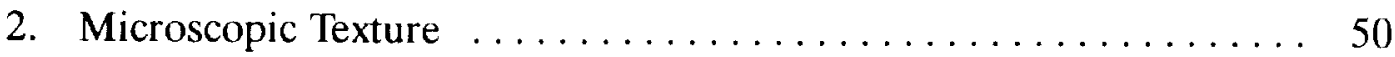

a. Selected Area Diffraction $\ldots \ldots \ldots \ldots \ldots \ldots \ldots \ldots \ldots$

b. Dark Field Study ........................ 55

c. High-Resolution (HR) Lattice Fringe Study ........... 61

d. P100 Fibers . . . . . . . . . . . . . . . . . . . . . . . 70

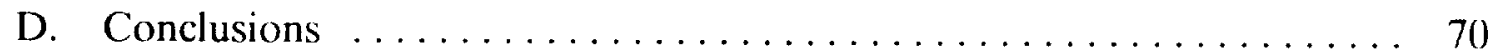

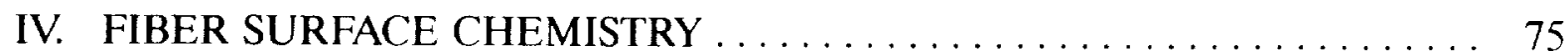

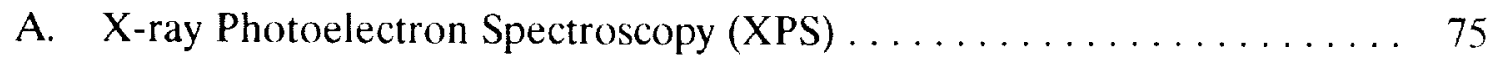

1. Background and Experimental .................... 75

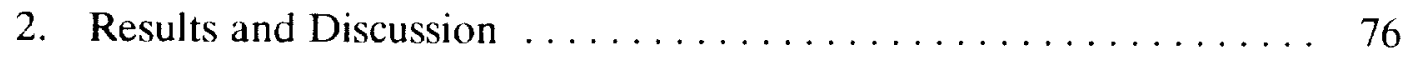

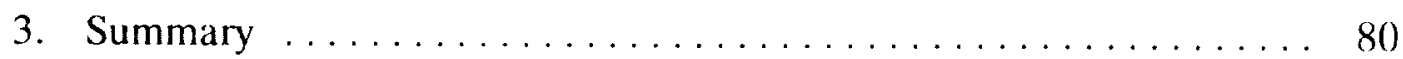

B. Acid/Base Character $\ldots \ldots \ldots \ldots \ldots \ldots \ldots \ldots \ldots \ldots \ldots \ldots$

V. FIBER SIZING LEVELS $\ldots \ldots \ldots \ldots \ldots \ldots \ldots \ldots \ldots \ldots \ldots \ldots \ldots$

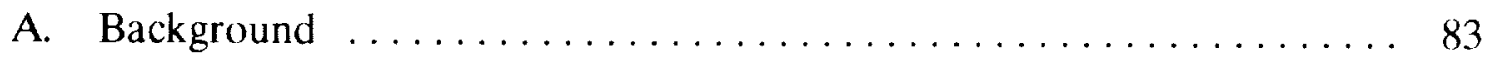

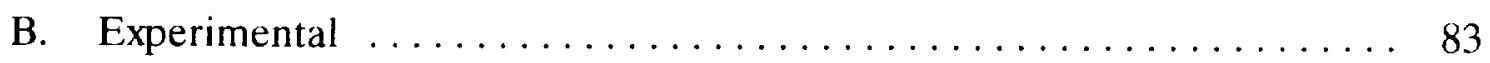

C. Results ................................ 83

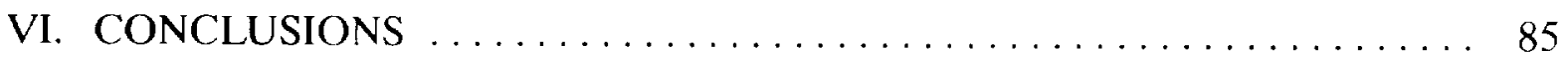

REFERENCES ...................................... 87

APPENDIX A - WIDE-ANGLE X-RAY DIFFRACTION SCANS ........ 91

APPENDIX B - PREFERRED-ORIENTATION SCANS . . . . . . . . . . . 107

APPENDIX C - SMALL-ANGLE X-RAY SCATTERING PLOTS $\ldots \ldots \ldots \ldots 113$ 


\section{FIGURES}

1. Effect of heat-treatment temperature on the thermal conductivity and tensile strength of PAN-based carbon fibers $\ldots \ldots \ldots \ldots \ldots \ldots \ldots \ldots$

2. Structure of three-dimensional and two-dimensional graphitic carbon ..... 6

3. Theta two-theta X-ray diffraction scans of ATJS graphite, DuPont E130 fibers, and Amoco T50 and T300 fibers . . . . . . . . . .

4. Flat-plate photographs (Mo radiation, $X=5 \mathrm{~cm}$ ) of (a) ATJS graphite, (b) DuPont E130 fibers, (c) Amoco T50 fibers, (d) Amoco $\mathrm{T} 300$ fibers $\ldots \ldots \ldots \ldots \ldots \ldots \ldots \ldots \ldots \ldots$

5. Schematics of various types of $\mathrm{X}$-ray diffractometers $\ldots \ldots \ldots \ldots \ldots \ldots$

6. Theta two-theta $X$-ray diffraction scans of DuPont E130 fibers . . . . . . 12

7. Low-angle and 002 reflection X-ray diffraction scans of low thermal conductivity PAN fibers $\ldots \ldots \ldots \ldots \ldots \ldots \ldots \ldots \ldots \ldots$

8. 10 and 11 reflection $X$-ray diffraction scans of low thermal conductivity PAN fibers $\ldots \ldots \ldots \ldots \ldots \ldots \ldots \ldots \ldots \ldots \ldots$

9. (a) Effect of heat treatment temperature on the preferred orientation of PAN- and pitch-based carbon fibers.

(b) Effect of pitch-based carbon fiber preferred orientation on modulus ...

10. Relationship between preferred orientation and tensile modulus for LTC and standard PAN fibers

11. Schematic of pore system in carbon fibers $\ldots \ldots \ldots \ldots \ldots \ldots \ldots \ldots \ldots$

12. Qualitative small-angle X-ray scattering photographs of (A) Amoco T50, (B) Amoco T300, and (C) CCA3 Rayon fibers .............. 24

13. Qualitative small-angle X-ray scattering photographs of (A) Amoco T350/23X, (B) Amoco T350/25X, (C) Hercules R879-01, and (D) Hercules R879-02 fibers

14. Qualitative small-angle X-ray scattering photographs of
(A) Textron Avcarb B-2, (B) Textron Avcarb G, (C) BASF

DG Rayon 1 , and (D)

15. Scanning electron microscope photographs of the surfaces of Amoco T50 and T300 fibers

16. Scanning electron microscope photographs of surfaces of Amoco T350/23X and Textron Avcarb 


\section{FIGURES (Continued)}

17. Scanning electron microscope photographs of surfaces of Hercules R879-02 and BASF DG Rayon 1 fibers .............. 30

18. Characteristic curves determined for Kodak direct exposure film . . . . . . 32

19. Gray scale/optical density calibration curves measured from photographic step tablet with different CCD

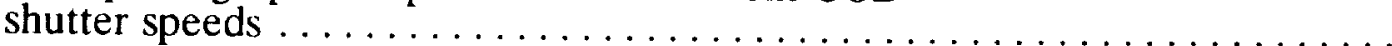

20. Equatorial lines traces of SAXS of carbon fibers obtained by digitizing SAXS photographs $\ldots \ldots \ldots \ldots \ldots \ldots \ldots \ldots \ldots \ldots \ldots \ldots$

21. SAXS intensity contour maps for (a) Amoco T50 and (b) T300 fibers .... 34

22. SAXS intensity contour maps for (a) BASF DG Rayon 1 and

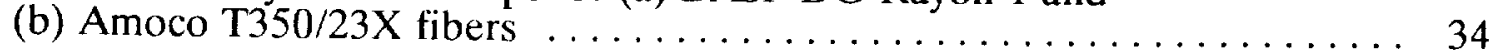

23. The proposed ribbon microtexture model $\ldots \ldots \ldots \ldots \ldots \ldots \ldots \ldots \ldots$

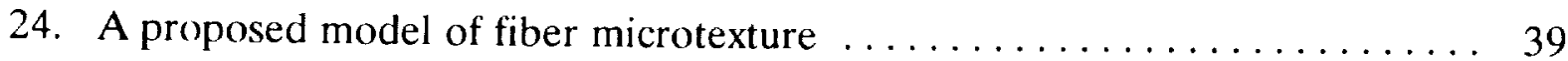

25. BF image showing the macrotexture of Amoco T350/23X

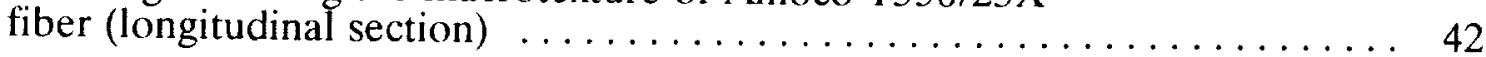

26. BF image showing the macrotexture of Amoco T350/25X

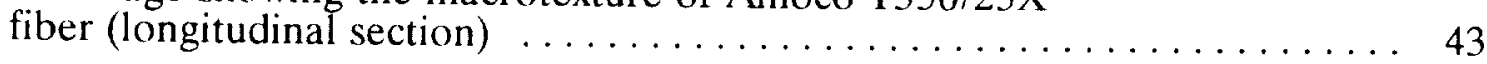

27. BF image showing the macrotexture of Amoco T300

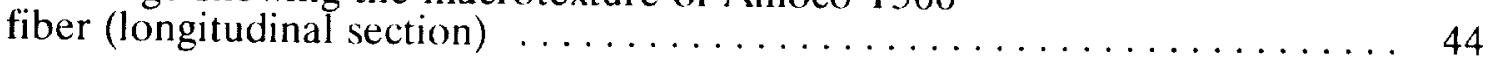

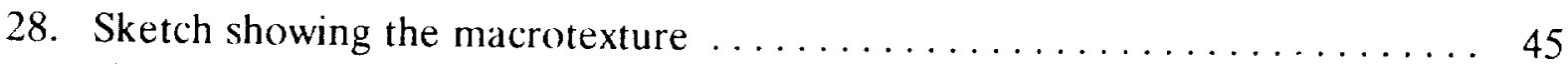

29. BF image of Amoco T350/23X fiber (transverse section) . . . . . . . . . 46

30. BF image of Amoco T350/25X fiber (transverse section) . . . . . . . . . . 47

31. BF image of Amoco T300 fiber (transverse section) ............ 48

32. $\mathrm{BF}$ image of Amoco $\mathrm{T} 50$ fiber (transverse section) . . . . . . . . . . . . . . 49

33. Transverse section of Amoco T50 fiber showing two-phase structure ..... 50

34. Sketch showing that the observed SAD pattern is composed of two different patterns resulting from "face-on" and "edge-on" grains 


\section{FIGURES (Continued)}

35. Sketch showing reflections of planes misoriented by an angle of $\pm \alpha \ldots \ldots \quad 52$

36. Diffraction patterns resulting from tilting the basal planes .......... 54

37. Diffraction patterns resulting from tilting the perpendicular basal planes.... 55

38. $002 \mathrm{DF}$ image of Amoco T350/23X fiber (transverse section) ......... 56

39. $002 \mathrm{DF}$ image of Amoco T350/25X fiber (transverse section) ......... 57

40. $002 \mathrm{DF}$ image of Amoco T300 fiber (transverse section) .......... 58

41. 002 DF image of Amoco T50 fiber (transverse section; no tilt angle) ..... 59

42. $002 \mathrm{DF}$ images of Amoco T50 fiber (transverse section;

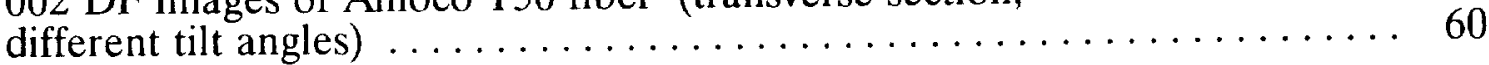

43. Lattice-fringe image of Amoco T350/23X fiber (transverse section) $\ldots \ldots 62$

44. Lattice-fringe image of Amoco T350/25X fiber (transverse/outer region) ... 63

45. Lattice-fringe image of Amoco T350/25X fiber (transverse/core) . . . . . 63

46. Lattice-fringe image of Amoco T300 fiber (transverse/outer region) . ..... 64

47. Lattice-fringe image of Amoco T300 fiber (transverse/core) ......... 64

48. Lattice-fringe image of Amoco T50 fiber (transverse) ........... 65

49. Lattice-fringe image of Amoco T350/23X fiber (longitudinal) . ....... 66

50. Lattice-fringe image of Amoco T350/25X fiber (longitudinal) . . . . . . 67

51. Lattice-fringe image of Amoco T300 fiber (longitudinal) $\ldots \ldots \ldots \ldots \ldots 68$

52. Lattice-fringe image of Amoco T50 fiber (longitudinal) $\ldots \ldots \ldots \ldots \ldots 69$

53. BF image and $\mathrm{SAD}$ pattern of Amoco $\mathrm{P} 100$ fiber $\ldots \ldots \ldots \ldots \ldots \ldots \ldots \ldots$

54. DF image of Amoco P100 fiber $\ldots \ldots \ldots \ldots \ldots \ldots \ldots \ldots \ldots \ldots \ldots \ldots \ldots \ldots \ldots \ldots \ldots$

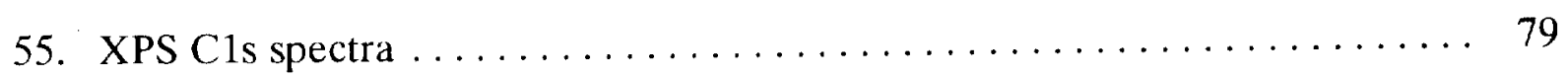




\section{TABLES}

1. Fiber Suppliers and Product Codes for Low Thermal Conductivity

PAN-based Fibers $\ldots \ldots \ldots \ldots \ldots \ldots \ldots \ldots \ldots \ldots \ldots \ldots \ldots \ldots \ldots, 2$

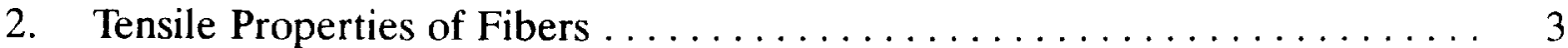

3. Summary of Wide-Angle X-Ray Diffraction Data $\ldots \ldots \ldots \ldots \ldots \ldots$

4. Fiber Orientation Parameters . . . . . . . . . . . . . . . . . . . . . . 17

5. Summary of Structural Information Derived from Small-Angle X-ray Scattering (SAXS) $\ldots \ldots \ldots \ldots \ldots \ldots \ldots \ldots \ldots \ldots \ldots \ldots \ldots$

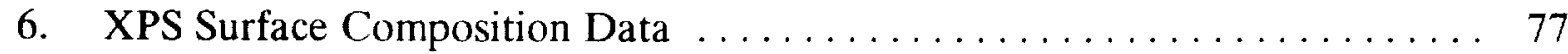

7. XPS Curve-Fit Data for C1s Photoelectron Peaks $\ldots \ldots \ldots \ldots \ldots \ldots$. 80

8. Acid/Base Character of Unsized Fiber Surfaces $\ldots \ldots \ldots \ldots \ldots \ldots \ldots$

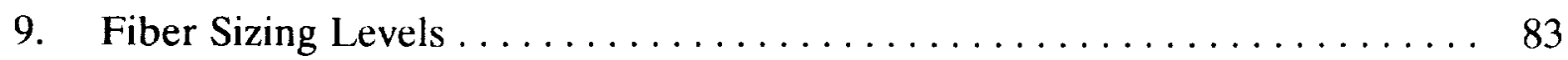




\section{INTRODUCTION}

Low thermal conductivity (LTC) polyacrylonitrile (PAN)-based carbon fibers are being developed as a substitute for rayon-based carbon fibers currently used in solid rocket motor (SRM) nozzles and exit cones. This development is being driven by the potential lack of availability of domestic rayon precursor fiber as a result of environmental restrictions on the manufacturing process and the declining commercial market for rayon. PAN-based carbon fibers are desirable because they are produced by a number of domestic suppliers by a relatively clean process, they can be manufactured with reproducible mechanical properties, and they are used extensively for other applications so that a relatively large property data base exists. Up until now, however, PANbased carbon fibers have been optimized for structural applications where their mechanical properties are more important than their thermal properties. SRM ablative applications, on the other hand, require low fiber thermal conductivity to minimize composite char depth and backface temperature rise. There is a need, therefore, to produce PAN-based carbon fibers with thermal conductivity less than that of standard PAN-based carbon fibers $(-13 \mathrm{~W} / \mathrm{mK})$, which is considerably higher than that of rayon-based carbon fibers $(-4 \mathrm{~W} / \mathrm{mK})$.

During the late 1970s, the Defense Nuclear Agency funded a joint program at The Aerospace Corporation and BASF Structural Materials, Inc. (Celanese). This program demonstrated the feasibility of producing low thermal conductivity fibers by carbonizing PAN precursor fibers at somewhat lower temperatures $\left(900-1100^{\circ} \mathrm{C}\right)$ than those used for standard processing $\left(1250-1500^{\circ} \mathrm{C}\right)$. Figure 1 presents the unpublished results of that program. The thermal conductivity and tensile strength of the fibers produced in that program are plotted as a function of heat-treatment temperature (HTT). The lower thermal conductivity of the fibers heat treated to lower temperatures is due primarily to their retention of a large amount of nitrogen. At higher temperatures, most of this nitrogen is volatilized, leaving a purer carbon fiber with higher thermal conductivity.

Eight LTC PAN fibers are currently being evaluated by NASA. These fibers were manufactured from commercial precursor PAN fibers by Amoco Performance Products, Inc., Hercules Graphite Fibers, Textron Specialty Materials, and BASF Structural Materials, Inc. (two fibers each). A list of these fibers according to product code designated by the manufacturers is shown in Table 1. Their properties have been measured at Lockheed Research and Development Division, Palo Alto, California, and the results are reported in Reference 1. Variations in the mechanical and thermal 


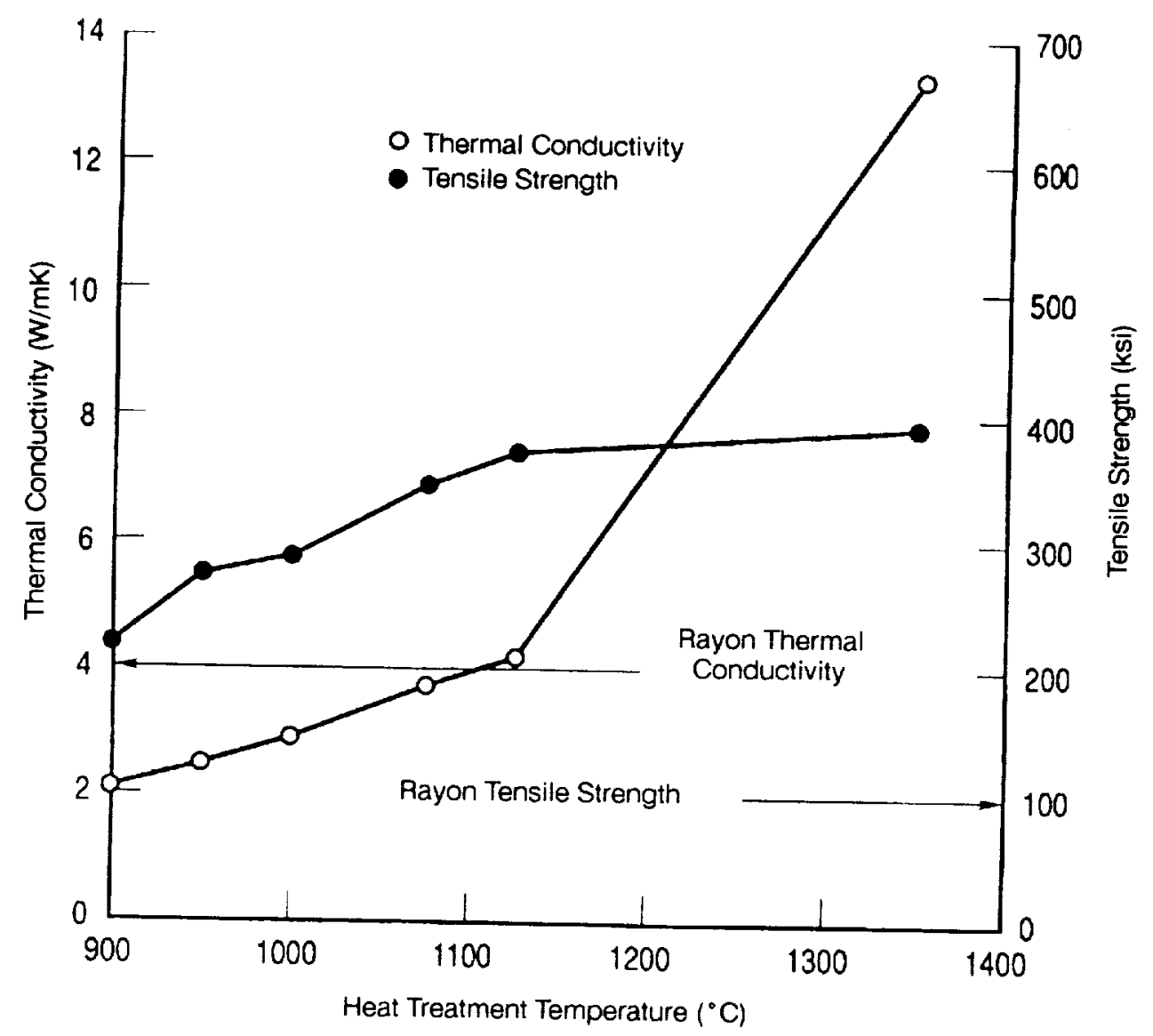

Figure 1. Effect of heat-treatment temperature on the thermal conductivity and tensile strength of PAN-based carbon fibers.

Table 1. Fiber Suppliers and Product Codes for Low Thermal Conductivity PAN-Based Fibers

\begin{tabular}{ll}
\hline \multicolumn{1}{c}{ Fiber Supplier } & Product Code \\
\hline Amoco Performance Products, Inc. & T350/23X \\
& T350/25X \\
BASF Structural Materials, Inc. (Celanese) & DG Rayon 1 \\
& DG Rayon 2 \\
Hercules Graphite Fibers & R879-01 (LF1) \\
& R879-02 (LF2) \\
Textron Specialty Materials & Avcarb G \\
& Avcarb B-2 \\
\hline
\end{tabular}


properties of the LTC PAN fibers are due to variations in (1) precursor PAN fibers (each manufacturer starts with a slightly different precursor), (2) oxidation stabilization parameters (time, temperature, environment, stress state), and (3) heat treatment schedule (final temperature, time at temperature, heating, and cooling rates). The tensile mechanical properties ${ }^{1}$ are shown in Table 2 . Included for comparison are properties of fibers that are heat treated at higher temperatures.

Table 2. Tensile Properties of Fibers

\begin{tabular}{lccc}
\hline \multicolumn{1}{c}{ Fiber } & Tensile Strength ${ }^{\mathrm{a}}$ (psi) & Tensile Modulus $^{\mathrm{a}}$ (Msi) & Strain-to-Failure $^{\mathrm{a}} \%$ ) \\
\hline R879-01 & 339,000 & 21.0 & 1.53 \\
R879-02 & 411,000 & 24.9 & 1.57 \\
Avcarb B-2 & 317,000 & 21.1 & 1.48 \\
Avcarb G & 190,000 & 10.5 & 1.77 \\
T350/25X & 320,000 & 24.2 & 1.28 \\
T350/23X & 348,000 & 22.8 & 1.44 \\
DG Rayon 1 & 462,000 & 25.3 & 1.54 \\
DG Rayon 2 & 454,000 & 23.8 & 1.61 \\
Reference Data & & & \\
\hline Shuttle-Grade Rayon & $50-100,000$ & $8-9$ & $0.6-1.1$ \\
Fabric & & & 1.58 \\
Amoco T300 PAN & 530,000 & 33.5 & 1.65 \\
Hercules AS4 PAN & 590,000 & 36.0 & 0.61 \\
Amoco T50 PAN & 350,000 & 57 & 0.30 \\
Amoco P100 Pitch & 325,000 & 105 & 0.27 \\
DuPont E130 Pitch & 350,000 & 130 & \\
\hline
\end{tabular}

$a_{\text {ASTM }}$ - D4018. 
The Aerospace Corporation task focused on the determination of the microstructures of the LTC PAN fibers utilizing X-ray diffraction (XRD) and transmission electron microscopy (TEM) techniques. The LTC PAN fibers were compared with the higher fired PAN fibers, T300 and T50, and with high-modulus, pitch-based fibers, P100 and E130. In addition, the surface chemistry of each LTC PAN fiber was investigated with $\mathrm{X}$-ray photoelectron spectroscopy (XPS). The goal of these efforts was to determine selected microstructural parameters in order to help understand the basis of the thermal and mechanical properties of the LTC PAN fibers. As a separate task, an evaluation of the sizing levels on the LTC PAN fibers was undertaken to help resolve a discrepancy in this measurement. The results of each of these facets of the study are reported in the following sections. 


\section{X-RAY DIFFRACTION}

\section{A. WIDE-ANGLE X-RAY DIFFRACTION}

\section{Background}

$X$-ray diffraction (XRD) has been widely used in the structural characterization of carbons and graphites, and wide-angle XRD (WAXD) has been used in the study of carbon fibers. ${ }^{2-6}$ Reviews of the structure of polyacrylonitrile (PAN)-based carbon fibers are given in References 7 and 8 , and the correlation of the microstructure of the fibers with mechanical properties is discussed in References 9-11.

Diffraction effects arise when $X$ rays interact with crystalline matter because the $X$-ray wavelengths are of the same order as the interatomic distances between the repeatable lattice planes in crystals. In the simplified model of XRD, diffraction occurs when the conditions of Bragg's Law are satisfied

$$
\mathrm{n} \lambda=2 \mathrm{~d} \sin (\theta)
$$

where $\mathrm{n}$ is an integer, $\lambda$ is the wavelength of the $\mathrm{X}$ rays, $\mathrm{d}$ is the interatomic spacing of the crystal lattice planes, and $\theta$ is the angle between the incident $X$-ray beam and the lattice planes. The crystal structure of hexagonal graphite is portrayed in Figures 2(a) and (b). In this crystal, a high degree of three-dimensional order exists, and XRD reflections are produced by the various lattice planes. The most prominent reflections $(001)$ are associated with the basal layer planes, which are perpendicular to the c-axis and have an interatomic spacing of $3.35 \AA$. The structure of lower heat-treatment temperature (HTT) carbons, however, is considerably different since only twodimensional (turbostratic) order is present [Figure 2(c)]. In this structure, there is no registry between atoms in successive layers, the distance between layers is greater than $3.4 \AA$, considerable disorder exists within the layers, and the size of domains with similar structure (crystallites) is small $(<100 \AA)$. As a result, the XRD pattern of low HTT carbon is much different from that of crystalline (three-dimensional) graphite. High-temperature heat treatment improves the structure of the disordered carbon, but the extent to which the structure approaches that of three-dimensional graphite strongly depends on the starting material. 


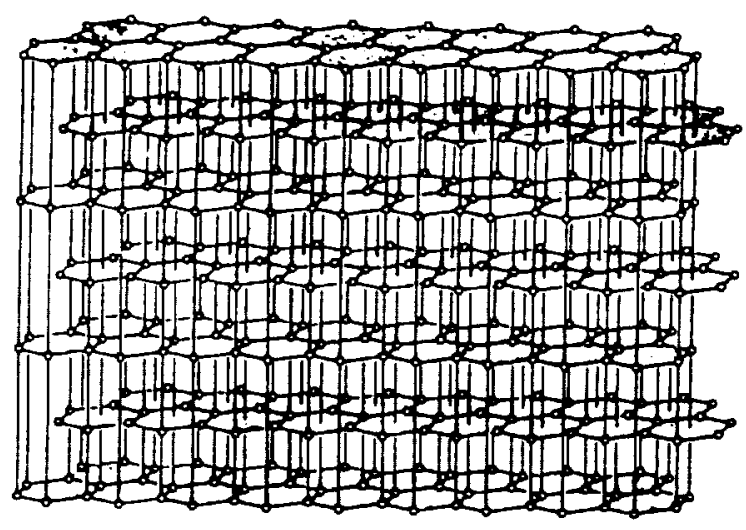

(a)

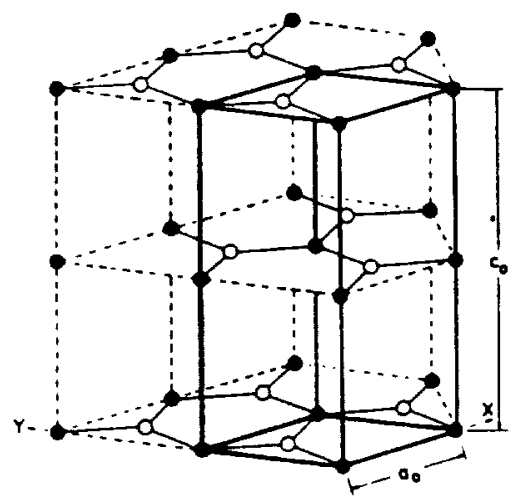

(b)

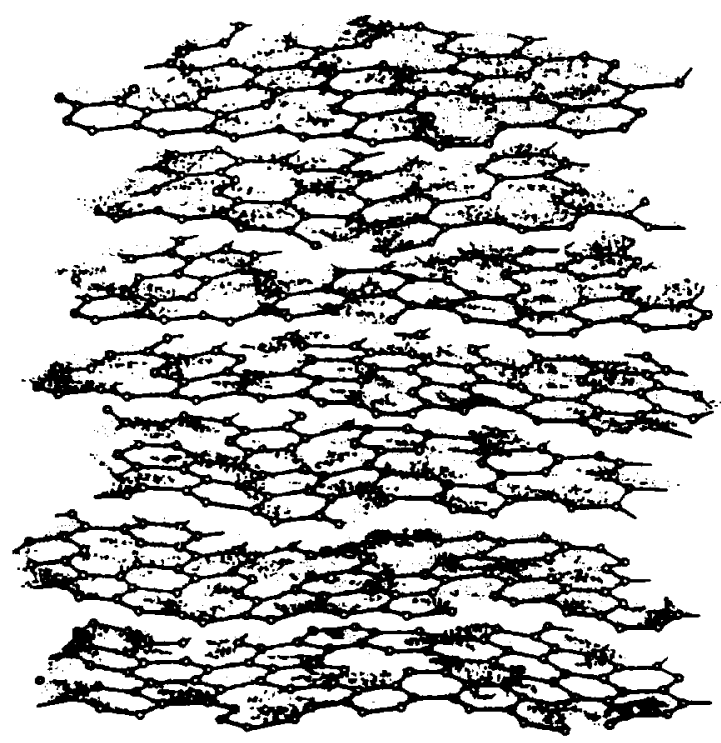

(c)

Figure 2. Structure of three-dimensional and two-dimensional graphitic carbon. (a) Graphite crystal lattice, (b) graphite crystal unit cell, (c) turbostratic graphitic carbon. 
The effect of these structural changes on the XRD pattern is illustrated in Figures 3 and 4. These figures compare the XRD patterns of well-crystallized bulk graphite (ATJS), a high-modulus, highly oriented, pitch-based fiber (E130 from DuPont), and PAN-based fibers (Amoco T50 and T300). The XRD patterns in Figures 3 and 4 were obtained with a powder diffractometer ( $\mathrm{Cu}$ radiation) and a flat plate camera (Mo radiation), respectively. As order increases, the spacing between the basal layer planes decreases and approaches $3.35 \AA$, and the crystallite size increases. These changes influence the XRD pattern by shifting the position of the 001 reflections $[002$ in Figure 3(b)] to higher angles and by decreasing the peak full-width at halfmaximum (FWHM), respectively. An estimate of the crystallite size perpendicular to the layer planes can be obtained from the Scherrer equation

$$
\mathrm{L}_{\mathrm{c}}=\mathrm{K} \lambda / \mathrm{B} \cos \theta
$$

where $L_{c}$ is the crystallite size along the c-axis of the crystals, $K$ is a constant $(0.89$ for the 002 reflection of graphite), $\lambda$ is the X-ray wavelength, B is the FWHM (in radians), and $\theta$ is the Bragg angle. The crystallite size along the a-axis $\left(L_{a}\right)$ of the crystals can also be estimated with the Scherrer equation; for that estimate, $\mathrm{K}$ in Eq. (2) is 1.84 .

The change from turbostratic to three-dimensional order can be monitored by the appearance of $\mathrm{h} 0 \mathrm{l}$ and $\mathrm{hkl}$ reflections, which result from the formation and alignment of lattice planes. This effect can be seen in Figures 3(c) and (d) for the 101 and 112 reflections, respectively. In turbostratic carbons, only a broad 10 reflection is observed [Figure 3(c)] as a result of the interatomic spacings $(-2.1 \AA)$ within individual layer planes. With the appearance of three-dimensional order, this single broad peak is replaced by a pair of reflections (100-101), as can be seen for highly graphitic ATJS. The development of three-dimensional order and its effect on the XRD pattern is also shown in Figure 3(d) for the 110-112 reflections. In turbostratic material, only a broad 11 reflection is observed as a result of an approximately $1.2 \AA$ interatomic spacing within the layer planes, while three-dimensional graphite exhibits a splitting of this peak into the 110 and 112 reflections. These effects are seen qualitatively in Figure 4.

\section{Experimental}

Wide-angle $\theta-2 \theta$ XRD scans were performed using copper $k \alpha$ radiation on a computer-controlled vertical powder diffractometer supplied by Philips Electronics Instruments. The diffractometer was equipped with a $\theta$-compensating slit, a diffracted-beam graphite crystal monochromator, and a scintillation detector. In an attempt to randomize the fibers, each type of low thermal conductivity (LTC) fiber and samples of 
e

흐
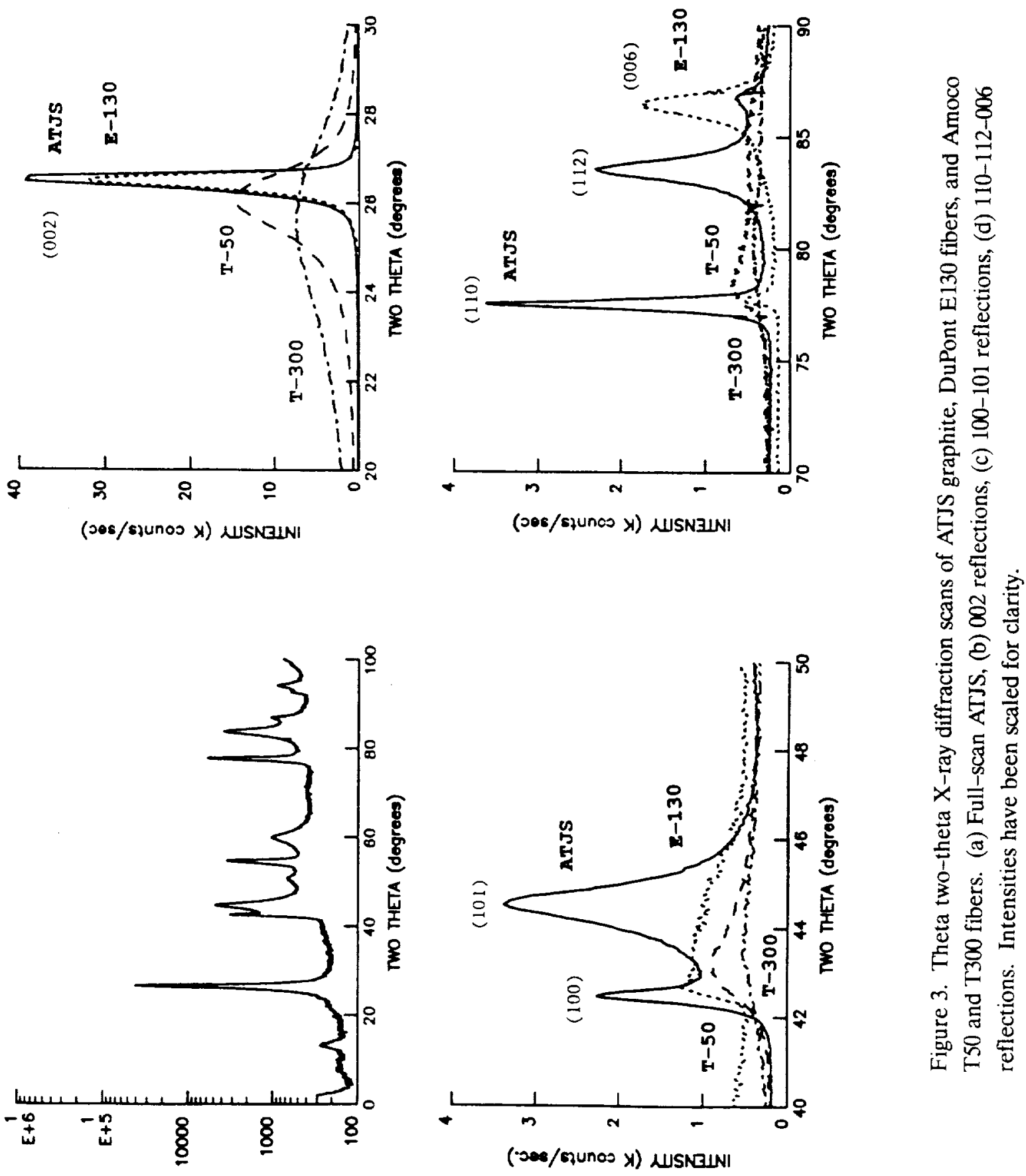

('ses/squnos) UUSNBLNI

$\widetilde{\sigma}$ 


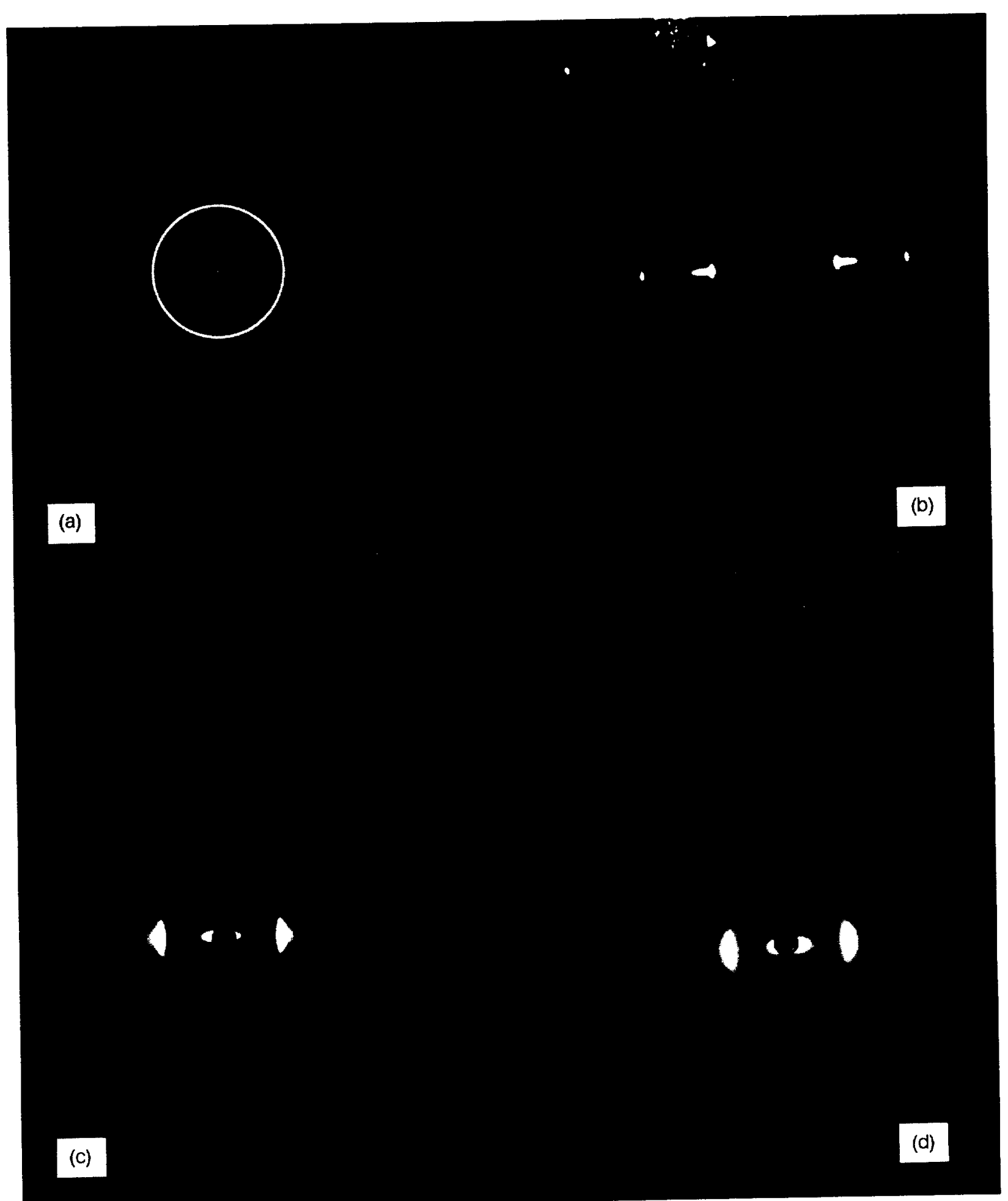

Figure 4. Flat-plate photographs (Mo radiation. $X=5 \mathrm{~cm}$ ) of (a) ATJS graphite, (b) DuPont E130 fibers, (c) Amoco T50 fibers. (d) Amoco T300 fibers. 
well-characterized higher HTT PAN-based fibers (Amoco T50 and T300) were ground in a mortar with a pestle until they passed through a 200-mesh sieve. The powder samples were pressed into a $100 \mu \mathrm{m}$ deep cavity in a standard Philips sample holder that was backed with a zero background plate. This plate consists of a single crystal of quartz, cut $6^{\circ}$ from the $c$-axis, which produces no XRD reflections and very little background scattering. Survey scans of the powder samples were run, varying $2 \theta$ between $2^{\circ}$ and $100^{\circ}$ in $0.02^{\circ}$ steps. In order to obtain more accurate measurements of the d-spacings of the graphite 002 reflections, a small amount of an internal standard was mixed with a portion of the powders, and $\theta-2 \theta$ scans were repeated between $15^{\circ}$ and $35^{\circ}$. National Institute of Standards and Technology (NIST) standard reference material No. 674 zinc oxide $(\mathrm{ZnO})$ was used as the internal standard, and the position of the $\mathrm{ZnO} 100$ reflection was used to calibrate the $\theta-2 \theta$ scans. The XRD reflections of turbostratic carbons are often very broad and may be asymmetric, thereby making it difficult to define or measure peak locations. For simplicity, the location of the 002 reflection was defined as the bisector of the full width at threefourth intensity (peak minus background).

Typical XRD patterns of ground carbon fibers display a high degree of preferred orientation because of the orientation of graphite layer planes along the fiber axes and the extreme difficulty of randomizing the ground fiber fragments during the mounting of samples. This can be seen qualitatively in the flat plate photographs in Figure 4. The randomly oriented ATJS specimen produces an XRD pattern that consists of complete concentric rings whereas the patterns of the carbon fibers exhibit arcs with varying lengths with the shorter arc indicating greater degree of preferred orientation. As a result, in $\theta-2 \theta$ scans, which represent an equatorial trace in the photographs in Figure 4, the 001 reflections are usually very strong; on the other hand, $\mathrm{h} 0 \mathrm{l}$ and hkl reflections, which give an indication of the in-plane and three-dimensional order/crystallite size, respectively, are very weak. It is possible to take advantage of the preferred carbon fiber orientation, however, to study the h0l and hkl reflections by analyzing fiber tows directly in a symmetric transmission geometry. This method maximizes the signal from the hk0 and hkl reflections, removes interferences from 001 reflections, and represents the equivalent of a meridional trace in Figure 4. This experimental arrangement is compared with the usual reflection geometry in Figure 5. To record the hkl reflections, the fibers are mounted with their axes rotated $20^{\circ}[\beta=$ $20^{\circ}$ (refer to Figures 4 and $5 \mathrm{c}$ )]. ${ }^{6}$ The selection of this orientation is based on the angle h0l/hkl planes (such as 101 and 112) make with the basal 001 planes, on the general alignment of the 001 planes parallel with the fiber axis, and on the fact that only lattice planes that satisfy the symmetric geometry will be recorded in the $\theta-2 \theta$ scans. Samples were analyzed in this geometry with a simple fixture consisting of a microscope slide with a narrow $(2 \mathrm{~mm})$ slot cut in it. This slot served as an aperture that defined a narrow beam of $\mathrm{X}$ rays along the diffractometer axis. Fiber bundles were 

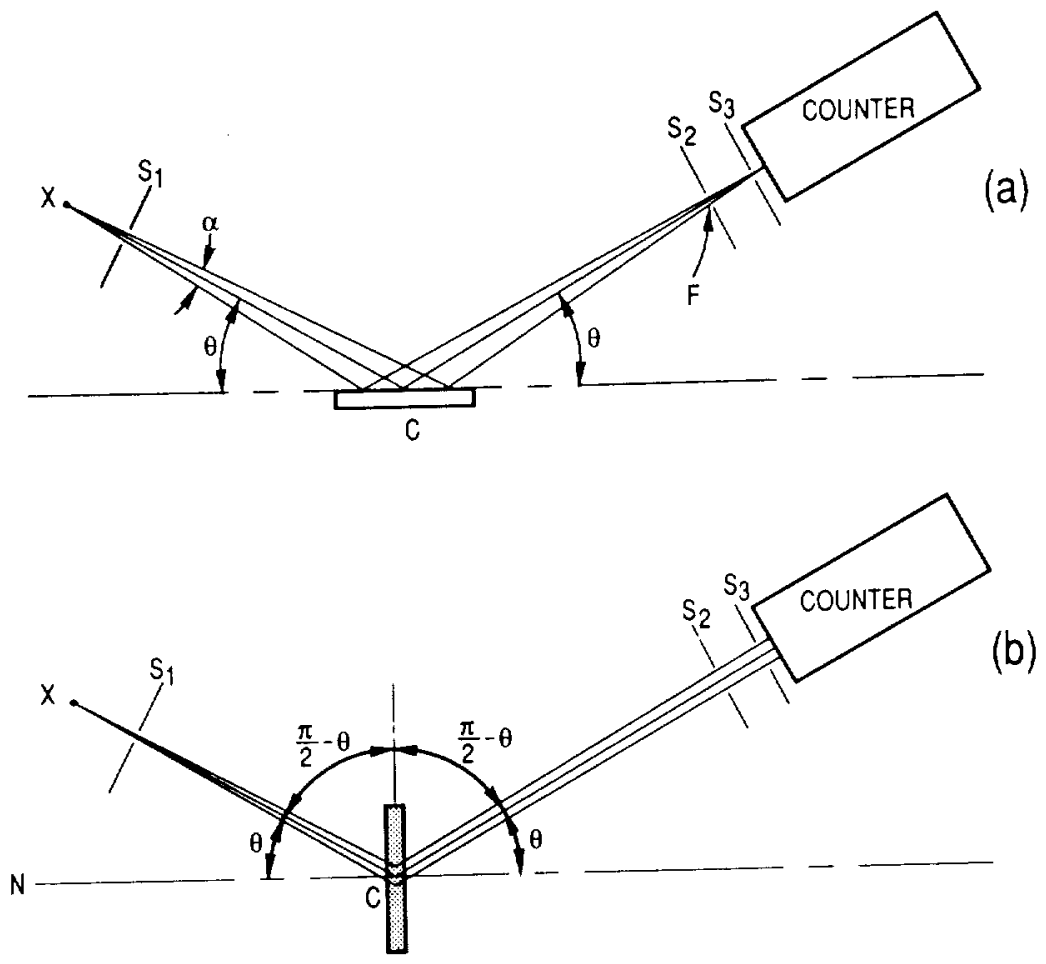

(b)

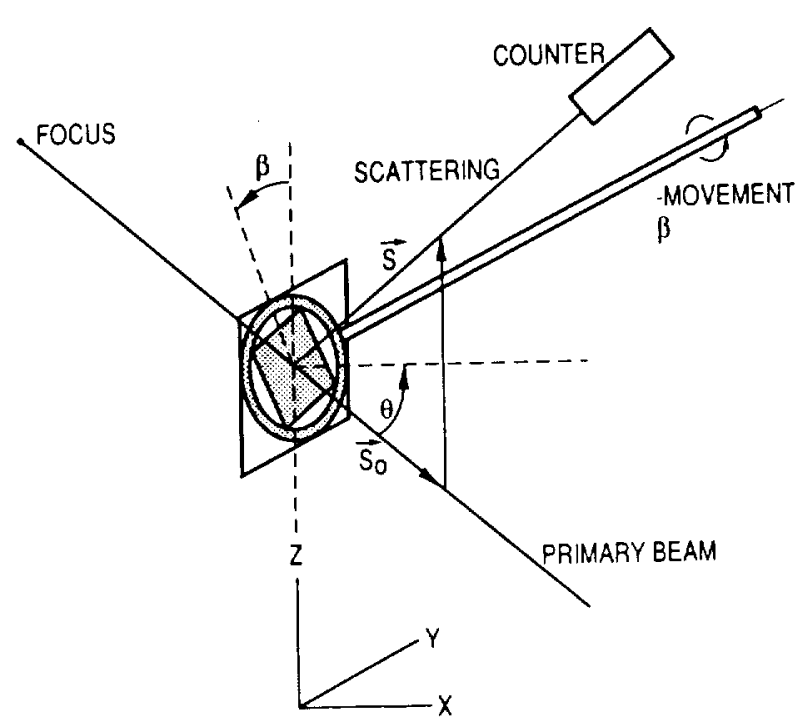

(c)

Figure 5. Schematics of various types of X-ray diffractometers. (a) reflection, (b) symmetric transmission, (c) transmission (perspective). 
positioned and aligned manually and secured with a collodion adhesive solution. In this geometry, with a narrow X-ray beam and thin $(-100 \mu \mathrm{m}$ ' poorly graphitic samples, it was necessary to run $\theta-2 \theta$ scans for $12 \mathrm{hr}$ to obtain a reasonable signal-tonoise ratio for the weak $\mathrm{h} 0 \mathrm{l} / \mathrm{hkl}$ reflections. An identical scan was recorded from the empty sample fixture and subtracted from the scans of the carbon fibers to remove the effects of amorphous scattering from the glass microscope slide.

In Figure 6, the effect of the sample geometry on the $\theta-2 \theta$ XRD scans is illustrated for highly graphitic mesophase pitch-based E130 fibers. In the scan of ground E130 powder taken in the reflection geometry, most reflections are seen. However, the 001 reflections are extremely strong because of the highly graphitic and oriented nature of the fibers and, therefore, tend to obscure some of the h0l/hkl reflections. In the transmission geometry, with the fiber axes at $\beta=0^{\circ}$, the 001 reflections are eliminated, but hkl reflections are missing because the correct alignment conditions are not satisfied. When the fiber axes are positioned at $\beta=20^{\circ}$, the 001 reflections are also not seen, but the 101 and 112 reflections are readily observable.
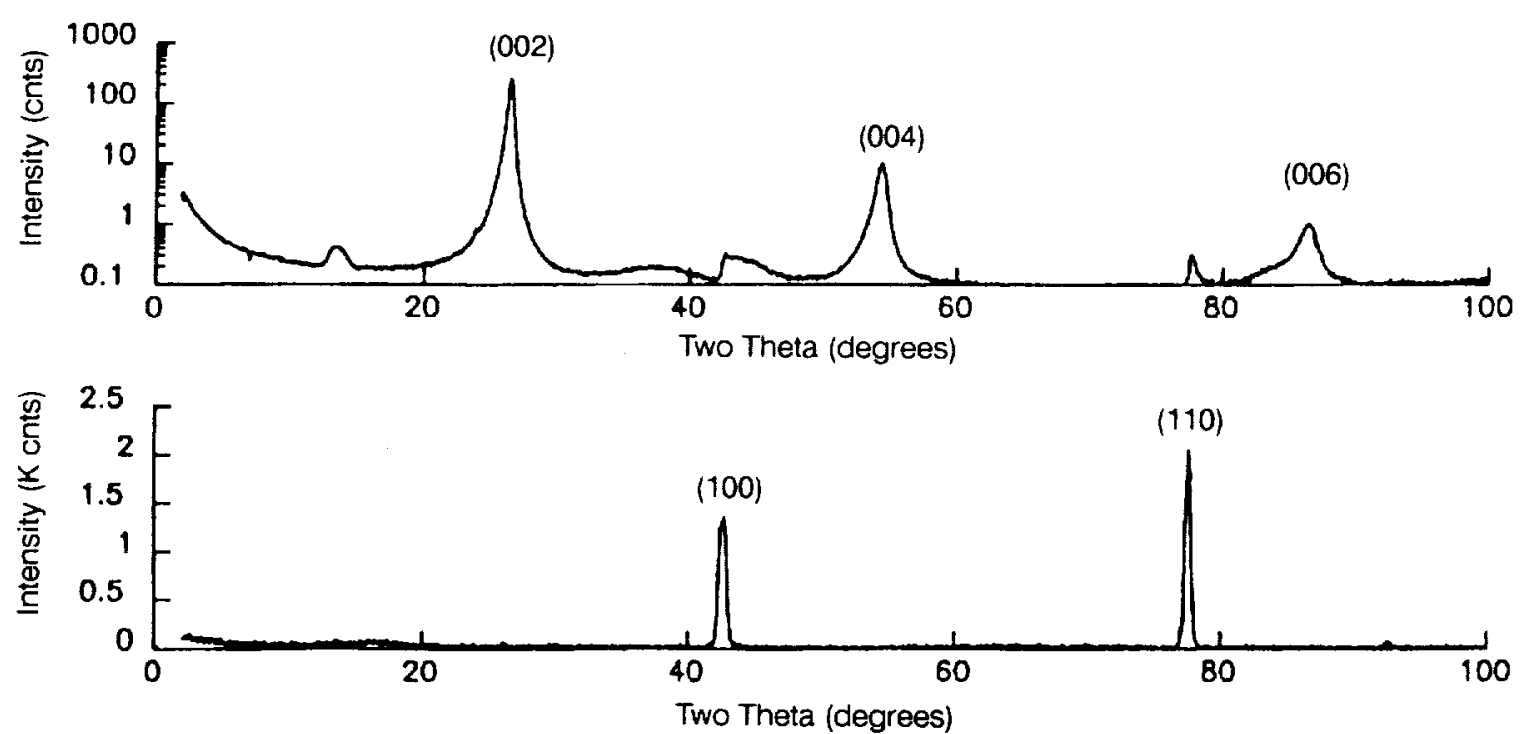

(b)

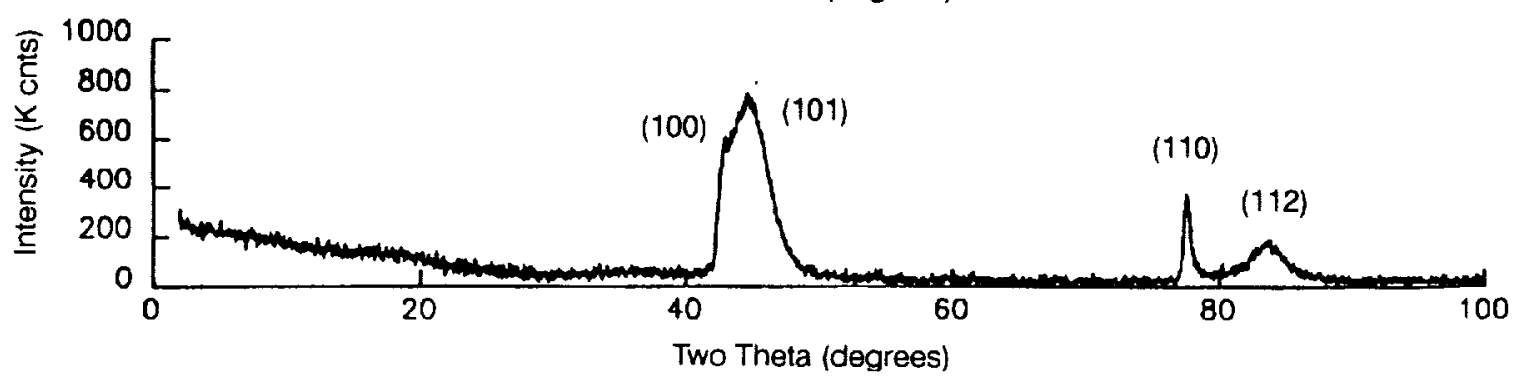

(c)

Figure 6. Theta two-theta X-ray diffraction scans of DuPont E130 fibers. (a) reflection/powder, (b) transmission/fiber $(\beta=$ $\left.0^{\circ}\right)$, (c) transmission/fiber $\left(\beta=20^{\circ}\right)$. 


\section{Results}

The complete $\theta-2 \theta$ XRD scans from all of the samples are included in Appendix A. Comparative plots of the 002,10 , and 11 reflections, along with low-angle scattering curves from the LTC fibers, are presented in Figures 7 and 8. Measurements from these scans are summarized in Table 3. All of the fibers examined are turbostratic, and the XRD patterns give no indication of three-dimensional order (they display no h0l or hkl reflections). The XRD patterns are similar in appearance, and only subtle differences exist between the various LTC fibers. The d-spacings (d) of the 002 reflections for the LTC fibers ranged from 3.48 to $3.53 \AA$, with the Hercules and Textron fibers exhibiting the smallest and largest values, respectively. For comparison, d-spacings of 3.51 and $3.43 \AA$ were recorded from the Amoco T300 and T50 fibers. The $L_{c}$ values calculated from the FWHMs of the 002 reflections are all very similar and very small (12.0-13.9 $\AA$ ), with the two Textron fibers displaying the smallest crystallite sizes. These values, calculated using the Scherrer equation, are not very meaningful because the unit cell in the c-axis direction for single-crystal graphite
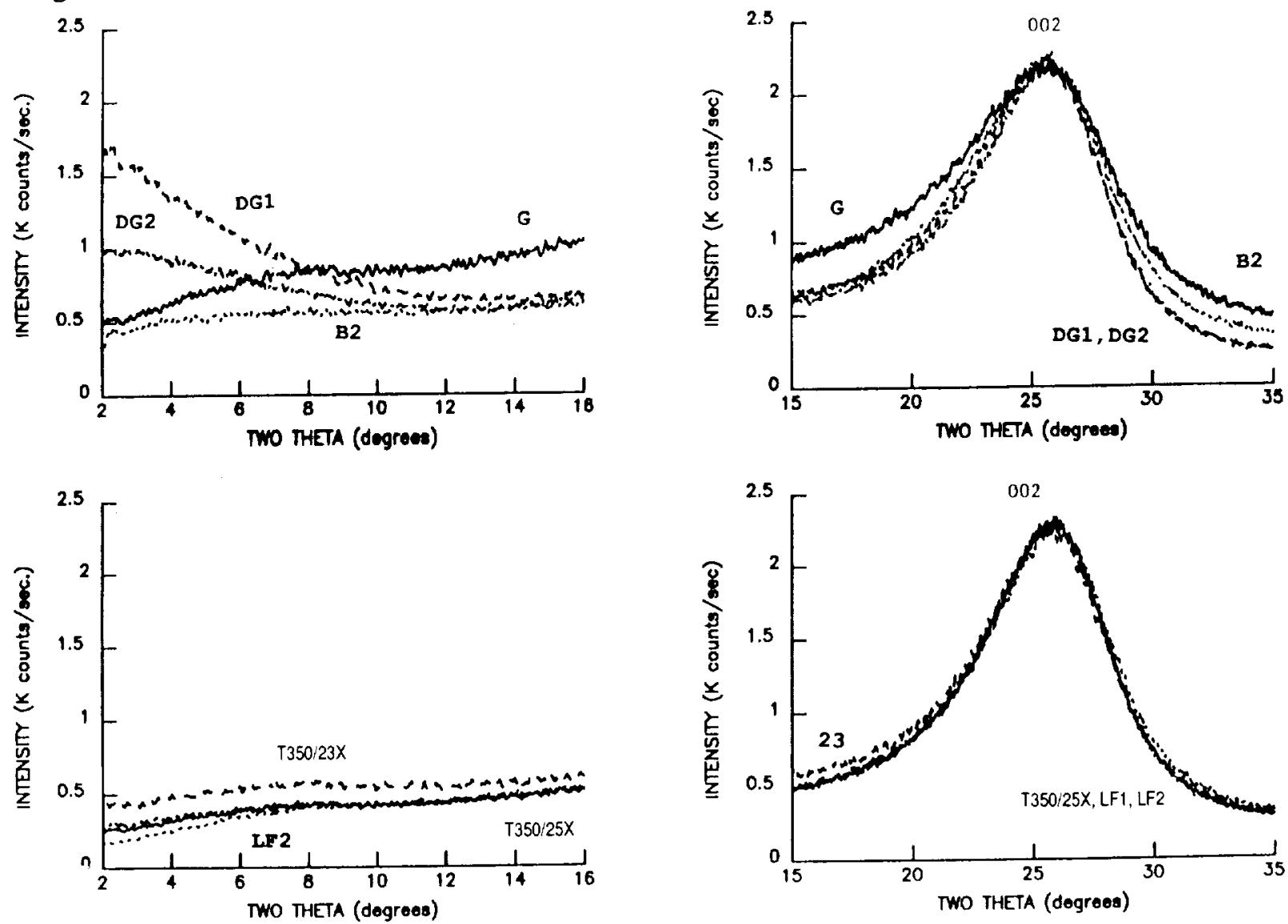

Figure 7. Low-angle and 002 reflection $\mathrm{X}$-ray diffraction scans of low thermal conductivity PAN fibers. Intensities have been scaled so that the heights of the 002 reflections are all equal. 

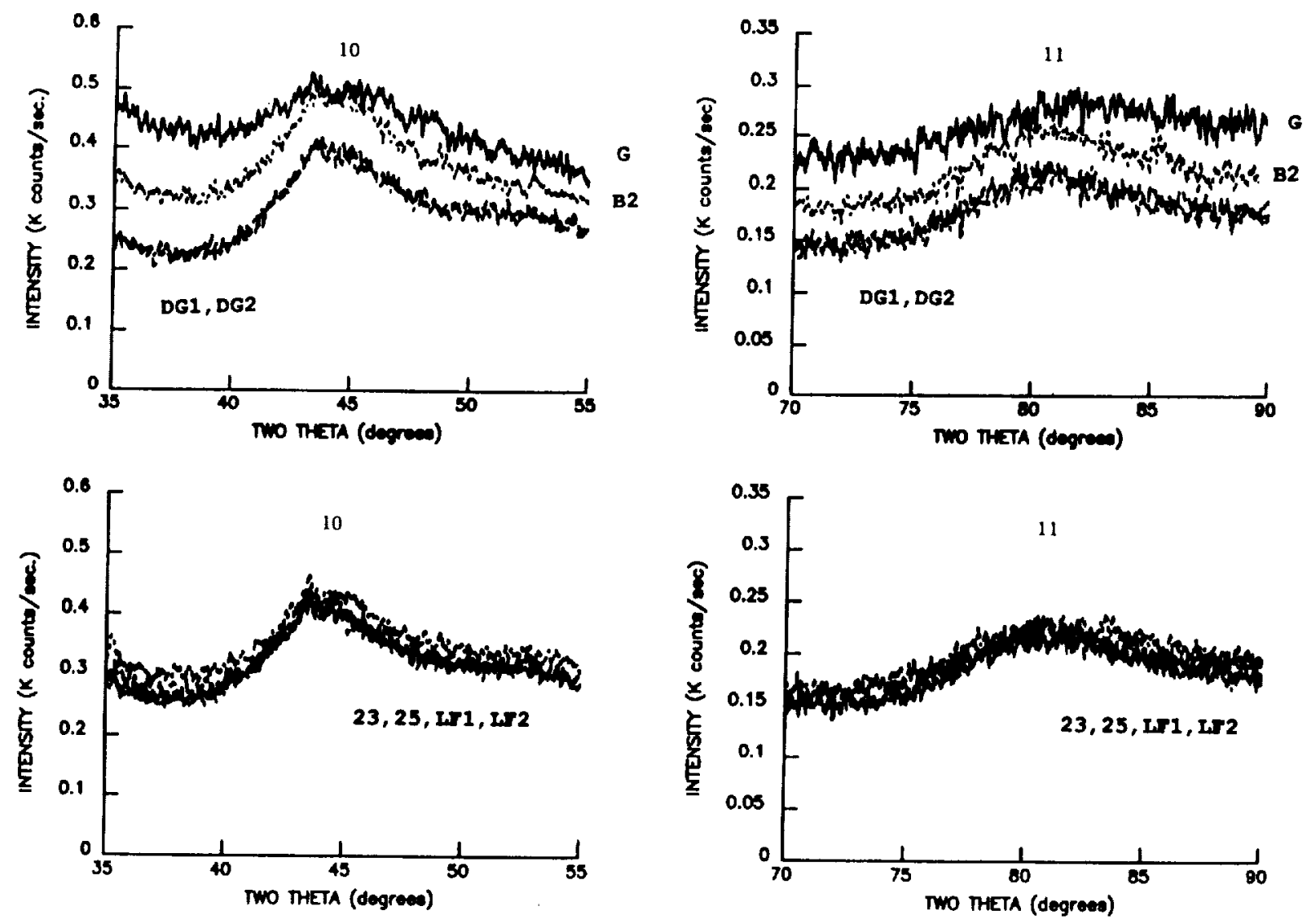

Figure 8. 10 and 11 reflection $\mathrm{X}$-ray diffraction scans of low thermal conductivity PAN fibers. Intensities have been scaled so that the heights of the 002 reflections are all equal.

Table 3. Summary of Wide-Angle X-ray Diffraction Data

\begin{tabular}{lccc}
\hline \multicolumn{1}{c}{ Fiber } & $\mathrm{d} \mathrm{002( \AA )( \pm 0.01)}$ & FWHM 002 $\left({ }^{\circ} 2 \theta\right)$ & $L_{c}(\AA)$ \\
\hline Amoco T350/23X & 3.50 & 6.08 & 13.3 \\
Amoco T350/25X & 3.50 & 6.07 & 13.3 \\
BASF DG Rayon 1 & 3.53 & 6.15 & 13.1 \\
BASF DG Rayon 2 & 3.52 & 6.24 & 12.9 \\
Hercules R879-01 & 3.49 & 5.79 & 13.9 \\
Hercules R879-02 & 3.48 & 5.92 & 13.6 \\
Textron Avcarb G & 3.53 & 7.10 & 11.3 \\
Textron Avcarb B-2 & 3.53 & 6.73 & 12.0 \\
CCA3 Rayon & 3.83 & 8.60 & 9.3 \\
Amoco T300 & 3.51 & 4.93 & 16.3 \\
Amoco T50 & 3.43 & 1.65 & 48.9 \\
\hline
\end{tabular}


$\left(C_{0}\right)$ is $6.7 \AA$. Since the fibers are turbostratic, these values represent the thicknesses of domains that have their basal planes aligned, rather than actual crystallite sizes.

Based on the wide-angle $\theta-2 \theta$ XRD analyses, the majority of the LTC fibers have similar turbostratic structures, with the exception of the Textron fibers, which consistently have the largest $002 \mathrm{~d}$-spacings and smallest crystallite sizes, indicating that they are the least graphitic and most disordered of the fibers examined.

\section{B. PREFERRED ORIENTATION}

\section{Background}

The crystal lattice of graphite is highly anisotropic (Figure 2) and consists of sheets of strong, covalently bonded carbon atoms held together by weak van der Waals forces. As a result, the orientation of basal planes in carbon fibers is expected to directly affect the fiber mechanical and physical properties, such as tensile modulus and thermal conductivity. Therefore, the greater the fraction of basal planes aligned parallel to the fiber axis, the higher the fiber modulus and thermal conductivity. To determine the degree of orientation using X-ray diffraction, the angle $(\beta)$ between the fiber axis and the $X$-ray scattering vector is varied, and the 002 reflection intensity is measured as a function of $\beta$. The orientation parameter, $Z$, is defined as the FWHM of the intensity profile as a function of sample rotation angle $(\beta)$. Approximately twothirds of the basal planes are oriented within this angle. Greater orientation (higher order) of the basal planes results in a decrease in the FWHM. Figure 9 shows textbook examples of how the FWHM varies as a function of HTT for PAN and mesophase pitch fibers and how the modulus of mesophase pitch fibers varies as a function of FWHM. ${ }^{12}$

\section{Experimental}

The degree of preferred orientation of the 001 planes in the carbon fibers can be seen qualitatively in flat-plate photographs (Figure 4). However, quantitative measurements were obtained using a computer-controlled sample spinning attachment in the symmetric transmission geometry. The intensity of the 002 reflection was measured as a function of azimuth from $\beta= \pm 90^{\circ}$ [refer to Figure 5(c)] at $1^{\circ}$ intervals. The raw data were fit to a Gaussian function, and the FWHM of this function is reported as the orientation parameter. With this technique, it was necessary to cover the 


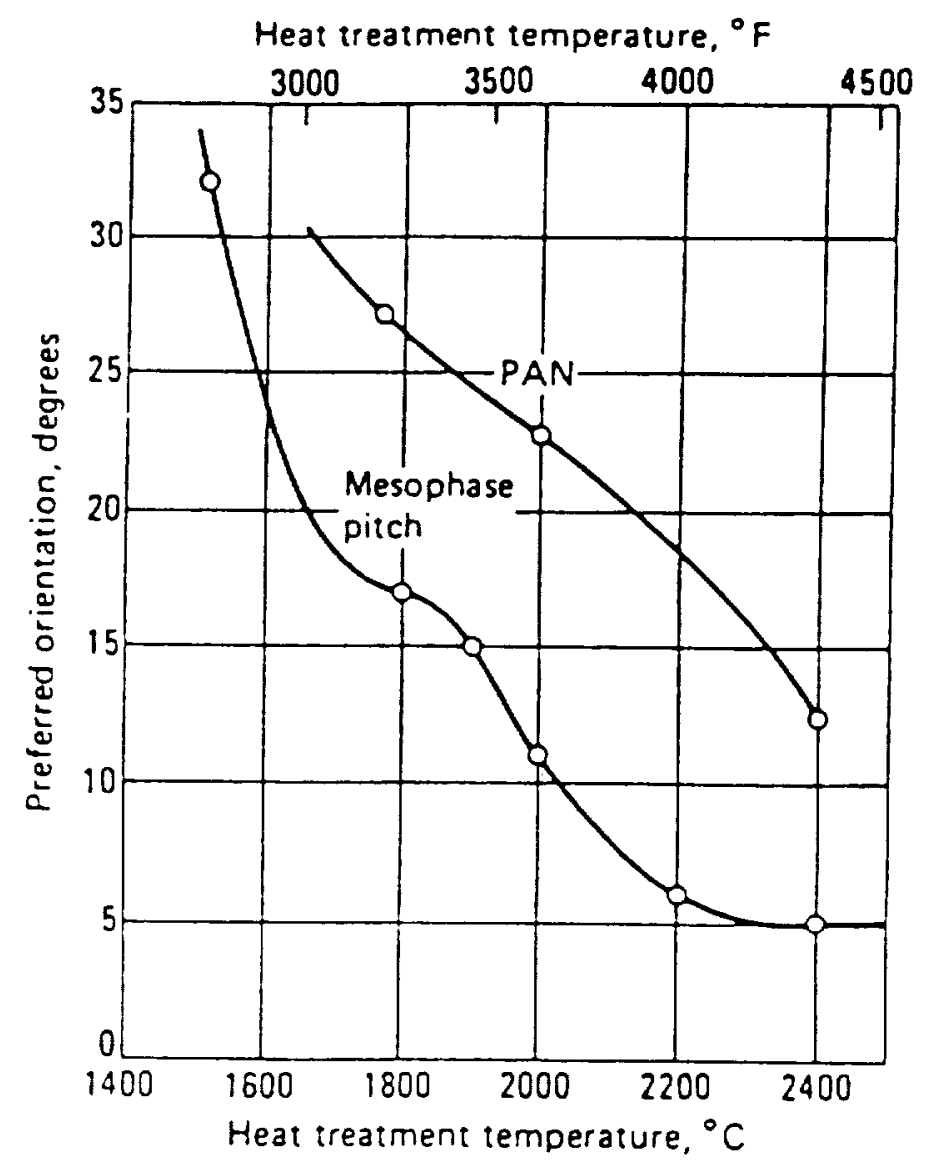

(a)

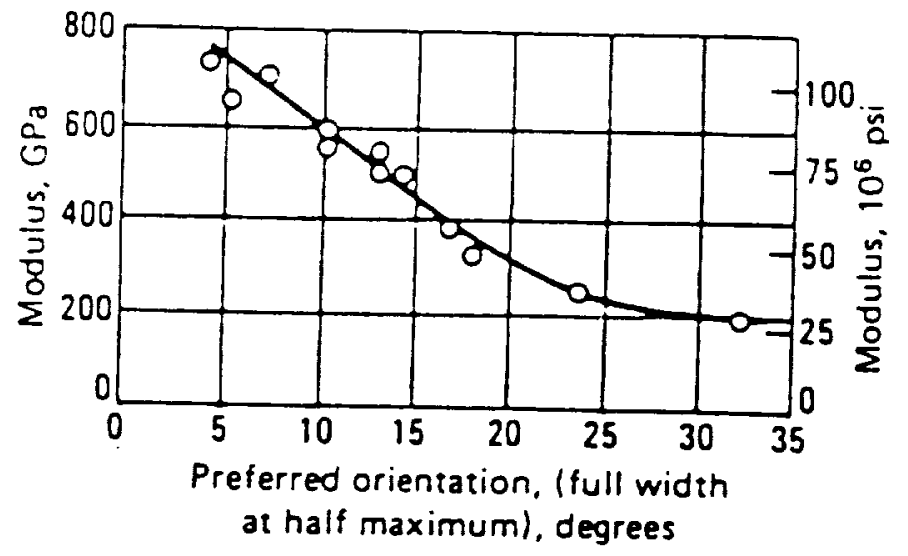

(b)

Figure 9. (a) Effect of heat-treatment temperature on the preferred orientation of PAN- and pitch-based carbon fibers. (b) Effect of pitch-based carbon fiber preferred orientation on modulus (from Ref. 12). 
1-in.-diam opening of the sample spinner with a large number of parallel fiber tows. As a result, the precision and minimum detectable orientation parameter angle is a function of how parallel and reproducible the fiber tows were manually mounted.

\section{Results}

Table 4 presents our data on the orientation parameter for the eight LTC PAN fibers as well as some other fibers for comparison. The azimuthal intensity scans are provided in Appendix B. Increasing FWHM corresponds to decreasing preferred orientation. The orientation parameter $(Z)$ for most of the LTC fibers is similar $\left(38.5-42.4^{\circ}\right)$ and almost within the measurement error of the analysis $\left( \pm 1.5^{\circ}\right)$ [with the exception of the Textron fibers, which were much less oriented $\left.\left(Z=49.3-54.0^{\circ}\right)\right]$. One would expect the lower degree of preferred orientation in the LTC fibers to influence their mechanical properties, which it does. All of the LTC PAN fibers exhibited a lower degree of preferred orientation than standard PAN fibers, and this is reflected in the lower tensile moduli of the LTC fibers. Figure 10 shows the relationship between preferred orientation (from Table 4) and tensile modulus (from Table 2) for LTC and standard PAN fibers. In addition to lower modulus, the lower degree of preferred orientation of the LTC PAN fibers is also partially responsible for their lower thermal conductivities.

Table 4. Fiber Orientation Parameters

\begin{tabular}{lc}
\hline Fiber & FWHM $\left({ }^{\circ}\right)^{\mathrm{a}}$ \\
\hline Hercules R879-01 & 41.9 \\
Hercules R879-02 & 38.5 \\
BASF DG Rayon 1 & 42.4 \\
BASF DG Rayon 2 & 39.2 \\
Amoco T350/25X & 39.5 \\
Amoco T350/23X & 41.1 \\
Textron Avcarb B-2 & 49.3 \\
Textron Avcarb G & 54.0 \\
Amoco T300 & 37.0 \\
BASF Celion & 37.0 \\
Amoco T50 & 20.8 \\
Amoco P-55 & 17.1 \\
Amoco P100 & 10.4 \\
DuPont E130 & 10.1 \\
\hline
\end{tabular}

aMeasurement Error $= \pm 1.5^{\circ}$. 


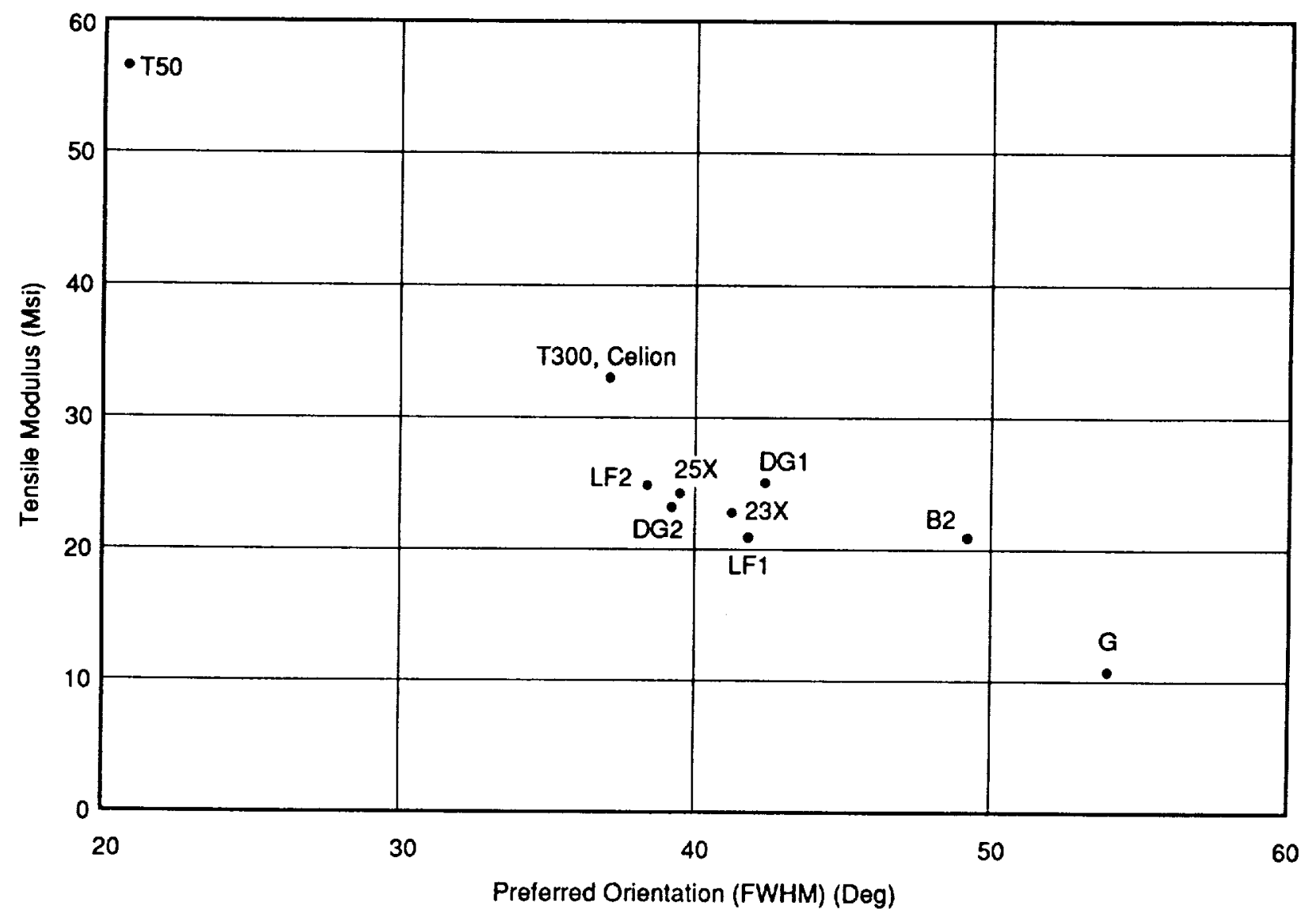

Figure 10. Relationship Between Preferred Orientation and Tensile Modulus for LTC and Standard PAN Fibers. 


\section{SMALL-ANGLE X-RAY SCATTERING}

\section{Background}

Both wide-angle X-ray diffraction (WAXD) and small-angle X-ray scattering (SAXS) are produced by the scattering of $X$ rays by electrons in materials. In the case of WAXD from a crystalline material, the electrons are confined to a periodic array determined by the positions of atoms in the crystal lattice. This produces constructive and destructive interference of the scattered $X$ rays, resulting in discrete reflections. In the absence of a periodic crystalline array, $X$ rays may still be scattered at small angles by differences in electron density resulting from the presence of more than one phase or from other differences in mass density. This scattering is more diffuse and is sensitive to differences in electron density within a material on the scale of 10 to $1000 \AA$. As a result, this scattering can detect pores of these dimensions in carbon fibers and can provide semiquantitative information on their size, shape, and orientation.

A variety of analytical models have been developed for deriving structural information from SAXS data and have been applied to carbon fibers. ${ }^{13-22}$ These models are often dependent on the type of instrumentation used (e.g., slit vs pinhole collimation) and the form of the samples (e.g., random powder vs fiber bundles). Comparisons of results from one model to another can also be difficult because of differing definitions for structural parameters. Reference 23 presents an excellent review of SAXS methods and attempts to show how the various models are related, to reconcile differences, and to systematize nomenclature.

The method of Debye ${ }^{24,25}$ for deriving the sizes of voids in materials and the internal surface area has been applied to carbon fibers ${ }^{13,14}$ and is relatively simple to implement. According to the Debye method, if the distribution of voids is random, a correlation length (a) that is a measure of the grain size of the material is related to the diffracted intensity (I) by

$$
\left(\mathbf{I}_{\theta=0} / \mathrm{I}\right)^{1 / 2}=1+16 \pi^{2} \theta^{2} \mathrm{a}^{2} / \lambda^{2}
$$

The correlation length (a) can then be derived from the slope (m)-to-intercept (b) ratio of a plot of $I^{-1 / 2}$ vs $\theta^{2}$ by

$$
\mathrm{m} / \mathrm{b}=16 \pi^{2} \mathrm{a}^{2} / \lambda^{2}
$$


provided the data fall on a straight line. Deviation from a straight line in these plots is an indication that the distribution of voids is nonrandom. The specific inner surface, $S_{v}$, of the voids, defined in terms of the overall volume in the system, can be estimated from the correlation length, a, using the expression

$$
S_{\mathrm{v}}=4(1-\mathrm{C}) / \mathrm{a} \text {, }
$$

where $\mathrm{C}$ is the fraction of the total volume occupied by carbon, which can be approximated from the density ratio of the carbon fiber to solid graphite. Other characteristics of the fibers, such as the mean chord intercept lengths in the crystallites $\left(l_{c}\right)$ and pores $\left(l_{p}\right)$, are given by

$$
\mathrm{l}_{\mathrm{c}}=4 \mathrm{C} / \mathrm{S}_{\mathrm{v}}=\mathrm{a} /(1-\mathrm{C}) \quad \text { and } \quad \mathrm{l}_{\mathrm{p}}=4(1-\mathrm{C}) / \mathrm{S}_{\mathrm{v}}=\mathrm{a} / \mathrm{C} .
$$

These parameters, more easily visualized in Figure 11, have also been referred to as transversal or inhomogeneity lengths. ${ }^{23}$ They are related to the correlation length by

$$
1 / \mathrm{a}=1 / 1_{\mathrm{c}}+1 / \mathrm{l}_{\mathrm{p}}
$$

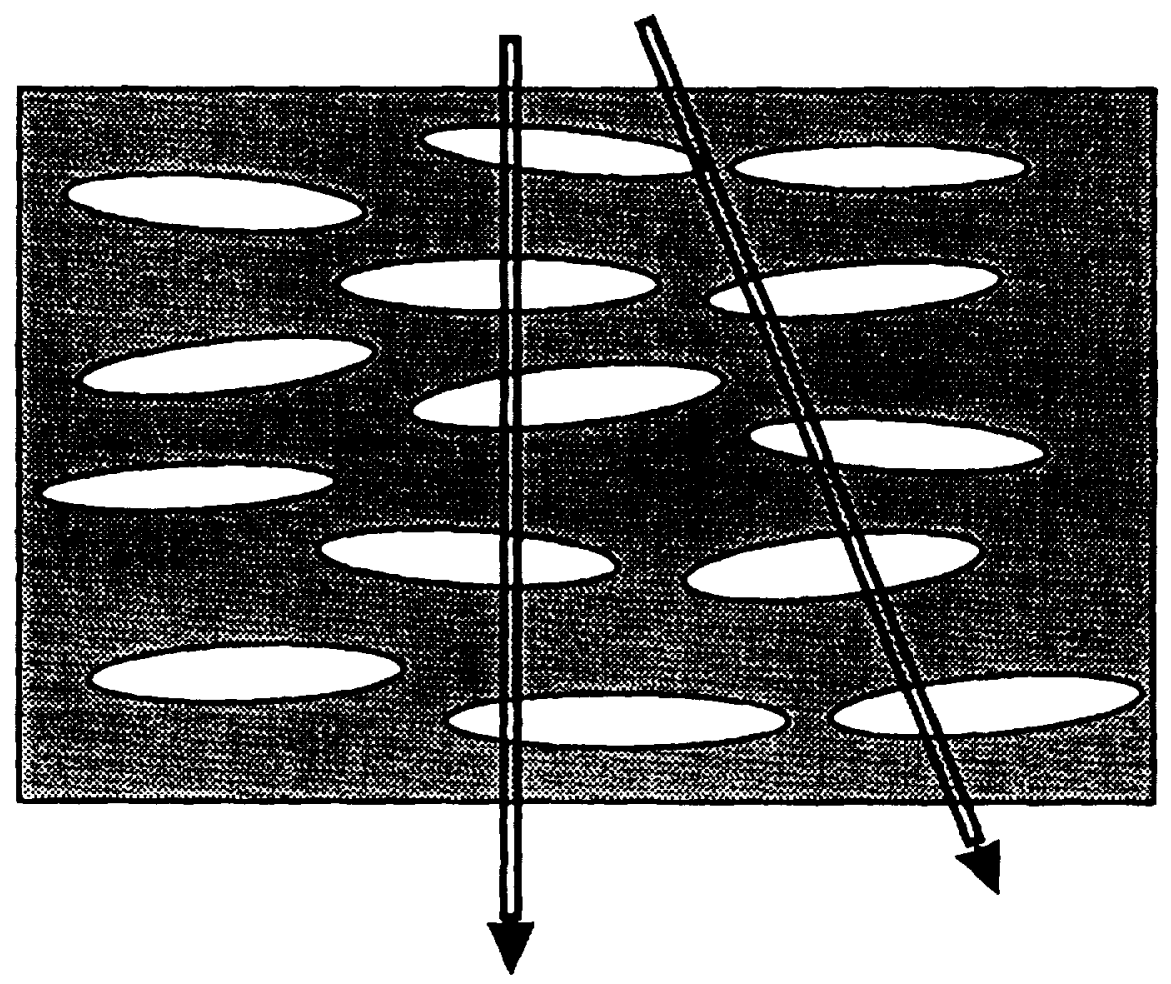

Figure 11. Schematic of pore system in carbon fibers. The average lengths of the dark areas of the arrow shafts represent $I_{C}$, and the average lengths of the light areas of the arrow shafts represent $I_{p}$. 
A distance of heterogeneity $\left(\mathrm{L}_{\mathrm{p}}\right)$ has also been defined ${ }^{13,14}$ that relates the probability that a line of length $r$ will have both its ends situated in pores. $L_{p}$ is related to a by

$$
\mathrm{L}_{\mathrm{p}}=2 \mathrm{a}
$$

$L_{p}$ may be more meaningful than $l_{c}$ and $l_{p}$ since it is independent of the packing fraction $\mathrm{C}$ and does not assume any particular form for the statistical distribution of pore size. ${ }^{14}$

The method of Porod ${ }^{23,26}$ has also been applied to carbon fibers ${ }^{15-19}$ and can be used to obtain another measure of the internal specific surface and other structural parameters. This method is more difficult to implement, however, and requires numerical integration. In Porod's theory, the tail end of the scattering curve should follow an asymptotic course of $s^{-4}$ for collimation with small pinholes, where $s=(2 \sin \theta) / \lambda$. As a result, plots of $\mathrm{s}^{4} \mathrm{I}$ vs $\mathrm{s}^{4}$ reach a limiting value at large angles. To determine structural parameters, it is also necessary to evaluate a quantity referred to as the invariant, $\mathrm{Q}_{\mathrm{s}}$, given by

$$
\mathrm{Q}_{\mathrm{s}}=\int_{0}^{\infty} \mathrm{s}^{2} \mathrm{I}(\mathrm{s}) \mathrm{ds}
$$

The experimental determination of the invariant, however, is often difficult because the scattered intensities at both very small and very large angles must be determined with acceptable accuracy. ${ }^{23}$ In addition, the intensities and their measurement are a function of the samples and the method of recording the data.

The method of Guinier, which applies to dilute systems, ${ }^{23}$ may also be applied to carbon, where it can be used to approximate the electronic radius of gyration, $R$. If Guinier's law is obeyed, a plot of $\log _{\mathrm{e}} \mathrm{I}(\mathrm{s})$ vs $\mathrm{s}^{2}$ will be linear over a large range, with an ordinate intercept of $\log _{\mathrm{e}} \mathrm{I}(0)$ and a slope of $-\mathrm{R}^{2} / 3$. Converting to logarithms to the base 10 ,

$$
R=(1 / 2 \pi)(3 \times 2.303 \times \text { slope })^{1 / 2}
$$




\section{Experimental}

The small-angle $X$-ray scattering from the fibers was recorded using nickel-filtered copper radiation with a flat-plate camera having pinhole collimation $(0.020$ in. pinholes). The camera was purchased from Blake Industries and could accommodate sample-to-film distances of 3 to $31 \mathrm{~cm}$. At the largest distance, a range of $0.3^{\circ}$ to $3.0^{\circ}$ $2 \theta$ could be recorded on the film, which can be correlated with pore features as large as $320 \AA$. The distance, $r$, of a feature on the film from the direct beam can be related to the diffraction angle, $2 \theta$, using simple geometry with the equation

$$
\tan (2 \theta)=\mathrm{r} / \mathrm{X}
$$

where $\mathrm{X}$ is the sample-to-film separation distance. This camera has the advantage that it is relatively inexpensive and the film can easily record SAXS intensity in two dimensions, which is important for studies of preferred orientation of nonspherical particulates or voids. It is difficult, however, to obtain good quantitative measurements of intensity from the film, as opposed to systems with electronic detectors, and the pinhole collimation system drastically reduces the intensity of the incident X-ray beam.

Qualitative survey photographs of one tow of each of eight LTC PAN fibers, along with Amoco T300 and T50, and CCA3 Rayon, were recorded at $45 \mathrm{kV} / 30 \mathrm{~mA}$ with a sample-to-film separation distance of $17 \mathrm{~cm}$ and an exposure time of $3 \mathrm{hr}$. The photographs were taken with Kodak direct exposure film (DEF). Samples were analyzed under a vacuum produced by a mechanical pump in order to eliminate the effects of scattering from air in the camera.

To make the conditions of analysis more reproducible for quantitative measurements, a sample fixture that fit over the collimator assembly was designed with a $0.050 \mathrm{in}$. wide channel to accept the fiber tows. Two fiber tows consisting of -3000 fibers each were placed in the channel and compacted with a microscope slide while an adhesive was applied to the ends of the tows. The exposure times and the power to the X-ray generator were selected to produce a maximum optical density (OD) for the SAXS pattern of less than approximately 3.0. For these analyses, a sample-to-film distance of $31 \mathrm{~cm}$ was used, and, with the exception of the Amoco T50 fibers, generator settings of $45 \mathrm{kV} / 30 \mathrm{~mA}$ and exposure times of $30 \mathrm{~min}$ were employed. Much lower settings $(30 \mathrm{kV} / 20 \mathrm{~mA} ; 30 \mathrm{~min})$ were used for the Amoco T50 fibers because of their intense SAXS. It was estimated that the intensity of the X-ray beam was $35 \%$ of that used for the other fibers. 
The characteristic curve, a plot of optical density vs log exposure, was generated for the DEF by exposing an Amoco T300 sample $(\mathrm{X}=5 \mathrm{~cm})$ for times ranging from 5 to 900 min and measuring the maximum darkening (optical density) of the 002 reflection using a densitometer with a 1-mm aperture. This curve is necessary for extracting quantitative information about structural parameters, such as pore sizes, from the SAXS photographs since it relates film darkening (optical density) directly to relative $\mathrm{X}$-ray flux (which correlates with relative exposure time).

Quantitative measurements were obtained from the SAXS photographs of Amoco T50, T300, T350/23X, T350/25X, and BASF DG Rayon 1 fibers by digitizing both the images and a Kodak photographic step tablet (No. 2). The digitizing was accomplished by backlighting the SAXS photographs and step tablet with a high-intensity light source. The optical system, consisting of a Pulnix TM 745 charge-coupled device (CCD) camera equipped with a Nikon 50-mm macro lens, was interfaced to a Macintosh II FX computer. The computer was operated with an NIH Image version 1.22 image analysis software package. The interface was accomplished by an 8-bit Data Translation DT2255 60-Hz frame grabber board. Each SAXS photograph and the step tablet were digitized using three shutter speeds for the CCD in order to extend the limited (0-255) gray scale range over a greater spread of optical density. Equatorial line profiles were obtained from the same pixel locations of the SAXS images at each shutter speed setting. These data were then transferred to a VAX $4000 \mathrm{com}$ puter for data processing. A composite OD equatorial line profile was constructed from the files taken at the three shutter speeds and the corresponding calibration curves obtained from the digitized step tablet images. The characteristic curve for the $\mathrm{X}$-ray film was then used to calibrate the OD to the relative $\mathrm{X}$-ray exposure.

\section{Results}

\section{a. Qualitative Observations}

The qualitative (with $X=17 \mathrm{~cm}$ ) and quantitative (with $X=31 \mathrm{~cm}$ ) SAXS photographs of the LTC PAN fibers, along with Amoco T300 and T50, and CCA3 Rayon, are presented in Figures 12-14. They cover a range of approximately $0.5^{\circ}$ to $4.8^{\circ} 2 \theta$. The white disc in the center of the photographs is the shadow of the direct beam stop supported by a thin wire. Note that the qualitative photographs have not been recorded under completely reproducible conditions. In particular, the SAXS from the Amoco T300 and T50 fibers was probably greater than the SAXS from the LTC fibers since the camera was better aligned during the exposures for the T300 and T50 fibers, and the X-ray beam was more intense. 


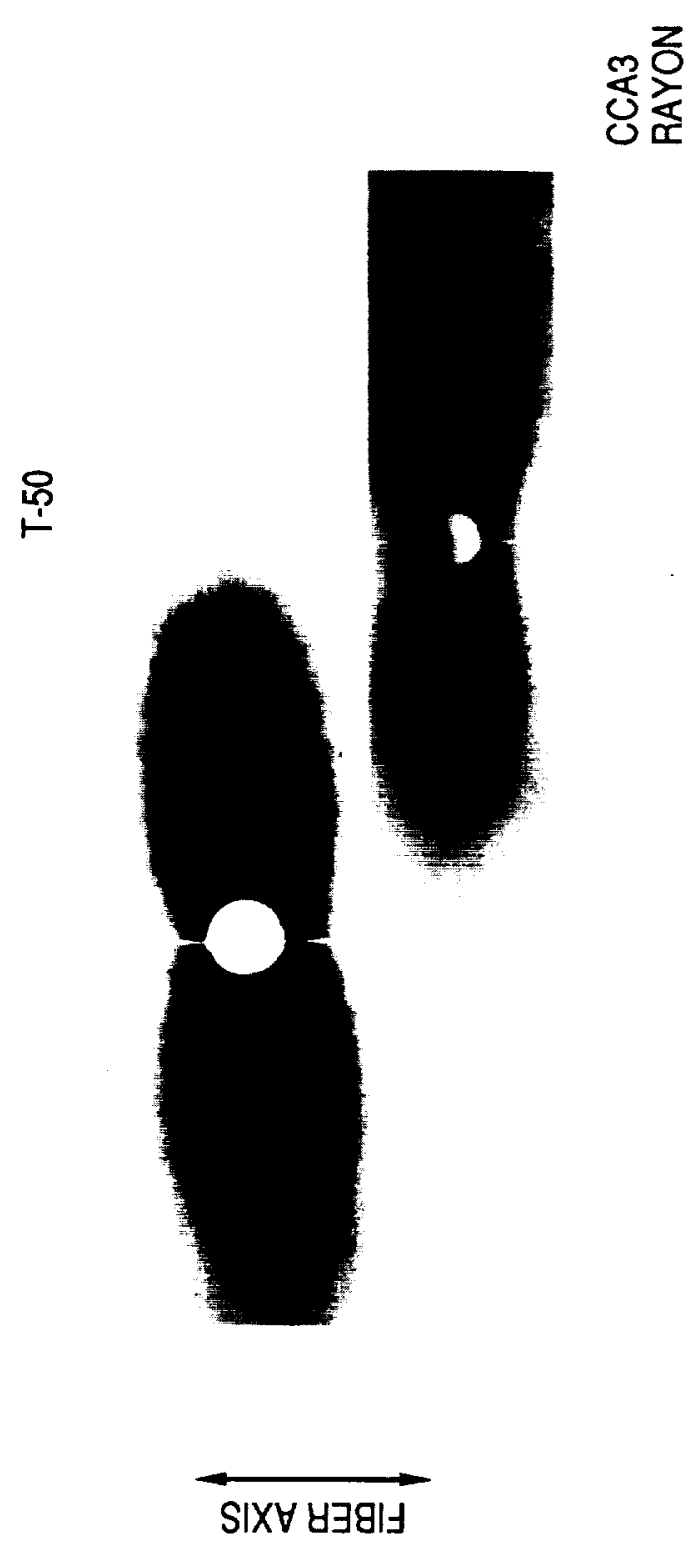

윰

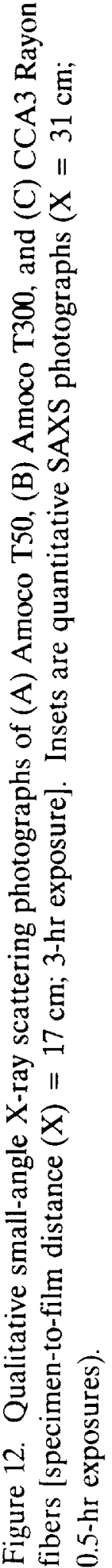



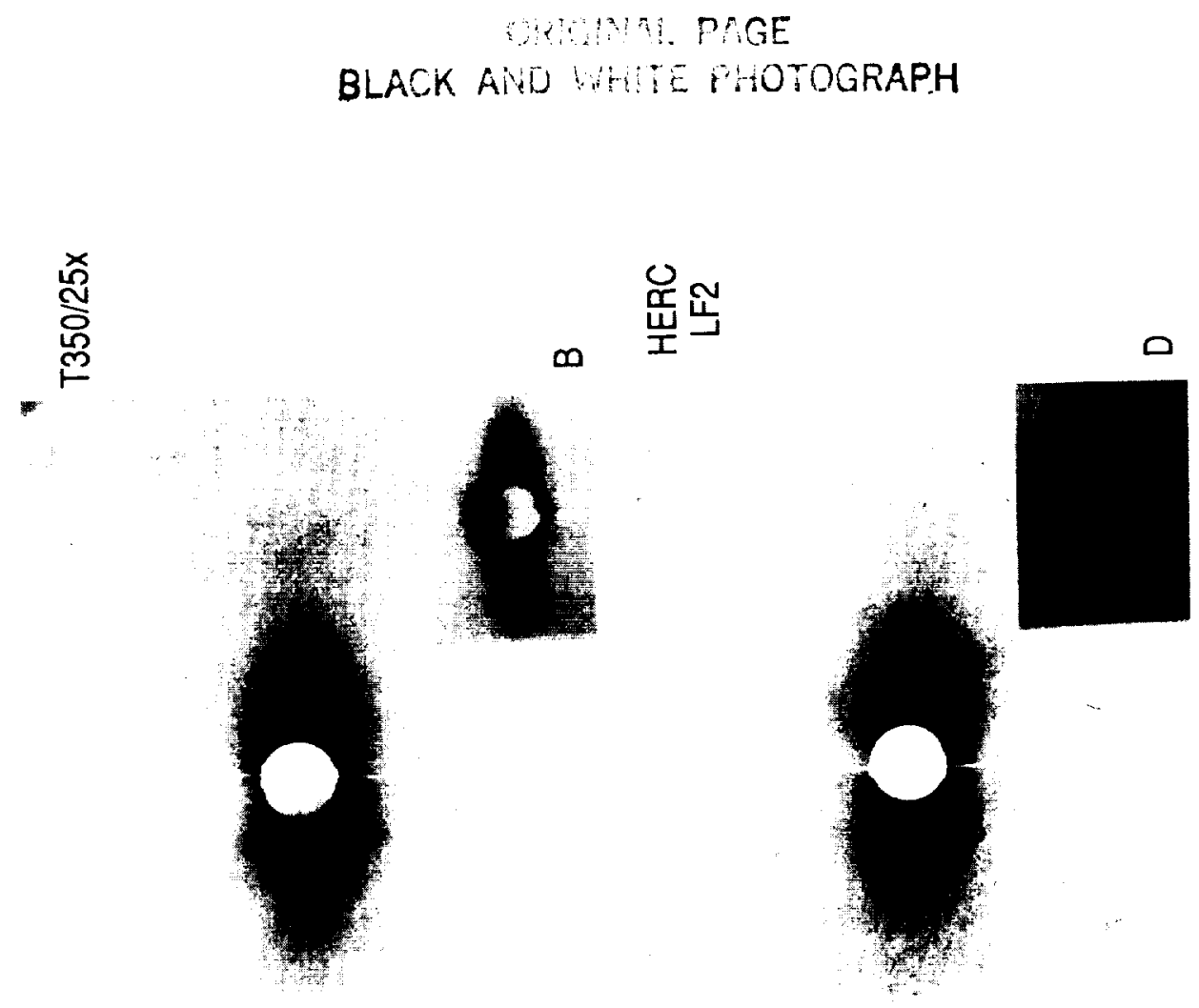

O̊

颃

芯芯

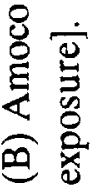

총

点

85

五

造造
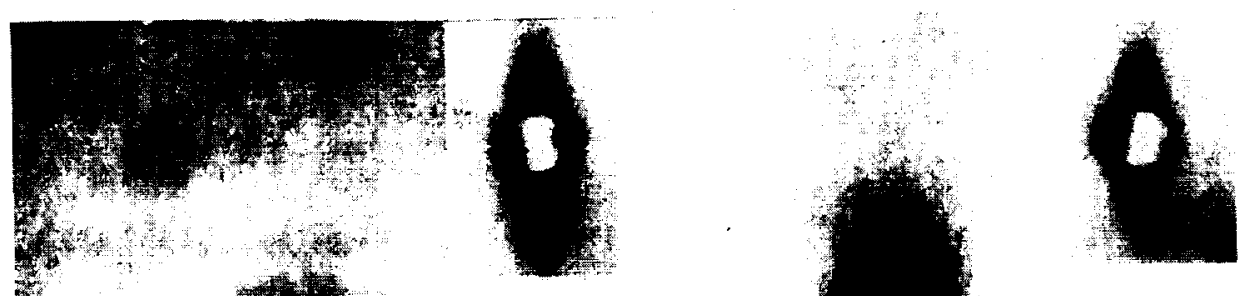

突

足

듬 $\frac{1}{11}$

品

志递

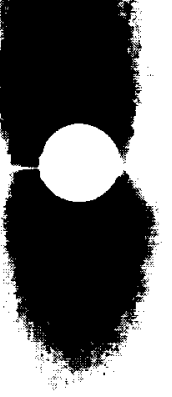

的品

灾造

菂

\% 웅

कृ

乐

质

需

:绨

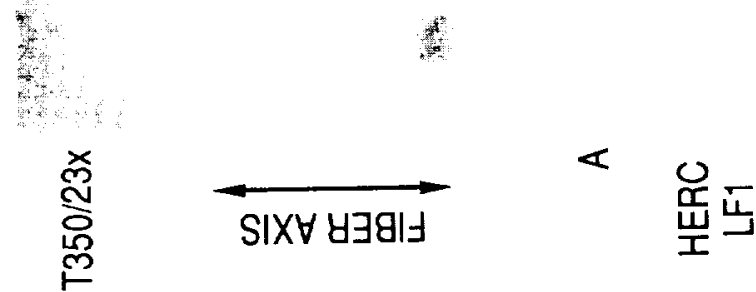

C

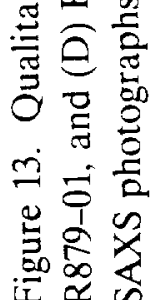


ORIGINAL PAGE

\section{BLACK AND WHITE PHOTOGRAPH}

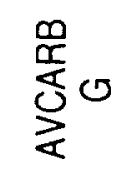

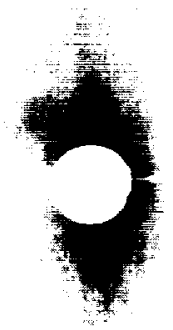

$\infty$ 放
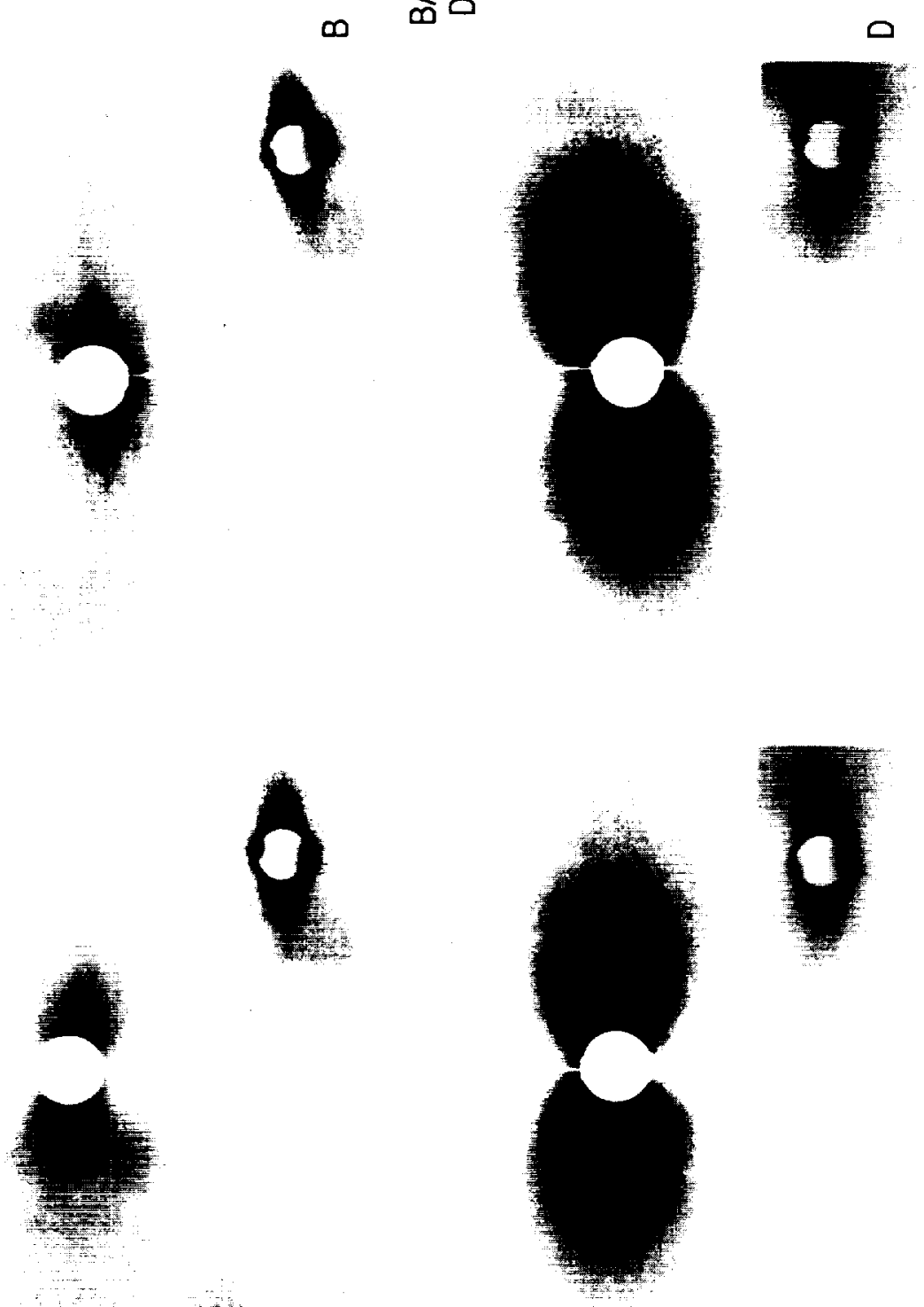

它皆

岁?

要

(0)

ن

ह

这

$\Xi \Xi$

혼

$\stackrel{\Xi}{\leftrightarrows}$

可

i

它春

을

安蕰

5.

氮

过兽

를

要

웅 1

동

.

影

氖

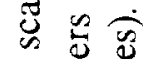

完远

政

등

踪

可

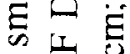

艾需

密的

䆑

0

峁安

品

$\checkmark$ 的

可

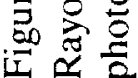


The CCA3 Rayon displays very little SAXS [Figure 12(c)], indicating that very few pores in the range of 10 to $320 \AA$ are present. The Amoco T50 and T300 fibers, on the other hand, display considerable SAXS in lobe-shaped patterns. These patterns have been attributed to the presence of needle-shaped pores aligned along the fiber axis. This interpretation is based on the observation that the SAXS does not extend very far in the direction of the fiber axis, which indicates the presence of a large-size scattering dimension. That is, $r$ is small, $\theta$ is small [from Eq. (11)], and, therefore, $d$ is large [from Eq. (1)]. Conversely, since the SAXS extends further in the direction perpendicular to the fiber axis, the size of the scattering dimension must be smaller, resulting in an elongate or needle-shaped feature. The fan-shaped lobes in the SAXS pattern from the T50 fibers are narrower than the lobes in the SAXS pattern from the T300 fibers. The narrower lobes have been attributed to a greater alignment of the pores, which, in PAN-based fibers, directly relates to the alignment of the graphitic basal planes in the fiber. ${ }^{15,16}$ Since the basal planes have a greater preferred orientation in the T50 fibers (see Table 4), it follows that the pores are also more highly aligned.

With the exception of the BASF DG Rayon 1 and DG Rayon 2 fibers, the SAXS patterns from the LTC fibers are very similar and show very little SAXS. The SAXS patterns from the BASF fibers are intermediate between T300 and the other LTC fibers, and display fan-shaped lobes in the longer exposure $(3 \mathrm{hr})$ photographs. These lobes are less evident in the shorter exposure $(0.5 \mathrm{hr})$ photographs. The intensities of SAXS from the BASF fibers are consistent with the low-angle portion of the WAXD $\theta-2 \theta$ scans (Figure 7).

The SAXS photographs of the LTC fibers display oriented and intense scattering at very low angles $\left(<0.4^{\circ} \theta\right)$ that may not be related to scattering from pores in the fibers. SAXS studies have been conducted where PAN-based fibers have been analyzed before and after soaking in glycerin. It was found that this intense scattering at very low angles was greatly diminished after soaking with glycerin, while other SAXS was minimally affected. ${ }^{16,17,22}$ From this observation, it has been concluded that the majority of the pores in the fibers were inaccessible to glycerin. However, the cause for the intense scattering at very low angles is unresolved. It has been suggested that multiple scattering within fibers with highly irregular cross sections is responsible, ${ }^{16,17}$ but a similar effect has been observed in fibers with nearly circular cross sections and minimal surface texture. In the latter case, it was thought that external reflection of $\mathrm{X}$ rays from the fiber surfaces produced the intense scattering at very low angles. ${ }^{22}$

Samples of T50 and T300 fibers and one LTC fiber from each of the manufacturers were examined in the scanning electron microscope (SEM) to determine whether surface irregularities were present that might contribute to the SAXS profiles. The SEM images are presented in Figures 15-17. Large axial grooves were observed on the 
ORIGINAL PAGE

BLACK AND WHHTE PHOTOGRATM
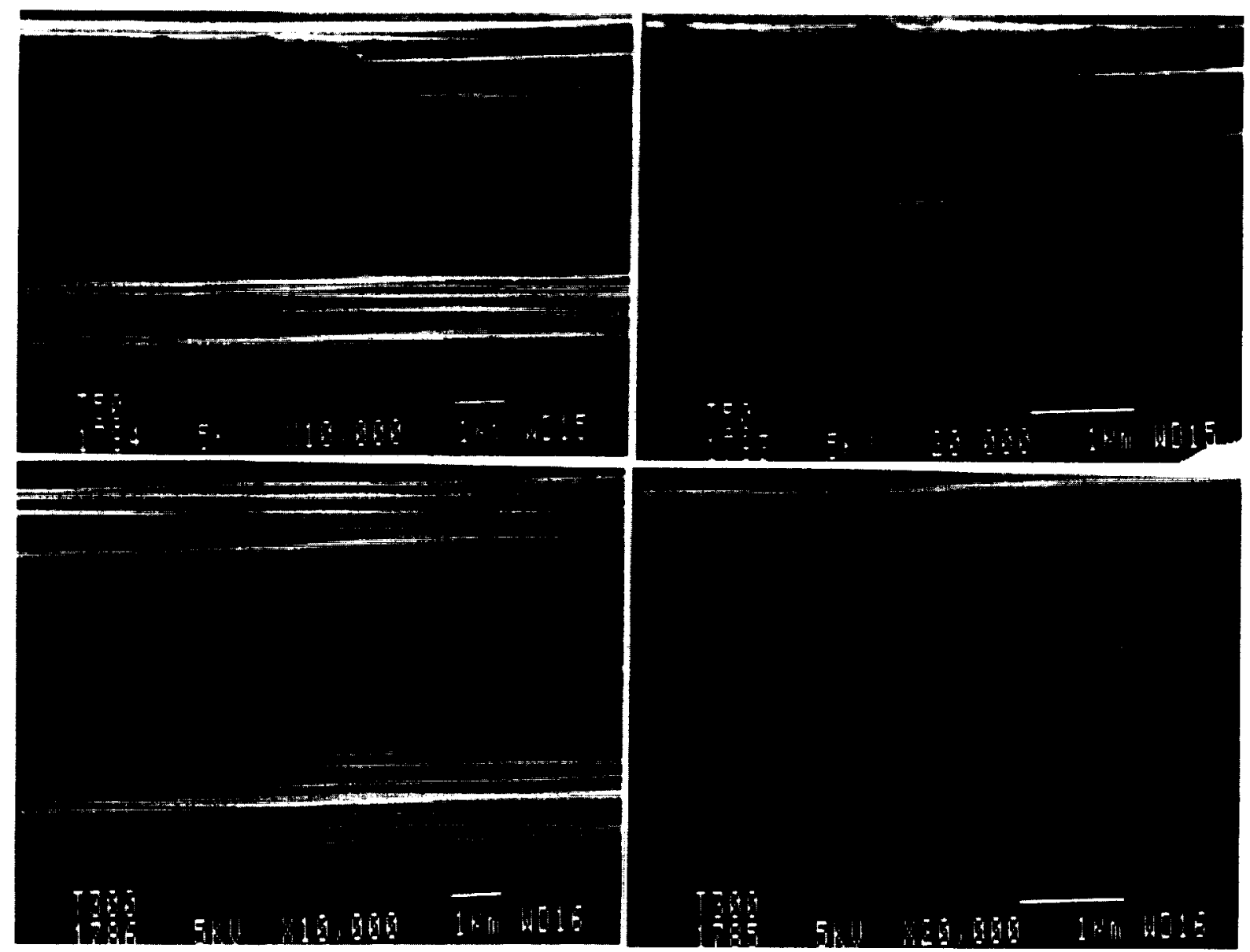

Figure 15. Scanning electron microscope photographs of the surfaces of Amoco T50 and T300 fibers. 
BLACK AND VUHTE PHOTOGRAPH

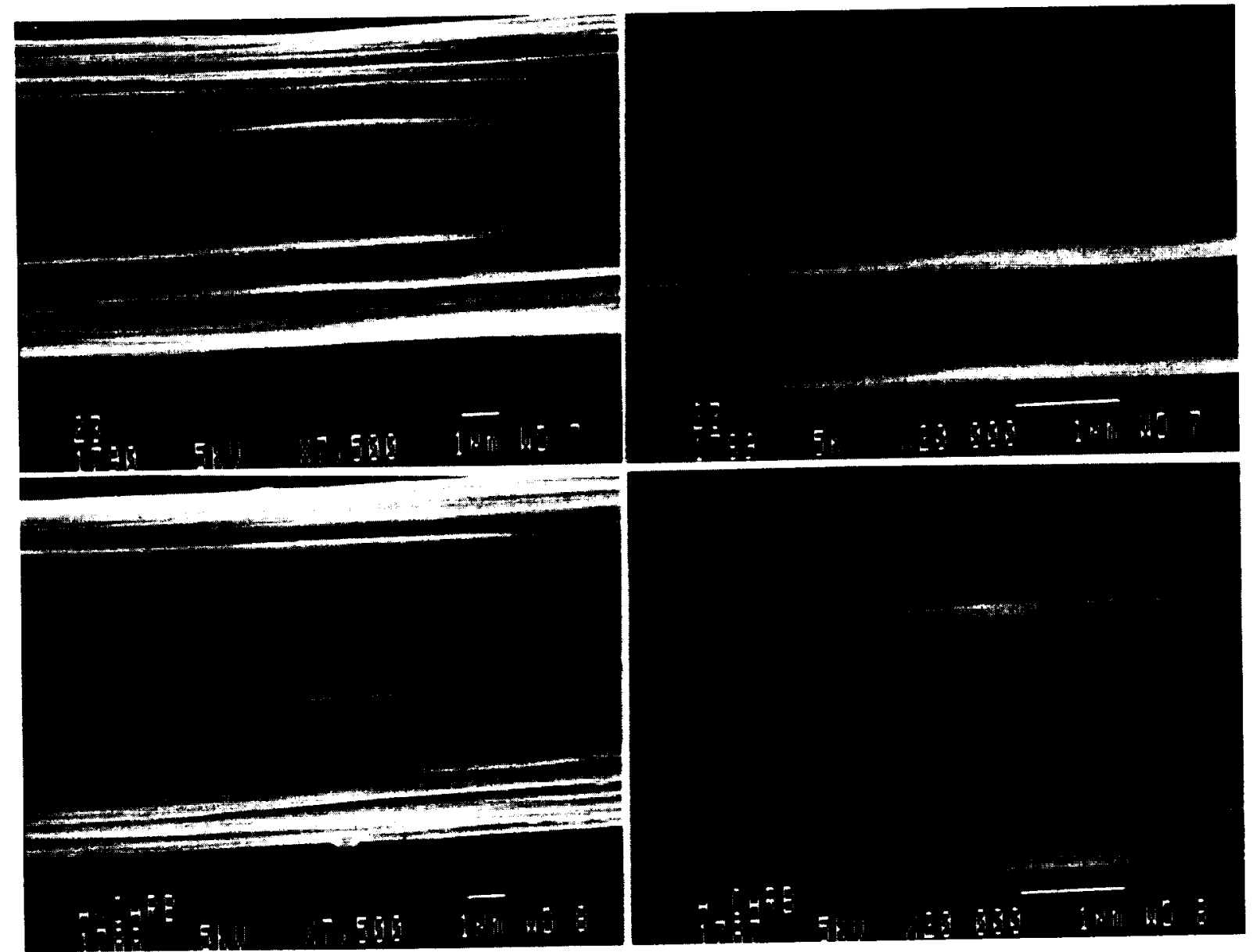

Figure 16. Scanning electron microscope photographs of surfaces of Amoco T350/23X and Textron Avcarb B-2 fibers. 

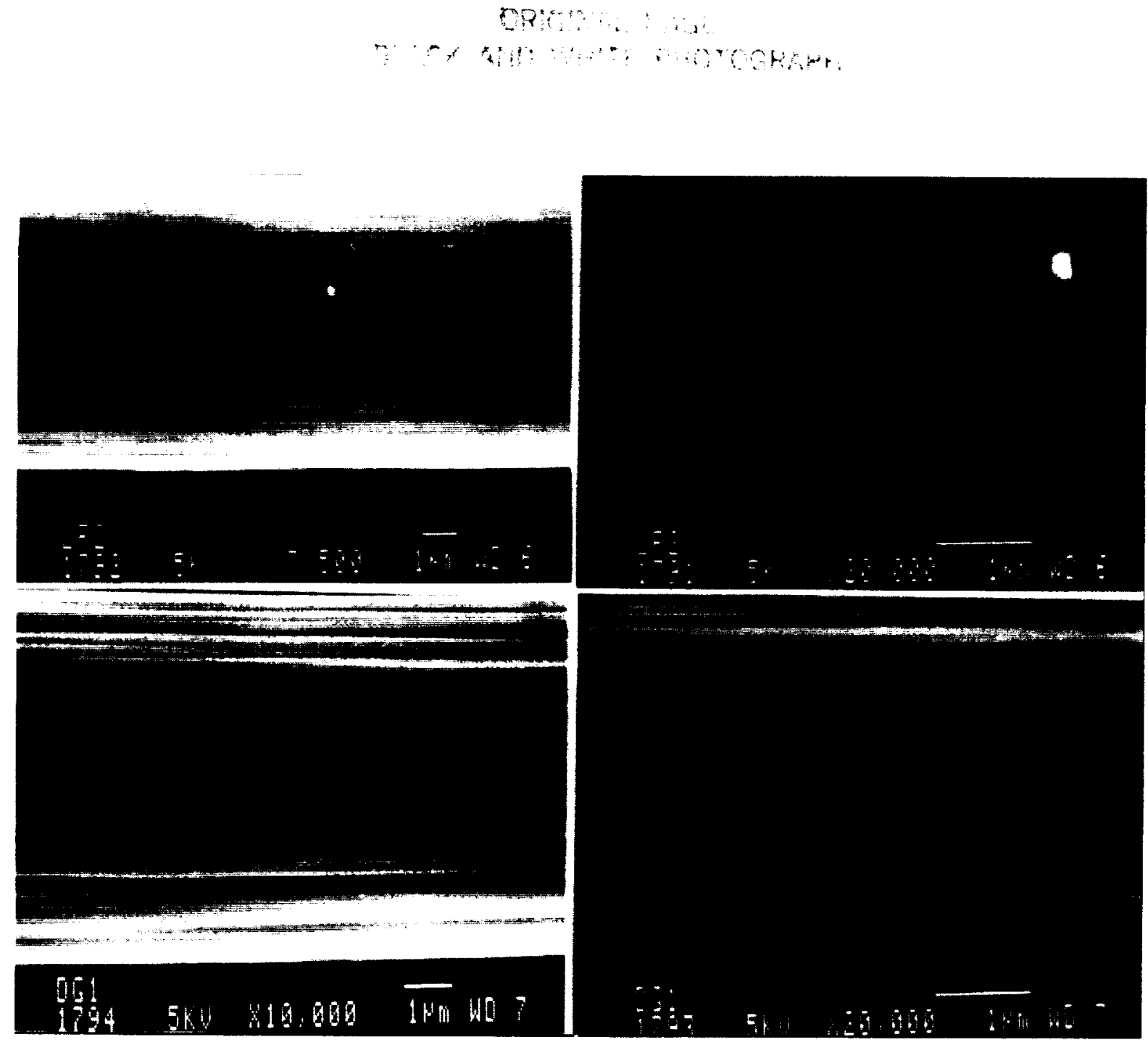

Figure 17. Scanning electron microscope photographs of surfaces of Hercules R879-02 and BASF DG Rayon 1 fibers. 
surfaces of the Amoco T50, T300, T350, and Textron fibers. The widths of these grooves were on the order of 0.1 to $1.0 \mu \mathrm{m}$. In contrast, the surface of the Hercules fiber (R879-02) was much smoother. However, those differences could not be easily correlated with the SAXS patterns.

\section{b. Quantitative Measurements}

Figure 18 presents the characteristic curve measured for Kodak DEF showing the near-linear relationship between $\mathrm{OD}$ and $\mathrm{X}$-ray exposure (exposure time) over a range of $\mathrm{OD}=0-3$, as shown in Figure 18(b). The gray scale/OD calibration curves obtained by digitizing the Kodak step tablet at various CCD shutter speeds are presented in Figure 19. The calibration curves represent either linear or polynomial fits to the data. Composite equatorial line traces of the SAXS data were assembled from individual traces at the three shutter speeds. Calibration for the OD ranges of $0-1$, $1-2$, and 2-3 were obtained from the digitized images taken with shutter speed settings of 2, 4, and 7, respectively (see Figure 19).

Comparative equatorial line traces of SAXS intensity (OD) as a function of $\theta$ for five fibers are presented in Figure 20. Intensity (OD) contour maps of these SAXS images are shown in Figures 21 and 22. Complete sets of SAXS data plots including OD vs $\theta$, Debye $\left(\mathrm{I}^{-1 / 2}\right.$ vs $\left.\theta^{2}\right)$, Guinier $\left(\log I\right.$ vs $\left.S^{2}\right)$ and Porod $\left(\mathrm{IS}^{4}\right.$ vs $\left.\mathrm{S}^{4}\right)$ plots are presented in Appendix C.

In Figure 20, it can be seen that the SAXS intensity from the Amoco T50 and T300 fibers is considerably greater than the intensity from the three LTC fibers that were examined. This is consistent with the model of pore formation in carbon fibers. As the fibers are heat treated, volatiles such as nitrogen are released, which contribute to the formation of pores. At higher HTTs, a greater fraction of the volatiles is expected to have been evolved, thereby resulting in larger and more numerous voids. In Figure 20, the strong SAXS intensity at very low angles $\left(<0.4^{\circ} \theta\right)$ is the most prominent feature of the profiles of the LTC fibers. As mentioned earlier, this SAXS may not be related to pores in the material. The SAXS differences between the LTC fibers seen in the qualitative photographs are not obvious in Figure 20 because they are lost in the noise in the tails of the profiles. This was a result of the much shorter exposure times used to record the quantitative photographs. The more lobe-shaped nature of the SAXS from the BASF DG Rayon 1 sample, however, may be seen in the digitized image of the quantiative SAXS photographs [Figure 22(a)].

A summary of the structural parameters derived from the SAXS data using the method of Debye is given in Table 5 . The values of $l_{c}, l_{p}$, and $L_{p}$ for the T50 and T300 fibers are similar to those reported for high-modulus carbon fibers graphitized to $2800^{\circ} \mathrm{C}^{13,14}$ and are consistent with the trend that these values increase with 

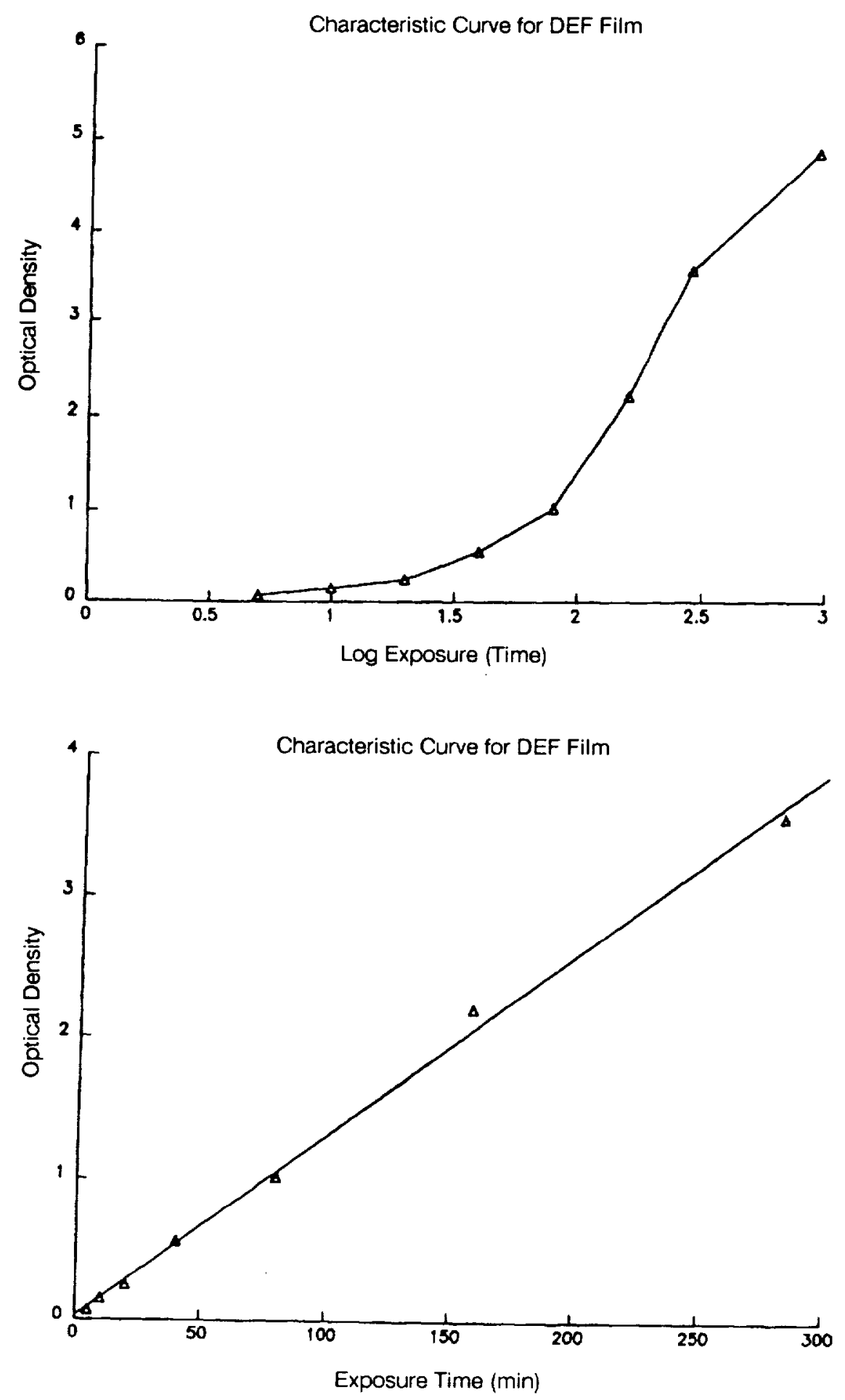

Figure 18. Characteristic curves determined for Kodak direct exposure film (DEF). 


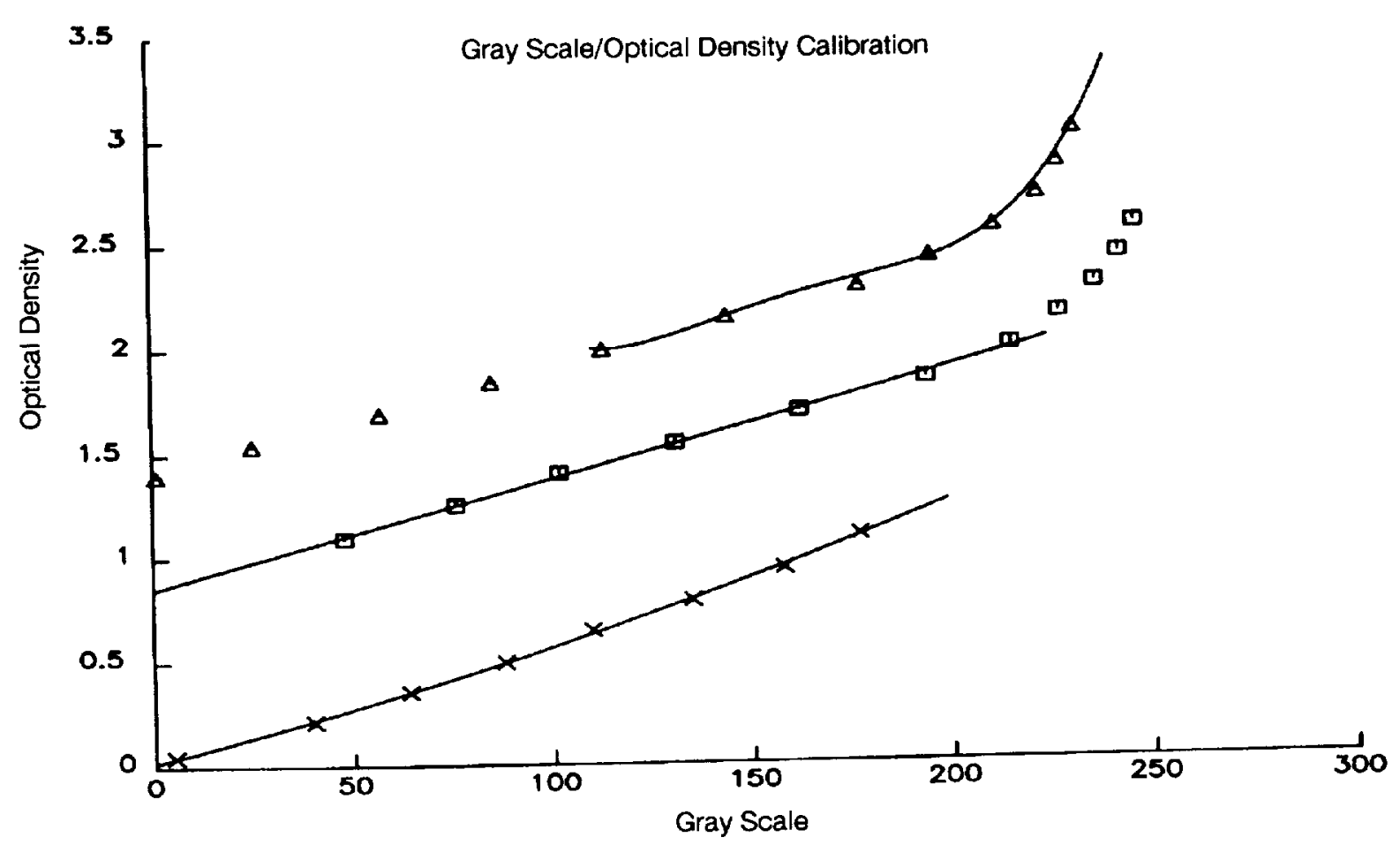

Figure 19. Gray scale/optical density calibration curves measured from photographic step tablet with different CCD shutter speeds.

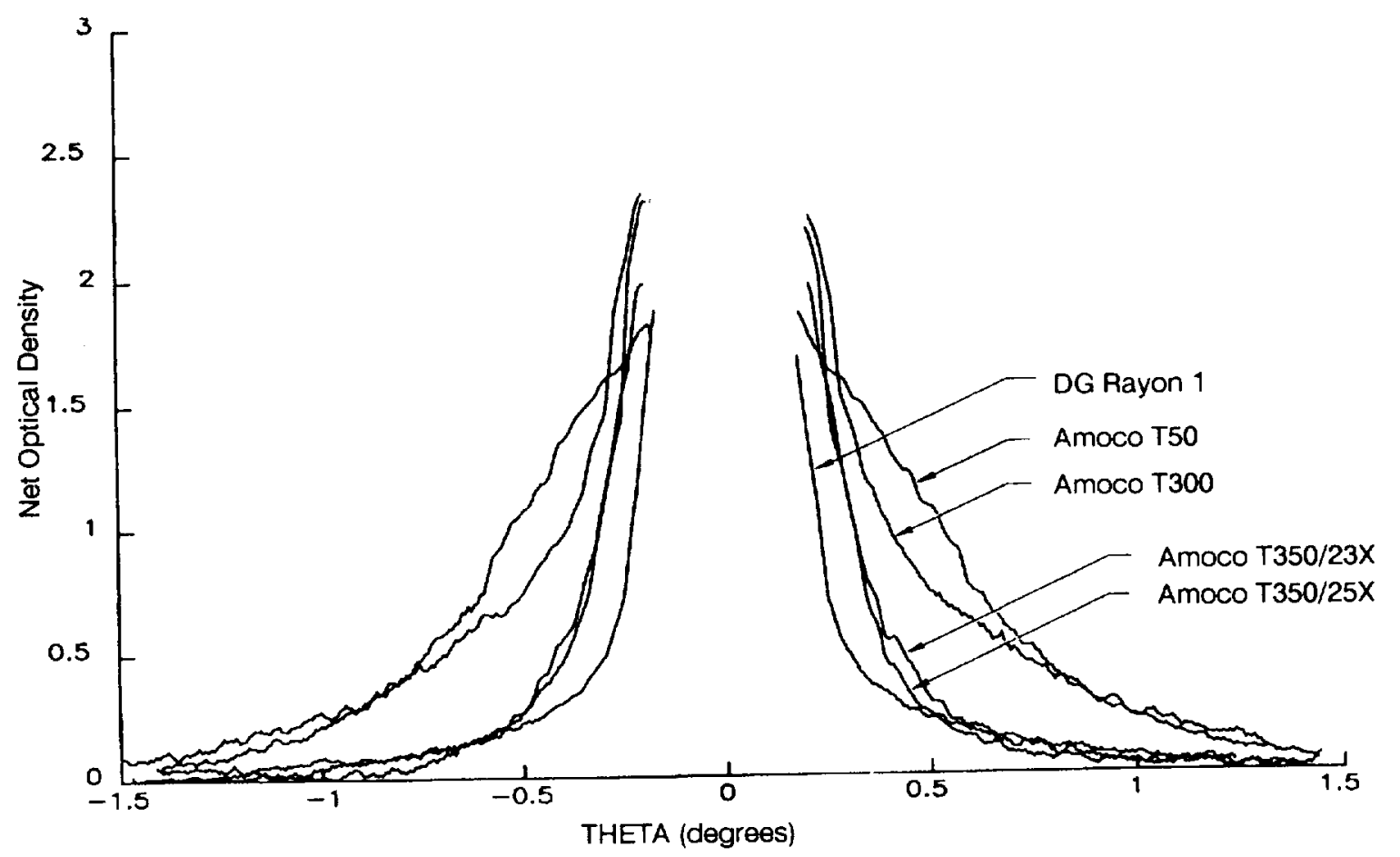

Figure 20. Equatorial lines traces of SAXS of carbon fibers obtained by digitizing SAXS photographs. Intensity of T50 $\times 0.35$. 


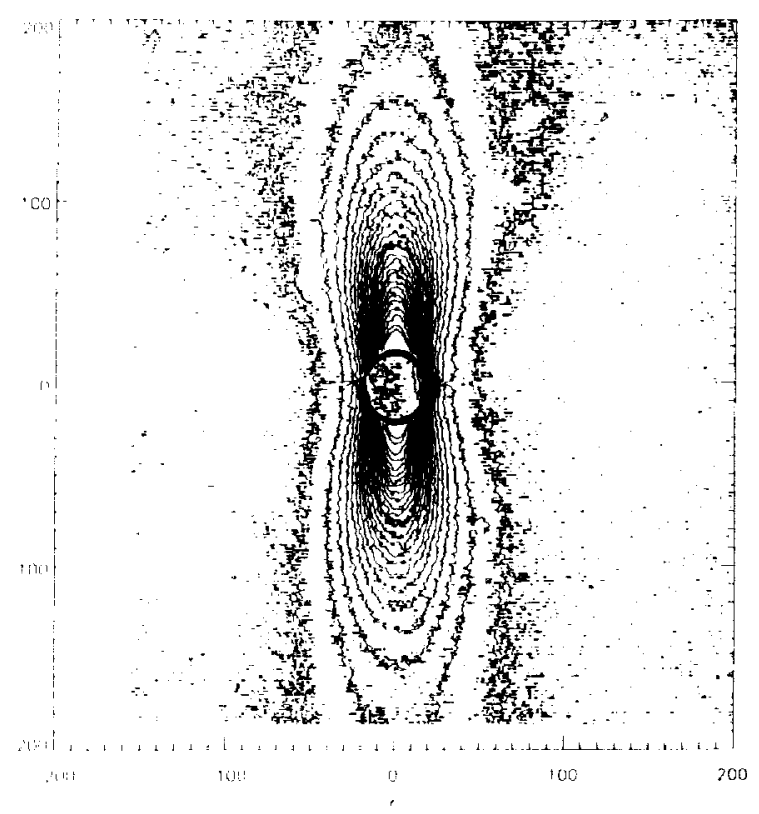

(a)

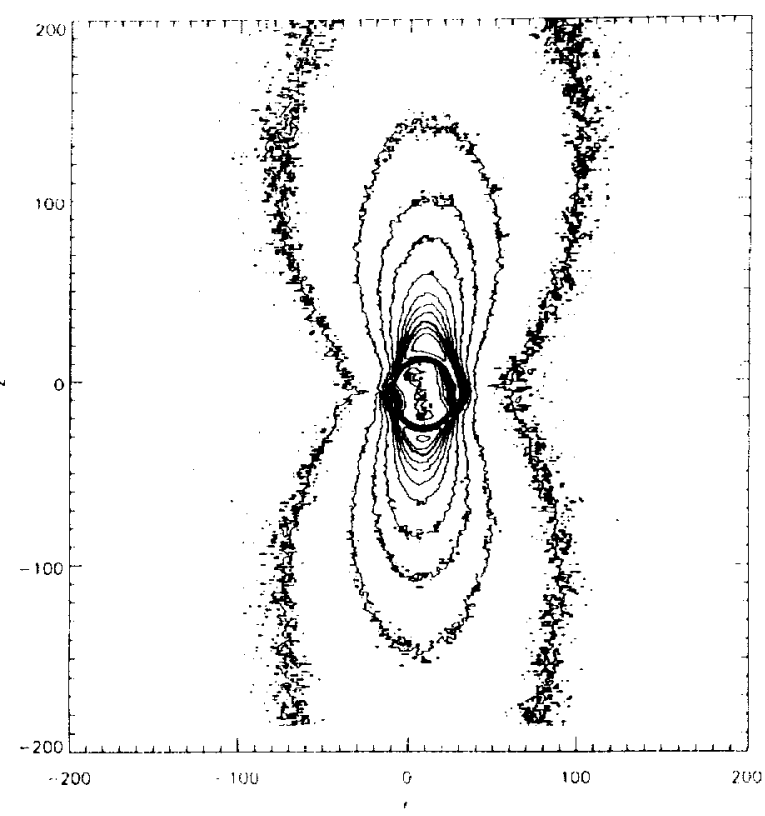

(b)

Figure 21. SAXS intensity contour maps for (a) Amoco T50 and (b) T300 fibers.

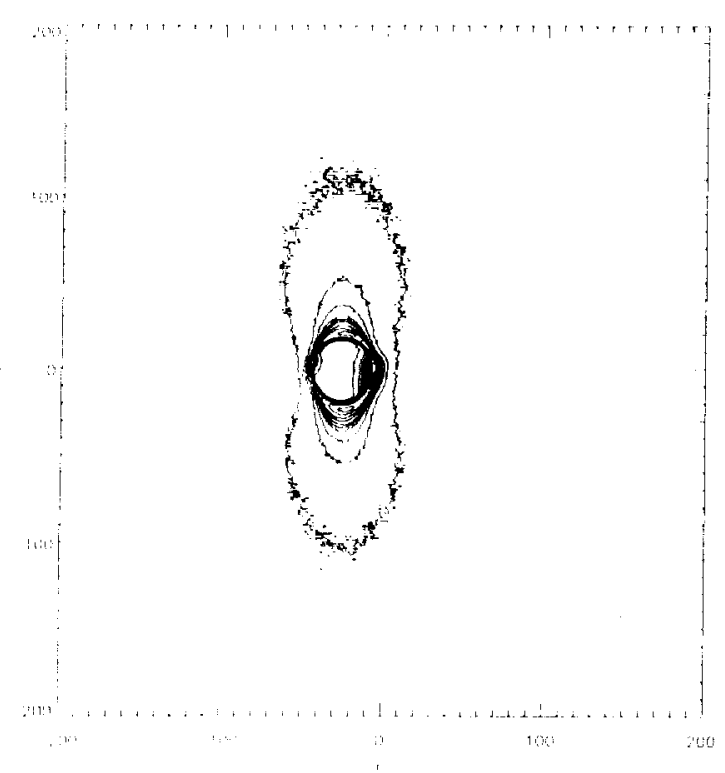

(a)

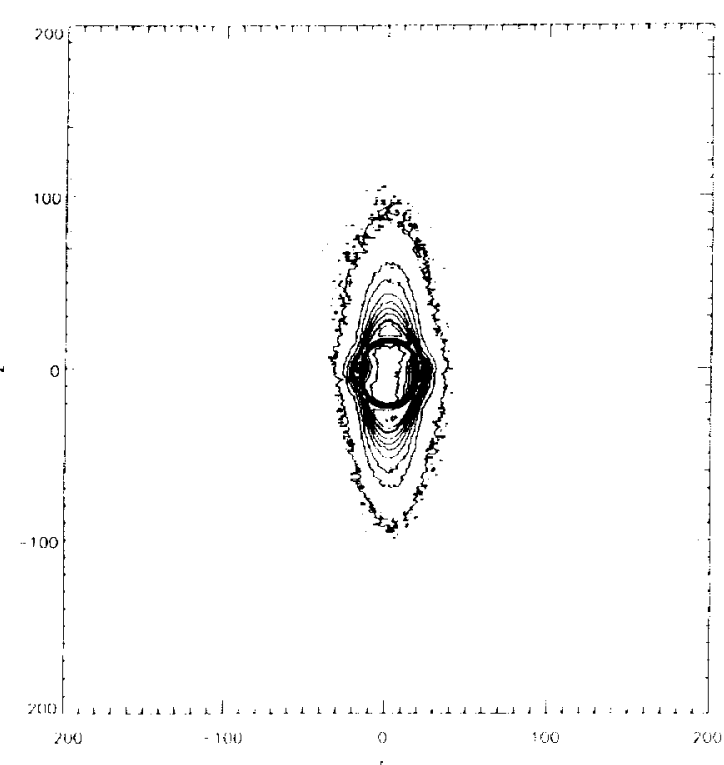

(b)

Figure 22. SAXS intensity contour maps for (a)BASF DG Rayon 1 and (b) Amoco T350/23X fibers. 
Table 5. Summary of Structural Information Derived from Small-Angle X-ray Scattering (SAXS)

\begin{tabular}{lcccccc}
\hline \multicolumn{1}{c}{ Sample } & $(\mathrm{a}), \AA$ & $\mathrm{S}_{\mathrm{v}} \AA^{-1}$ & $\mathrm{I}_{\mathrm{c}}, \AA$ & $\mathrm{I}_{\mathrm{p}}, \AA$ & $\mathrm{L}_{\mathrm{p}} \AA$ & $\mathrm{R}, \AA$ \\
\hline Amoco T50 & 11.9 & 0.049 & 67.2 & 14.5 & 23.8 & 20.8 \\
$\begin{array}{l}\text { Amoco T300 } \\
\text { Amoco }\end{array}$ & 10.8 & 0.056 & 58.1 & 13.3 & 21.6 & 14.0 \\
$\begin{array}{l}\text { T350/23X } \\
\begin{array}{l}\text { Amoco } \\
\text { T350/25X }\end{array}\end{array}$ & 32.2 & 0.024 & 168.6 & 39.8 & 64.4 & $\star$ \\
$\begin{array}{l}\text { BASF DG } \\
\text { Rayon1 }\end{array}$ & 33.4 & 0.023 & 174.9 & 41.4 & 66.8 & * \\
\hline
\end{tabular}

* Not determined.

increasing HTT. ${ }^{15}$ Perret and Ruland ${ }^{15}$ have published values of $l_{c}$ and $l_{p}$ for PANbased fibers heat treated from $2000^{\circ}$ to $3000^{\circ} \mathrm{C}$ that are smaller than those in Table 5 by approximately a factor of 2 . However, they used the Porod model for deriving these values. In addition, their instrumentation and experimental conditions, while requiring different data treatment, were capable of easily measuring a greater range ( 3 to 4 orders of magnitude) of scattering intensity than the film technique employed by us. Therefore, the values for the structural parameters in Table 5 convey the correct magnitude for the various features and for the relative differences between samples. However, it is difficult to compare these values directly with other data in the literature.

The $l_{c}, l_{p}$, and $L_{p}$ values derived for the two Amoco LTC fibers (T350/23X and $\mathrm{T} 350 / 25 \mathrm{X}$ ) are similar to each other and considerably greater than those for the T50 and T300 fibers. This is "out of trend" since these values are usually expected to increase with increasing HTT. It was previously noted that the LTC fibers exhibit intense SAXS at very low angles $\left(0.4^{\circ} \theta\right)$, which may not be related to the pore structure of the fiber, and that the associated pore-related SAXS is very weak. As a result, the structural parameter values derived from the SAXS data may be erroneous. The qualitative SAXS photographs for both BASF DG Rayon fibers display weak lobeshaped features that more closely resemble the photograph of T300. As a result, the SAXS is intermediate between the other LTC fibers and T300. The structural parameters for DG Rayon 1 are more similar to those for the T50 and T300 fibers, but do not follow the correct trend in that $l_{p}$ and $L_{p}$ are greater than in the two higher heat treatment fibers. There is a reasonable amount of scatter in the data from the BASF DG Rayon 1 sample (Appendix C), and as a result, the uncertainties in the structural parameter measurements are greater for this sample than for T50 or T300. While the 
structural parameters derived for the BASF DG Rayon 1 fibers are more similar to T50 and T300, it should be noted that the overall SAXS intensity is much lower (Figure 20), indicating that while the dimensions of pores in those fibers may be similar, they are more prevelant in the T50 and T300 fibers.

From Guinier plots of the SAXS data (Appendix C), the radius of gyration for the T50 and T300 fibers was calculated to be 20.8 and $14.0 \AA$, respectively (Table 5). The Guinier plots of the data from the Amoco LTC and BASF DG1 fibers exhibited significant deviations from linearity. Therefore, an estimation of the radius of gyration was not possible. Porod plots (Appendix C) of the SAXS data from the T50 and T300 fibers show the general trend of reaching a limiting value at large $s$ values. The noise in the Porod plots of the LTC fiber data, however, was too large for any conclusions to be drawn.

\section{SUMMARY}

Based on the wide-angle $\theta-2 \theta$ XRD scans, the LTC PAN fibers all appear to have a similar turbostratic structure with large $002 \mathrm{~d}$-spacings, small "crystallite sizes," and moderate preferred orientation. The Textron Avcarb fibers (B-2 and G), however, consistently have the least-ordered graphitic structure as measured by the preceding parameters, whereas the Hercules fibers exhibit the most order of the LTC fibers. Limited SAXS results indicate that the LTC PAN fibers have a poorly developed pore structure, with the exception of the BASF fibers (DG Rayon 1 and DG Rayon 2), which produce SAXS patterns intermediate between T300 and the other LTC fibers. 


\section{TRANSMISSION ELECTRON MICROSCOPY}

\section{A. BACKGROUND}

There are several proposed models for the microstructure of PAN-based fibers based on transmission electron microscopy (TEM). Several studies ${ }^{16,33-35}$ have shown that these fibers have a ribbon structure with a high degree of crystallite orientation along the fiber axis. The undulating ribbons lie predominantly parallel to the fiber axis, are connected together through a network of branched fibrils, and are separated by elongated pores (see Figure 23). Johnson et al. ${ }^{14,36,37}$ suggested that the structure consists of arrays of misoriented turbostratic graphitic crystallites stacked approximately end to end in a columnar manner, forming tilt and twist boundaries between them. In later work with exceptionally high-modulus PAN-based carbon fibers, Johnson et al. ${ }^{37}$ suggested a model of interlinked crystallites arranged perpendicular to each other, consisting of a complex arrangement of subgrains. Guigon et al. ${ }^{38}$ recently proposed that high-modulus and high-strength PAN-based fibers consist of sheets of aromatic layers folded with various concave radii along the fiber axis (see Figure 24).

Our TEM study was undertaken to determine the microstructure of the two Amoco LTC PAN fibers and to compare them with those of Amoco fibers that utilize the same PAN precursor and experience the same oxidation stabilization, but are heat treated to higher temperatures, T300 $\left(\right.$ HTT $\left.=1300-1500^{\circ} \mathrm{C}\right)$ and T50 $($ HTT $=$ $2000-2200^{\circ} \mathrm{C}$ ). The heat-treating schedule for the LTC fibers is also expected to be different from those for T300 and T50.

\section{B. EXPERIMENTAL}

Amoco T350/23X, T350/25X, T300, and T50 PAN-based and P100 pitch-based fibers were examined. Various techniques have been developed for preparation of thin samples of fibers for TEM examination. One is grinding with a mortar and pestle, ${ }^{27-29}$ another is ultramicrotomy. ${ }^{30-32}$ However, these two techniques have been criticized because they can cause mechanical damage to the fibers and alter their microstructure. Therefore, in this study we used the technique of mechanical dimpling the sample to a certain thickness and then ion-milling until perforation. This technique has been widely used in preparing TEM specimens of ceramic materials. and since it works by removing atoms layer by layer, mechanical damage is minimized. 


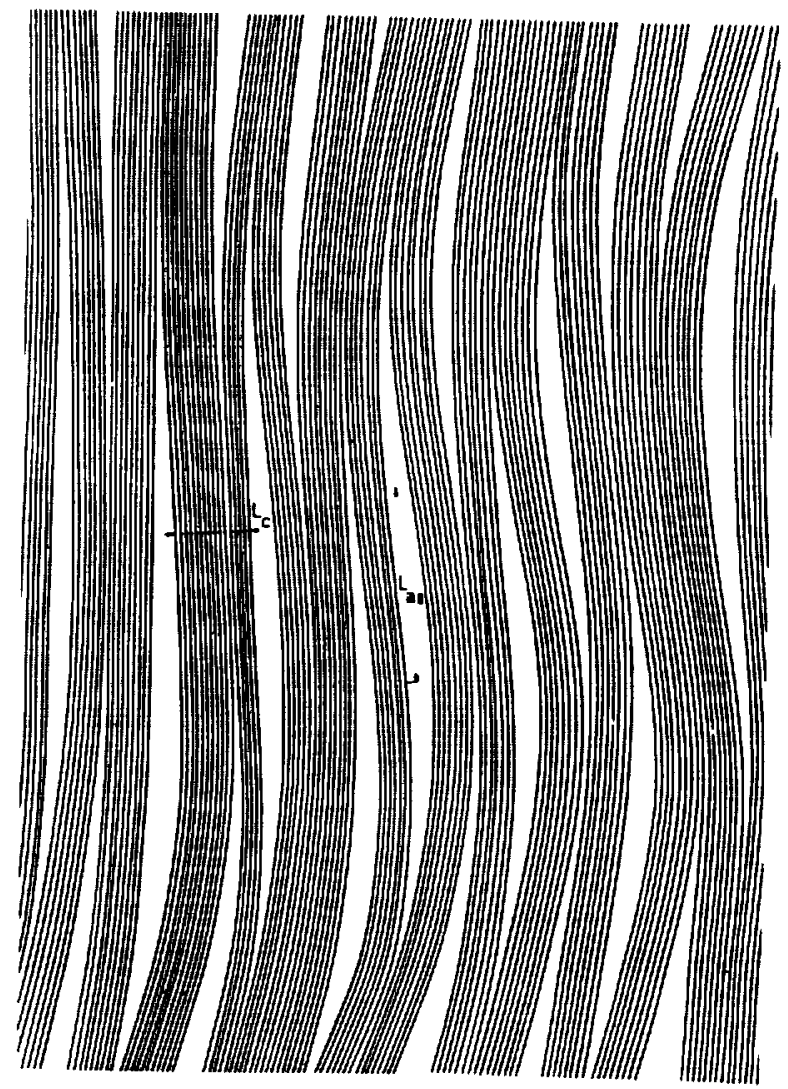

Figure 23. The proposed ribbon microtexture model (from Ref. 17). 


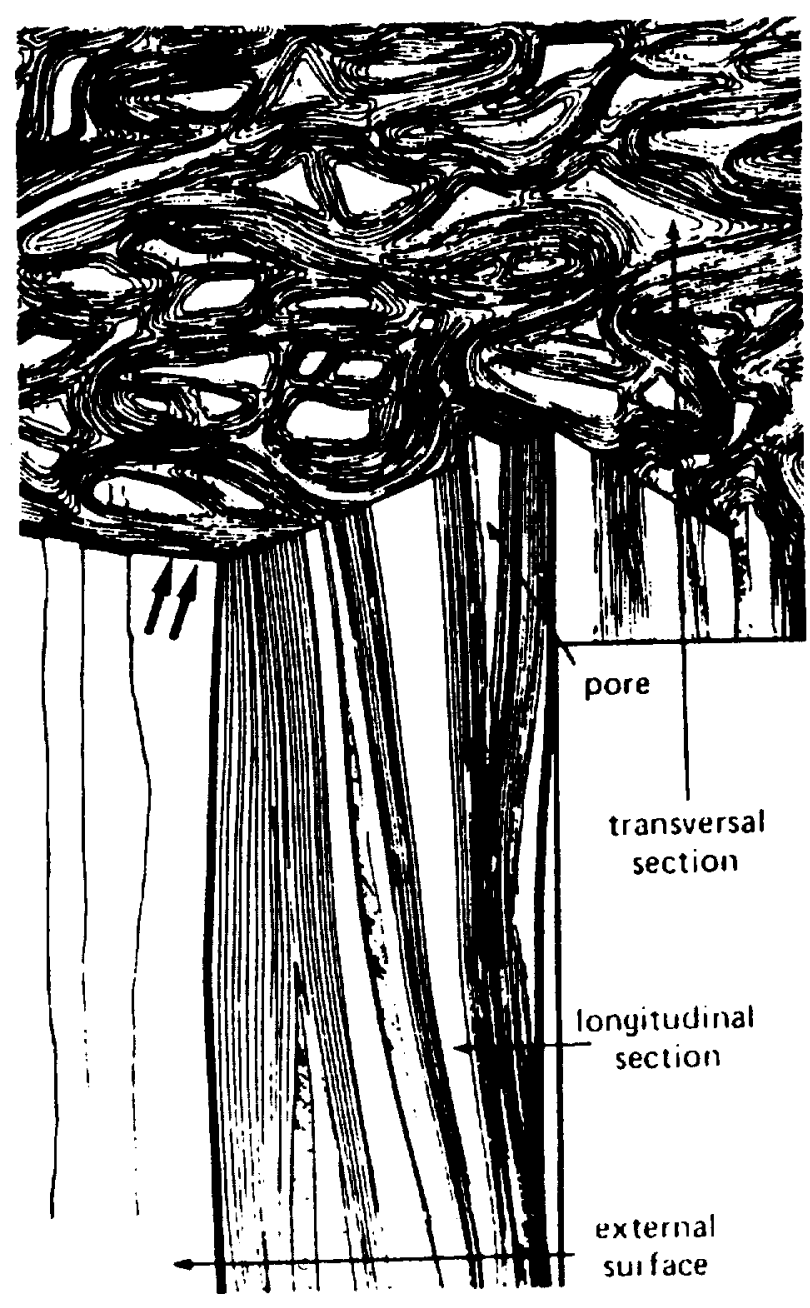

Figure 24. A proposed model of microtexture (from Ref. 38). 
In our preparation technique for longitudinal samples, a bundle of fibers was cut to a length of approximately $2 \mathrm{~cm}$ and laid flat at the bottom of a mold. Epoxy resin was gently poured over the fibers, and the mold was put in a vacuum chamber to remove dissolved air and gas bubbles. After the resin was cured, samples were cut with a diamond saw blade to $2-\mathrm{mm}$ squares with fibers oriented in the longitudinal direction. The bottom surfaces were lightly polished on a $3-\mu \mathrm{m}$ diamond sheet to remove a thin layer of epoxy. This polishing was carefully monitored with an optical microscope until the bottom fibers were barely touched. The polished sample was then turned over and ground on the opposite surface until a final thickness of about $150 \mu \mathrm{m}$ was reached. The samples were then dimpled with $3-\mu \mathrm{m} \mathrm{Al}{ }_{2} \mathrm{O}_{3}$ paste and again carefully monitored by optical microscopy until the bottom fibers were barely touched. The dimpled samples were mounted on single-hole $\mathrm{Nb}$ rings using a quick-setting resin, and then dried and argon-ion milled. Both surfaces of the samples were simultaneously ion milled on a cold stage with $5 \mathrm{kV}$ accelerating voltage, $1 \mathrm{~mA}$ current, and the argon-ion beam inclined at an angle of $12^{\circ}$ to the sample surface. The samples were milled until the middle section of the fibers, where the ion beam was concentrated, were electron transparent.

Because of the significant difference in the milling rates of graphite fibers and the epoxy matrix, the transverse thin sections tended to disintegrate before the fibers were thin enough to be electron transparent. The transverse TEM samples were, therefore, prepared differently. Several bundles of fibers were tightly packed in a heatshrinkable tube. They were then impregnated under vacuum with a mixture of epoxy and $0.1 \mu \mathrm{m} \mathrm{Al} \mathrm{O}_{3}$ powder. The $\mathrm{Al}_{2} \mathrm{O}_{3}$ powder increases the hardness of the matrix, thereby reducing the disparity of the milling rates. After being cured, the fully packed tube was sliced transversely and went through the same preparation process as the longitudinal samples.

The Philips EM420 electron microscope used in this study was equipped with a $\mathrm{LaB}_{6}$ filament, and operated at $120 \mathrm{keV}$. The images were recorded in the bright field (BF), dark field (DF), and high-resolution (HR) mode. In BF mode, the image is formed by allowing only the incident beam through the objective aperture. DF images were obtained by tilting the 002 reflection to center with the aperture. The aperture was chosen so that all undesirable transmissions were excluded. Stereo pairs were produced by taking the fiber images at the same location after tilting $30^{\circ}$. Each of these techniques is described in more detail in the following sections.

\section{RESULTS AND DISCUSSION}

This section is divided into two parts. In the first part, the macrotextures of the fibers obtained by the BF and stereographic images are presented and discussed. In the second part, microstructure is analyzed based on the results of BF and DF observations 
of the fibers at various tilt angles and lattice fringe images. A model for the structure of the fibers studied is developed and compared with previous models. ${ }^{14,17,33-38}$

\section{Macroscopic Texture}

\section{a. Longitudinal}

Figures 25 to 27 show BF electron micrographs of Amoco T350/23X, T350/25X, and T300 fibers, respectively. T50 fibers were not examined in the longitudinal direction. The three micrographs have similar features. In addition, the selected area diffraction (SAD) patterns of these fibers show basically the same features: 100,110 , and 002 reflections. A typical SAD pattern of T300 is shown in Figure 27. Figure 25 shows that the texture of the T350/23X fiber consists of three distinctive features: a solid core representing the fiber axis, extending along the whole length of fiber; and two sets of striation features, one set (marked as I) running obliquely to the fiber axis and the other set (marked as II) with edges running almost normal to the core. It was seen in the stereo viewer that Set I represents layers stacked one on top of the other in an arrangement parallel to the core. The observed striations are the edges of these layers cut at a slant angle and forming steps. Set II has distinctive layers also stacked parallel to the core with wider, uneven spacing, but arranged at a different tilt angle with respect to the core axis. They interweave with Set $I$, forming a three-dimensional network with the core as the zone axis. This three-dimensional structure is depicted in Figure 28. Figures 26 and 27 show the texture of T350/25X and T300 fibers, also consisting of stacking layers, extending along the length of the fiber, and oriented parallel to the fiber axis. Stereomicroscopy shows that these stacking layers are also arranged at different tilt angles with respect to the fiber axis. As shown in Figure 27, the left set, tilted further away from the plane of view, shows more closely spaced edges than the one on the right, which is less tilted. These two sets are interconnected by an oblique, slightly curved layer in the middle, forming a wide step.

\section{b. Transverse}

The TEM cross-section images of T350/23X, T350/25X, T300, and T50 fibers are shown in Figures 29-32. In all cases, a complex arrangement of interwoven, wavy, twisted features were revealed. As expected, these features are more prominent and coarser in the higher HTT fibers (T300 and T50). In the cases of the T300 and T50 fibers, two distinctive regions are seen. A typical two-phase structure is shown in Figure 33. In both $\mathrm{T} 300$ and T50, the core shows a highly complex, irregular, turbulent arrangement similar to the observed overall texture of the two LTC fibers (T350/23X and $/ 25 \mathrm{X}$ ). However, the texture of the outer regions of T300 and T50 exhibits better order and is more oriented than the T350/23X and T350/25X fibers. The thickness of 


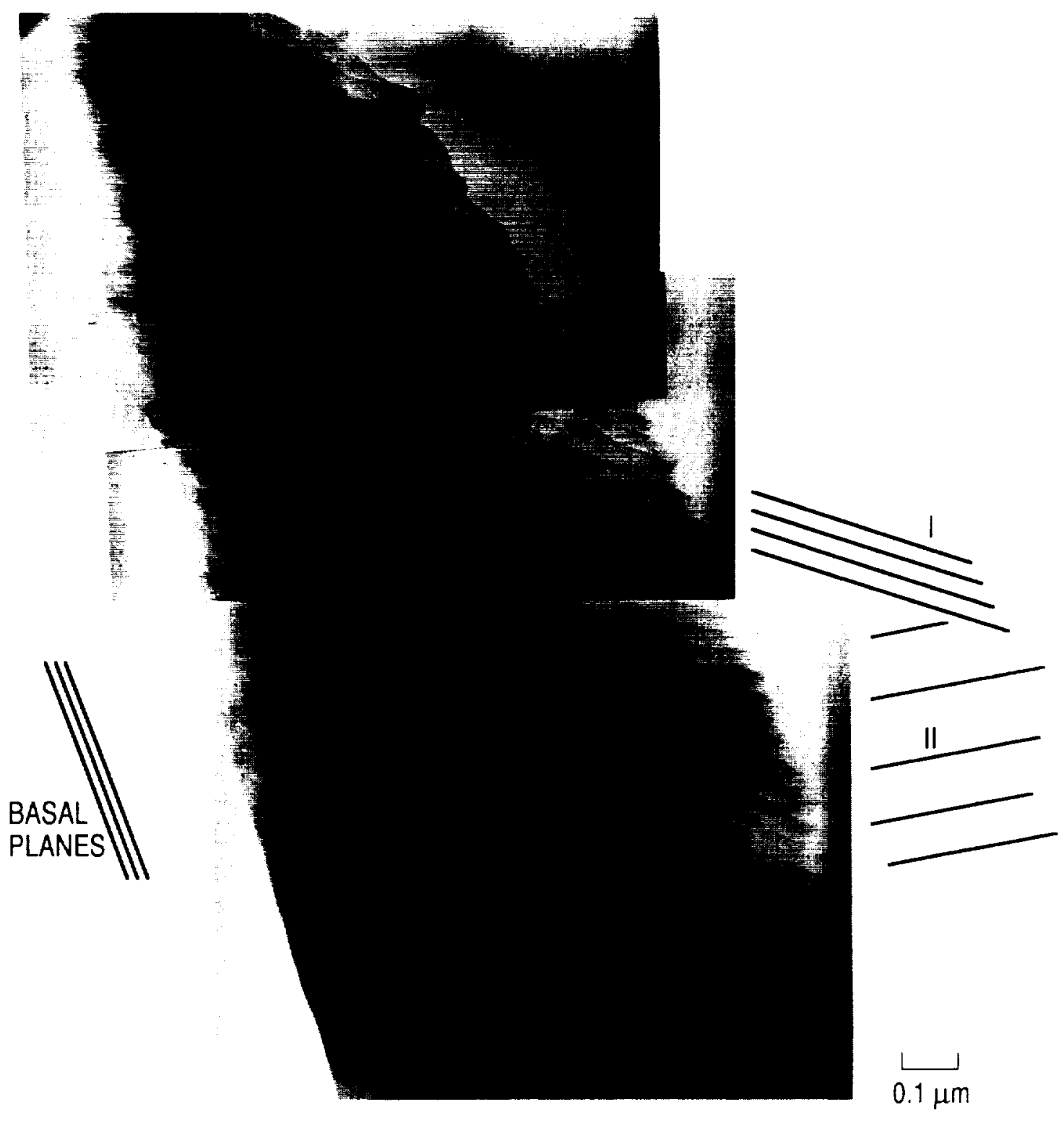

Figure 25. BF image showing the macrotexture of Amoco T350/23X fiber (longitudinal section). 


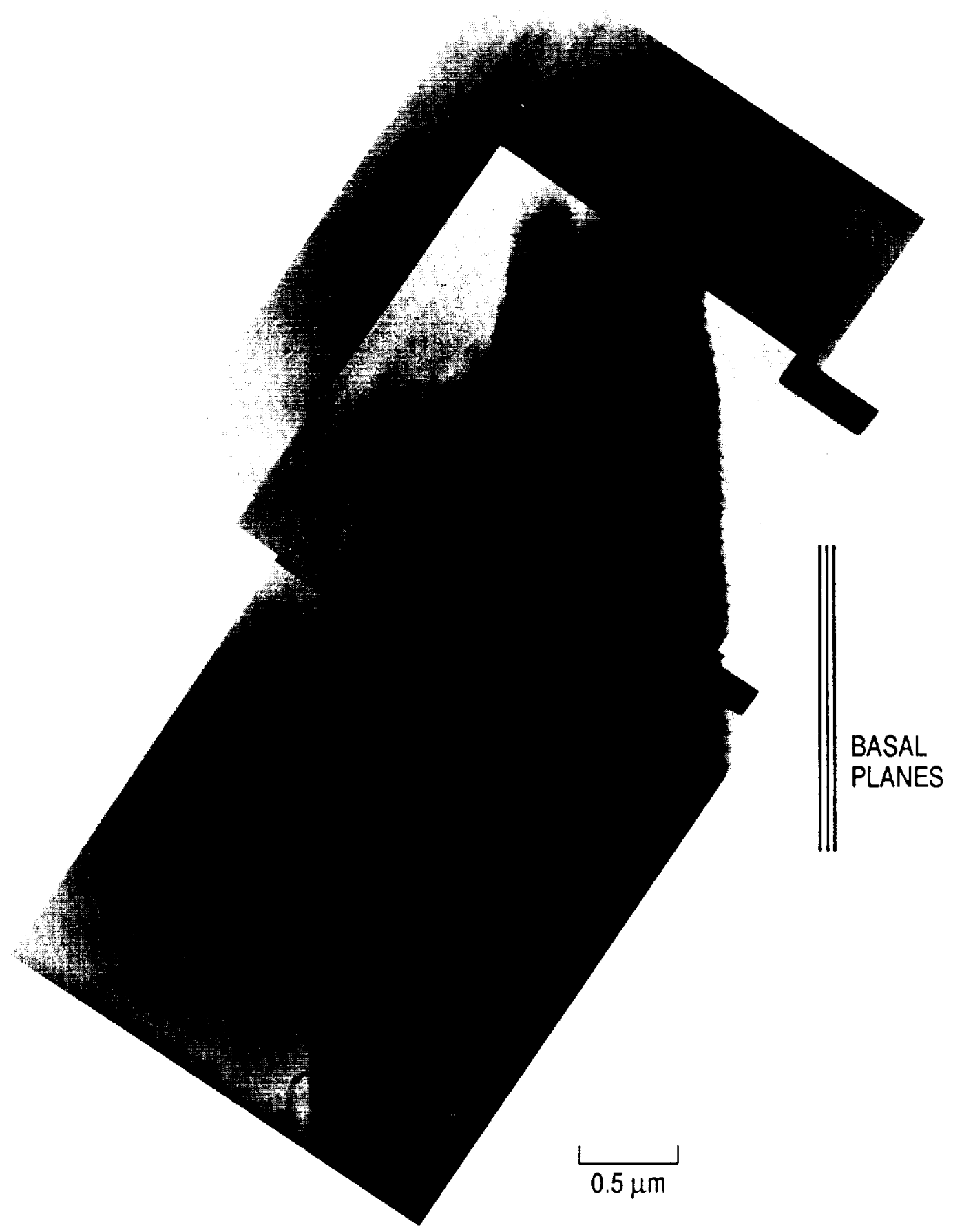

Figure 26. BF image showing the macrotexture of Amoco T350/25X fiber (longitudinal section). 


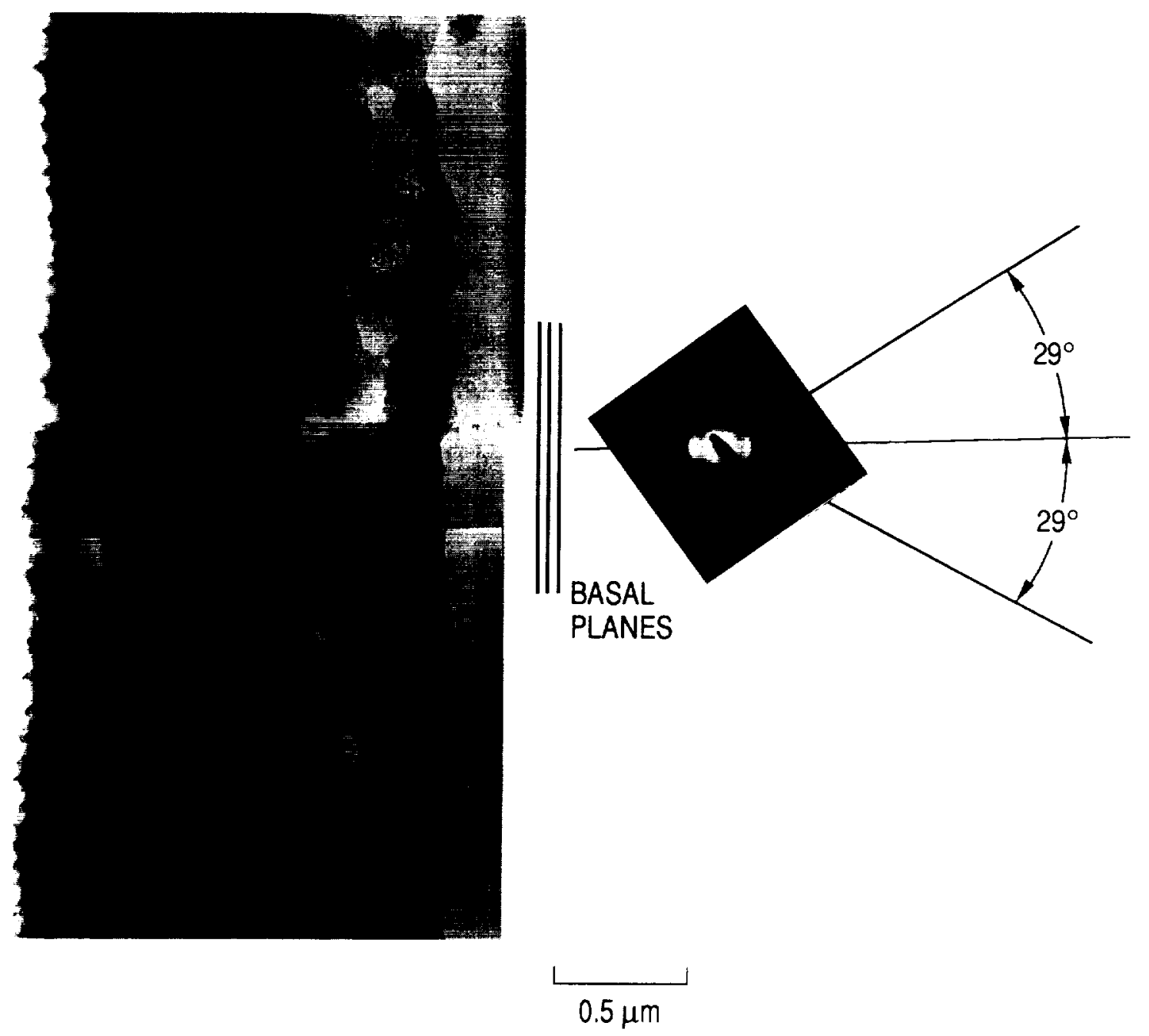

Figure 27. BF image showing the macrotexture of Amoco T300 fiber (longitudinal section). 


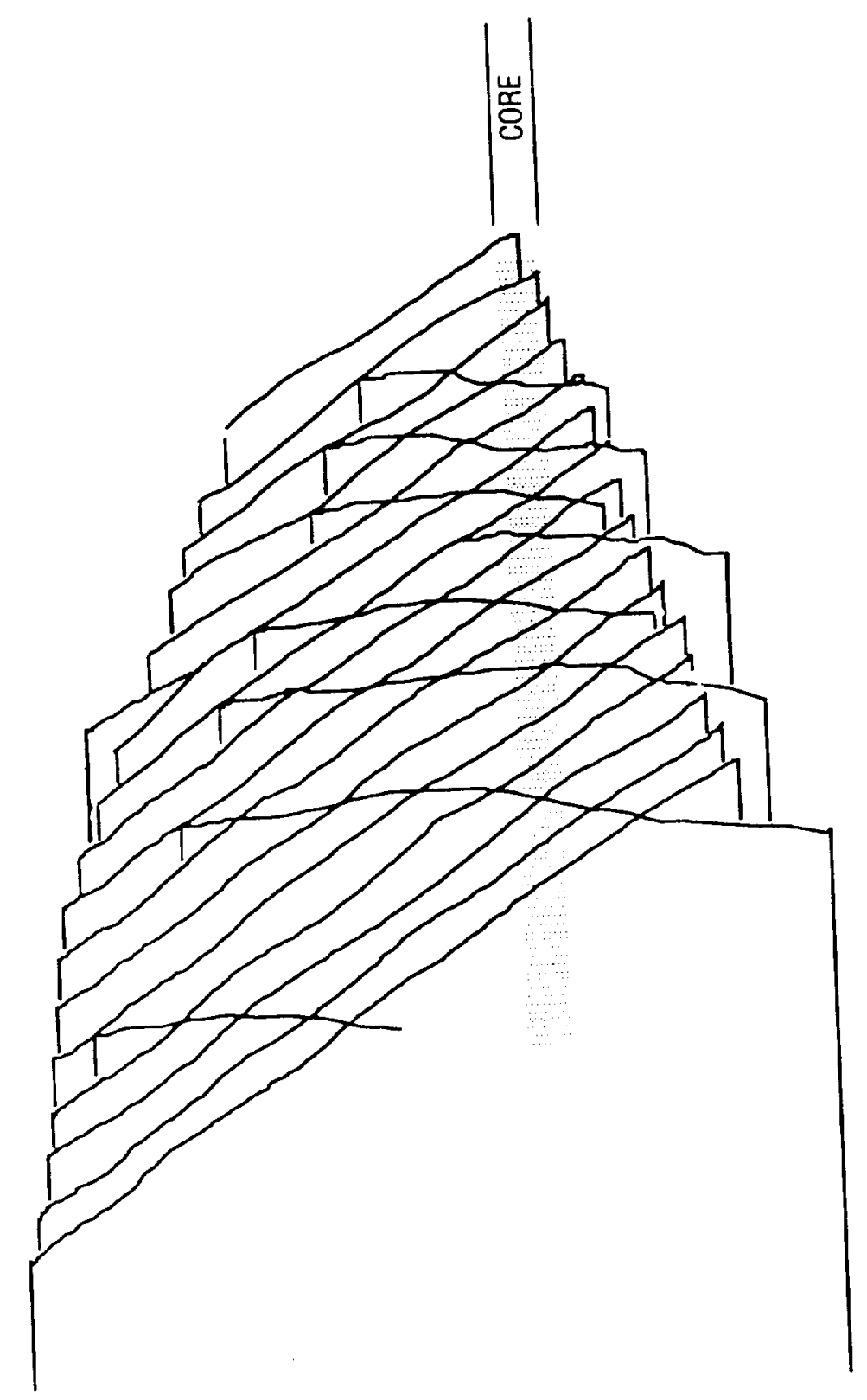

Figure 28. Sketch showing the macrotexture. 


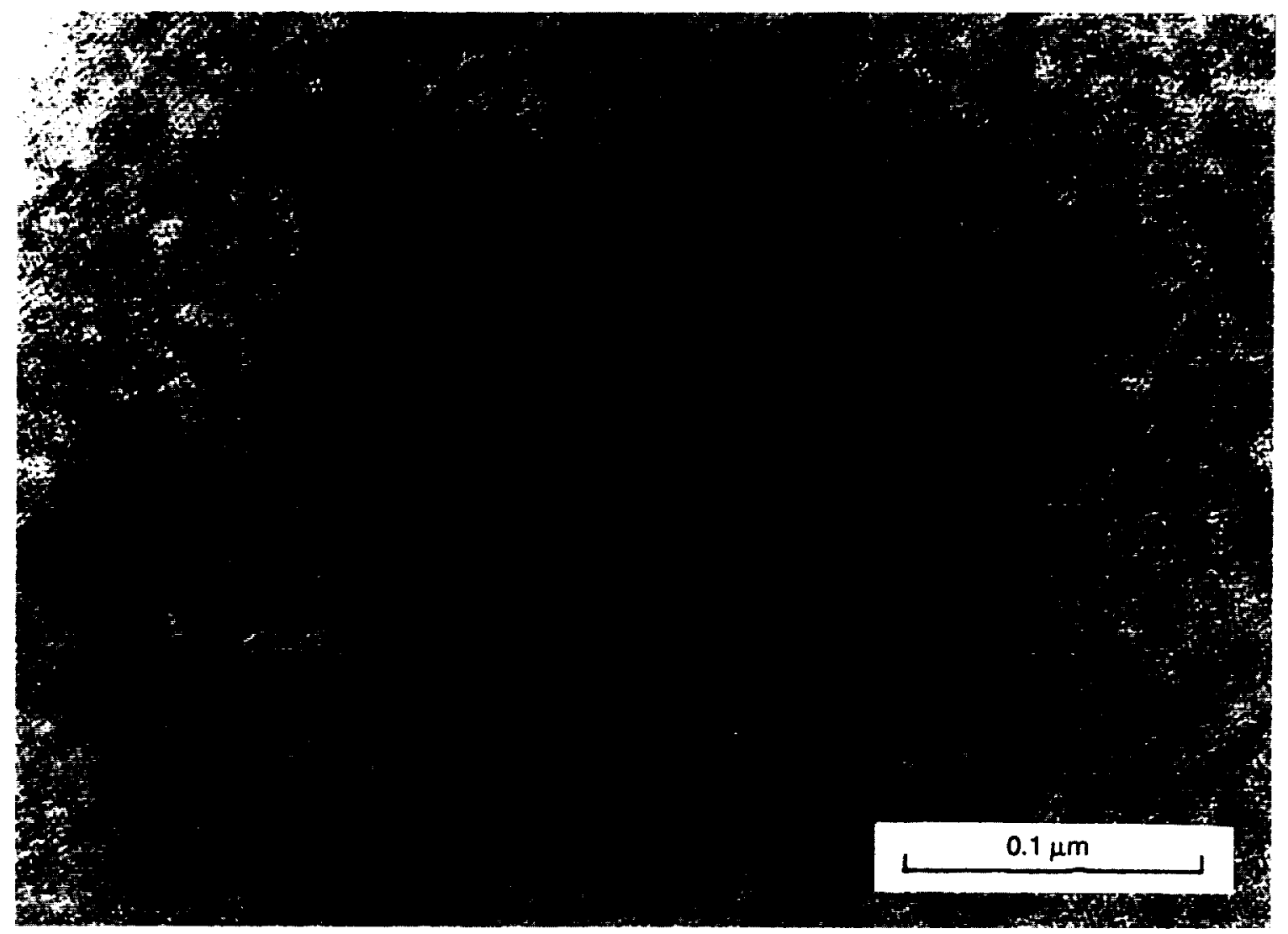

Figure 29. BF image of Amoco T350/23X fiber (transverse section). 


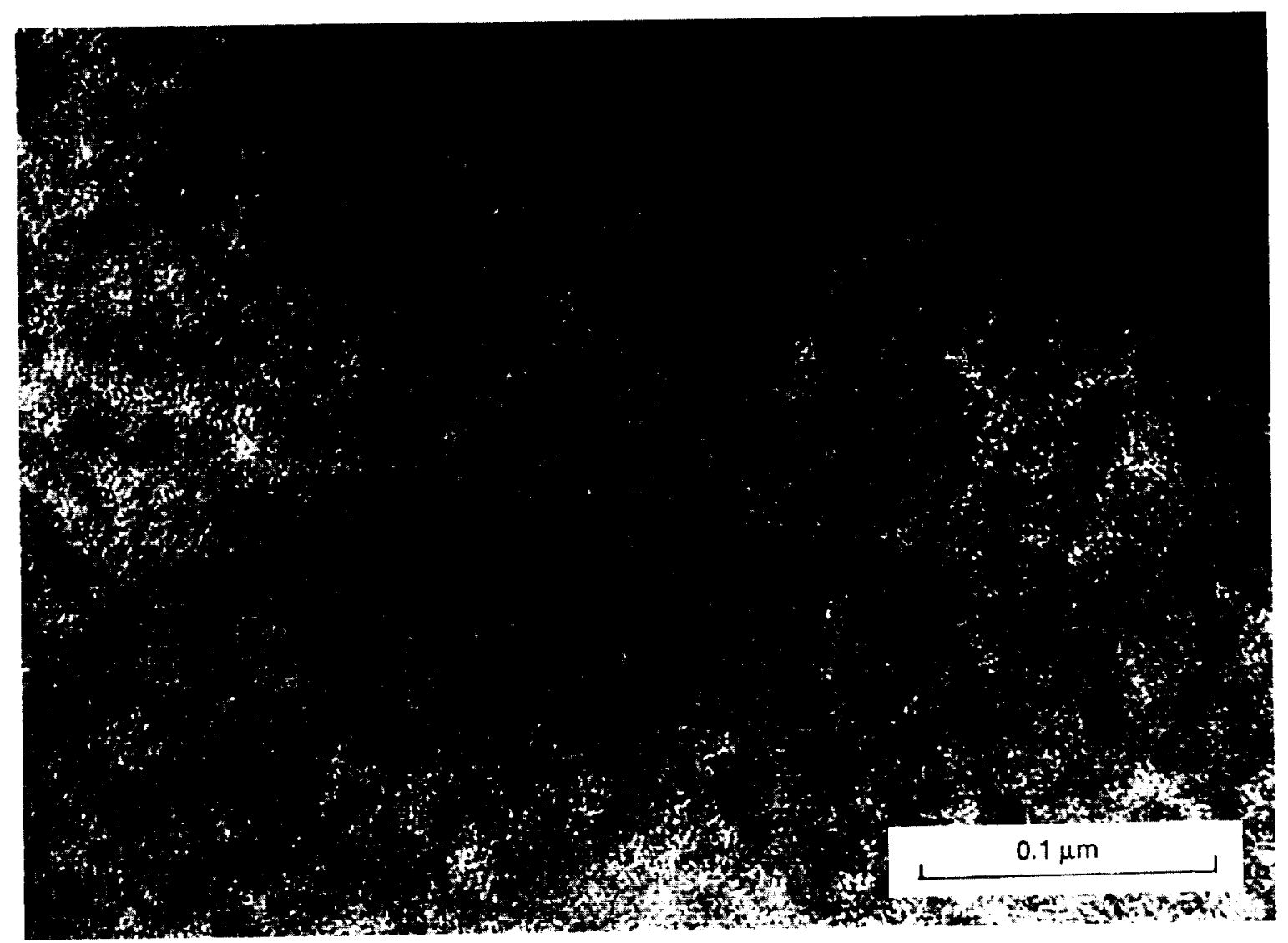

Figure 30. BF image of Amoco T350/25X fiber (transverse section). 


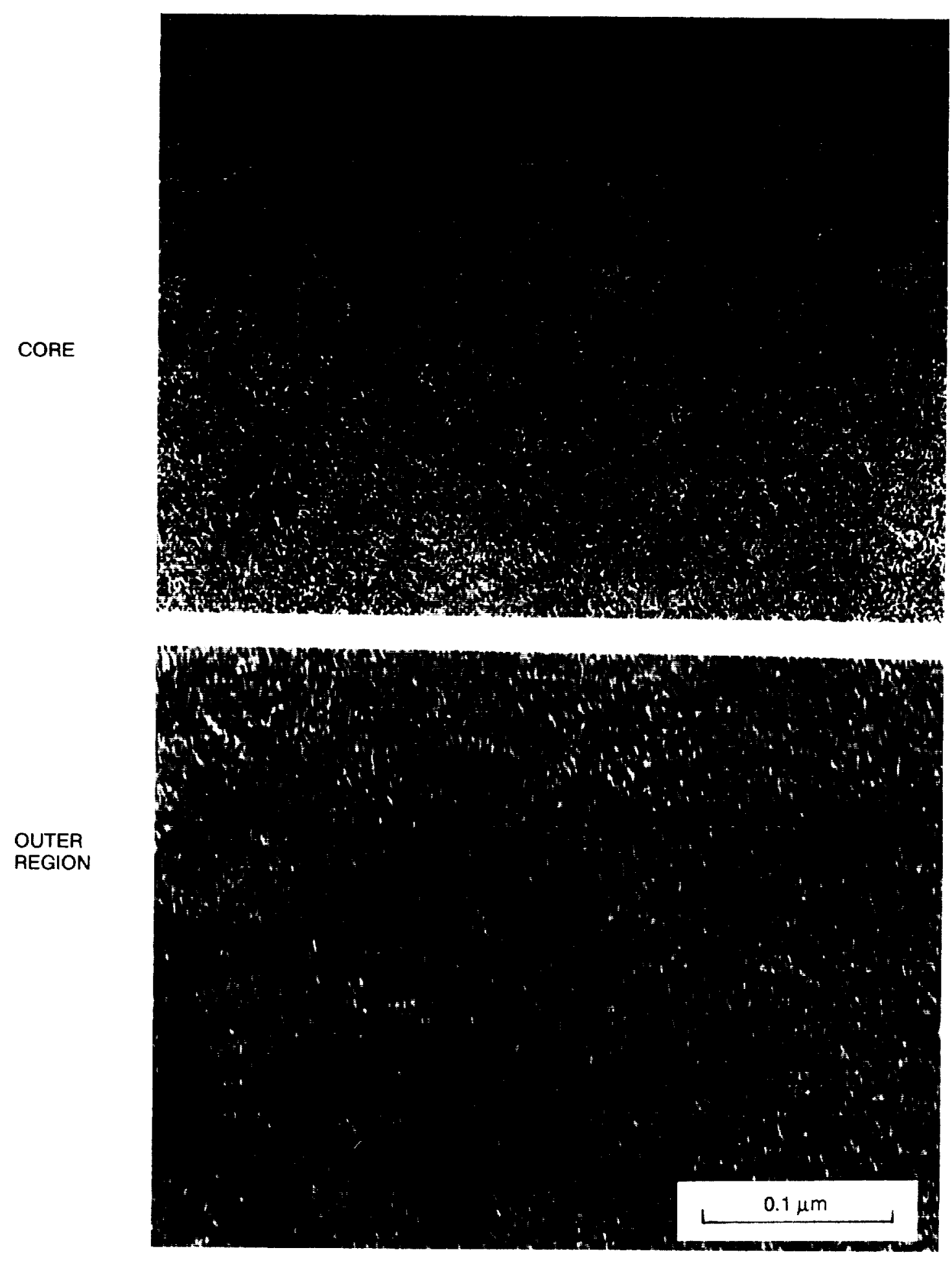

Figure 31. BF image of Amoco T300 fiber (transverse section). 


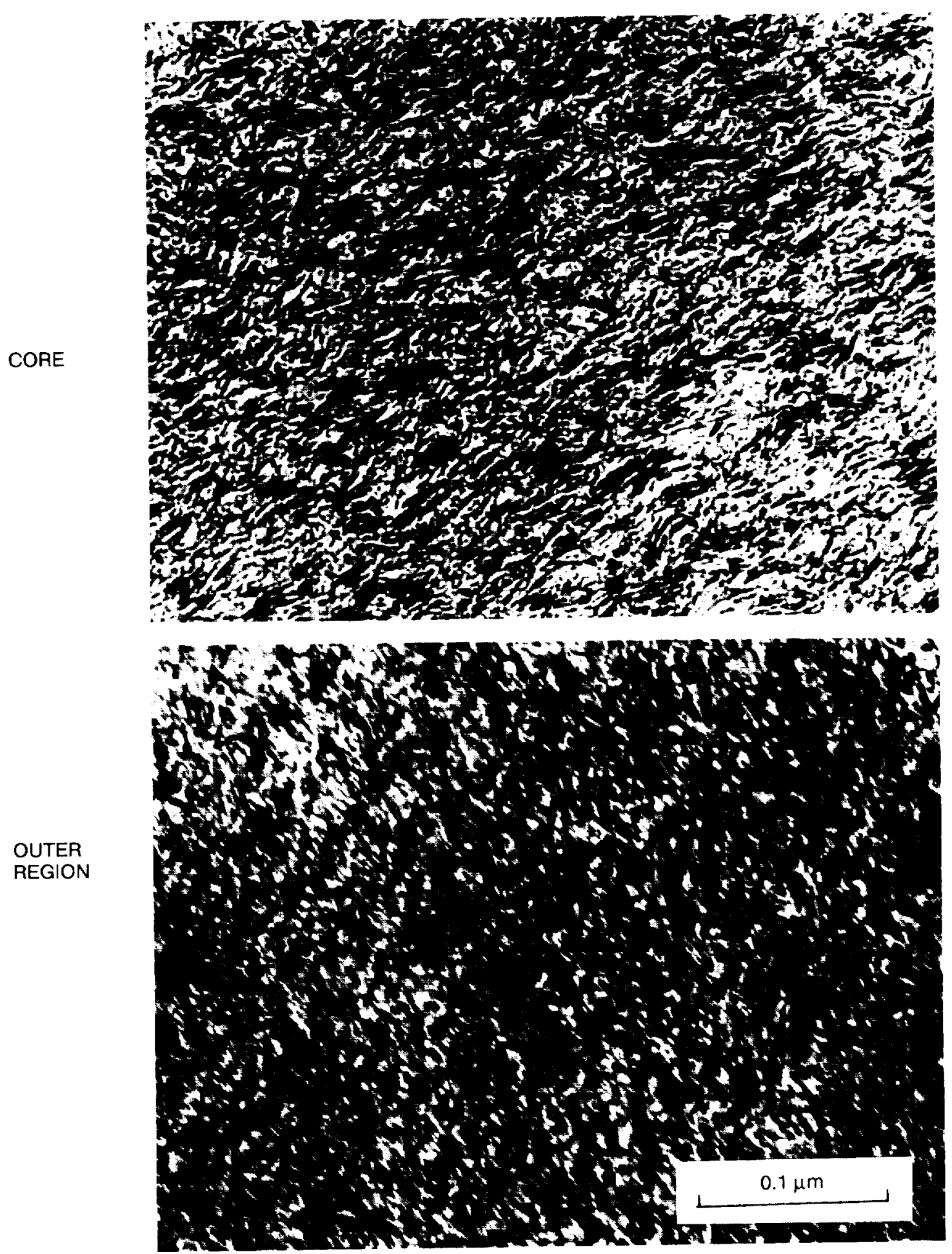

Figure 32. BF image of Amoco T50 fiber (transverse section). 


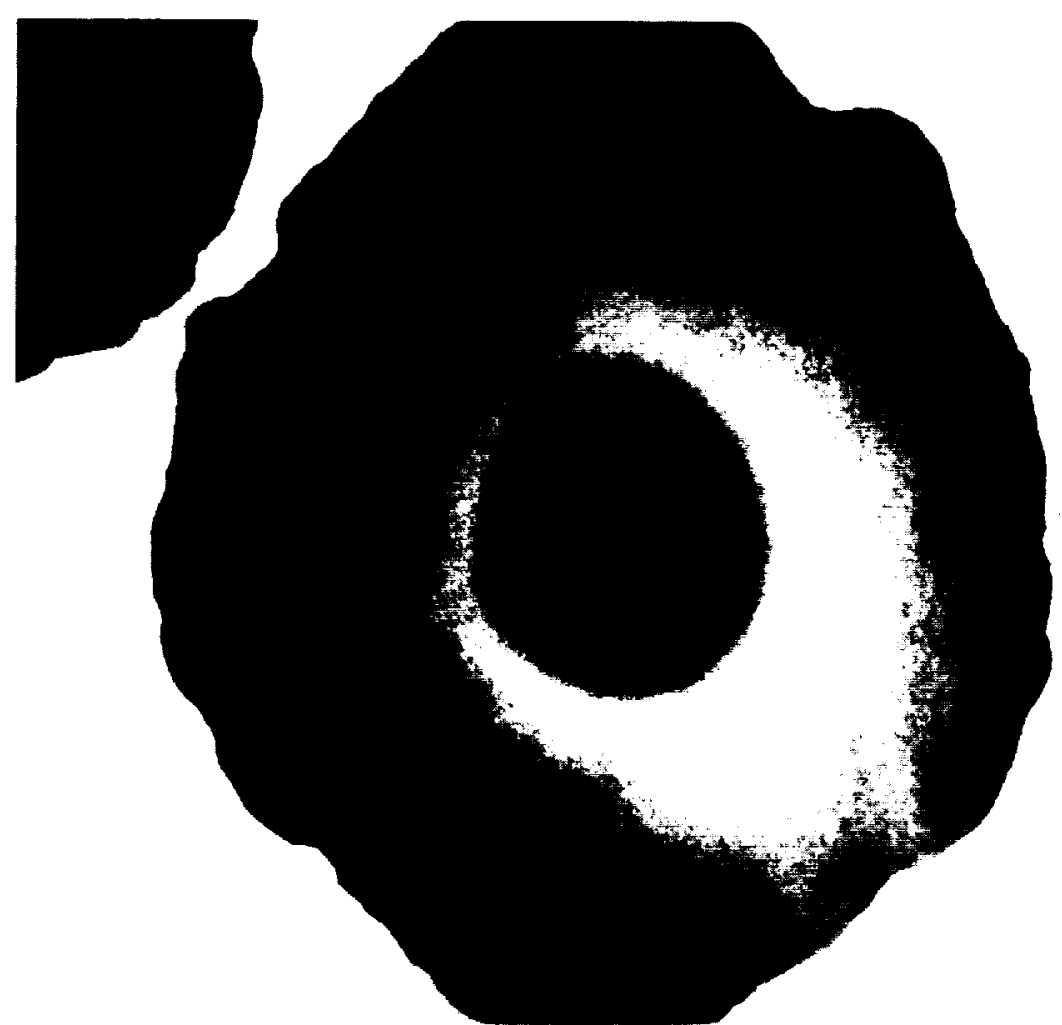

Figure 33. Transverse section of Amoco T50 fiber showing twophase structure.

the outer region is dependent on the preoxidation stage in fiber processing, which can result in a fully stabilized outer region and a partially stabilized core. The core texture inherits more of the structure of the precursor. The four fibers basically have the same original texture inherited from their precursors. Depending on the preoxidation condition, the texture evolves into two distinctive phases during heat treatment. However, higher HTTs than those used for the LTC PAN fibers are necessary for the outer layers to order.

\section{Microscopic Texture}

\section{a. Selected Area Diffraction}

Before discussing the microtexture of the fibers, it is necessary to point out some features of the selected area diffraction $(\mathrm{SAD})$ patterns and their significance. Electrons produce diffraction effects similar to $\mathrm{X}$ rays when they pass through crystalline materials. The lattice planes that are properly oriented for diffraction can be thought of as being aligned parallel with the electron beam, and only lattice planes satisfying the 
Bragg condition contribute to the SAD pattern. The SAD patterns from longitudinal sections of four PAN-based fibers actually represent a combination of two superimposed SAD patterns, ring patterns from the 100 and 110 reflections and arc features associated with 002 reflections (Figure 34). These result from the reflections of two distinct sets of basal planes oriented at different angles with respect to the beam direction. The orientation of turbostratic crystallites that produce the 002 arcs is different from those producing the complete 100 and 110 rings. Crystallites whose basal planes lie perpendicular to the beam direction, i.e., "face-on," give rise to 100 and 110 rings. The diffuse ring pattern that we observed indicates that the structure is not highly crystallized, the crystallized grains are ultrafine, and their basal planes are not well ordered. Basal planes oriented approximately parallel to the beam direction, i.e., "edge-on," produce 002 and 004 reflections. Rotating the SAD pattern to a proper angle with respect to the associated BF image shows that the edge-on basal planes are aligned predominately parallel to the fiber axis in all cases (marked by triple lines in Figures 25-27).

The arc features of 002 reflections are a characteristic of the basal planes. Figure 35 schematically illustrates three sets of basal planes. They are oriented such that the Bragg condition is satisfied for all three and emit 002 reflections; i.e., the basal planes are parallel to the electron beam. However, Sets II and III are twisted by an angle $\pm \alpha$ relative to Set $\mathbf{l}$. Each of the basal planes in Sets II and III will produce its own 002 diffracted beam at an angle $\alpha$ relative to the one diffracted by Set $I$. This is true for all intermediate situations where the planes are twisted at an angle from 0 to $\pm \alpha$. An arc fanning out from the 002 spot of Set $I$ at an angle of $\pm \alpha$ is therefore observed. In the case of T300, it is seen in Figure 27 that the 002 reflection shows an arc feature with the measured angle $\approx \pm 29^{\circ} . \mathrm{T} 350 / 23 \mathrm{X}$ and T350/25X fibers are similar. This indicates that the aromatic planes in these fibers are not perfectly oriented. In fact, they undulate with a deflection angle that varies from 0 to $\pm 29^{\circ}$

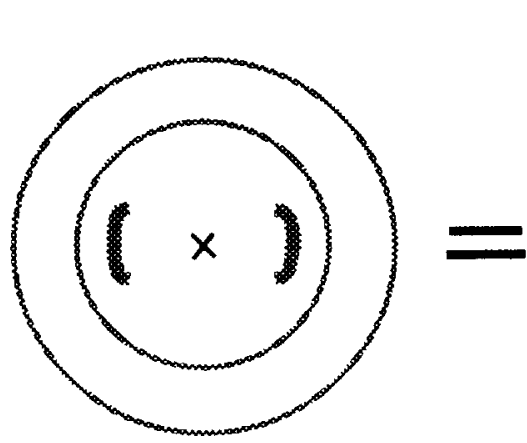

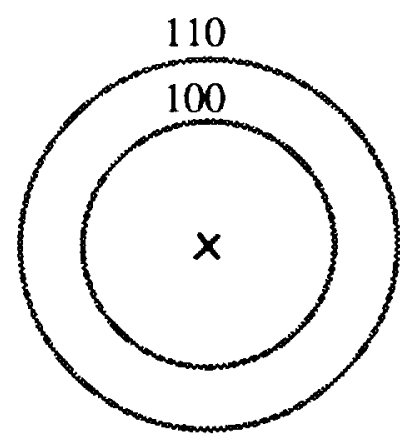

"Face-on" grains

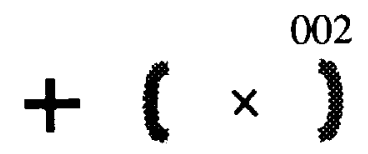

"Edge-on" grains

Figure 34. Sketch showing that the observed SAD pattern is composed of two different patterns resulting from "face-on" and "edge-on" grains. 


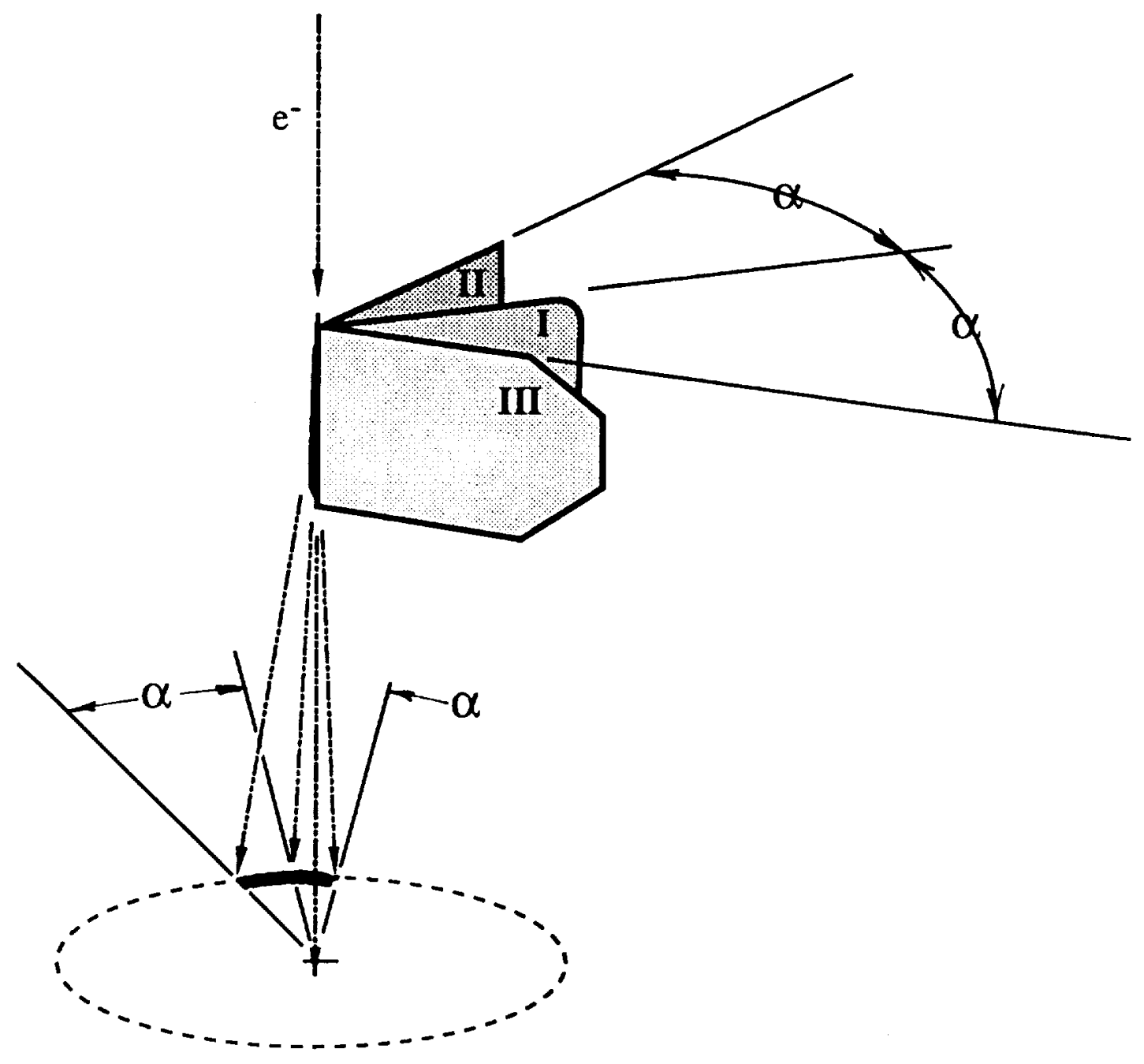

Figure 35. Sketch showing reflections of planes misoriented by an angle of $\pm \alpha$.

relative to the principal direction. This is confirmed by lattice fringe images of the basal planes, which will be shown and discussed in a later section and agrees with previous studies, which have shown the wavy nature of the basal planes in PAN-based fibers. ${ }^{8}$

The SAD patterns observed result from crystallites arranged in a particular orientation. It is, therefore, difficult to arrive at a complete three-dimensional understanding of the microstructure of the fibers from just one SAD pattern. Electron diffraction at various tilt angles around the fiber axis is necessary. Before further discussing our results, we will continue our review of the characteristic electron diffraction of 
aromatic graphite layers. This has been extensively described before. ${ }^{45-47}$ Imagine a thin layer of basal planes of fine graphite grains oriented randomly relative to each other. The reciprocal space of this layer is represented by concentric hollow 100 and 110 cylinders as depicted in Figure 36. The diffraction pattern seen in TEM results from the intersection of the Ewald sphere with the reciprocal lattice. In the case of "face-on" orientation of the layer planes, the resultant diffraction pattern is represented by concentric 100 and 110 rings as depicted in Figure 36(a). Tilting the layer by an angle around a particular axis results in tilting the reciprocal lattice an equal angle around the same axis. The resulting diffraction pattern is now elliptical, extending along the direction normal to the tilting axis as shown in Figure 36(b). Upon further tilting of the layer until it is oriented parallel to the beam direction (i.e., the grains are seen edge-on), the diffraction pattern consists of 100,110 streaks due to the intersection of Ewald sphere with the horizontal reciprocal lattice, in addition to 002 , 004, etc., reflections from edge-on planes [Figure 36(c)].

Returning to the case of PAN-based fibers, by tilting the fiber around the fiber axis, the edge-on basal planes start to move away from the incident beam, and their 002 , 004 reflections are expected to become progressively weaker and completely disappear when the Bragg condition is no longer fulfilled. The resultant SAD pattern of the face-on grains is expected to become elliptical, elongated along the direction normal to the fiber axis, depending on the tilt angle, as depicted in Figure $37(\mathrm{~b})$. In this study, the longitudinal sections were tilted around the fiber axis to angles of $20^{\circ}$, $30^{\circ}$, and $45^{\circ}$. The corresponding SAD patterns do not evolve into elliptical patterns, and the 002 reflections do not disappear, but the same features as shown in the diffraction pattern in Figure 27 remain through large tilt angles. These observations are true for all fibers studied. This indicates that at any tilt angle, there exists similar sets of normal basal planes satisfying the Bragg condition and emitting consistent diffraction patterns.

At this point, the results of the electron diffraction study conforms to two models. First, the microstructure can be viewed as multiple randomly distributed crystallites with basal planes oriented parallel to and tilted at different angles around the fiber axis. These crystallites could be interlinked by either tilt or twist grain boundaries forming long strips of graphite along the fiber axis. We have found that when the sample is tilted to other orientations around the fiber axis, additional stacks of basal planes appear. This implies that the observed individual strips of graphite are present at all radial angles throughout the fiber and might crosslink in a complex threedimensional manner to structure the whole fiber. Second, it might be fitted to a model proposed by Guigan ${ }^{38}$ that crystallites are not randomly distributed but arranged in an orderly manner edge to edge, forming multifolded aromatic layers (see Figure 24). 

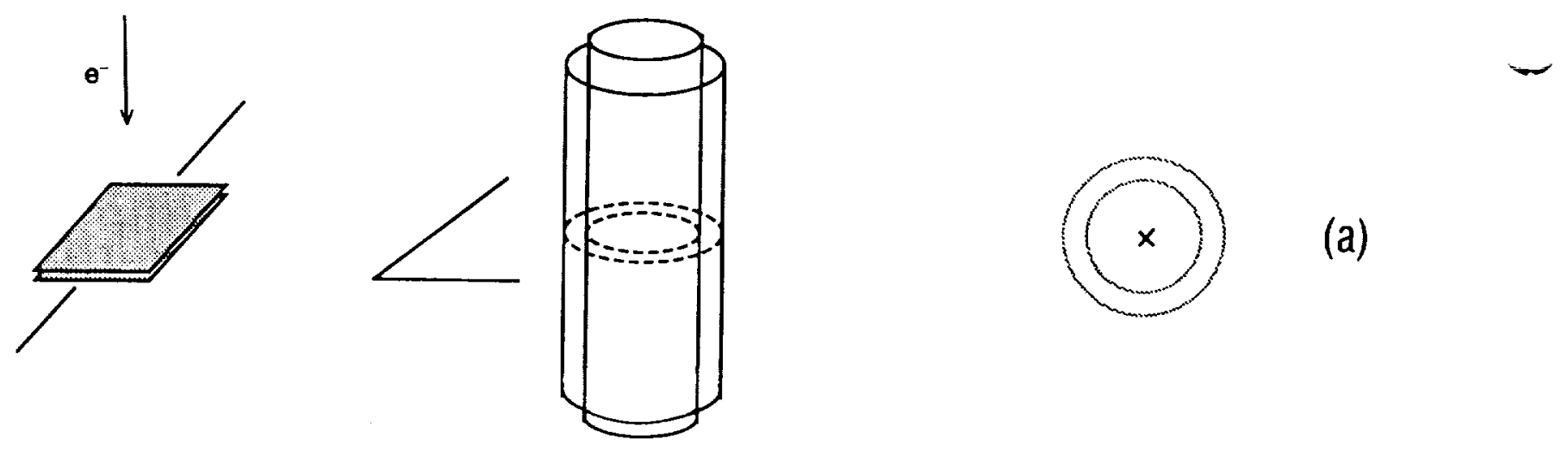

(a)
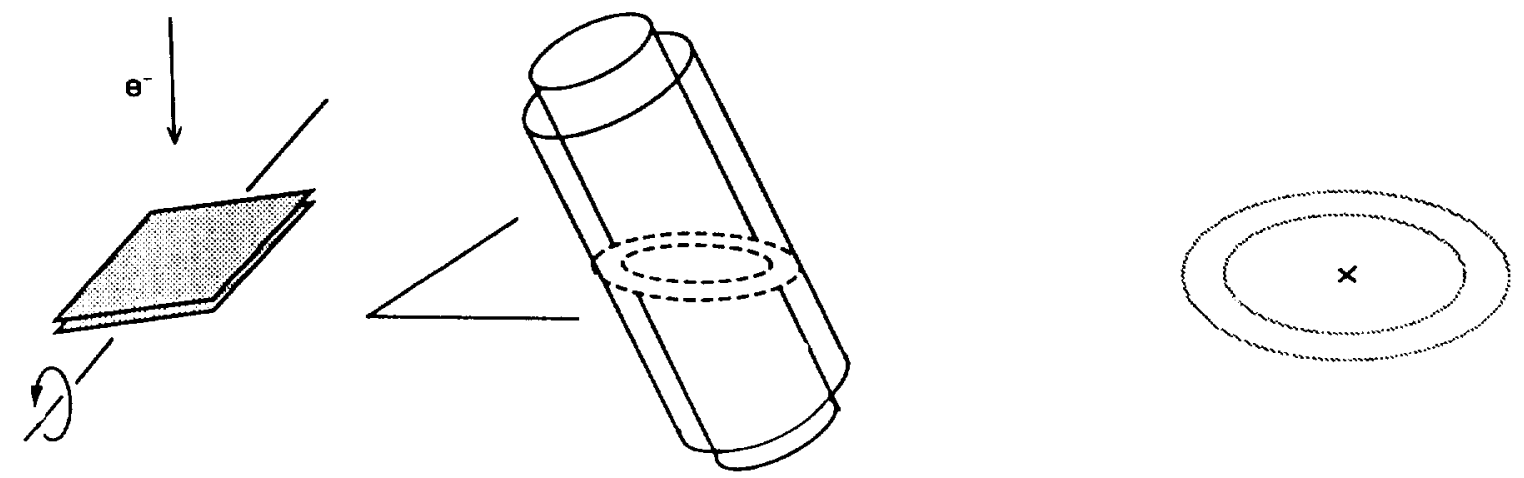

(b)
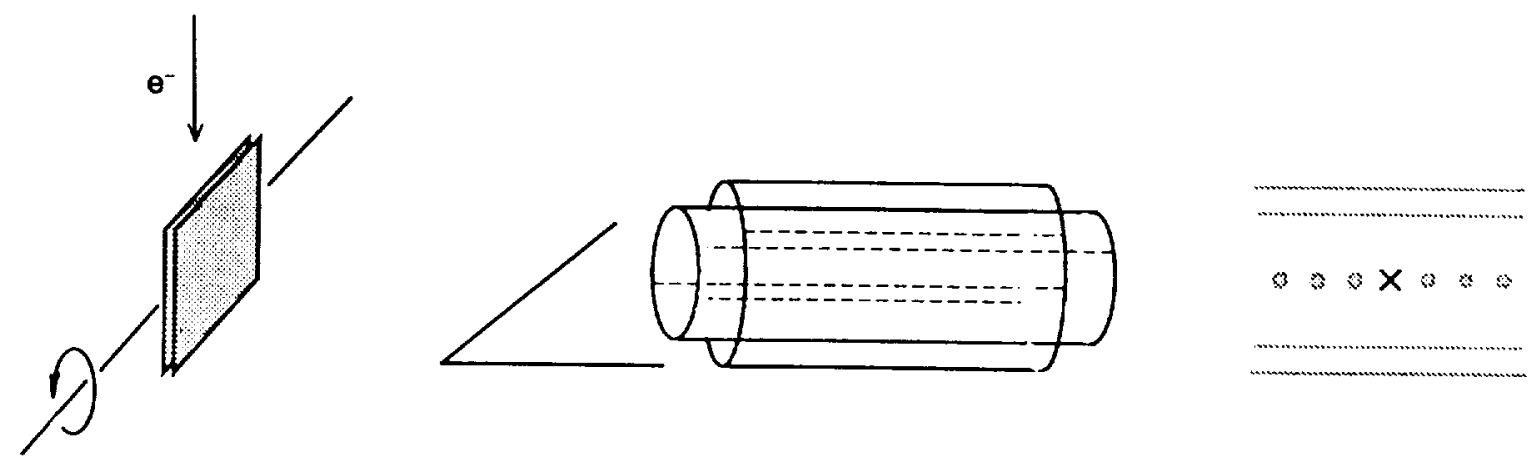

$\beta \leqslant \circ \times 0 *$

(c)

Figure 36. Diffraction patterns resulting from tilting the basal planes. 

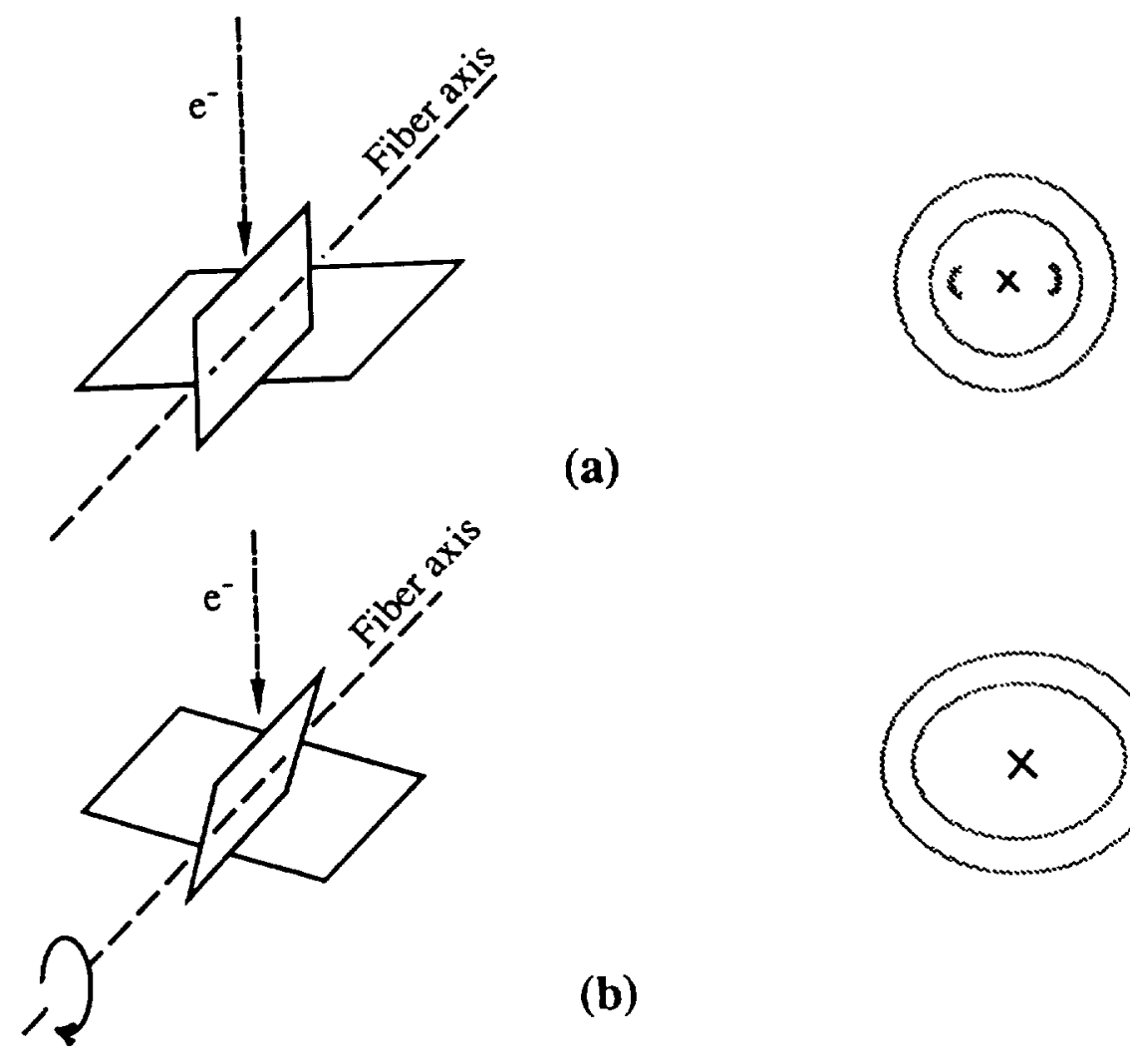

(a)

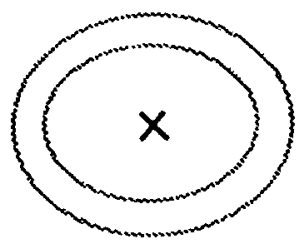

(b)

Figure 37. Diffraction patterns resulting from tilting the perpendicular basal planes.

To further explore which model is more suitable, we supplemented the electron diffraction investigation with DF and high-resolution lattice fringe image studies in both the longitudinal and transverse directions of the fiber.

\section{b. Dark Field Study}

In the DF mode, the objective aperture was set paraxial, and the incident beam was tilted to let the scattered beam through the aperture. The aperture was chosen small enough to allow only a given hkl diffracted beam to go through. Those regions that reflect that particular chosen diffracted beam appear bright in the DF image and provide the projection images of the lattice planes along the lens optical axis while the other regions are completely dark. With the selection of the 002 reflection for DF imaging, the bright regions represent locations where the basal planes are approximately parallel to the electron beam. (The Bragg angle is very small due to the short electron wavelength emitted by the $\mathrm{LaB}_{6}$ filament.) In other words, $002 \mathrm{DF}$ will image the whole domain of aromatic layer stacks oriented edge-on, providing information on their qualitative distribution and the crystallite thicknesses. Figures 38 to 40 show the transverse $002 \mathrm{DF}$ images of the T350/23X, T350/25X, and T300 fibers, 
ORIGINAL PIOE

BLACK AND WHITE BHOTOGRATH

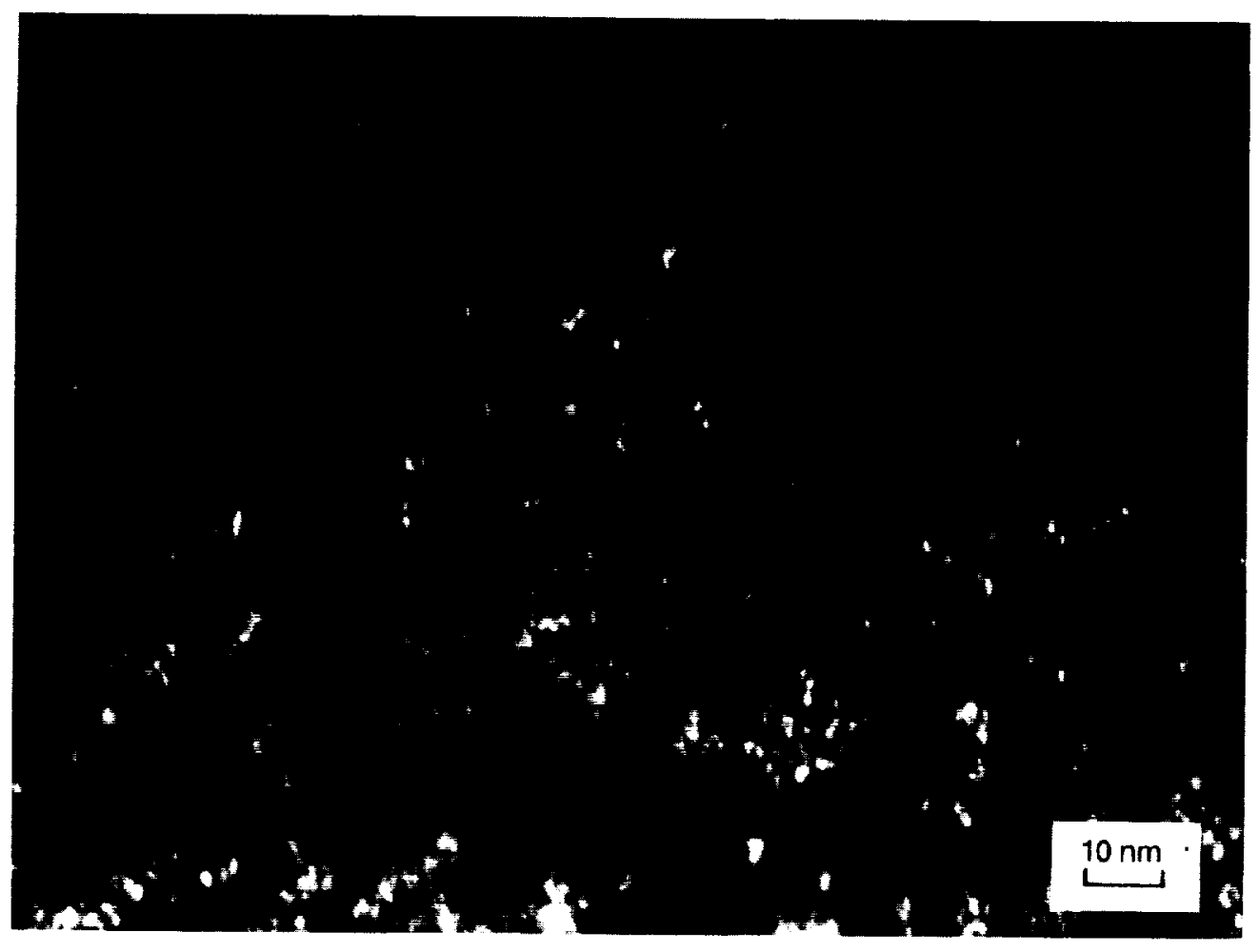

Figure 38. 002 DF image of Amoco T350/23X fiber (transverse section). 


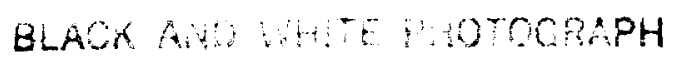

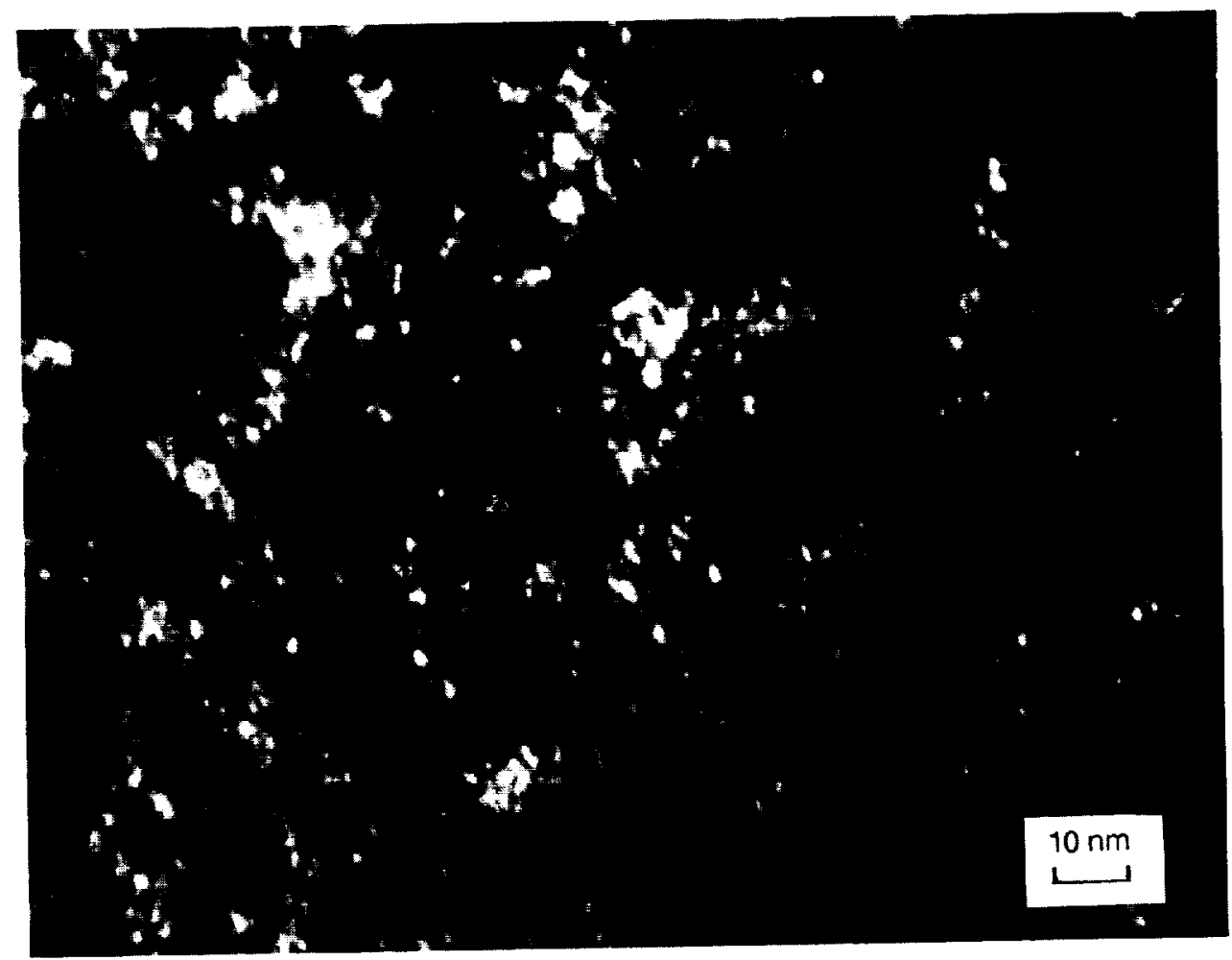

Figure 39. 002 DF image of Amoco T350/25X fiber (transverse section). 


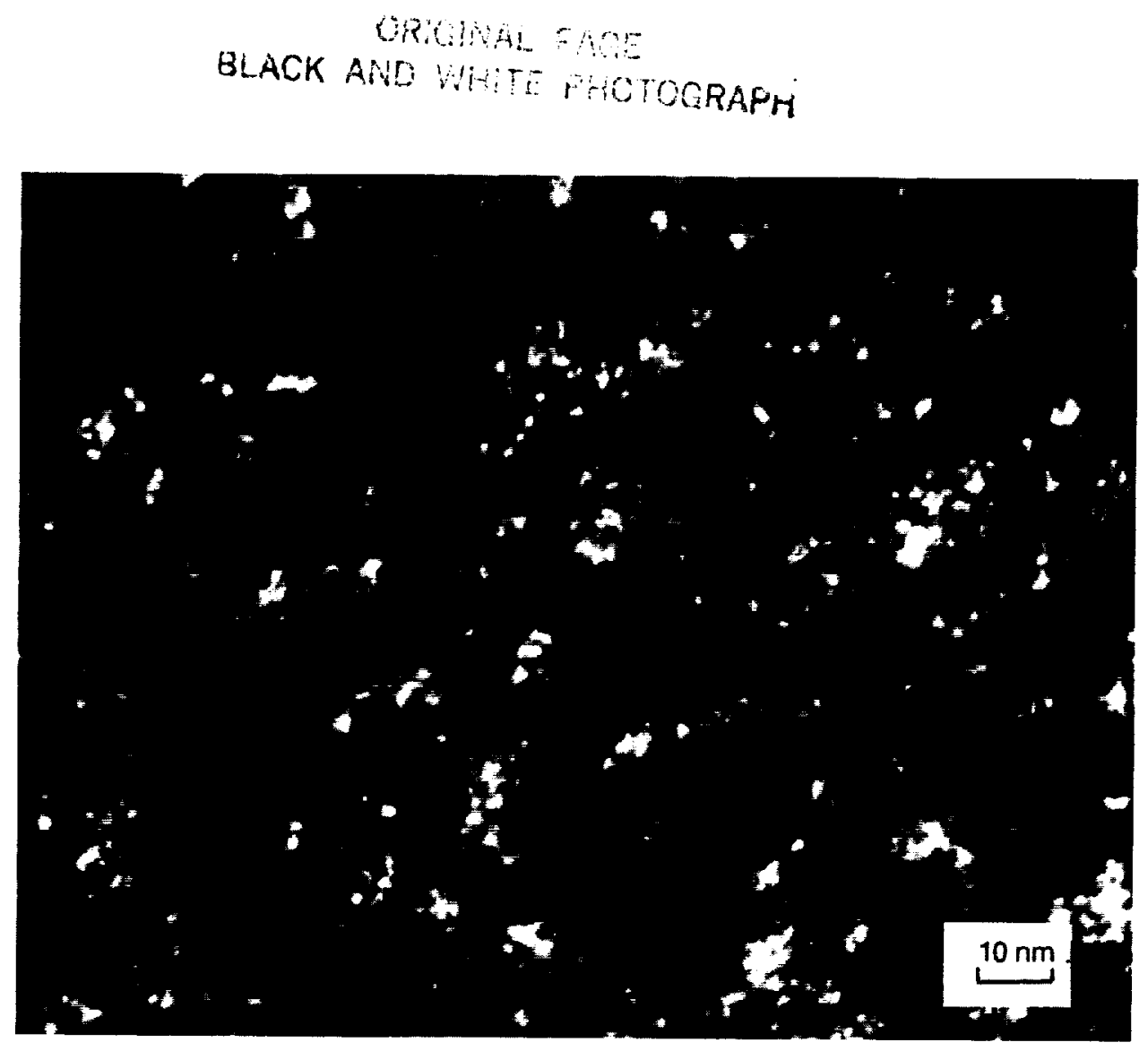

Figure 40. 002 DF image of Amoco T300 fiber (transverse section). 
respectively. The DF images reveal an abundance of randomly distributed crystallites, or some short extended sheet-like features. As expected, in T50 fibers, the bright domains are much better oriented, as shown in Figure 41 . However, long-range features were not observed.

In order to take into account the possibility that the adjacent crystallites might be oriented at slightly different angles, such that they do not all satisfy the Bragg condition to appear in the DF image, transverse samples of T50 fibers were examined in the DF mode at tilt angles from $0^{\circ}$ to $4^{\circ}$, in $1^{\circ}$ increments, with the aperture set at a fixed location of the 002 ring. The purpose of the tilting was to bring the crystallites that happen to be slightly misoriented into view. This was done to determine whether the crystallites, when matched together, would line up in a continuous multifolded sheet of graphite. However, as seen in Figure 42, this is not the case. The DF images at different tilt angles show the in and out of contrast of multiple randomly distributed, isolated crystallites, or in an extreme case, an arrangement of shortly extended features. It was noted that the large, chunky, or shortly extended bright regions were split into many smaller segments due to tilting. This indicates that the crystallites are

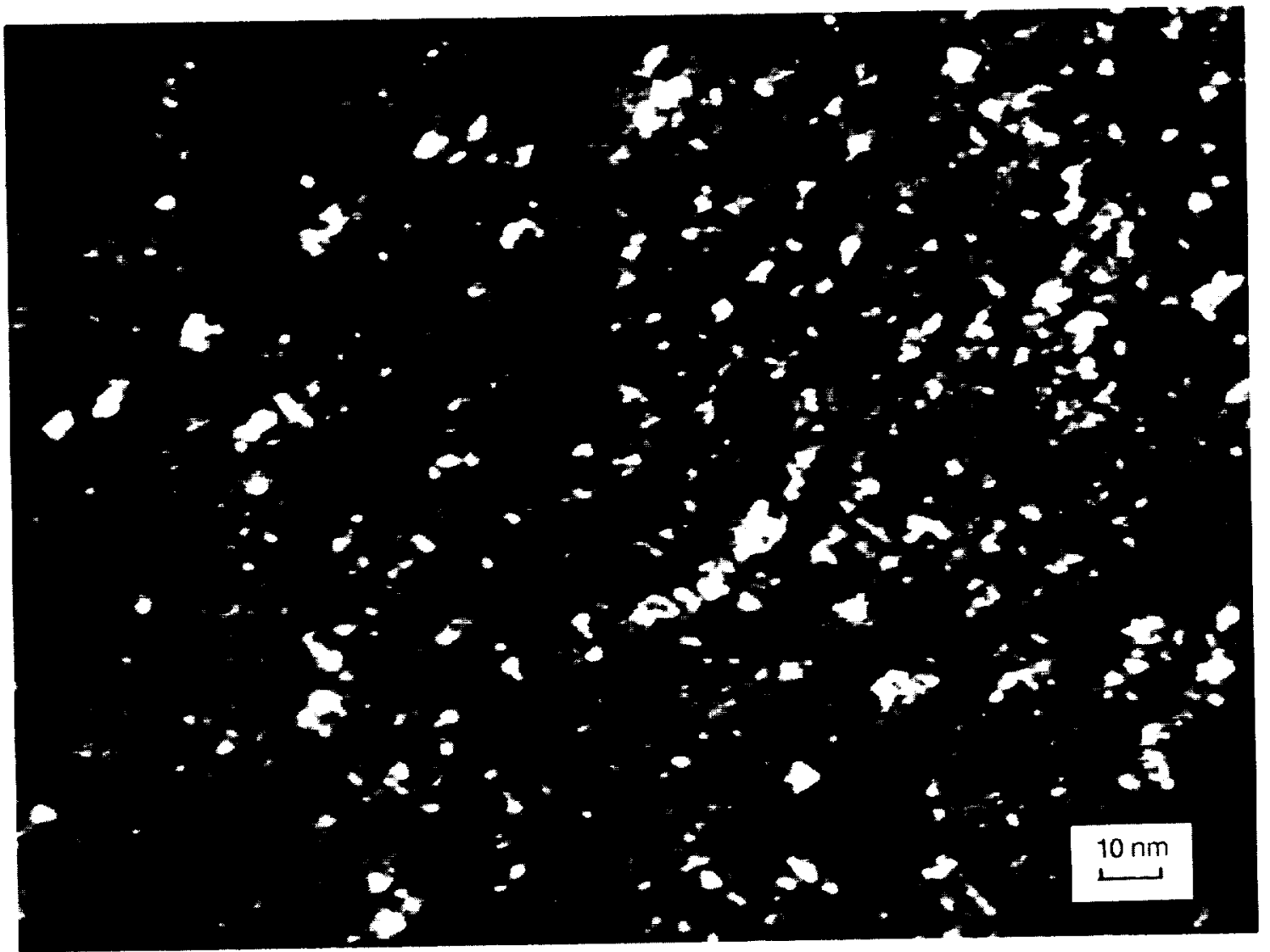

Figure 41. 002 DF: image of Amoco T50 fiber (transverse section; no tilt angle).

BLACK AN W ARAPH 


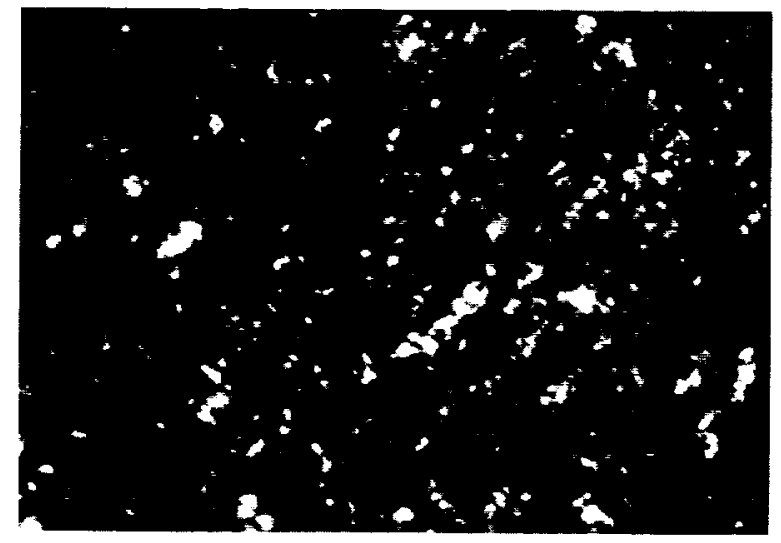

(a) Tilting $1^{\circ}$

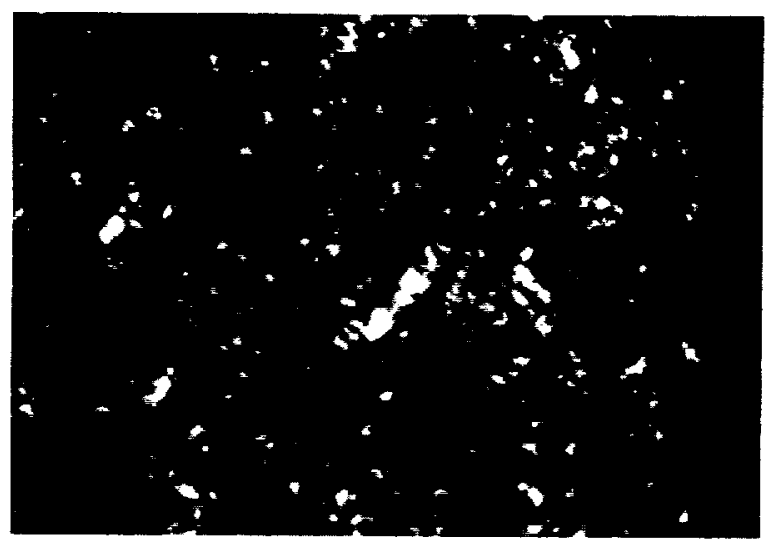

(c) Tilting $3^{\circ}$

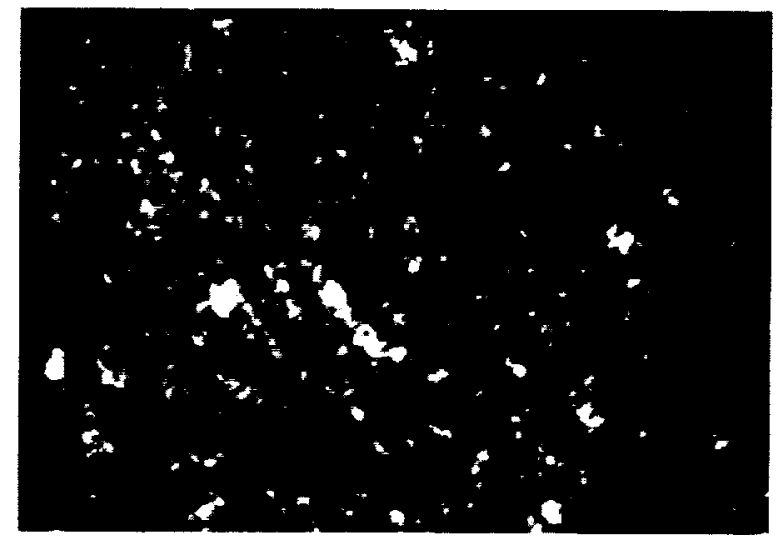

(b) Tilting $2^{\circ}$.

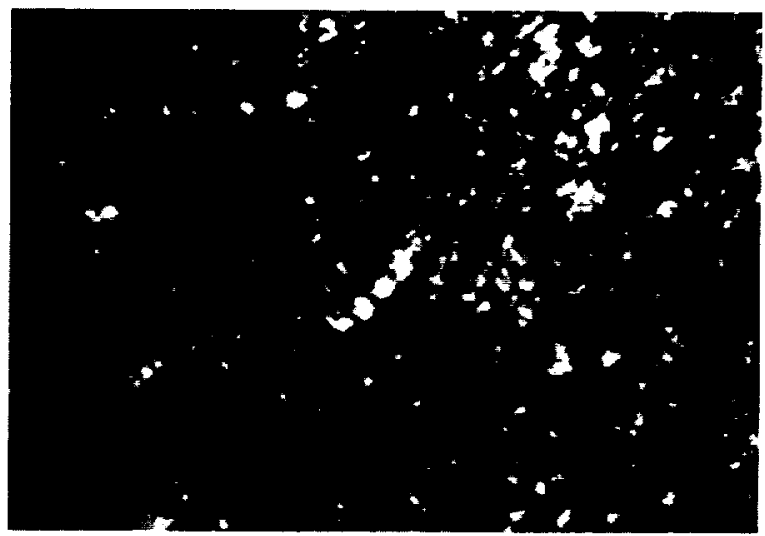

(d) Tilting $4^{\circ}$.

Figure 42. 002 DF images of Amoco T50 fiber (transverse section; different tilt angles). 
arranged side by side to form short, thick strips of basal planes. In certain areas, there is a high density of bright areas due to overlapping images of superimposed domains. Thus, the dark field study does not support Oberlin's model.

In areas where the sample is thin enough such that individual domains can be discerned, size measurements can be estimated. By comparing these DF images, it is seen that the crystallite size increases in the order of T350/23X, $25 \mathrm{X}, \mathrm{T} 300$, and T50 corresponding to HTT. The crystallite thicknesses $\left(l_{\mathrm{c}}\right)$ of each fiber were measured as approximately 10 to $20 \AA$ (T350/23X, T350/25X), 25 to $40 \AA$ (T300), and 60 to $120 \AA$ (T50). The associated SAD patterns of the transverse sections show that the 002 arc reflection is extended into a complete ring. This indicates that there is no preferred orientation in the transverse sections; i.e., the basal planes have preferred orientation along the fiber axis, but their c-axes are randomly oriented throughout the fiber's cross section.

\section{c. High-Resolution (HR) Lattice Fringe Study}

To confirm the DF results, high-resolution (HR) lattice fringe images of the graphite planes composing the observed crystallites in DF images were obtained for the PAN fibers in both longitudinal and transverse sections. Figures 43 to 52 show lattice fringe images of T350-23X, $-25 \mathrm{X}$, T300, and T50 fibers in both the transverse and longitudinal directions. These HR micrographs were obtained in the beam-tilted condition such that individual planes could be brought into sharp contrast and identified as black and white fringes running in almost parallel stacks. Overall, the transverse HR images show several domains of stacking fringes, representing individual, isolated crystallites. The thickness of crystallites varies over a wide range in each case, but clearly show the trend of increasing crystallite size with HTT. For lower HTT fibers (T350/23X, /25X, and T300), the fringe patterns are not well developed, graphite planes undulate, and are not well ordered. In the T50 fiber, the wavy turbostraticplanes are more planar and stacked in a better order. Figures 44 to 47 show that lattice fringe images of transverse sections of T350/25X and T300 fibers are more complicated. In the core region, the lattice planes are arranged randomly in a turbulent fashion throughout the core. This observation is consistent with the macrotexture of the core of the fiber and again suggests that the core structure is not radially oriented. This type of structure is expected to also exist in the core of the T50 fiber, but unfortunately, the core of the T50 specimen was too thick for effective imaging of the lattice fringes. In contrast, lattice fringe images of the outer region of T50 fibers show that the lattice planes are well oriented and arranged in better order. This indicates a strong relation between the micro- and macro-texture of the fibers. It could not be discerned if the basal planes in the outer region are arranged radially, circumferentially, or randomly. The lattice spacings measured directly from these images are $\approx 3.5$ to 


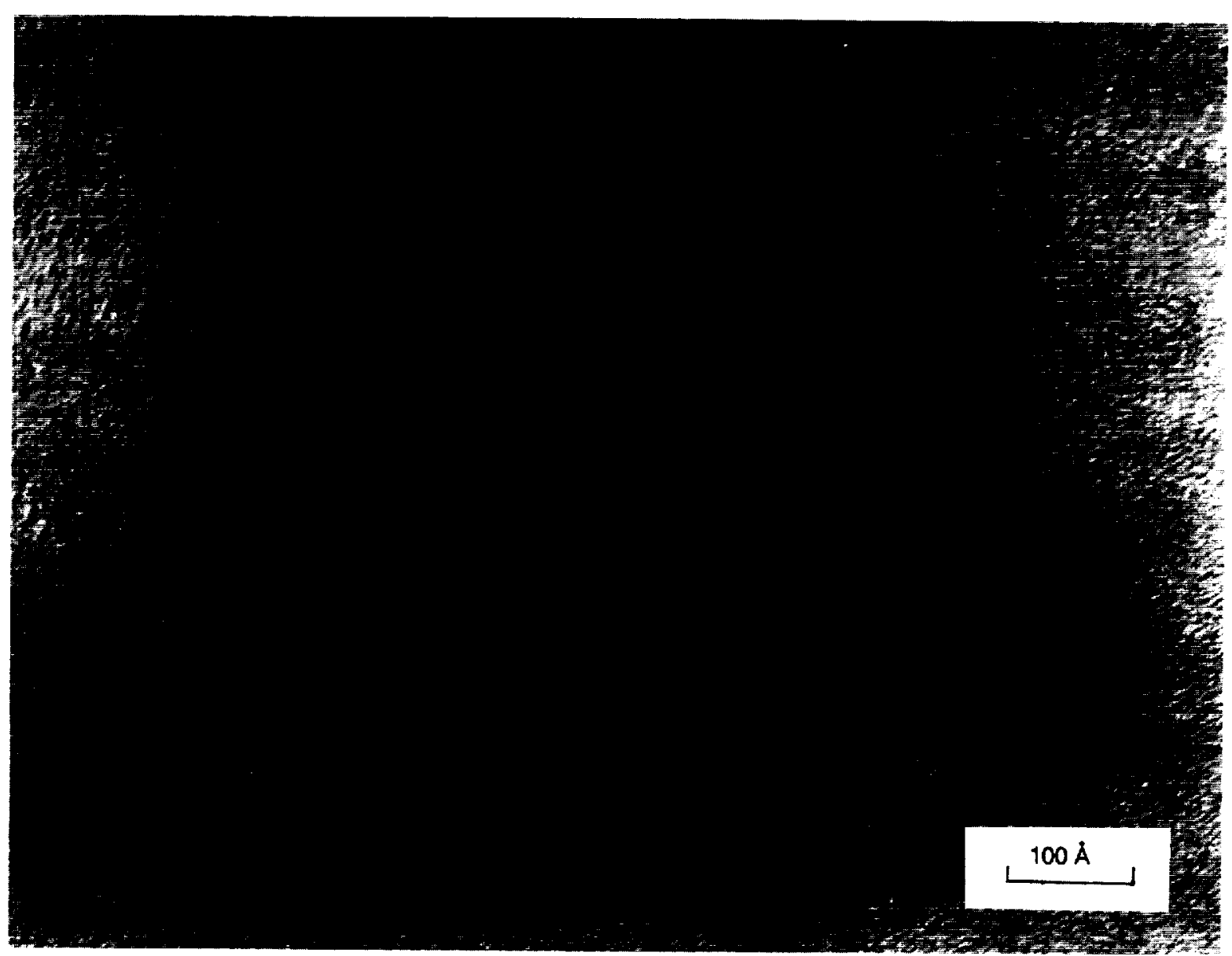

Figure 43. Lattice-fringe image of Amoco T350/23X fiber (transverse section). 


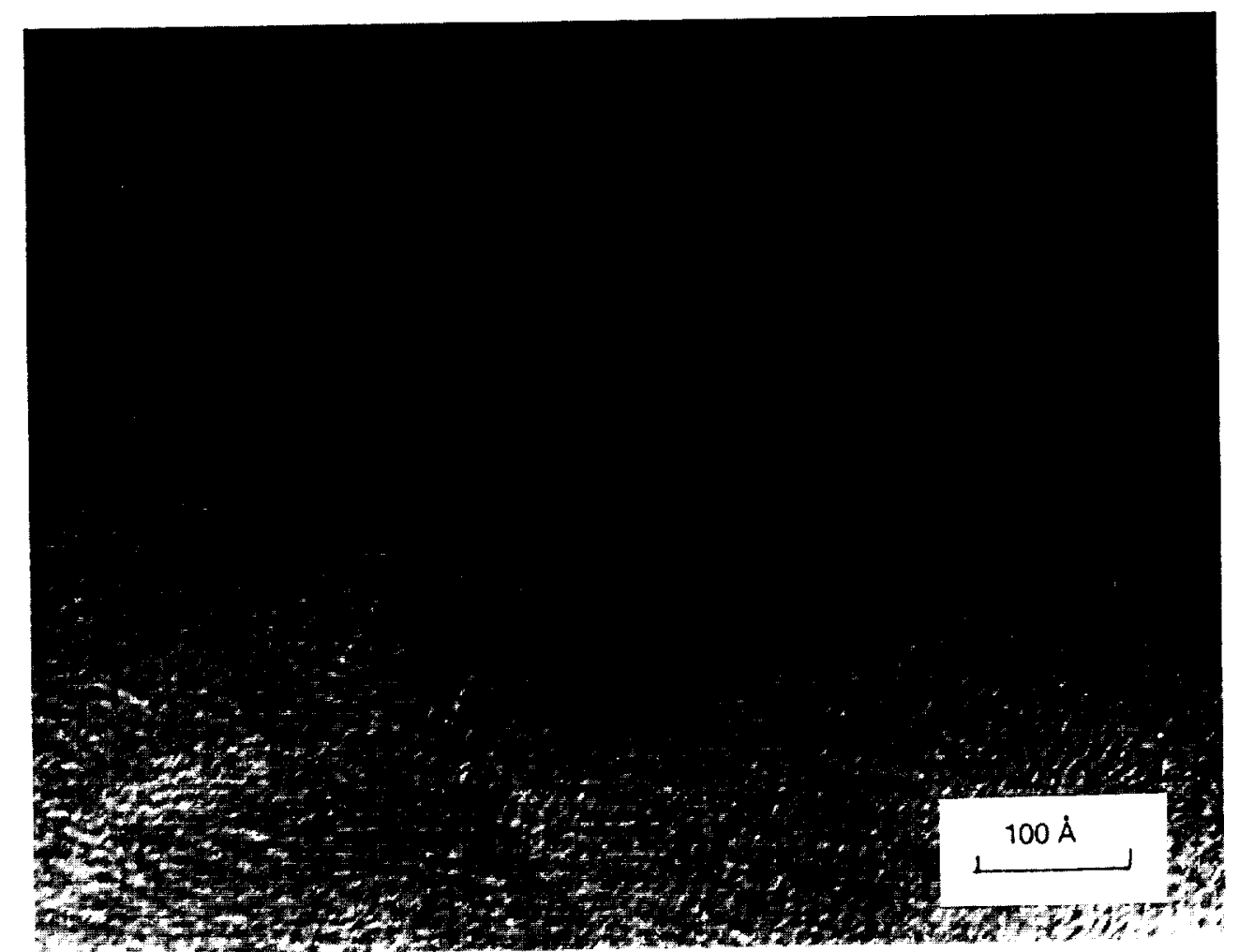

Figure 44. Lattice-fringe image of Amoco T350/25X fiber (transverse/outer region).

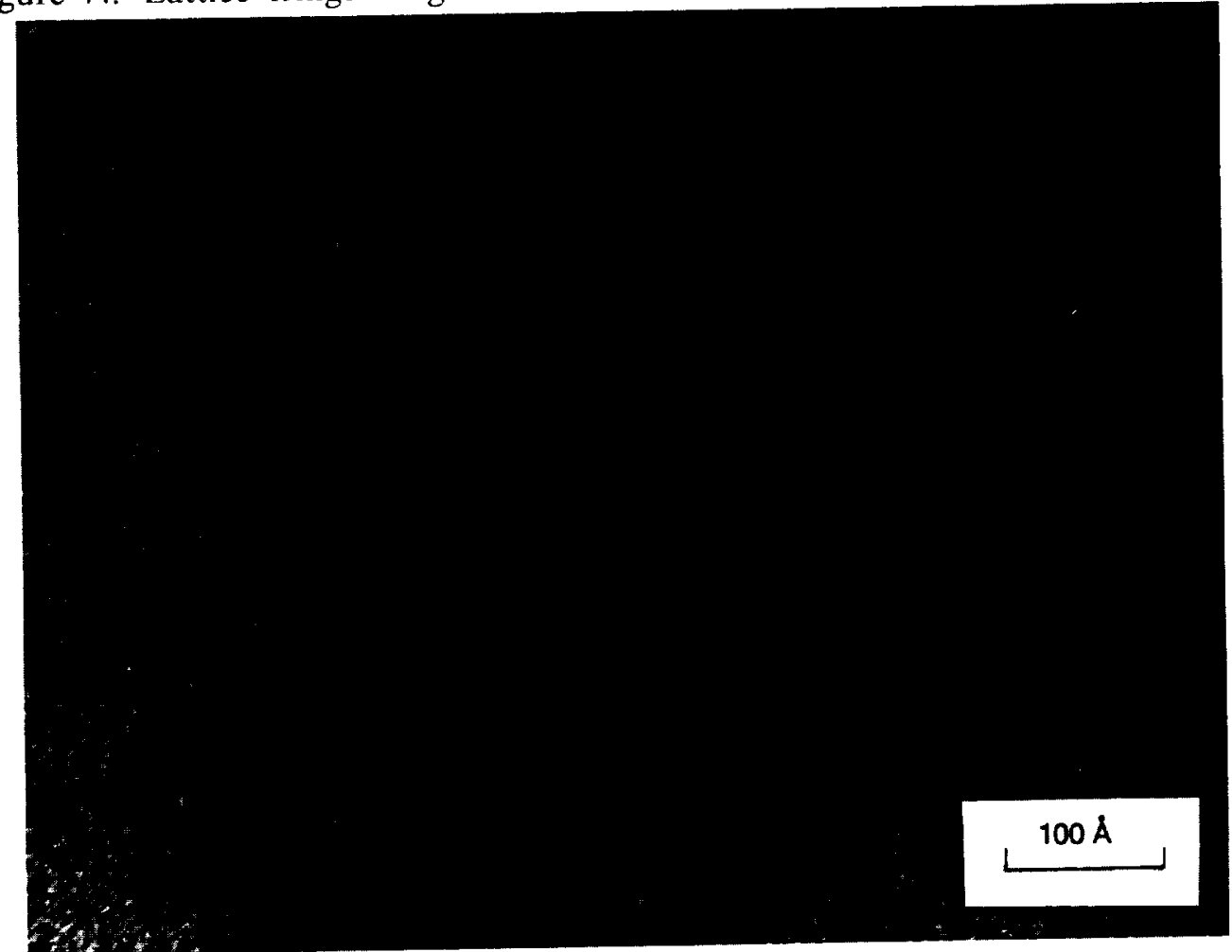

Figure 45. Lattice-fringe image of Amoco T350/25X fiber (transverse/core). 


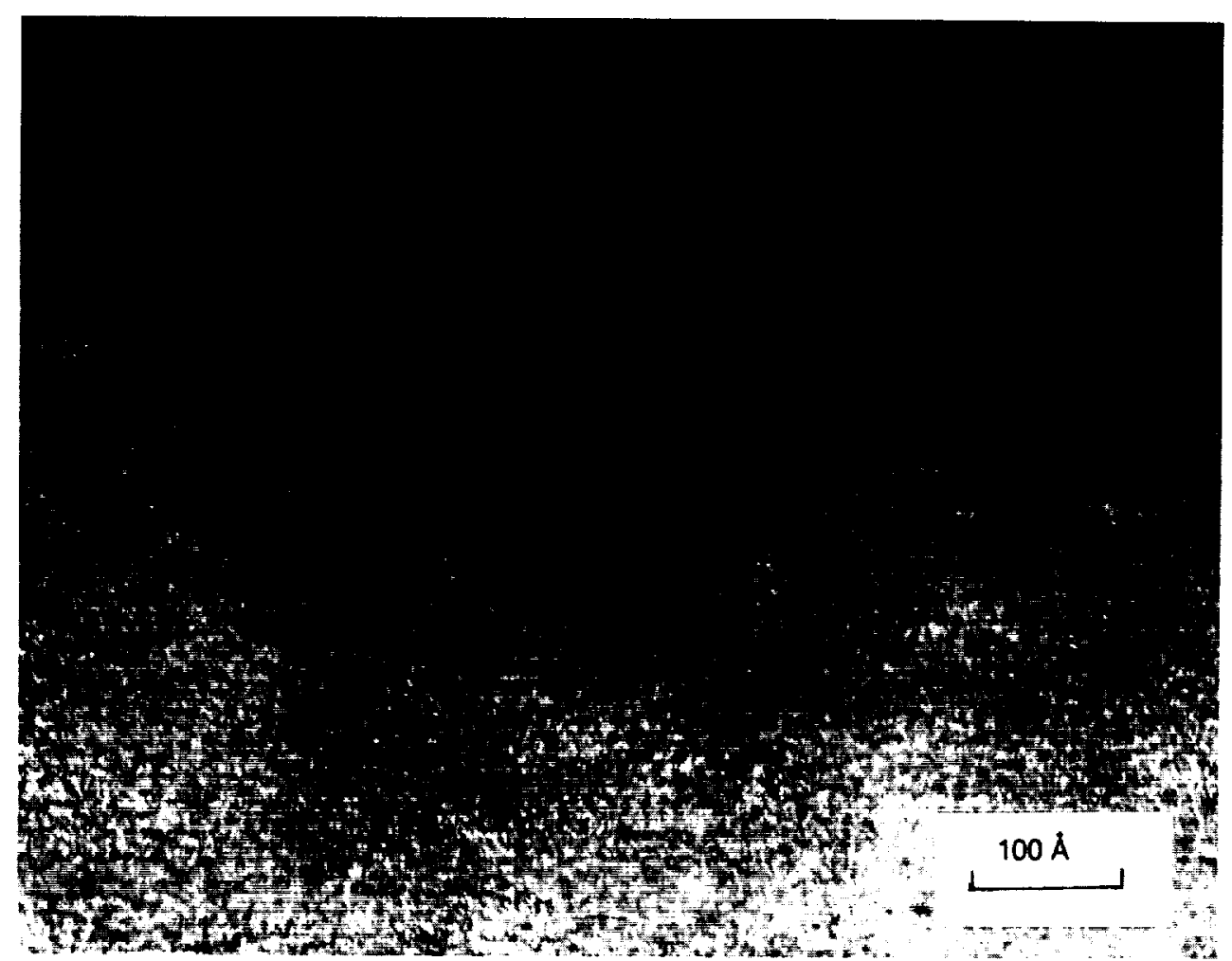

Figure 46. Lattice-fringe image of Amoco T300 fiber (transverse/outer region).

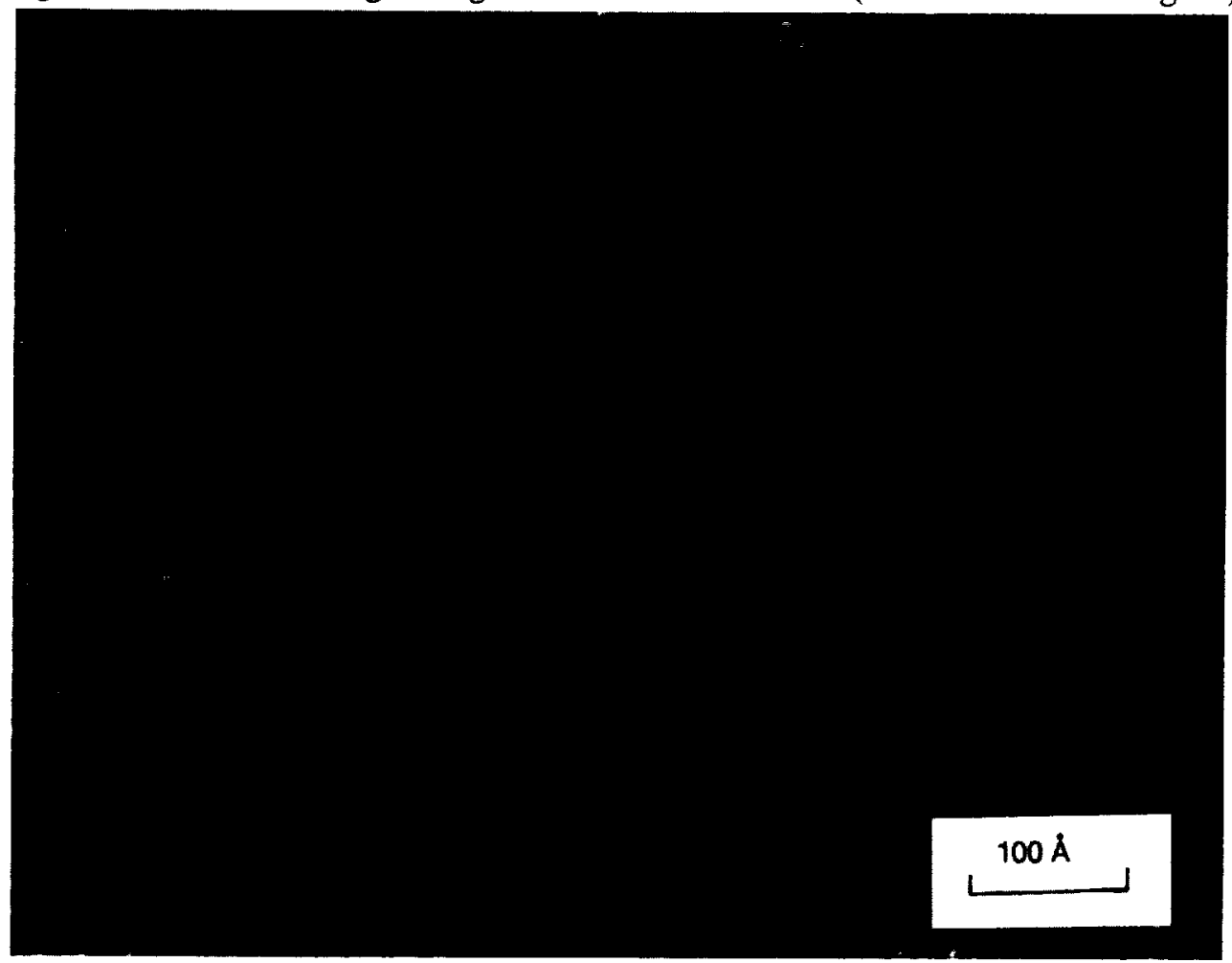

Figure 47. Lattice-fringe image of Amoco T300 fiber (transverse/core). 
BLAN A A FHOTOGRAPH

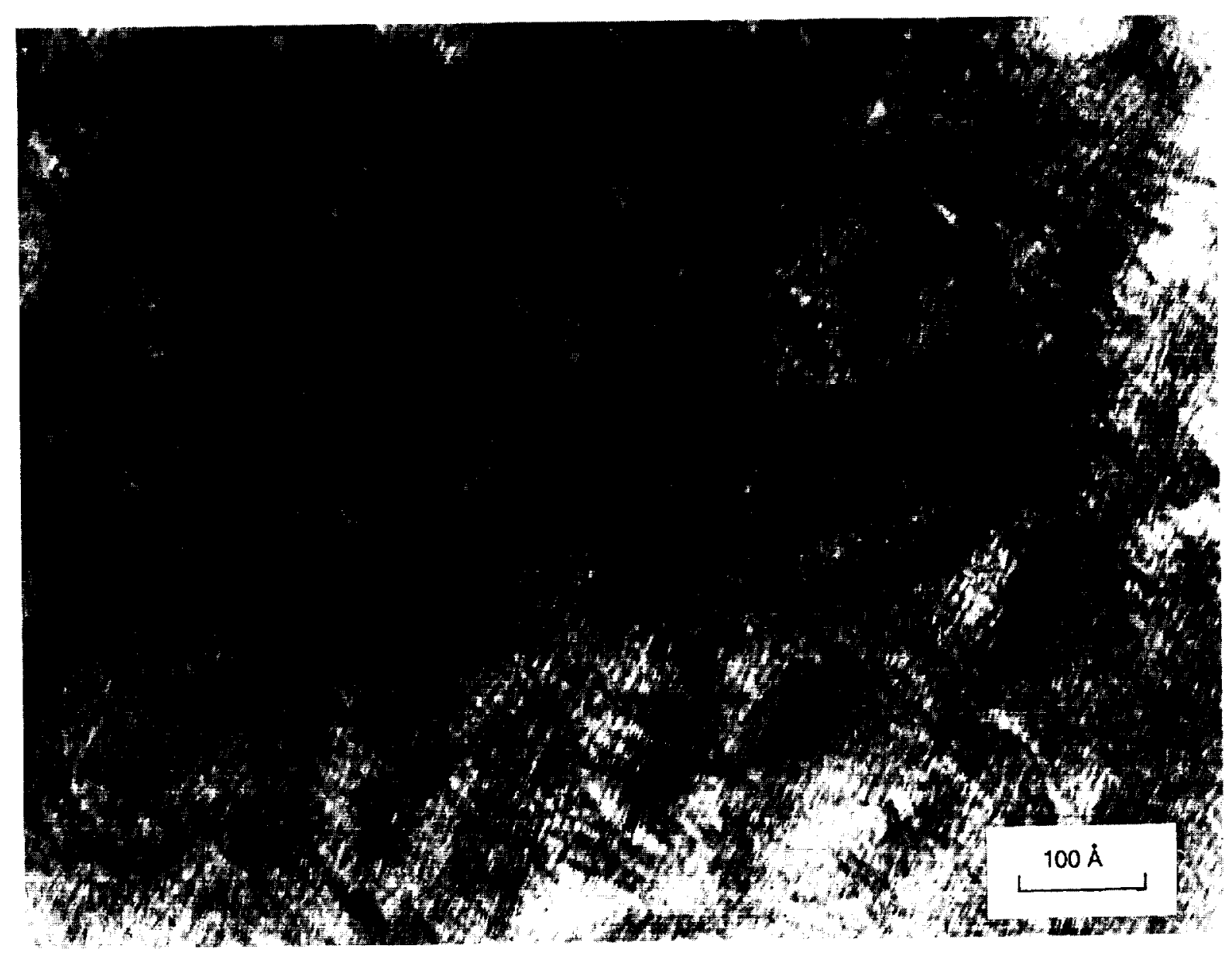

Figure 48. Lattice-fringe image of Amoco T50 fiber (transverse). 
BLACK AND WHITE FHOTOGRARH

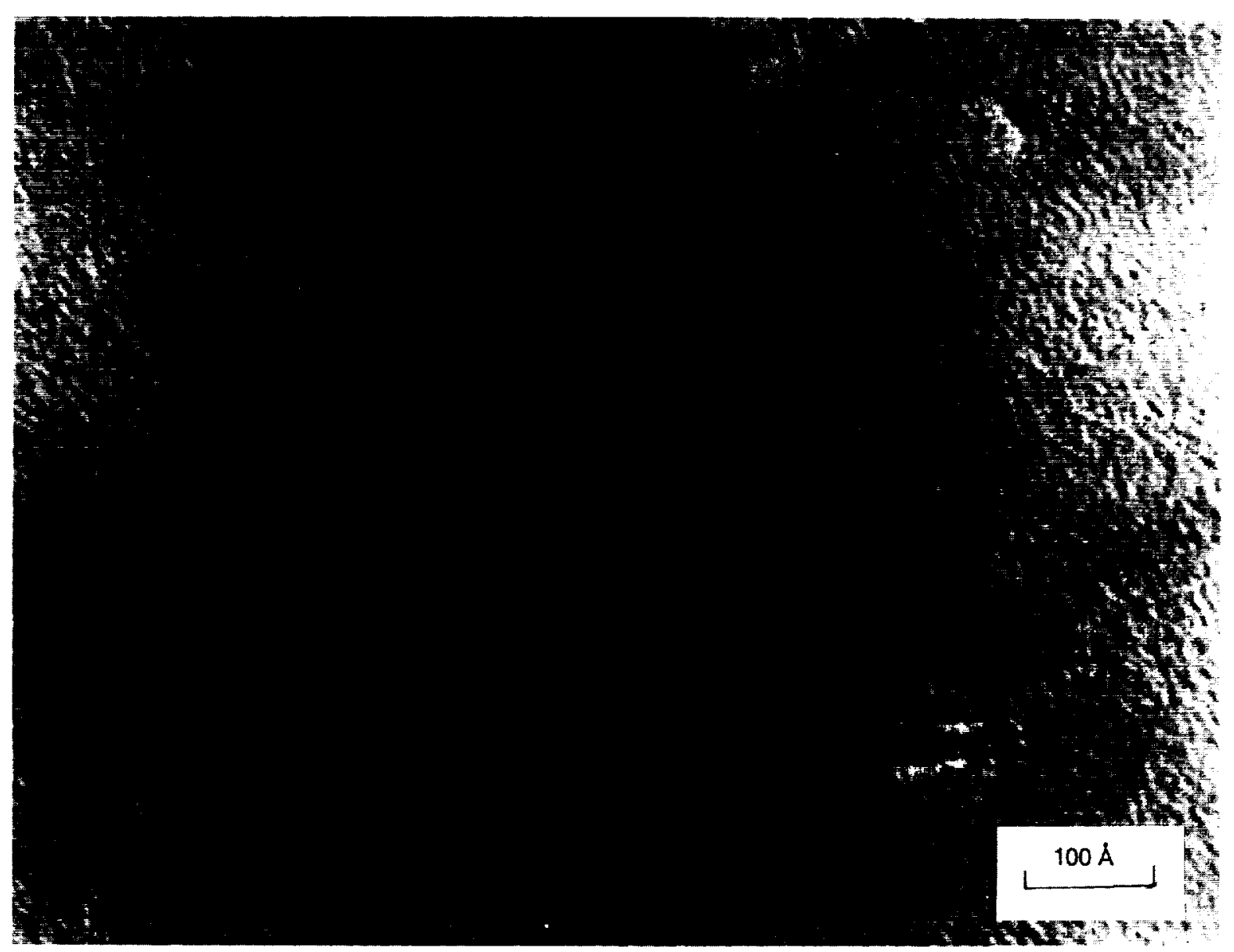

Figure 49. Lattice-fringe image of Amoco T350/23X fiber (longitudinal). 


\section{M.M. ?GE

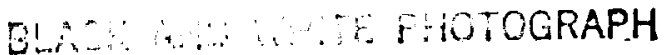

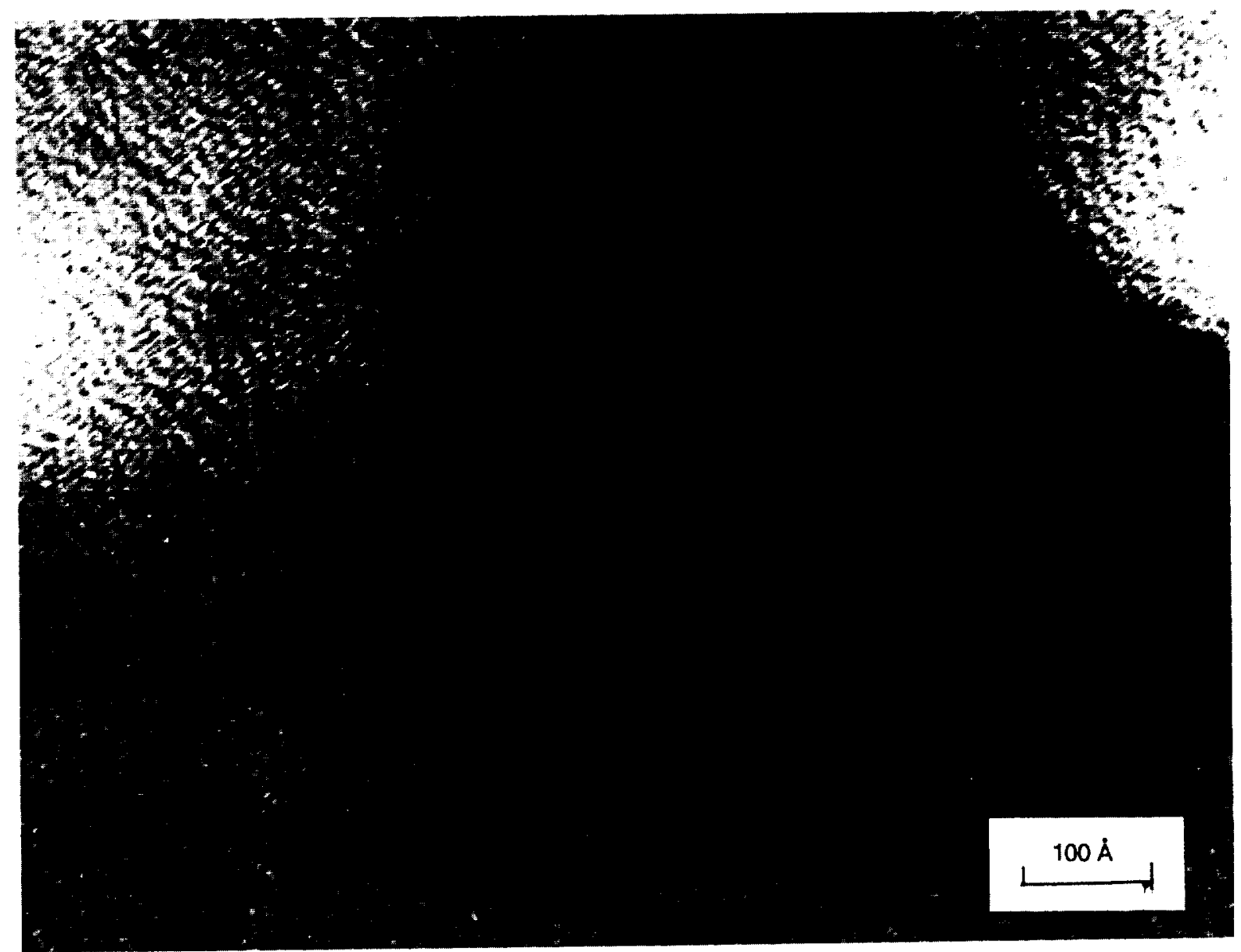

Figure 50. Lattice-fringe image of Amoco T350/25X fiber (longitudinal). 


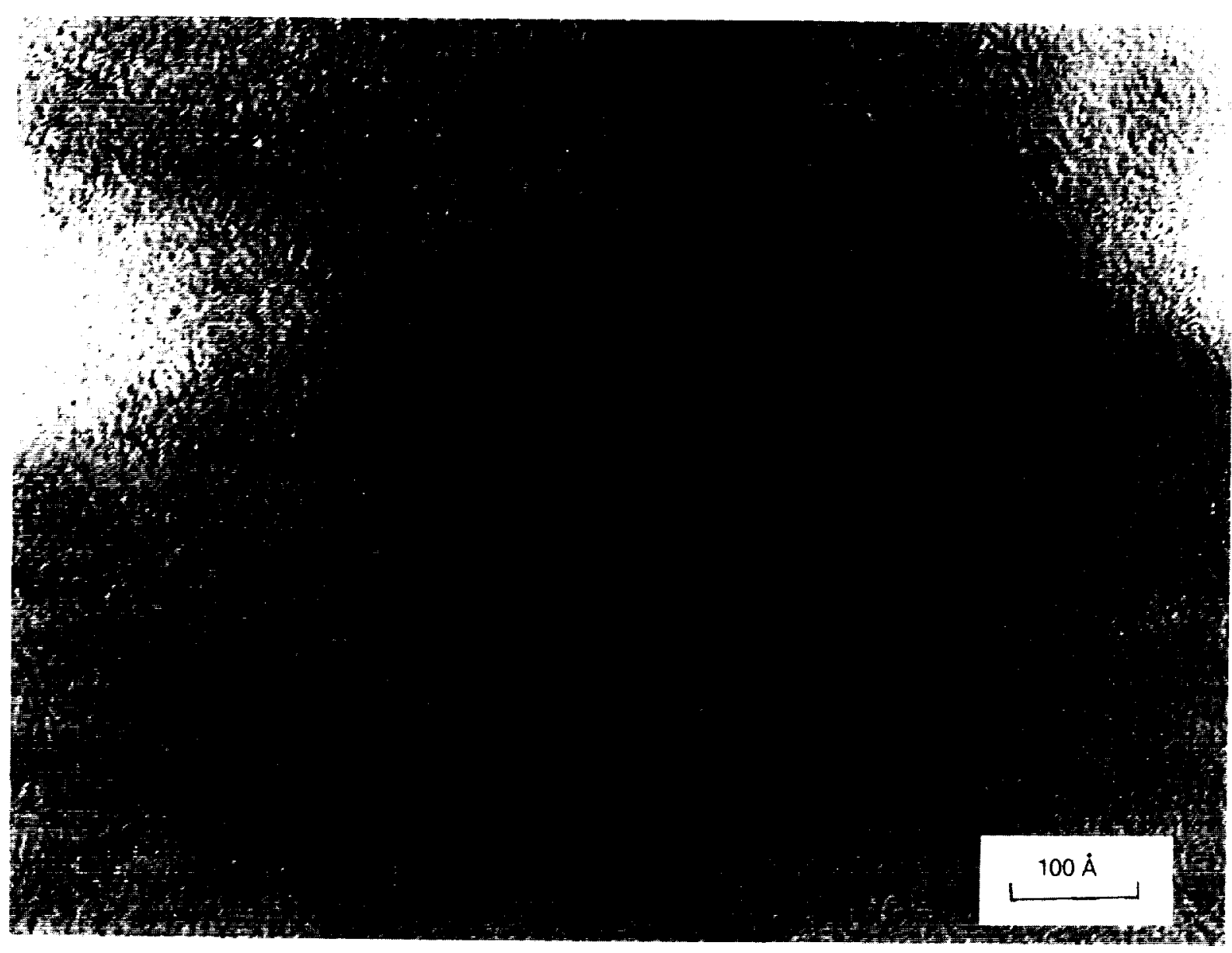

Figure 51. Lattice-fringe image of Amoco T300 fiber (longitudinal). 


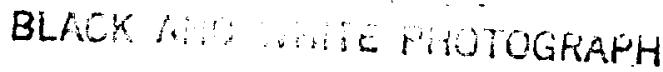

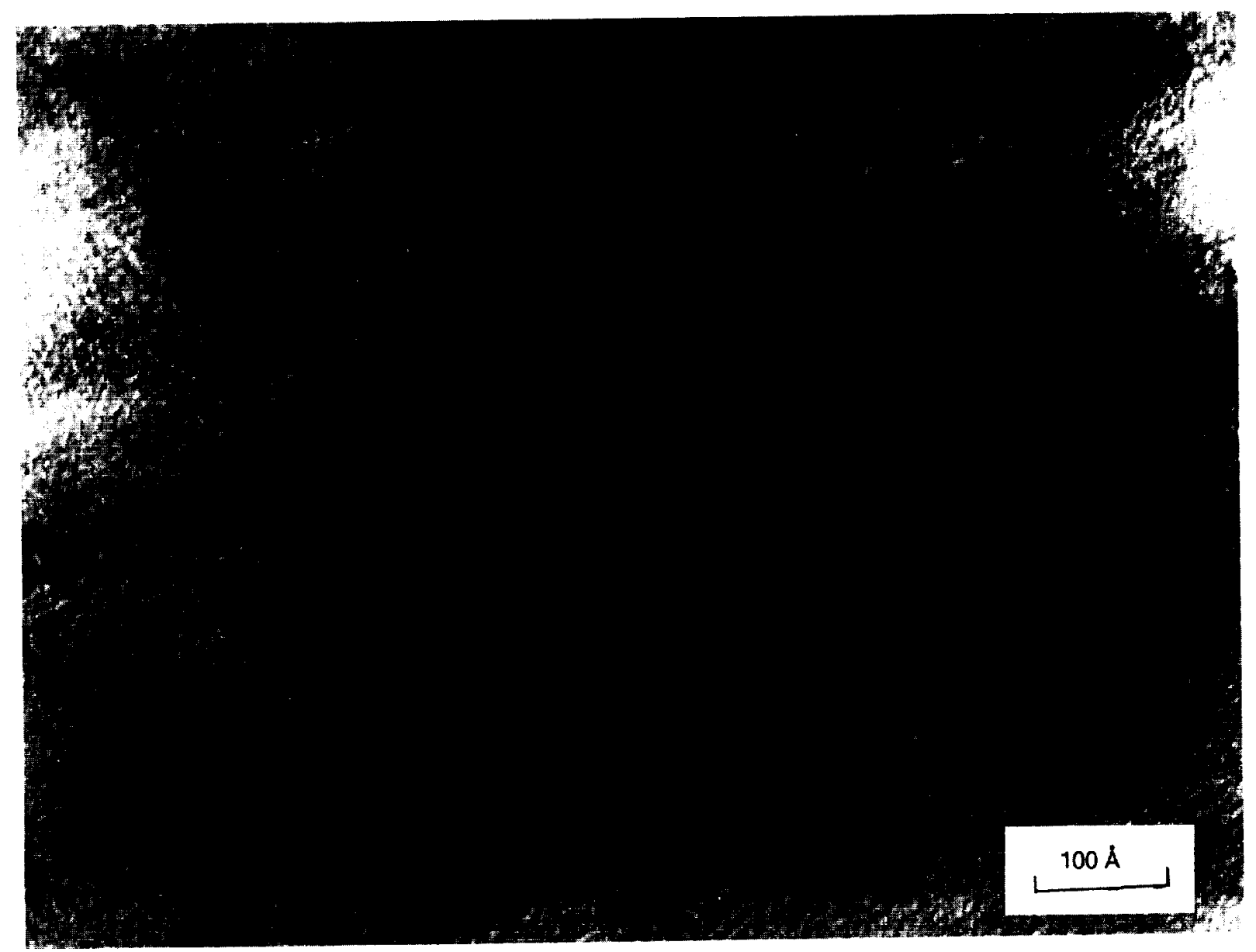

Figure 52. Lattice-fringe image of Amoco T50 fiber (longitudinal). 
$3.7 \AA$ for all lower HTT fibers and $\approx 3.45 \AA$ for T50 fibers. In the longitudinal direction, all features are consistent with those seen in the transverse direction, except that the single crystallites are longer. The lattice fringes indicate that multiple crystallites are interconnected or interwoven smoothly, continuously forming strips of basal planes extending over a long distance along the fiber axis. The evidence of a large number of lattice defects can be discerned along the fiber axis. The evidence of a large number of lattice defects can be discerned from the faults in the fringe patterns. In particular, some nonbasal edge dislocations were observed forming low-angle grain boundaries separating individual crystallites.

\section{d. P100 Fibers}

In order to compare our results on PAN fibers with a more ordered type of fiber, the structure of P-100 pitch-based fiber was examined (Figures 53 and 54). This fiber is known to have a high HTT and a high modulus. The structure of this fiber has been extensively discussed in many previous studies. ${ }^{42-44}$ It is evident in the DF image that the graphite crystallites are much larger and more highly oriented along the fiber direction. The SAD pattern shows sharp, higher-order diffractions (e.g., 004, 006), indicating that the P-100 fiber has a higher degree of graphitization. It is also noted that the arc associated with the 002 reflection is not as wide as the one of the PANbased fibers. This implies that the crystallites are more perfect; i.e., the basal planes are less undulated and appear straight when observed edge-on. As expected, these fibers exhibit a higher degree of graphitization and better oriented, larger, and more perfect graphite crystallites. Treatment at higher temperatures induces grain growth, causing the disappearance of tilt and twist boundaries, leading to flat, more perfect carbon layers.

\section{CONCLUSIONS}

The texture of the LTC PAN-based fibers studied (T350/23X and /25X) consists of multiple sets of parallel, wavy, bent layers that interweave with each other forming a complex three-dimensional network oriented randomly around the fiber axis. In the cases of higher HTT fibers (T300 and T50), the texture consists of two distinct regions, with the core's texture being similar to low HTT fiber's, whereas the outer region is better ordered and oriented. The two-phase structure was not observed in the LTC fibers.

Based on our observations, the following is postulated: under tension during preoxidation and at low HTT, ordered domains, consisting of a few parallel basal planes, develop from an initially amorphous polymer matrix. These isolated domains, which could be envisioned as short strip-like segments, form randomly and tend to grow preferentially along the fiber axis. As the HTT increases, two simultaneous 


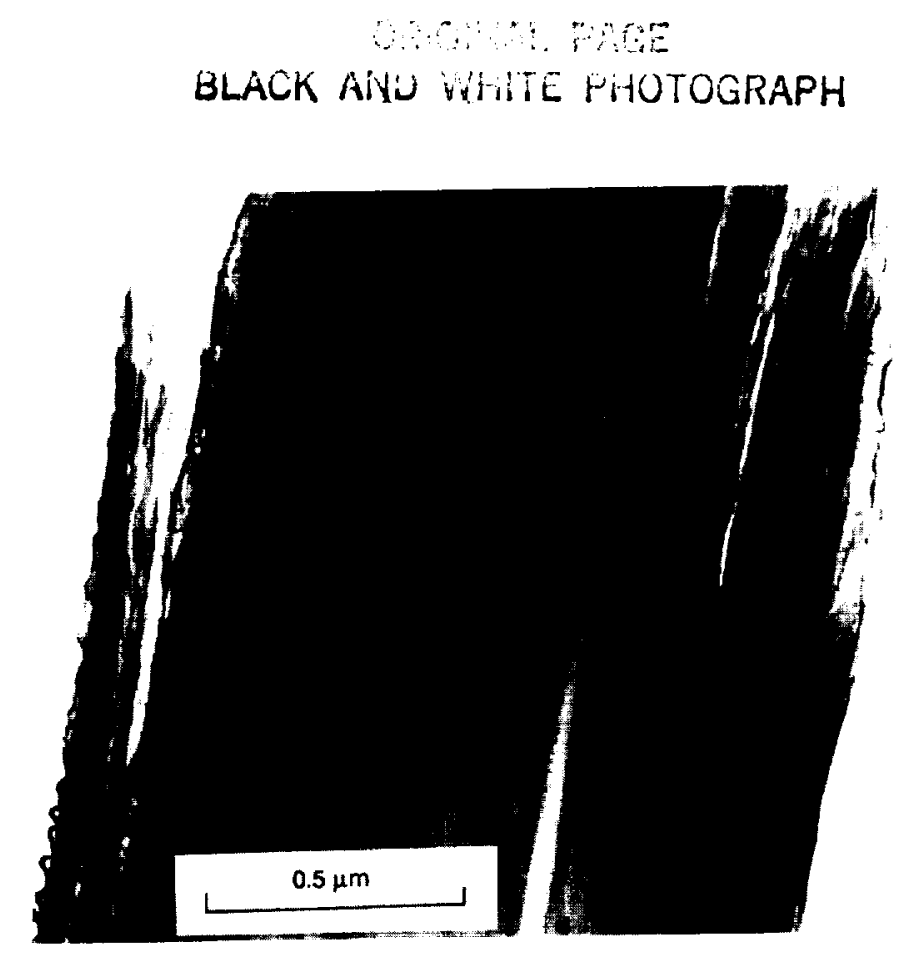

(a) BF Image

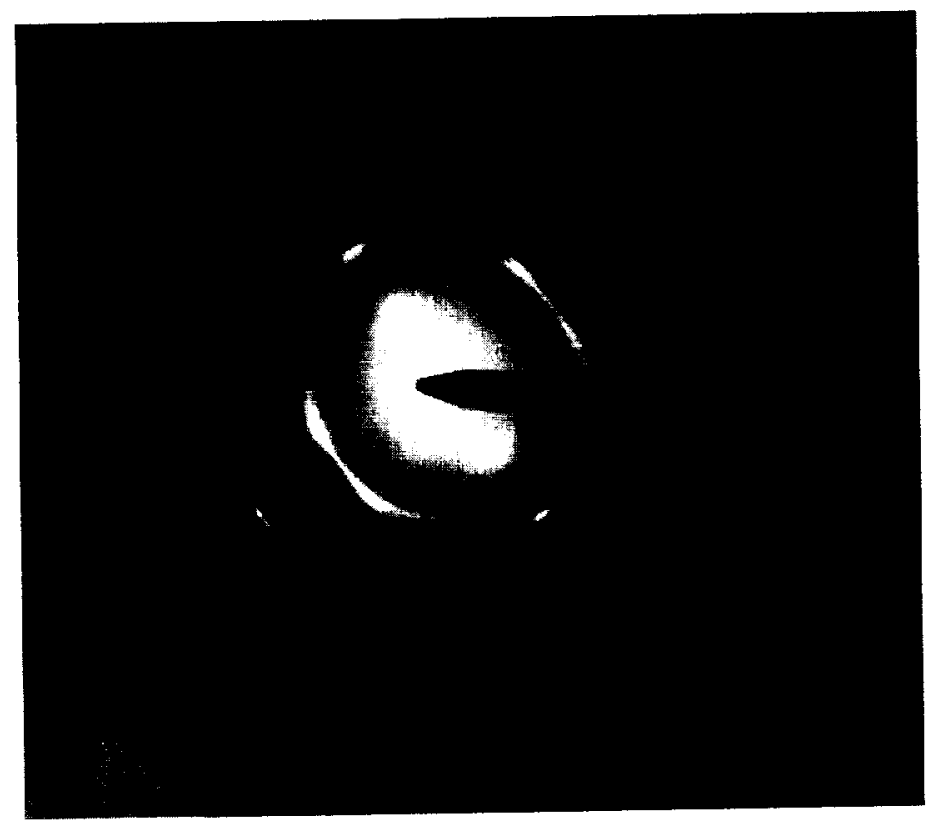

(b) SAD Pattern

Figure 53. BF image and SAD pattern of Amoco P100 tiber. 
ORIGINAL PAGE

BLACK AND WHITE PHOTOGRAPH

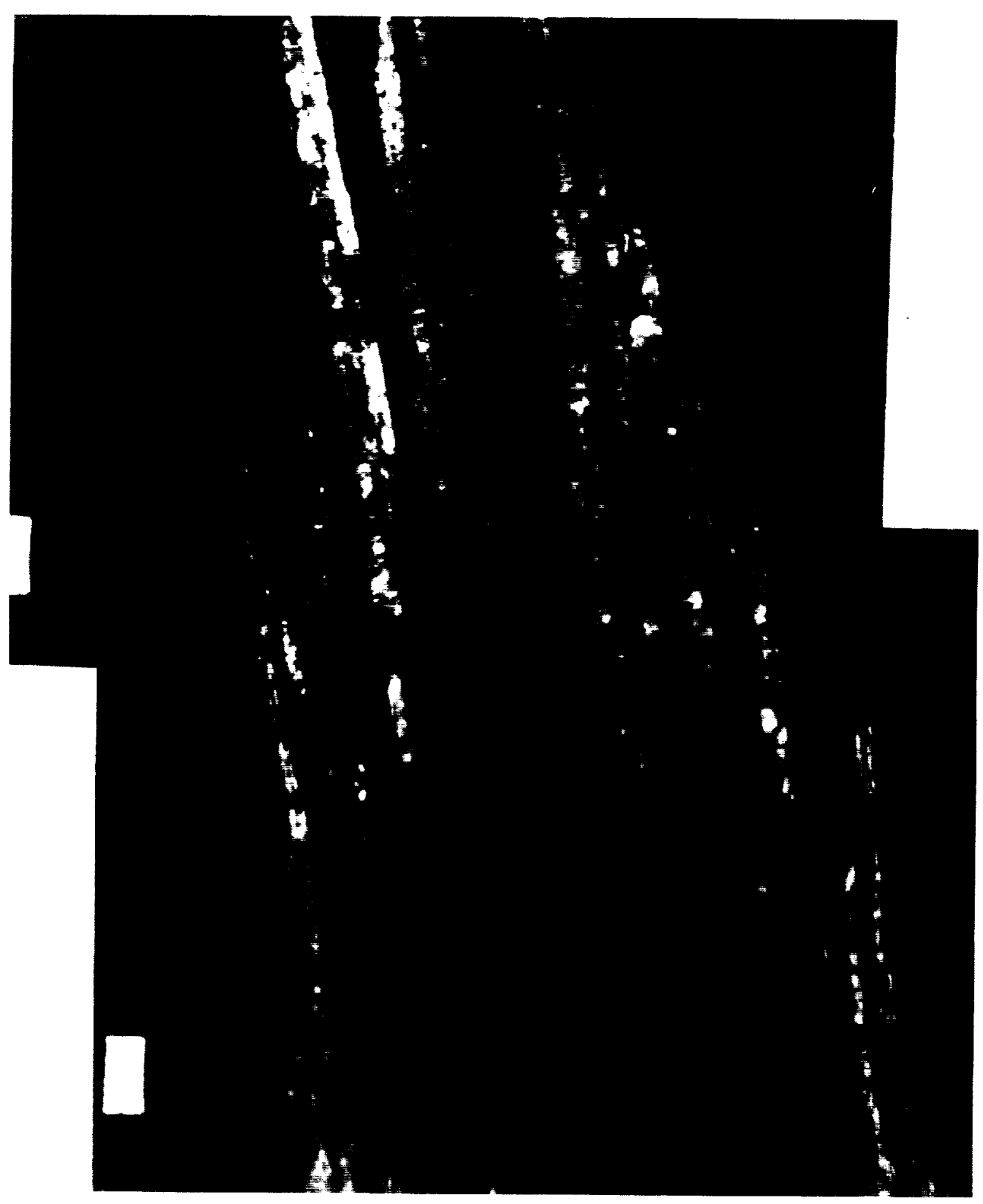

Figure 54. DF image of Amoco P100 fiber. 
phenomena occur, more domains form and grow concurrently with those already existing. At even higher HTT, the domains grow wider and longer until they merge into each other. Depending on their original orientation, they could be separated by either tilt or twist low-angle grain boundaries, forming a long string of edge-to-edge interconnecting regions of certain thicknesses. This sequence of events is expected to develop further at higher temperature, arising in a structure similar to the proposed interlinking ribbon model ${ }^{17,33-35}$ with which the results of this study are in good agreement. The microstructure of the fibers develops from short individual strips of basal planes which grow both normal and parallel to the formed layers. Finally, the small basal-plane segments join to form large, thick stacks of near-perfect basal planes. Depending on the HTT, the observed crystalline defects in the structure may be annealed out, leading to a more perfect, better-ordered morphology of basal planes. The evidence of consistent diffraction patterns over a large tilt angle indicates that this type of structure is present at any radial angle of the fiber. This confirms the belief that these ribbons crosslink in a highly complex three-dimensional manner along the fiber axis. 


\section{FIBER SURFACE CHEMISTRY}

\section{A. X-RAY PHOTOELECTRON SPECTROSCOPY (XPS)}

\section{Background and Experimental}

Analysis of the LTC carbon fibers by X-ray photoelectron spectroscopy (XPS) was included to provide information on surface elemental composition and surface chemistry. It was anticipated that the surface composition and chemistry might be a function of the temperature and time at temperature during carbonization. Only unsized fibers were examined. The XPS analyses were performed on a VG ESCALAB MkII surface analysis instrument. The analysis starts with photon-source irradiation of the sample (in this case with $\mathrm{Mg} \mathrm{K} \alpha \mathrm{X}$ rays at $300 \mathrm{~W}, \mathrm{~h} \nu=1253.6 \mathrm{eV}$ ), which causes ejection of photoelectrons from the surface. Only photoelectrons from the surface are detected because photoelectrons generated in the bulk are reabsorbed and do not escape the solid, giving rise to a surface sensitivity typically in the range of 50 to 100 $\AA$ deep. The kinetic energies (KE) of the ejected photoelectrons are analyzed, which gives binding energy (BE) information about electrons in the solid according to the simplified relationship, $\mathrm{h} \nu=\mathrm{KE}+\mathrm{BE}$. A typical XPS spectrum shows electron intensity (count rate) as a function of BE. Each element is characterized by a unique set of electron binding energies. Quantitative surface compositions can be obtained from measurement of peak areas, and identification of chemical states can often be deduced from the exact positions and shapes of the peaks.

Two fiber tows approximately $3 \mathrm{~cm}$ long were glued at one end with conductive, silverfilled epoxy to a standard 1-cm diameter flat-topped sample stub for analysis. Scanning electron beam imaging was used to choose an analysis area on the unglued end of the bundles where the fibers were overhanging the stub. Analysis chamber pressure during XPS data acquisition was $<5 \times 10^{-10}$ torr to minimize sample contamination. Comprehensive wide scans were run initially for each sample to determine which elements were present in the surface region. The XPS detection limit is about $0.1 \mathrm{~mol} \%$ for most elements ( $\mathrm{H}$ and $\mathrm{He}$ cannot be detected). Binding energy and peak area measurements were made from high-resolution (HR) spectral scans (20-40 eV wide) of appropriate elemental regions. Data acquisition and analyses were done on a system-dedicated DEC PDP 11/73 computer.

PRECEDING PAGE BLANK NOT FILMED

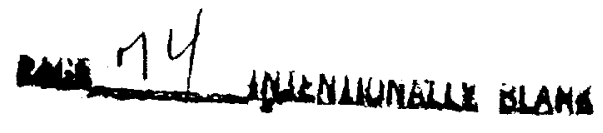


Surface concentrations are calculated as follows. Peak areas are measured from the HR elemental scans, scaled by elemental sensitivity factors, then normalized to report as mol\%. It is important to note that these normalized concentrations do not reflect the presence of elements not detected (including hydrogen) or not measured. Also, elemental sensitivity factors are of limited accuracy for complex solid matrices. Consequently, "absolute" surface concentrations can be in error by as much as a factor of 2 or more, but relative concentrations for a given element in comparable matrices should be accurate to about $10 \%$ for all but trace components. The elemental sensitivity factors used in this study for $\mathrm{O}$ relative to $\mathrm{C}$ and for $\mathrm{Si}$ relative to $\mathrm{O}$ give the expected stoichiometry within $10 \%$ for adsorbed $\mathrm{CO}$ and fused silica, respectively.

The depth of analysis by XPS varies from about 50 to $100 \AA$, and is most strongly dependent on the KE of the emitted photoelectrons. Electrons with low kinetic energy have a shorter mean free path in the solid and, consequently, have a lower probability of escaping the solid without energy loss. Differences in mean free path are included in calculations of relative elemental sensitivity factors, but significant errors still arise when surface composition is heterogeneous, e.g., in the presence of contamination overlayers. The apparent stoichiometry of a substrate can be substantially altered by an overlayer's different attenuation of electron signals with widely different KE.

\section{Results and Discussion}

XPS surface composition data for the eight unsized LTC carbon fibers is tabulated in Table 6. For comparison, data from two PAN-based fibers, T300 and T50, a pitchbased fiber, P55, and HOPG graphite are included in the table. The surfaces of all the LTC fibers were found to incorporate moderate concentrations of nitrogen and moderate to high concentrations of oxygen. Silicon was a moderate level contaminant on the surfaces of the Textron and Hercules fibers. The measured BE of the Si2p photoelectron peaks on these four fiber samples was $103-104 \mathrm{eV}$, indicating that the silicon is present as $\mathrm{SiO}_{2}$. The XPS data do not provide any clues as to the source of this considerable silica contamination. Silicon was present at a low concentration, less than 1\%, on the BASF and Amoco fiber samples. Trace concentrations of sulfur, sodium, chlorine, and calcium were detected on some of the LTC sample surfaces. Moderate sodium contamination was detected on the T300 fibers analyzed for comparison. 
Table 6. XPS Surface Composition Data

\begin{tabular}{|c|c|c|c|c|c|c|c|c|}
\hline \multirow[b]{2}{*}{ Unsized PAN Fibers } & \multicolumn{8}{|c|}{ Surface mol\% } \\
\hline & $\mathrm{C}$ & 0 & $\mathbf{N}$ & $\mathrm{Si}$ & $S$ & $\mathrm{Na}$ & $\mathrm{Cl}$ & $\mathrm{Ca}$ \\
\hline Avcarb B-2 & 74 & 17 & 5 & 5 & $<0.1$ & nd & nd & nd \\
\hline Avcarb G & 68 & 18 & 8 & 5 & $<0.1$ & nd & nd & nd \\
\hline Hercules R879-01 & 57 & 29 & 4 & 9 & 0.3 & nd & $<0.1$ & nd \\
\hline Hercules R879-02 & 53 & 30 & 6 & 10 & 0.4 & 0.4 & nd & nd \\
\hline DG Rayon 1 & 82 & 11 & 4 & 1 & 0.5 & 0.2 & $<0.1$ & $<0.1$ \\
\hline $\begin{aligned} \text { DG Rayon } 2 & \# 1 \\
& \# 2\end{aligned}$ & $\begin{array}{l}84 \\
86\end{array}$ & $\begin{array}{r}10 \\
9\end{array}$ & $\begin{array}{l}5 \\
4\end{array}$ & $\begin{array}{l}0.8 \\
0.6\end{array}$ & $\begin{array}{r}0.1 \\
0.1\end{array}$ & $\begin{array}{l}<0.1 \\
<0.1\end{array}$ & $\begin{array}{r}0.1 \\
<0.1\end{array}$ & $\begin{array}{l}\text { nd } \\
\text { nd }\end{array}$ \\
\hline $\begin{array}{r}\text { Amoco T350/23X \#1 } \\
\# 2\end{array}$ & $\begin{array}{l}87 \\
85\end{array}$ & $\begin{array}{r}8 \\
10\end{array}$ & $\begin{array}{l}5 \\
5\end{array}$ & $\begin{array}{l}0.2 \\
0.2\end{array}$ & $\begin{array}{l}<0.1 \\
<0.1\end{array}$ & $\begin{array}{l}\text { nd } \\
\text { nd }\end{array}$ & $\begin{array}{l}\text { nd } \\
\text { nd }\end{array}$ & $\begin{array}{l}\text { nd } \\
\text { nd }\end{array}$ \\
\hline $\begin{array}{l}\text { Amoco T350/25X } \\
\text { (shear treated) }\end{array}$ & 79 & 15 & 6 & $<0.1$ & 0.1 & nd & $<0.1$ & $<0.1$ \\
\hline $\begin{array}{l}\text { Amoco T300 } \\
\text { (not shear treated) }\end{array}$ & 87 & 8 & 2 & nd & 0.1 & 4 & tr & nd \\
\hline Amoco T50 & 96 & 3 & 0.2 & nd & 0.1 & 0.2 & nd & nd \\
\hline Amoco P55 (pitch) & 96 & 4 & nd & nd & 0.1 & nd & $\operatorname{tr}$ & nd \\
\hline HOPG graphite & 100 & 0.4 & nd & nd & nd & nd & nd & nd \\
\hline
\end{tabular}

nd $=$ Not detected.

It is seen in Table 6 that there is a correlation between the surface nitrogen and oxygen concentrations and the degree of graphitization. HOPG graphite has only a trace (tr) level of oxygen, T50 has $4 \%$ oxygen, T300 has $8 \%$ oxygen (about $2 \%$ of this oxygen can be assumed to be associated with the sodium oxide surface contamination), and the LTC fibers have 7 to $13 \%$ oxygen that is not associated with $\mathrm{SiO}_{2}$ contamination. The Amoco T350/25X sample is shear treated and has a slightly higher surface oxygen concentration (16\%) than the nonshear-treated fibers. The presence of widely varied concentrations of surface silica and the apparent variability in surface oxygen between different samples of the same fiber type make it impossible to correlate the surface oxygen concentrations of the LTC fibers with the degree of graphitization determined by X-ray diffraction.

The lower thermal conductivity of the LTC fibers is due to their retention of a large amount of nitrogen. At higher temperatures, most of this nitrogen is driven off, leaving a purer carbon fiber with higher thermal conductivity. Comparing the PAN-based 
fibers, it can be seen that residual surface nitrogen from the precursor PAN correlates with the temperature and time at temperature during carbonization. The nitrogen concentration was measured to be $0.2 \%$ on T50, $2 \%$ on T300, and 4 to $8 \%$ on the LTC fibers. There was no consistent difference between the LTC carbon fibers. Heterogeneity makes it difficult to correlate surface nitrogen levels with the extent of graphitization. The N1s photoelectron peak on the LTC samples is split into two peaks, one of which can be assigned to nitrides or $\mathrm{CN}$ at about $398.5 \mathrm{eV} \mathrm{BE}$, and the other of which can be assigned to $\mathrm{NH}_{4}$ or $\mathrm{NR}_{4}$ at about $400.5 \mathrm{eV} \mathrm{BE}$. On most of the samples, the ratio of the lower $\mathrm{BE}$ peak to the higher BE peak was about 2:3. Additionally, on some of the N1s spectra it was necessary to add a third peak at about $402.5 \mathrm{eV}$ to obtain a smooth curve fit. This peak accounted for about $10 \%$ of the total peak intensity and can be assigned to oxidized nitrogen. Shear treatment does not appear to decrease the amount of nitrogen on the LTC fiber surface.

The C1s photoelectron peaks measured for the LTC carbon fibers have significant intensity at higher binding energy due to the presence of oxygen-containing functionalities bonded to the fiber surfaces. This is illustrated in Figure 55a, where the higher $\mathrm{BE}$ peaks are seen to give rise to an asymmetric tail on the dominant carbon peak arising from the carbonized surface. The C1s peaks of the LTC fibers have been curve fit to determine the relative contribution of different classes of oxygencontaining functionalities to the high BE tail. These data are shown in Table 7. A study of well-characterized polymers ${ }^{48}$ has shown that each bond formed between a carbon atom and an oxygen atom leads to an electron withdrawing shift to higher $\mathrm{BE}$ on the carbon atom of about $1.5 \mathrm{eV}$. The LTC carbon fiber C1s data could be fit by assuming the presence of functionalities with one, two, and three bonds to oxygen (e.g., alcohol or ether, ketone or ketal, and acid or ester, respectively). The major limitation to this approach arises from the observation that a clean, essentially nonfunctionalized graphite surface has an asymmetric $\mathrm{C} 1$ s photoelectron peak, as seen in Figure 55b for an HOPG graphite freshly cleaved surface. Although this surface was measured to have $0.4 \%$ surface oxygen, a standard $\mathrm{C} 1 \mathrm{~s}$ curve-fitting approach indicates about $15 \%$ of the surface carbon to have one or more bonds to oxygen, as seen in Table 7. It is not legitimate to do a simple subtraction of the clean graphite spectrum from a more oxidized fiber $\mathrm{C} 1 \mathrm{~s}$ spectrum because the line width changes with graphitization along with the line shape. Thus, the observations made on the basis of the C1s curve fits are relative and at best semiquantitative.

The FWHM of the dominant carbon peak at 284 to $285 \mathrm{eV} \mathrm{BE}$ is also tabulated in Table 7 with the curve-fit information. It can be seen that the more graphitized fibers, T50 and P55, have a FWHM comparable to HOPG graphite at about $1 \mathrm{eV}$. T300 and the LTC fibers have significantly broader peak widths, in the range 1.6 to $1.8 \mathrm{eV}$. The carbon fiber surfaces all have significantly increased levels of $\mathrm{C} 1 \mathrm{~s}$ higher binding 


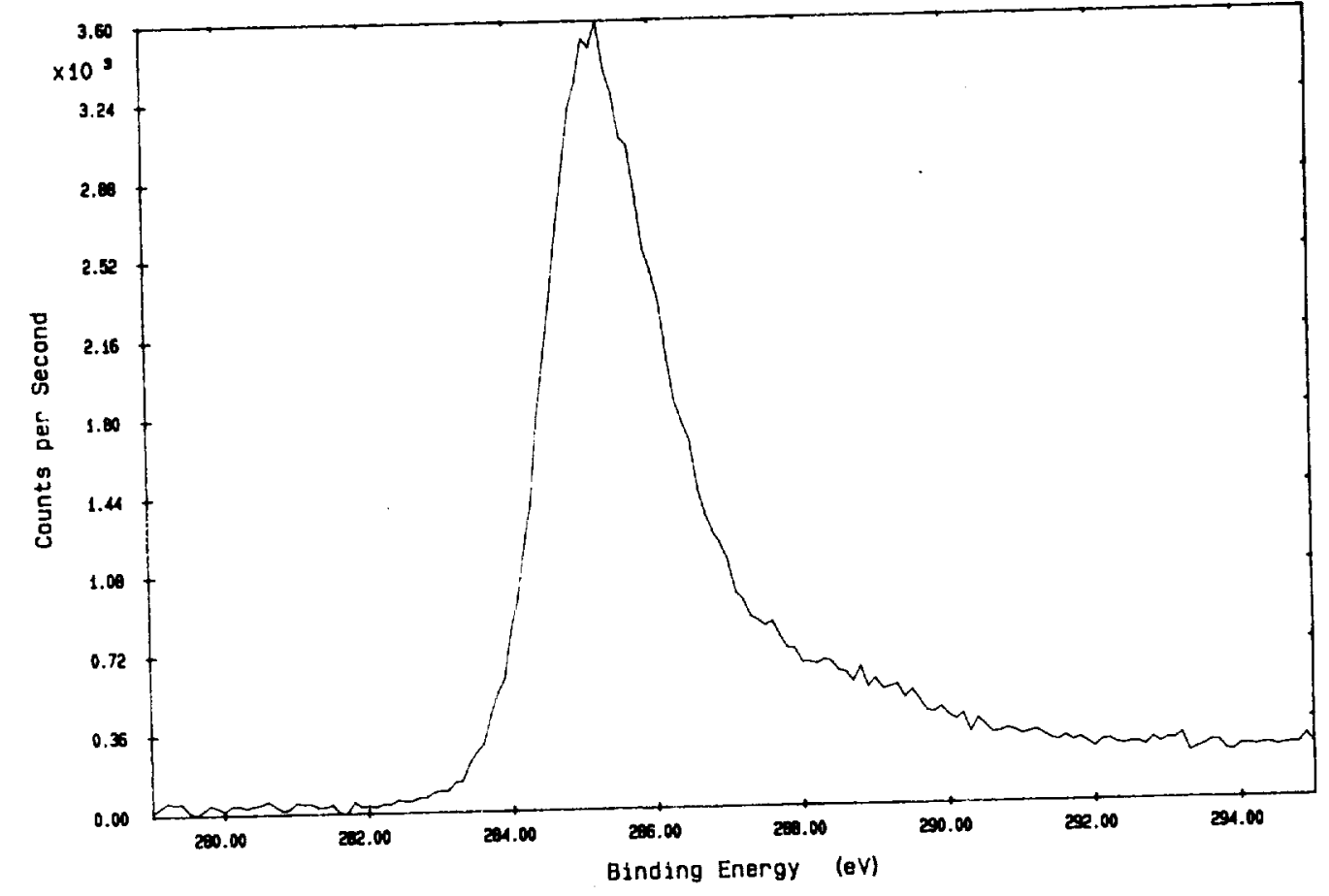

(a)

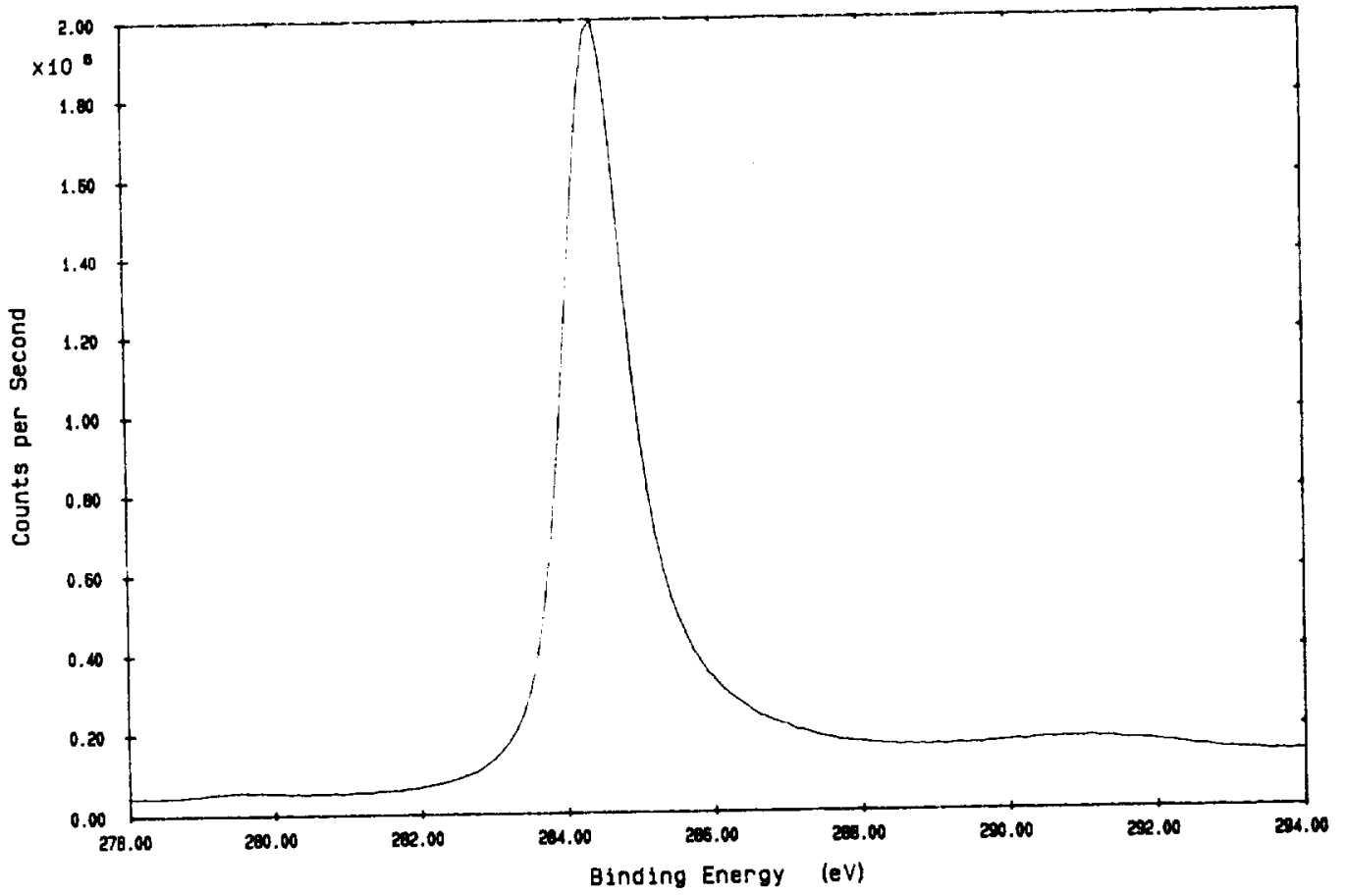

(b)

Figure 55. XPS C1s spectra. (a) Amoco T350/23X fiber, (b) HOPG cleaved surface. 
Table 7. XPS Curve-Fit Data for C1s Photoelectron Peaks

\begin{tabular}{|c|c|c|c|c|c|c|}
\hline \multirow[b]{2}{*}{ Unsized Fibers } & \multicolumn{6}{|c|}{$\begin{array}{l}\text { C1s Curve Fit Data } \\
\text { (Normalized) }\end{array}$} \\
\hline & $\begin{array}{l}\mathrm{C}-\mathrm{C} \\
\mathrm{C}-\mathrm{H}\end{array}$ & $\begin{array}{c}\mathrm{C}-\mathrm{OR} \\
(\mathrm{R}=\mathrm{C}, \mathrm{H})\end{array}$ & $\begin{array}{l}\text { RO-C-OR } \\
\text { or } \mathrm{C}=0\end{array}$ & $\begin{array}{l}0 \\
\text { C-OR }\end{array}$ & $\pi \rightarrow \pi^{*}$ & $\begin{array}{l}\text { FWHM } \\
\text { of C-C }\end{array}$ \\
\hline Avcarb B-2 & 79 & 12 & 5 & 2 & 2 & 1.8 \\
\hline Avcarb G & 74 & 18 & 5 & 2 & 1 & 1.8 \\
\hline Hercules R879-01 & 77 & 15 & 5 & 3 & 1 & 1.8 \\
\hline Hercules R879-02 & 73 & 16 & 6 & 3 & 1 & 1.8 \\
\hline DG Rayon 1 & 74 & 17 & 6 & 3 & 1 & 1.7 \\
\hline $\begin{aligned} \text { DG Rayon } 2 & \# 1 \\
& \# 2\end{aligned}$ & $\begin{array}{l}71 \\
71\end{array}$ & $\begin{array}{l}20 \\
18\end{array}$ & $\begin{array}{l}5 \\
6\end{array}$ & $\begin{array}{l}2 \\
3\end{array}$ & $\begin{array}{l}2 \\
2\end{array}$ & $\begin{array}{l}1.8 \\
1.8\end{array}$ \\
\hline $\begin{aligned} \text { Amoco T350/23X } & \# 1 \\
& \# 2\end{aligned}$ & $\begin{array}{l}75 \\
70\end{array}$ & $\begin{array}{l}16 \\
18\end{array}$ & $\begin{array}{l}5 \\
5\end{array}$ & $\begin{array}{l}2 \\
3\end{array}$ & $\begin{array}{l}2 \\
3\end{array}$ & $\begin{array}{l}1.7 \\
1.6\end{array}$ \\
\hline $\begin{array}{l}\text { Amoco T350/25X } \\
\text { (shear treated) }\end{array}$ & 72 & 15 & 7 & 4 & 1 & 1.7 \\
\hline Amoco T300 & 74 & 14 & 4 & 3 & 3 & 1.7 \\
\hline Amoco T50 & 77 & 14 & 3 & 3 & 3 & 1.1 \\
\hline Amoco P55 & 76 & 14 & 3 & 2 & 3 & 1.1 \\
\hline HOPG graphite & 81 & 13 & 1 & 1 & 3 & 1.0 \\
\hline
\end{tabular}

intensity compared to the HOPG graphite. Most of the LTC fiber surfaces have an additional increase in the $\mathrm{C} 1 \mathrm{~s}$ higher binding energy intensity compared to T50 and $\mathrm{P}-55$. This additional increase falls primarily into the curve-fit peaks associated with one and two bonds between carbon and oxygen. The shear-treated T350/25X has an additional increase in the surface acid/ester functionality compared to the nonsheartreated LTC fibers. The $\pi \rightarrow \pi^{*}$ transition peak indicated in Table 7 is a C1s peak feature at $291 \mathrm{eV} \mathrm{BE}$ associated with delocalized bonding in the carbon network, and is expected to be strongest for the most highly graphitized materials.

\section{Summary}

XPS analysis finds that there are correlations between the HTT and the surface composition and chemistry for carbon fiber samples. The concentration of surface oxygen and nitrogen (PAN-based fibers only) is shown to decrease with increasing HTT. The details of the C1s photoelectron peak, i.e., the FWHM of the dominant carbon peak 
and the intensity of the higher binding energy tail, also indicate major changes. The line width of the dominant carbon peak decreases, and the percentage of the higher binding energy intensity decreases with increasing graphitization. None of the abovementioned indicators measured from the XPS data was found to have adequate resolution to distinguish differences in the extent of graphitization of the set of LTC carbon fibers analyzed in this study. The comparative analyses were hindered by significant variability in surface contamination levels, particularly of silica, and by variability in surface composition between different samples taken from the same batch of fibers.

\section{B. ACID/BASE CHARACTER}

In order to gain some insight into the acid/base character of the fiber surfaces, the $\mathrm{pH}$ of water in which unsized fibers were immersed for $4 \mathrm{hr}$ at room temperature was measured. These data are shown in Table 8 , along with the $\mathrm{pH}$ of the water before fiber addition. With the exception of T300 fibers, the addition of fibers to water results in very little $\mathrm{pH}$ change. The addition of the $\mathrm{T} 300$ fibers significantly raises the $\mathrm{pH}$, indicating the presence of basic material on the surface. This is most likely due to the sodium contamination found on these fibers by XPS. Shear treatment does not appear to effect the acid/base character of the fiber surfaces.

Table 8. Acid/Base Character of Unsized Fiber Surfaces

\begin{tabular}{lcc}
\hline & \multicolumn{2}{c}{$\mathrm{pH}$ of Distilled Water } \\
\cline { 2 - 3 } Fiber Designation & Before Fiber Addition & After Fiber Addition \\
\hline Hercules R879-01 & 6.6 & 6.4 \\
Hercules R879-02 & 6.6 & 6.7 \\
Textron Avcarb G & 5.8 & 5.9 \\
Textron Avcarb B-2 & 5.8 & 6.3 \\
Amoco T350/25X (shear treated) & 6.1 & 6.4 \\
Amoco T350/23X & 5.8 & 6.3 \\
BASF DG Rayon 1 & 5.8 & 6.2 \\
BASF DG Rayon 2 & 5.8 & 5.9 \\
Amoco T300 (shear treated) & 6.1 & 9.1 \\
Amoco T300 (not shear treated) & 6.1 & 8.7 \\
\hline
\end{tabular}




\section{FIBER SIZING LEVELS}

\section{A. BACKGROUND}

Fiber size is designed to protect the fibers from damage during weaving and handling. Each fiber manufacturer was given the option of sizing the fibers with a phenoliccompatible size of their choice. Each also chose the preferred sizing level for each candidate fiber. Applied-sizing levels were measured both at Lockheed Research and Development Division and at the Weaver, Katema Textile Product Division. Lockheed used a burnoff technique, and Katema used an acetone solvent extraction technique. Results of the two techniques differed, and Aerospace was requested by NASA to make an independent evaluation.

\section{B. EXPERIMENTAL}

We used the acetone extraction technique, but we dried the fibers in a vacuum oven (at $30 \pm 5^{\circ} \mathrm{C}$ and 250 torr for $16 \mathrm{hr}$ ) before solvent extraction. This was not done at Katema. The fibers were dried, weighed before extraction, refluxed in acetone, rinsed with acetone, and then dried and reweighed. The entire weight loss was assumed to be due to sizing removal.

\section{RESULTS}

The results are shown in Table 9, which also includes the fiber sizing data obtained at Lockheed (burnoff technique) and Katema (acetone extraction technique). We found that the fibers must be vacuum dried before extraction in order to obtain consistent

Table 9. Fiber Sizing Levels

\begin{tabular}{lccc}
\hline Fiber Designation & $\begin{array}{c}\text { \% Sizing, wt/wt } \\
\text { (Lockheed) }\end{array}$ & $\begin{array}{c}\text { \% Sizing, wt/wt } \\
\text { (Aerospace) }\end{array}$ & $\begin{array}{c}\text { \% Sizing, wt/wt } \\
\text { (Katema) }\end{array}$ \\
\hline Hercules R879-01 & 0.32 & 0.26 & 3.4 \\
Hercules R879-02 & 0.43 & 0.76 & 5.1 \\
Textron Avcarb G & 9.22 & 0.57 & 6.1 \\
Textron Avcarb B-2 & 2.88 & 2.64 & 3.5 \\
Amoco T350/25X & 1.56 & 1.63 & 2.9 \\
Amoco T350/23X & 1.3 & 1.48 & 4.6 \\
BASF DG Rayon 1 & 0.28 & 0.8 & 0.8 \\
BASF DG Rayon 2 & 0.56 & 1.16 & 1.0 \\
\hline
\end{tabular}


results. We suspect that the fiber sizing levels observed by Katema are too high because the fibers were vacuum dried after extraction, but not before. The weight loss reported by Katema is probably the sum of the weights of absorbed water and sizing.

The sizing values obtained by the Lockheed fiber burnoff technique are in substantial - agreement with the extraction values obtained by us, with the exception of Avcarb G. The two most likely possibilities for this discrepancy are: (1) the burnoff technique drives off volatile fiber fragments. The Avcarb G fibers have the lowest carbon content and may be easier to oxidize than the other fibers, resulting in high burnoff values; or (2) the values obtained by each method are correct, but the sizing content from spool to spool is nonuniform. 


\section{CONCLUSIONS}

Based on wide-angle X-ray diffraction, the LTC PAN fibers all appear to have a similar turbostratic structure with large $002 \mathrm{~d}$-spacings, small crystallite sizes, and moderate preferred orientation (Tables 3 and 4). The Textron Avcarb fibers show the least-ordered structure, whereas the Hercules fibers exhibit the most order. All the LTC fibers are slightly less ordered than T300 fibers, which are much less ordered than T50 fibers. This orientation is consistent with relative heat-treatment temperatures (HTTs) of the fibers.

Limited small-angle X-ray scattering (SAXS) results indicate that, with the exception of the BASF fibers, the LTC fibers do not have well-developed pores (Table 5). This suggests that they have not been subjected to a high enough HTT to drive off all of their volatile constituents (mainly nitrogen). The BASF fibers produce SAXS patterns intermediate between T300 and the other LTC fibers (Figures 21 and 22).

Transmission electron microscopy shows that the texture of the LTC PAN-based fibers studied (Amoco T350/23X and /25X) consists of multiple sets of parallel, wavy, bent layers that interweave with each other forming a complex, three-dimensional network oriented randomly around the fiber axis. In the cases of higher HTT fibers (T300 and T50), the texture consists of two distinct regions with the core's texture being similar to that of the LTC fibers, whereas the outer region (Figure 32) is better ordered and oriented. In LTC fibers (T350/23X and /25X), the two-phase structure was not observed. The results of our study are in good agreement with the proposed interlinking ribbon model ${ }^{17.33-35}$ (Figure 23). With increasing HTT, the microstructure of these fibers evolves from the formation of isolated, short strip-like domains to a long, interconnected ribbon structure. Crystallite size and the extent of graphitization, the latter based on latticed spacing, and perfection of basal planes, both increased with increased HTT. These results are consistent with those from X-ray diffraction.

X-ray photoelectron spectroscopy (XPS) analysis finds that there are correlations between the HTT and the surface composition and chemistry for carbon fiber samples (Table 6). The concentration of surface oxygen and nitrogen for PAN-based fibers decreases with increasing HTT, which is consistent with increased volatilization of nitrogen and greater extent of graphitization. The details of the $\mathrm{C} 1 \mathrm{~s}$ photoelectron peak, i.e., the full-width at half-maximum (FWHM) of the dominant carbon peak and the intensity of the higher binding energy tail, indicate an increasing extent of graphitization with increasing HTT (Table 7). The line width of the dominant carbon peak decreases, and the percentage of higher binding energy intensity decreases with increasing graphitization. None of the above-mentioned indicators measured from the XPS data was found to have adequate resolution to distinguish differences in the 
extent of graphitization of the LTC carbon fibers analyzed in this study. The comparative analyses were also hindered by significant variability in surface contamination levels, particularly of silica, and by variability in surface composition between different samples taken from the same batch of fibers. 


\section{REFERENCES}

1. R. G. Clinton, P. C. Pinoli, and A. R. Canfield, "Development of Low Thermal Conductivity PAN-Based Fibers for Solid Rocket Nozzle Applications," presented at the JANNAF Rocket Nozzle Technology Subcommittee meeting, Pasadena, CA, October 1990 (published in the proceedings).

2. J. S. Tsai and C. H. Lin, "The Change of Crystal Orientation from Polyacrylonitrile Precursor to Its Resulting Carbon Fiber," J. Mater. Sci. 9, 921-922 (1990).

3. D. J. Johnson, "Recent Advances in Studies of Carbon Fibre Structure," Phil. Trans. R. Soc. Lond. A 294, 443-449 (1980).

4. M. Shioya and A. Takaku, "Characterization of Crystallites in Carbon Fibres by Wide Angle X-ray Diffraction," J. Appl. Cryst. 22, 222-230 (1989).

5. A. Takaku and M. Shioya, "X-ray Measurements and the Structure of Polyacrylonitrile- and Pitch-based Carbon Fibres," J. Mater. Sci. 25, 4873-4879 (1990).

6. D. P. Anderson, "Carbon Fiber Morphology: Wide Angle X-ray Studies of Pitch and PAN-Based Carbon Fibers," WRDC-TR-89-4072, U.S. Air Force Technical Report, July 1989.

7. M. K. Jain and A. S. Abhiraman, "Conversion of Acrylonitrile-based Precursor Fibres to Carbon Fibres," J. Mater. Sci. 22, 278-312 (1987).

8. D. J. Johnson, "Structural Studies of PAN-based Carbon Fibers," in Chemistry and Physics of Carbon (ed.) P. Thrower, Vol. 21, 1-58 (1987).

9. A. Deurbergue and Oberlin, "Stabilization and Carbonization of PAN-based Carbon Fibers as Related to Mechanical Properties," Carbon 29, 621-628 (1991).

10. S. C. Bennet, D. J. Johnson, and W. Johnson, "Strength-structure Relationships in PAN-based Carbon Fibers," J. Mater. Sci. 18, 3337-3347 (1983).

11. D. P. Anderson, "Carbon Fiber Morphology, II: Expanded Wide Angle X-ray Diffraction Studies of Carbon Fibers," WRDC-TR-90-4137, U.S. Air Force Technical Report, February 1991.

12. R. J. Diefendorf, "Carbon/Graphite Fibers," in Engineering Materials Handbook, Vol. 1, "Composites," ASM International, Metals Park, OH, 49-53 (1987). 
13. D. Johnson and C. N. Tyson, "The Fine Structure of Graphitized Fibres," J. Phys. D 2, 787-795 (1969).

14. D. J. Johnson and C. N. Tyson, "Low Angle X-ray Diffraction and Physical Properties of Carbon Fibers," J. Phys. D 3, 526-534 (1970).

15. R. Perret and W. Ruland, "X-ray Small-angle Scattering of Non-graphitizing Carbons," J. Appl. Cryst. 1, 308-313 (1968).

16. R. Perret and W. Ruland, "Single and Multiple X-ray Scattering of Carbon Fibres," J. Appl. Cryst. 2, 209-218 (1969).

17. R. Perret and W. Ruland, "The Microstructure of PAN-based Carbon Fibres," $J$. Appl. Cyst. 3, 525-532 (1970).

18. R. Perret and W. Ruland, "X-ray Small-Angle Scattering of Glassy Carbon," $J$. Appl. Cryst. 5, 183-187 (1972).

19. W. Ruland, "Small Angle Scattering of Two Phase Systems: Determination and Significance of Systematic Deviations from Porod's Law," J. Appl. Cryst. 4, 70-73 (1971).

20. M. Shioya and A Takaku, "Characterization of Microvoids in Carbon Fibers by Absolute Small-angle X-ray Measurements on a Fiber Bundle," J. Appl. Phys. 58, 4074-4079 (1985).

21. A. Takaku and M. Shioya, "Characterization of Microvoids in Polyacrylonitrilebased Carbon Fibres," J. Mater. Sci. 21, 4443-4450 (1986).

22. M.Tang, G. G. Rice, J. F. Fellers, and J. S. Lin, "X-ray Scattering Studies of Graphite Fibers," J. Appl. Phys. 60, 803-808 (1986).

23. L. Alexander, "X-ray Diffraction Methods in Polymer Science," John Wiley, New York, NY, 280-386 (1968) .

24 P. Debye and A. M. Bueche, "Scattering by an Inhomogeneous Solid," J. Appl. Phys. 20, 518-525 (1949).

25. P. Debye, H. R. Anderson, Jr., and H. Brumberger, "Scattering by an Inhomogeneous Solid. II. The Correlation Function and its Application," J. Appl. Phys. 8, 679-683 (1957).

26. G. Porod, "Die Röntgenkleinwinkelstreuung von Dichtgepacken Kolloiden Systemen." Kolloid-Z 124, 83-114 (1951). 
27. D. J. Johnson, "Structure-Property Relationships in Carbon Fibres," J. of Phys. D Appl. Phys. 30, 286 (1987).

28. M. A. A. Jarro, W. R. Ladner, and T. D. Rantell, "Characteristics of Coal-Based Carbonised Fibres," Carbon 14, 219 (1976).

29. M. Guigon, A. Oberlin, and G. Desarmot, "Microtexture and Structure of Some High Tensile Strength, PAN-Based Carbon Fibres," Fibre Sci. and Technol. 20, 55 (1984).

30. D. J. Johnson, "Direct Lattice Resolution of Layer Planes in Polyacrylonitrile Based Carbon Fibres," Nature 226, 750 (1970).

31. M. Guigon and A. Oberlin, "Preliminary Studies of Mesophase-Pitch-Carbon Fibres: Structure and Microtexture," Composite Sci. and Technol. 25, 231 (1986).

32. B. J. Wicks, "Direct Observations of the Internal Structure of Carbon Fibers," J. Mater. Sci. 23, 173 (1971).

33. W. Watt and W. Johnson, "The Effect of Length Changes During the Oxidation of Polyacrylonitrile Fibers on the Young's Modulus of Carbon Fibers," Appl. Polymer Symp. 9, 215 (1969).

34. D. V. Badami, J. C. Joiner, and G. A. Jones, "Microstructure of High Strength, High Modulus Carbon Fibres," Nature 215, 386 (1967).

35. W. T. Brydges, D. V. Badami, and J. C. Joiner, "The Structure and Elasltic Properties of Carbon Fibres," App. Polymer Symp. 9, 255 (1969).

36. D. J. Johnson and C. N. Tyson, "The Fine Structure of Graphitized Fibres," Br. J. Appl. Phys. D2, 787 (1969).

37. D. J. Johnson, D. Crawford, and C. Oates, "The Fine Structure of a Range of PAN-Based Carbon Fibers," 10th Bienn. Conf., Carbon, Lehigh Univ., Bethlehem, PA, 29 (1971).

38. M. Guigon, J. Ayache, and A. Oberlin, "Structure and Microstructure of Some Glassy Polymers-Carbon Fibers Composites," 15th Bienn. Conf., Carbon, Philadelphia, PA, 288-289 (1981).

39. F. R. Barnet and M. K. Noor, "Carbon Fiber Etching in an Oxygen Plasma," Carbon 11, 281 (1973).

40. S. C. Bennett and D. J. Johnson, "Electron-Microscope Studies of Structural Heterogeneity in PAN-Based Carbon Fibres," Carbon 17, 25 (1979). 
41. B. J. Wicks and R. A. Coyle, "Microstructural Inhomogeneity in Carbon Fibres," J. Mater. Sci. 11, 376 (1976).

42. R. J. Diefendorf and E. Tokarsky, "High-Performance Carbon Fibers," Polymer Eng. Sci. 15, 150 (1975).

43. D. D. Edie, N. K. Fox, B. C. Barnett, and C. C. Fain, "Melt-Spun Non-Circular Carbon Fibers," Carbon 24, 477 (1986).

44. M. Endo, "Structure of Mesophase Pitch-Based Carbon Fibers," J. Mater. Sci. 23, 598 (1988).

45. S. C. Bennett, D. J. Johnson, and R. Murray, "Structural Characterization of a High-Modulus Carbon Fibre by High Resolution Electron Microscopy and Electron Diffraction," Carbon 14, 117 (1976).

46. G. R. Millward and D. A. Jefferson, "Lattice Resolution of Carbons by Electron Microscopy," in Chem. and Phys. of Carbon, Vol. 14, P. L. Walker and P. A. Thrower, eds., Marcel Dekker, NY, 1-82 (1978).

47. A. Oberlin, "Application of Dark-Field Electron Microscopy to Carbon Study," Carbon 17, 7 (1979).

48. D. T. Clark and H. R. Thomas, "Applications of ESCA to Polymer Chemistry, XVII. Systematic Investigation of the Core Levels of Simple Homopolymers," J. of Polymer Sci.: Polymer Chem. Edition, 16, 791-820 (1978). 
APPENDIX A

WIDE-ANGLE X-RAY DIFFRACTION SCANS 


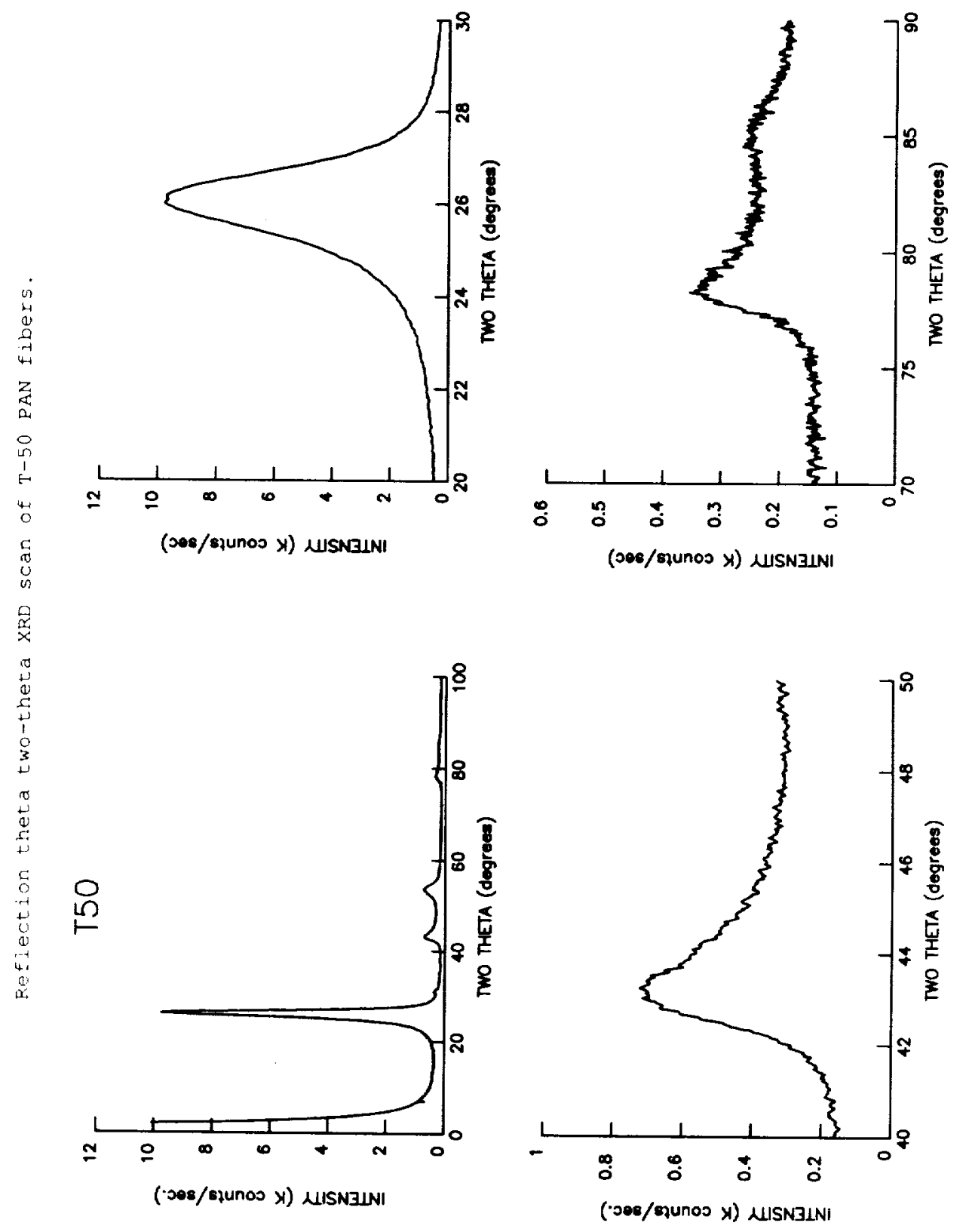




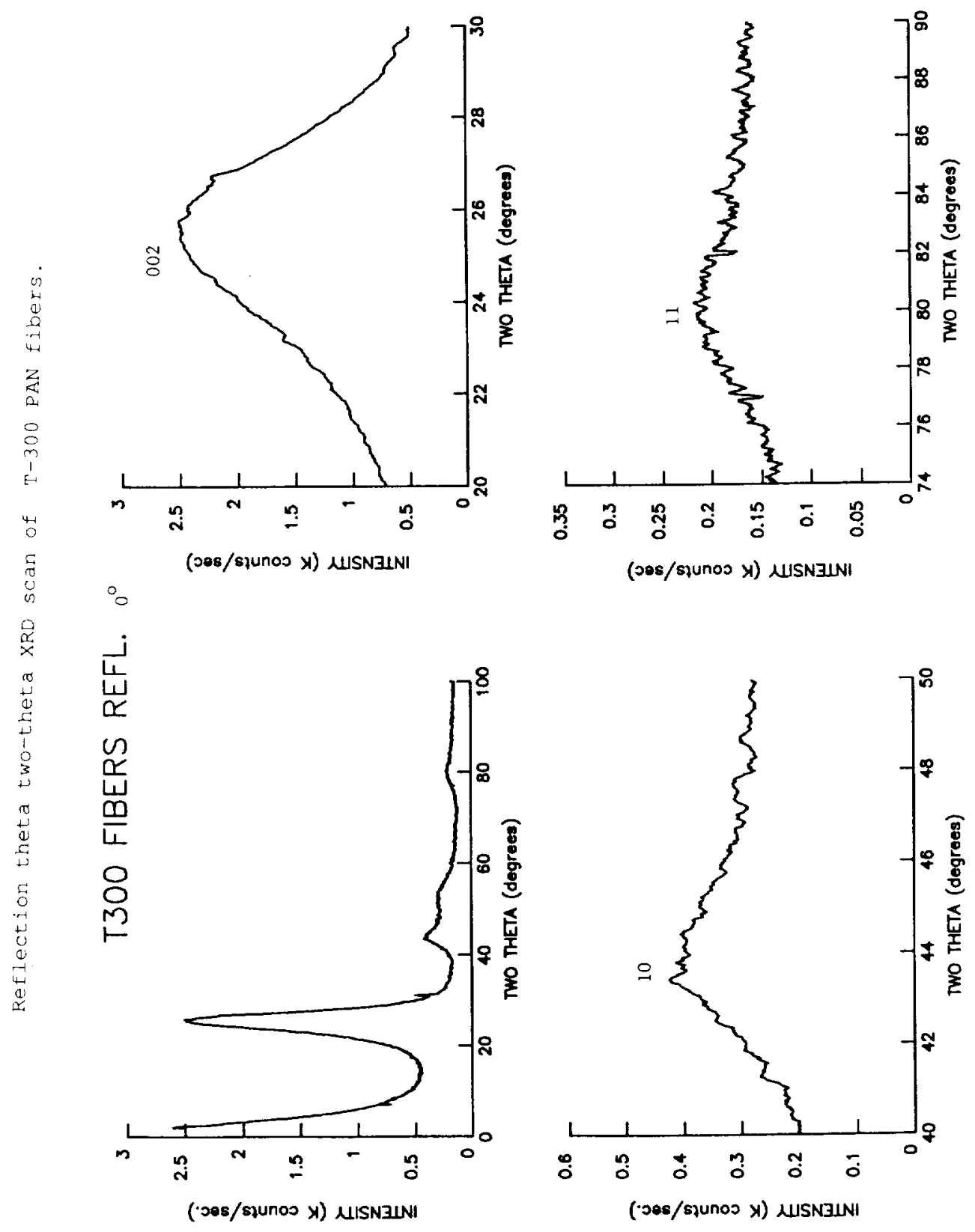




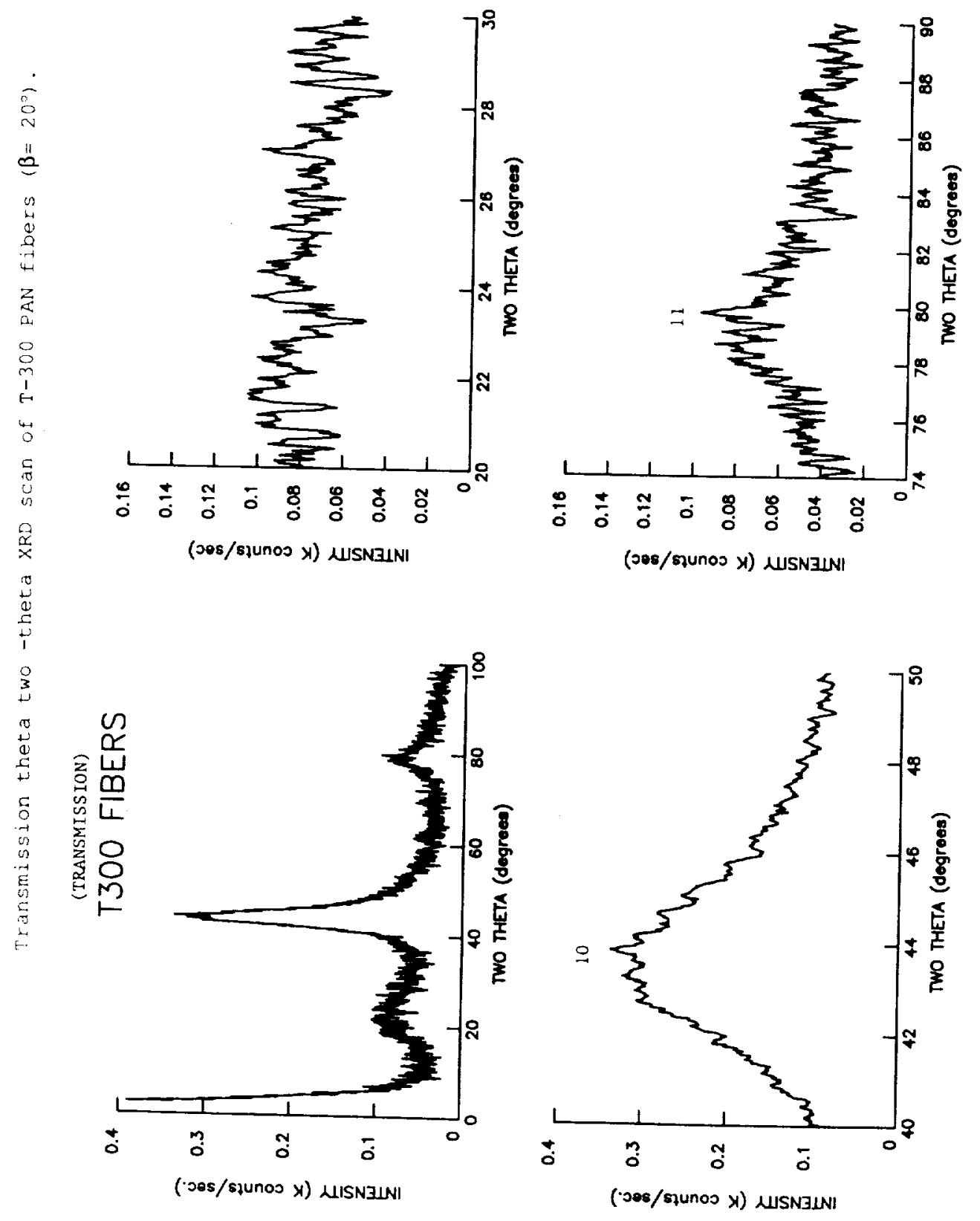



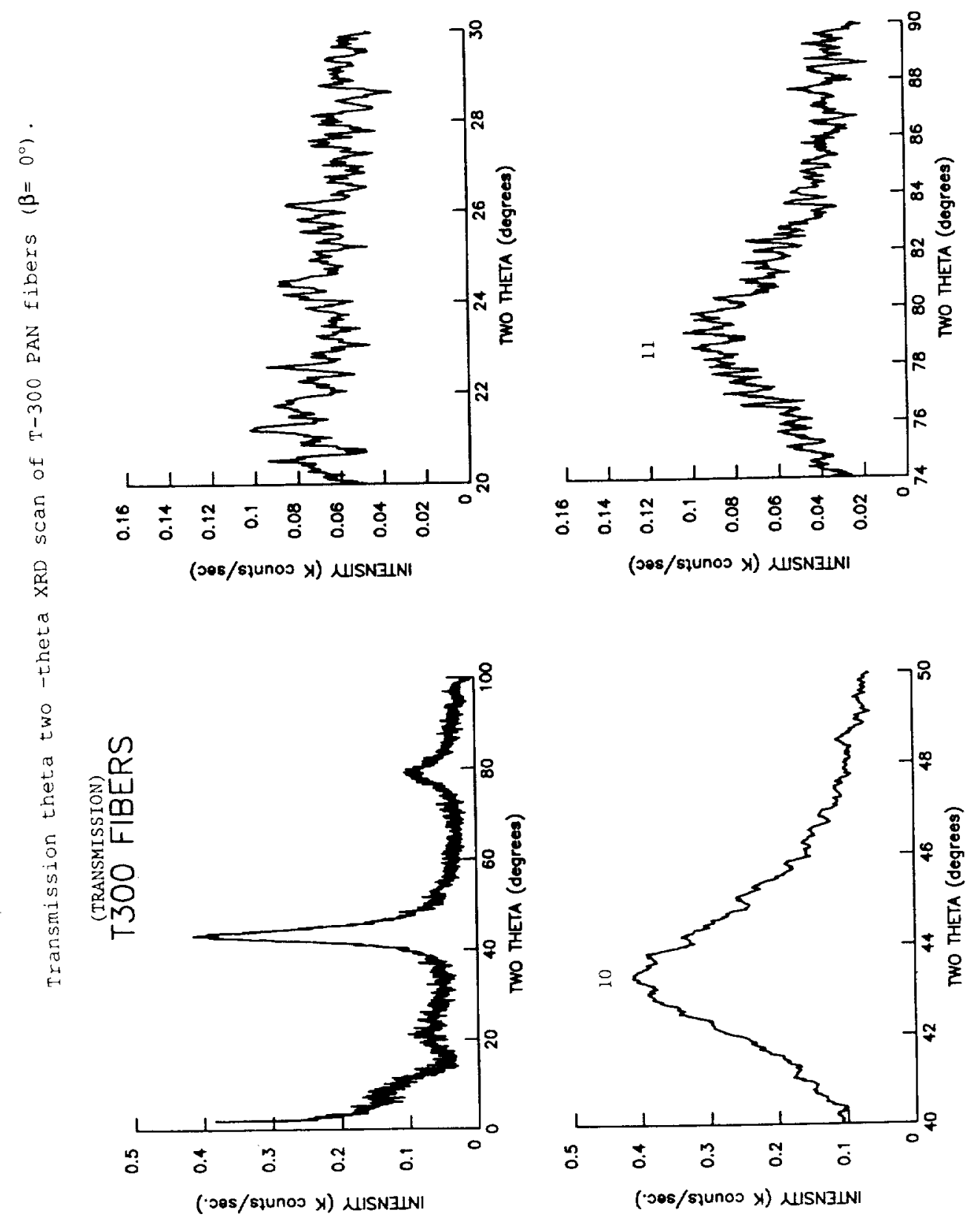


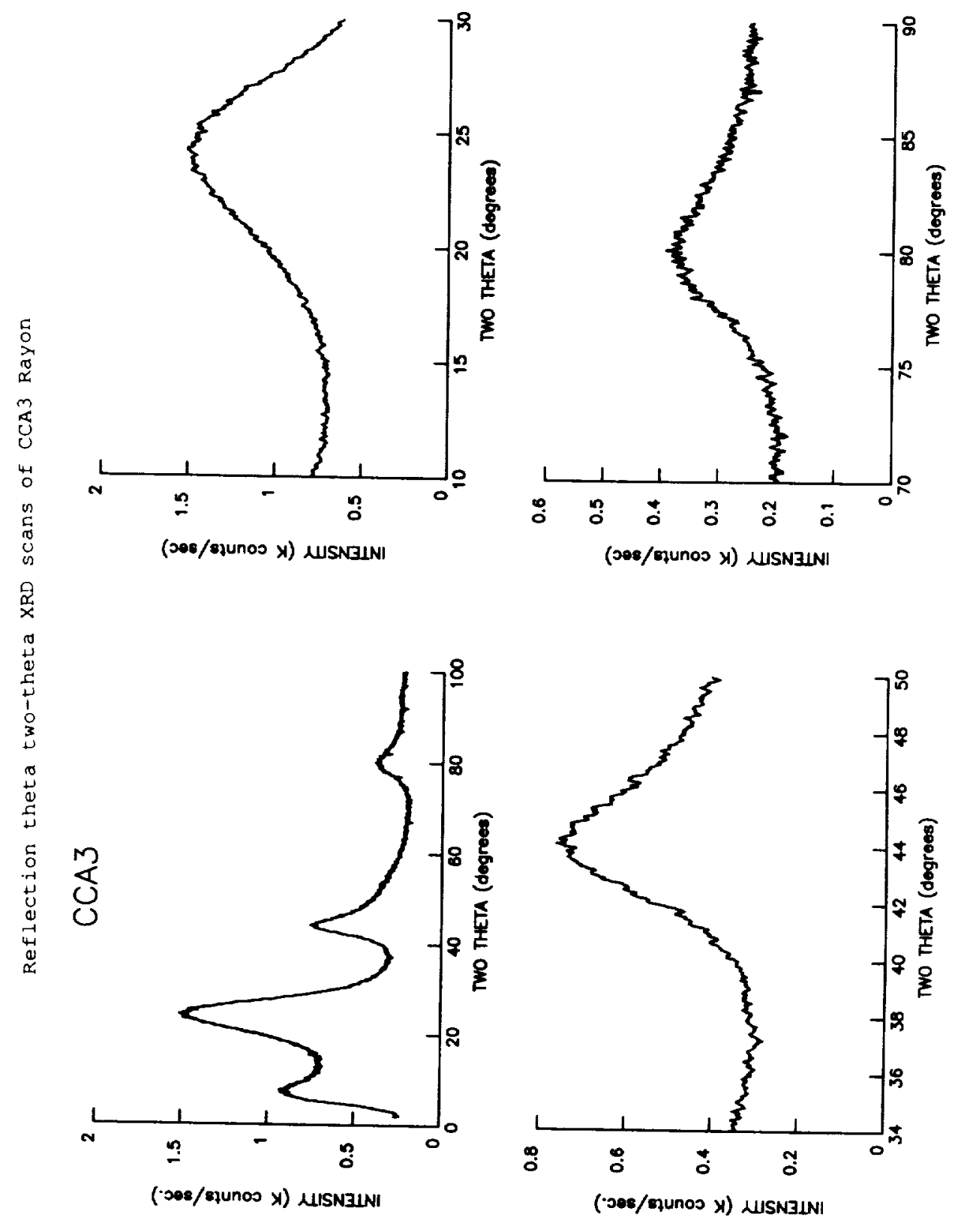




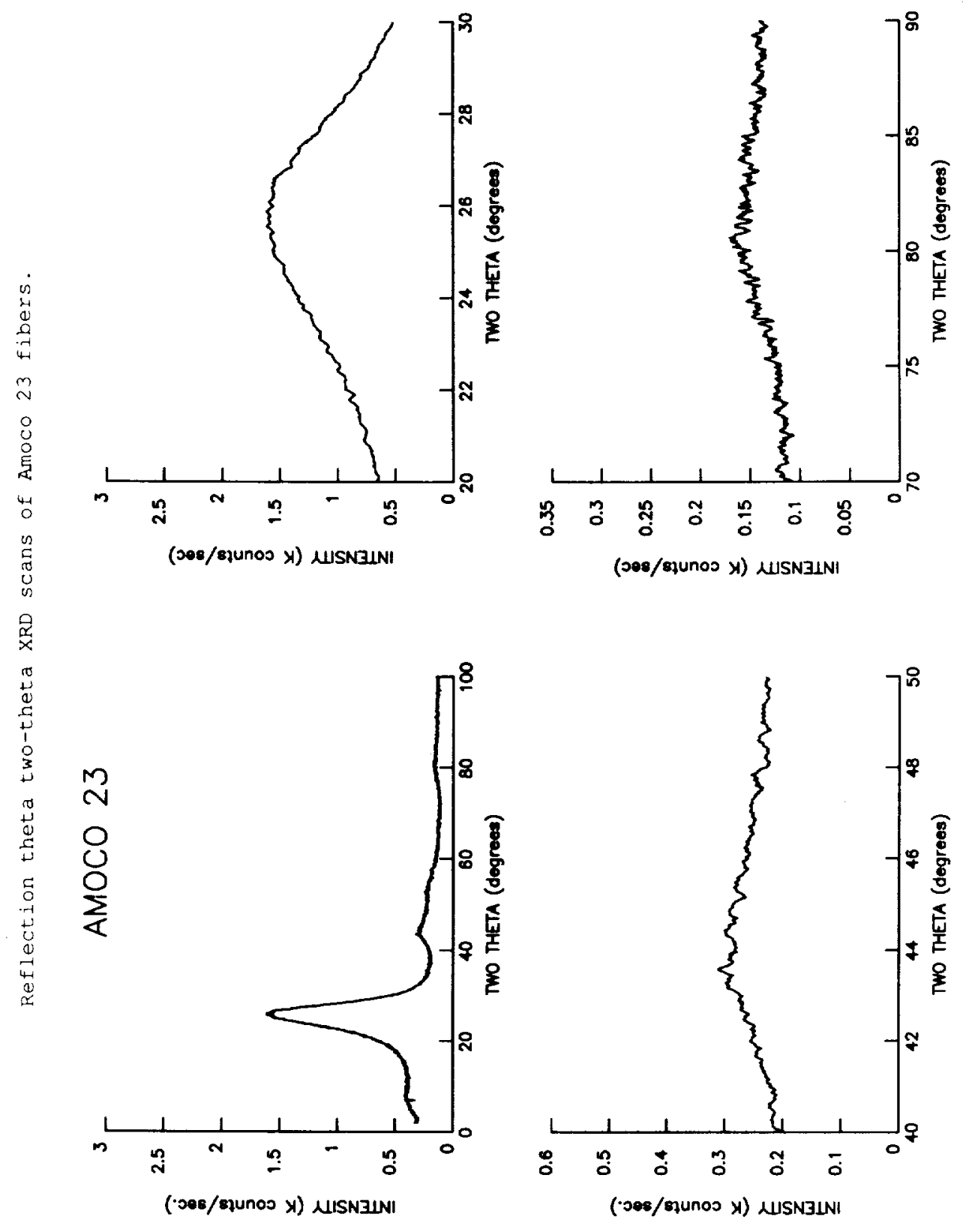




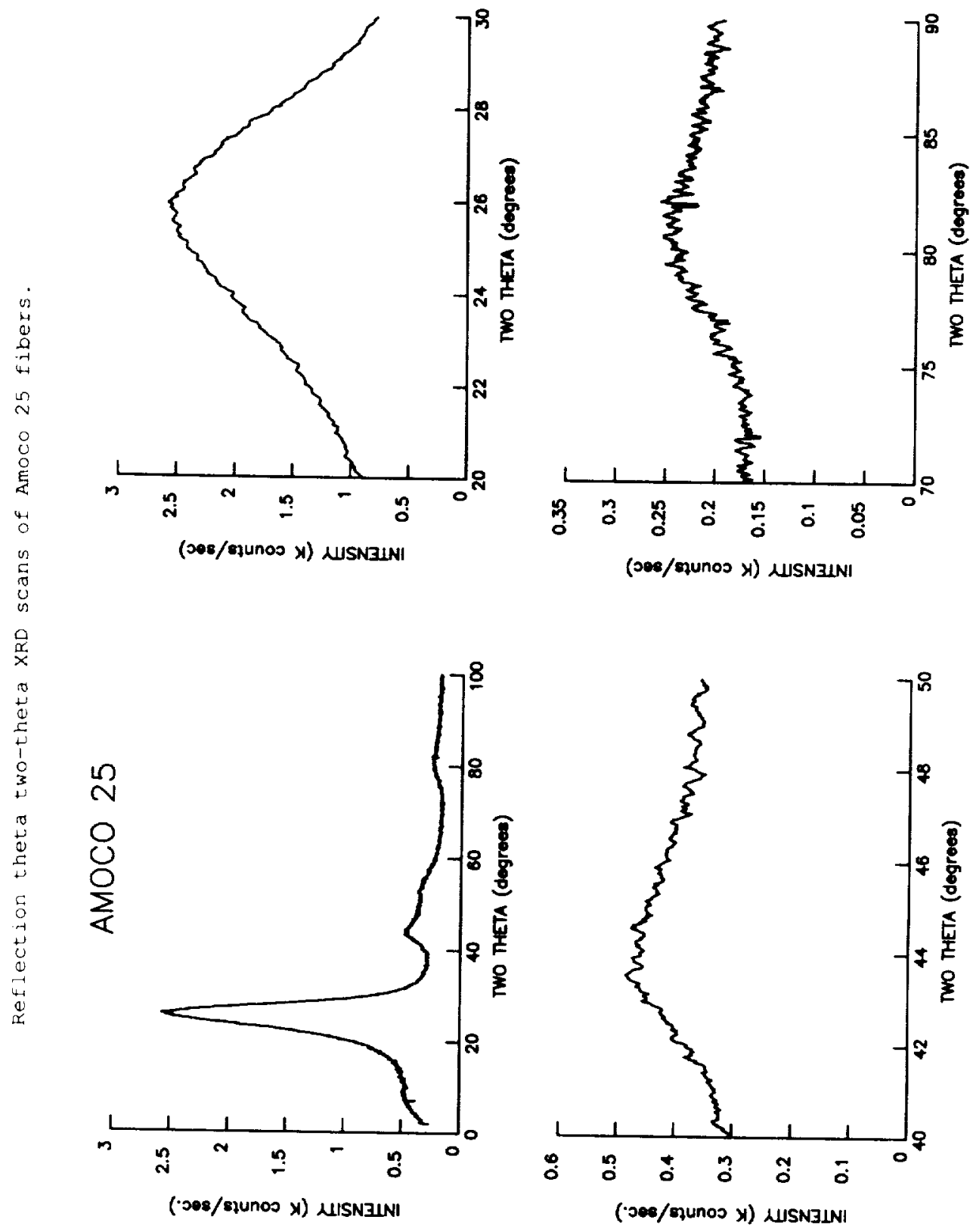




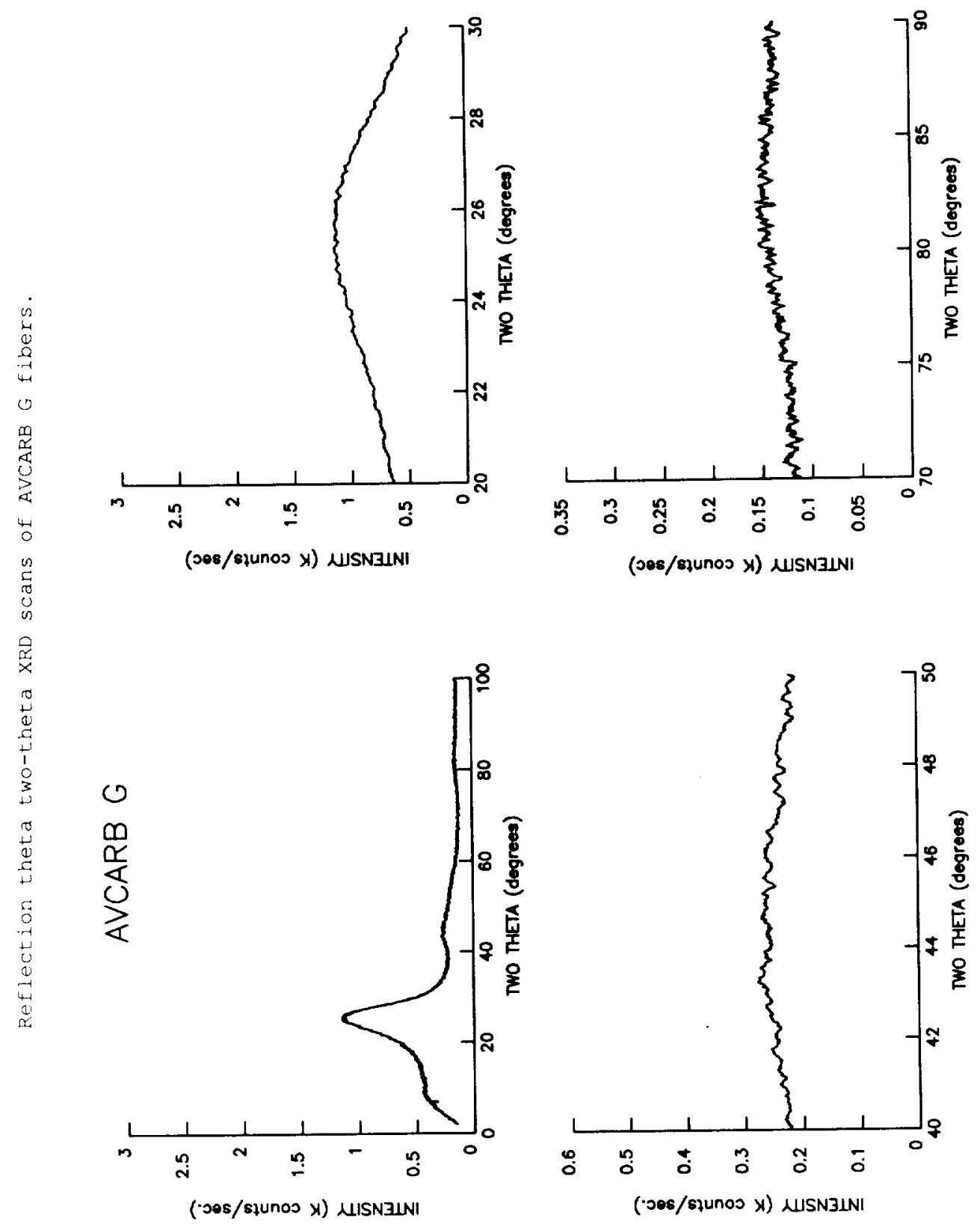




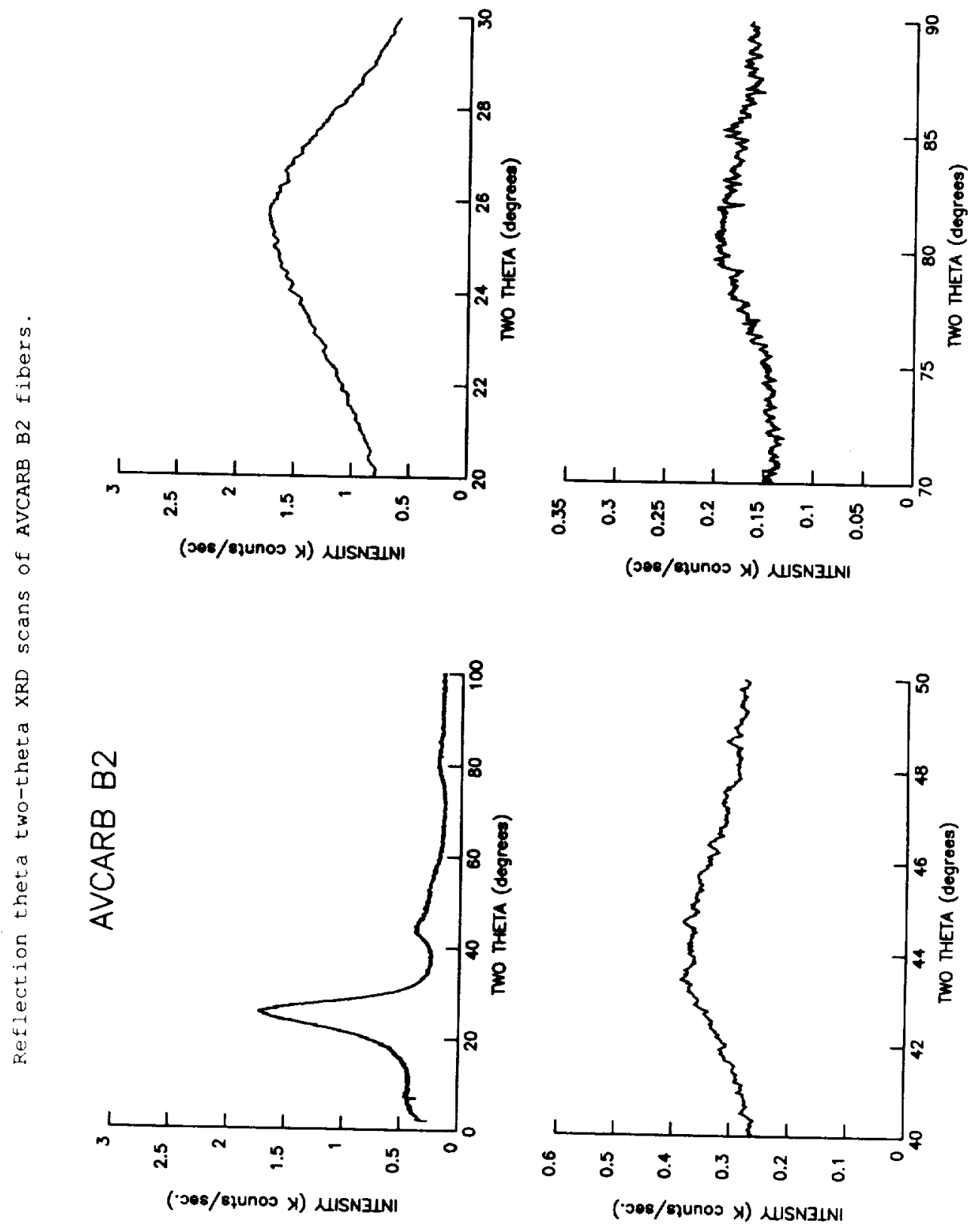




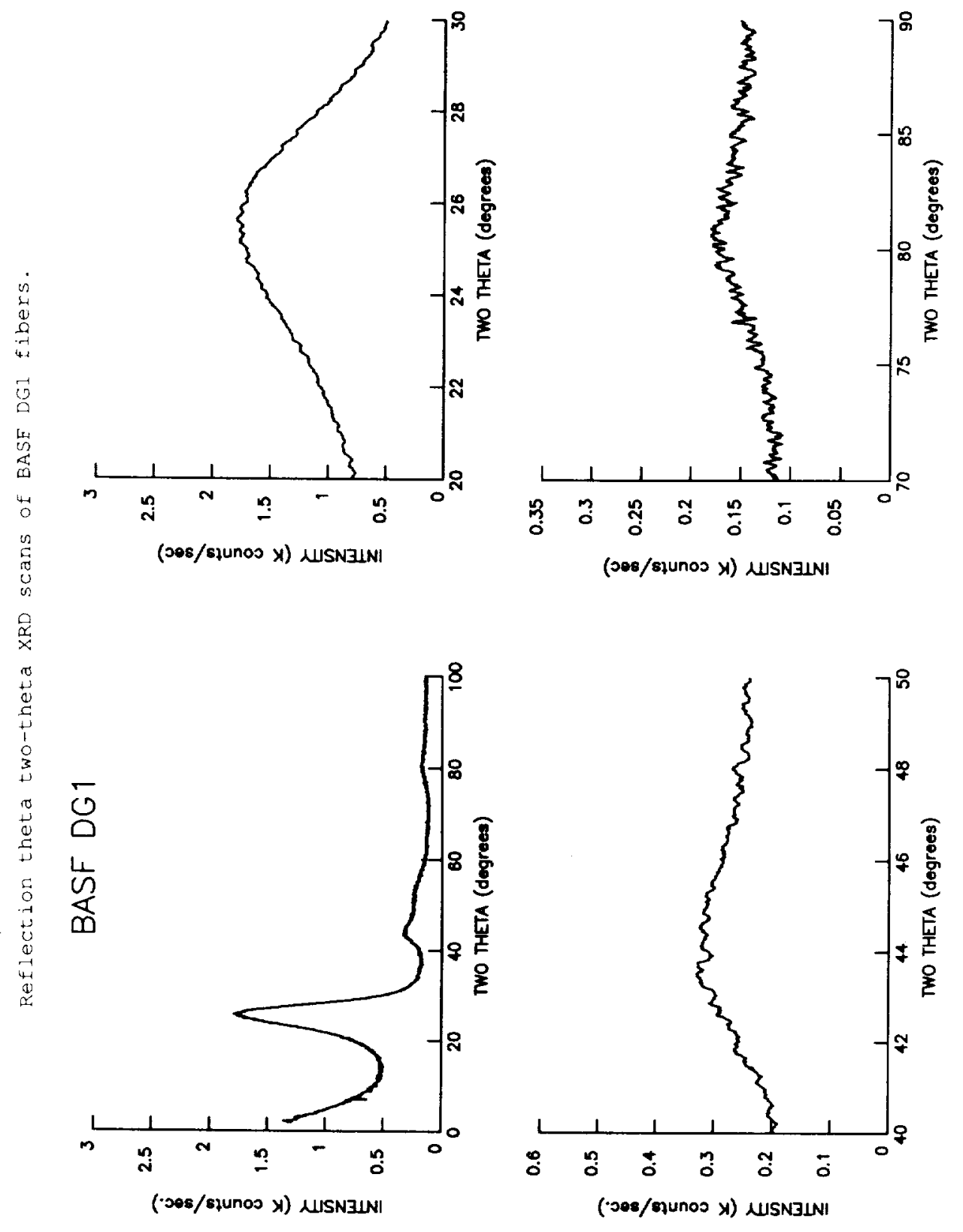




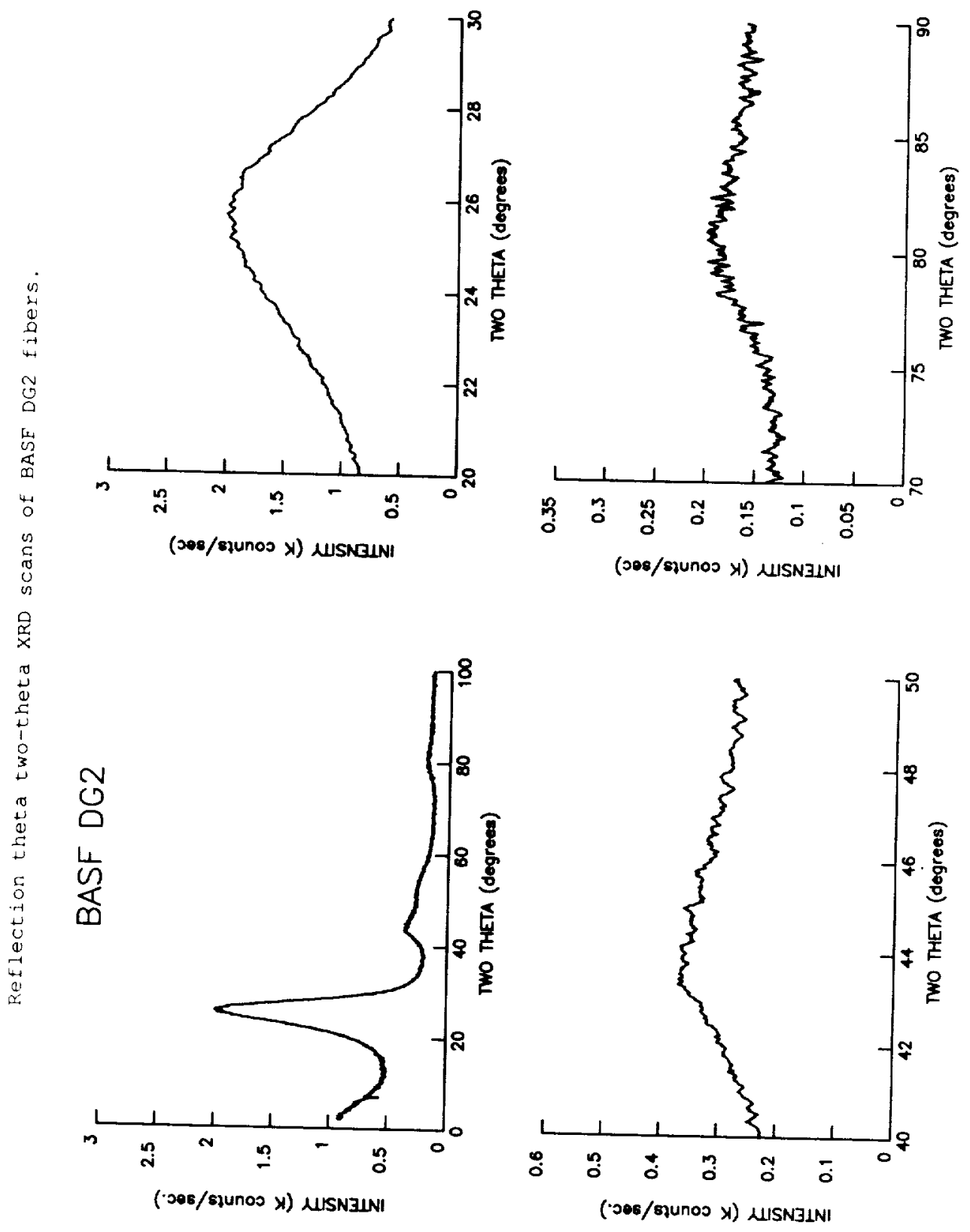




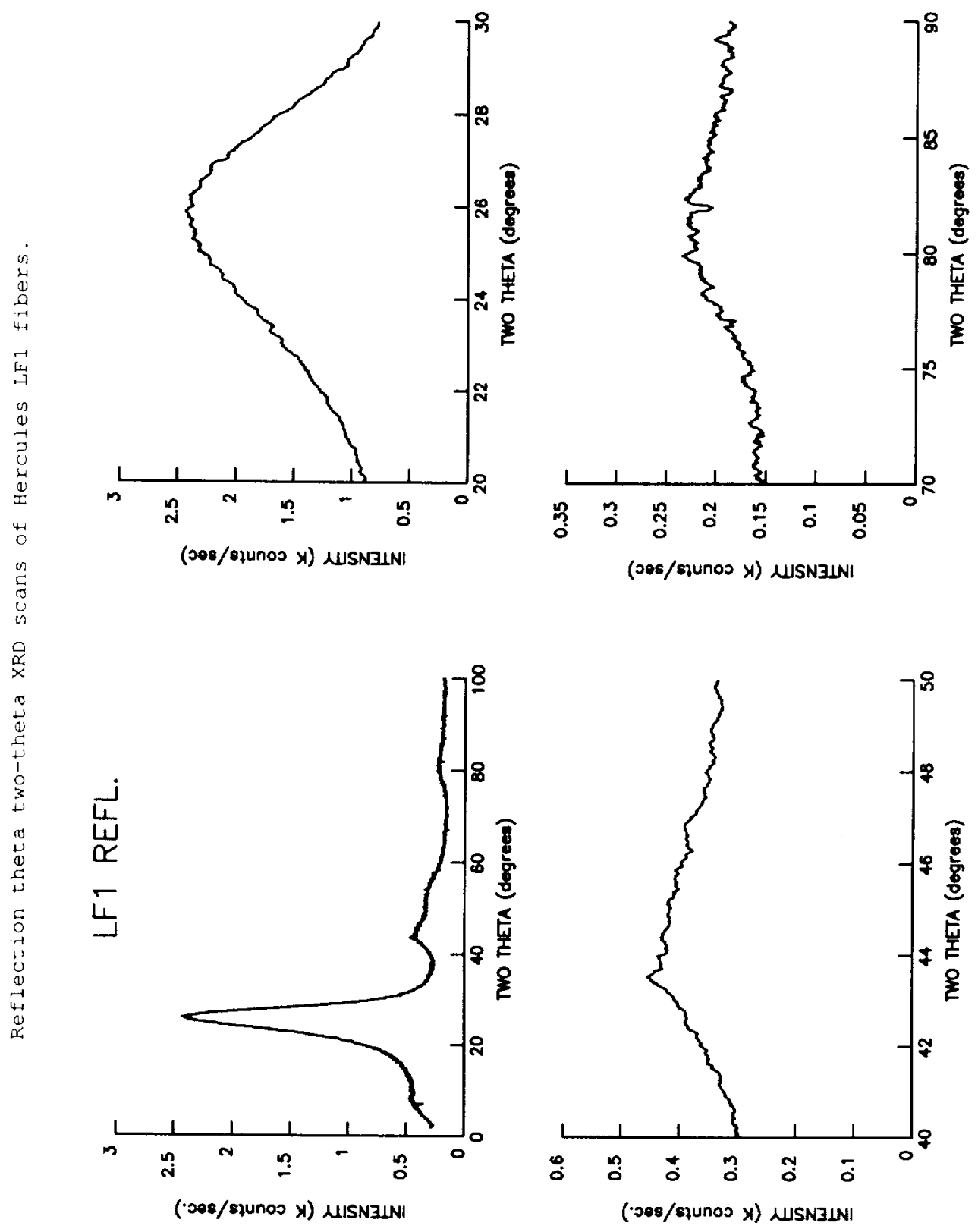




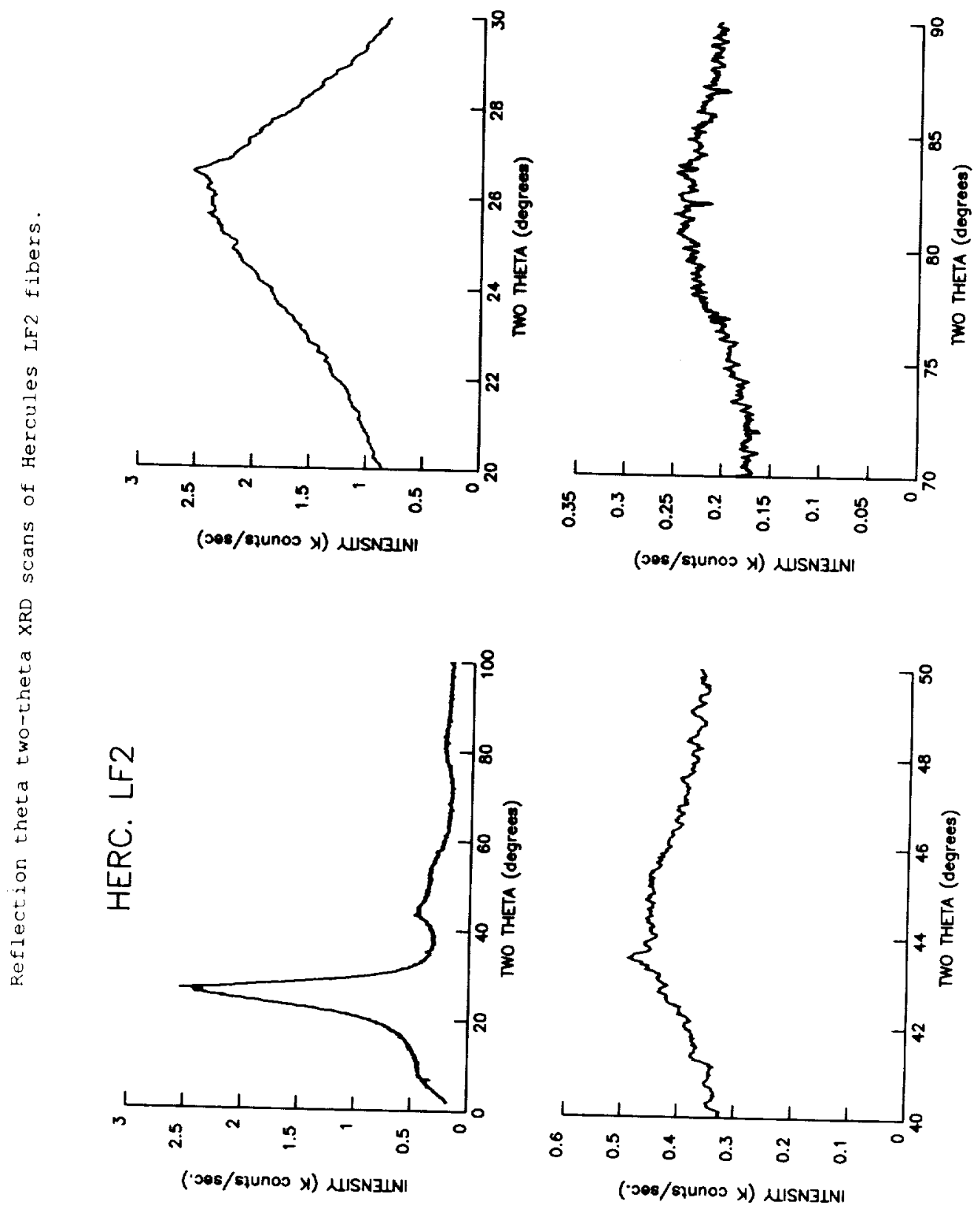




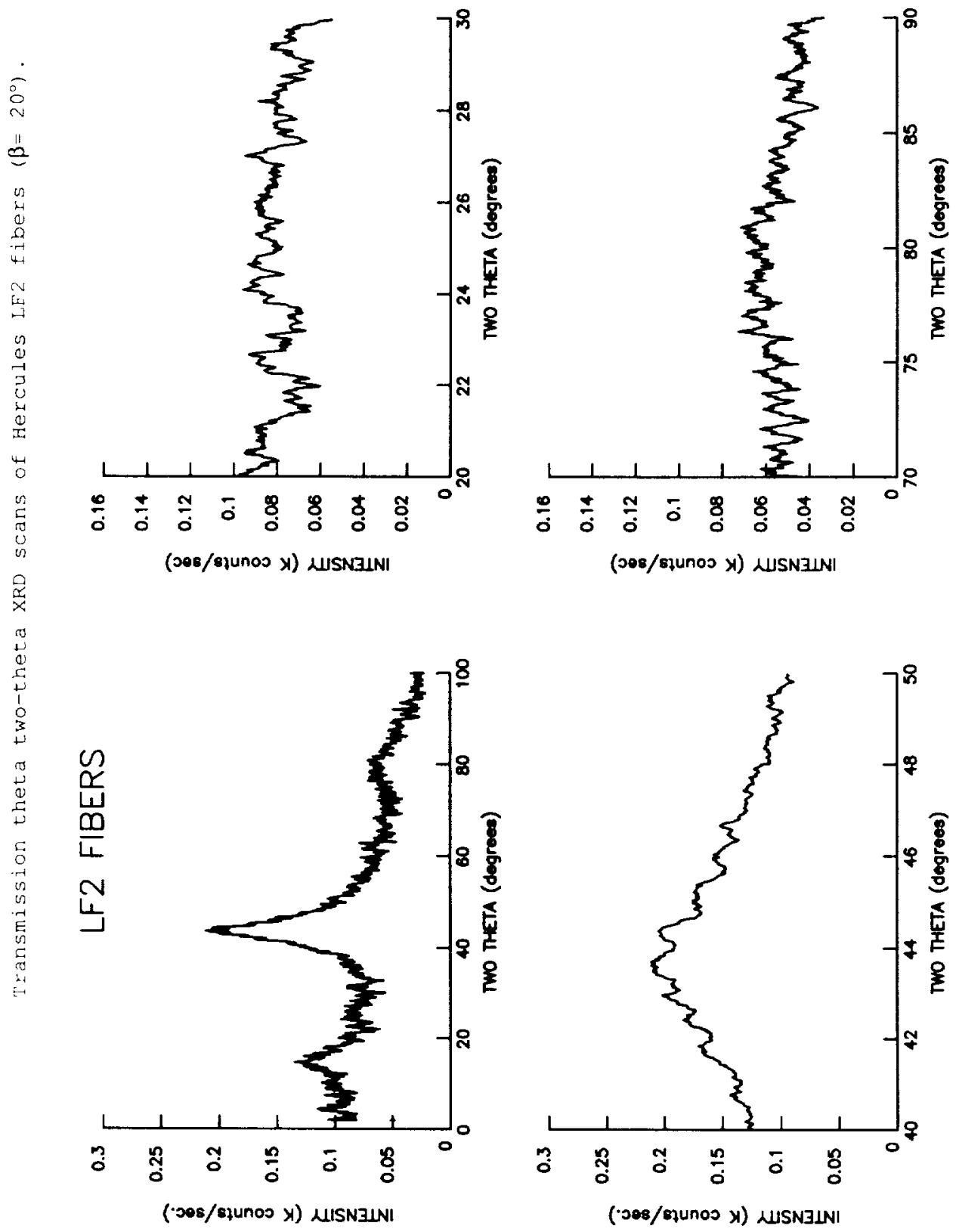


APPENDIX B

\section{PREFERRED-ORIENTATION SCANS}


Plot of fiber orientation angle $(\beta)$ vs. intensity of $\{002\}$ reflection for
Hercules LF1 and LF2 fibers.
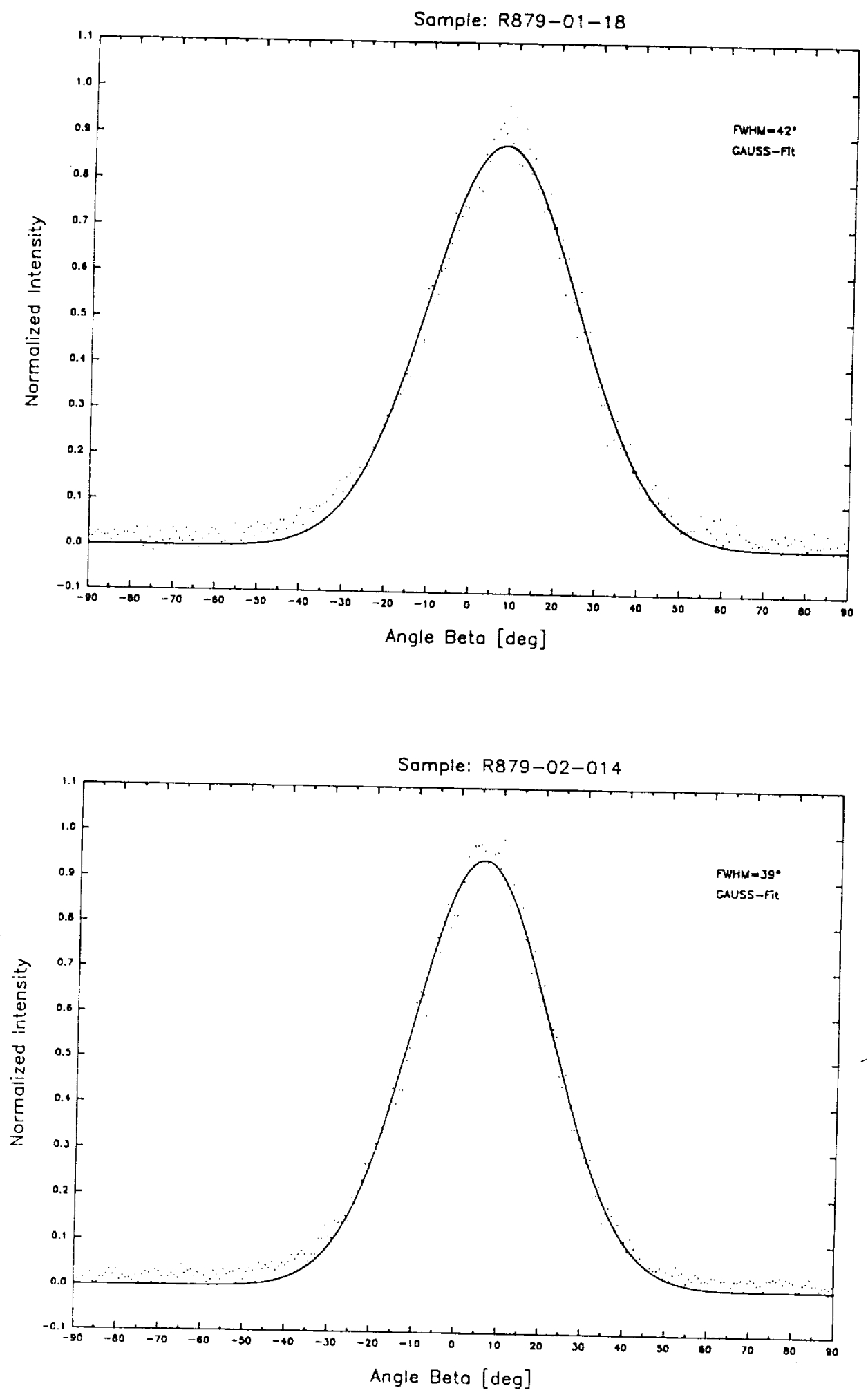
Plot of fiber orientation angle $(\beta)$ vs. intensity of $\{002\}$ reflection for BASF DG1 and DG2 fibers.
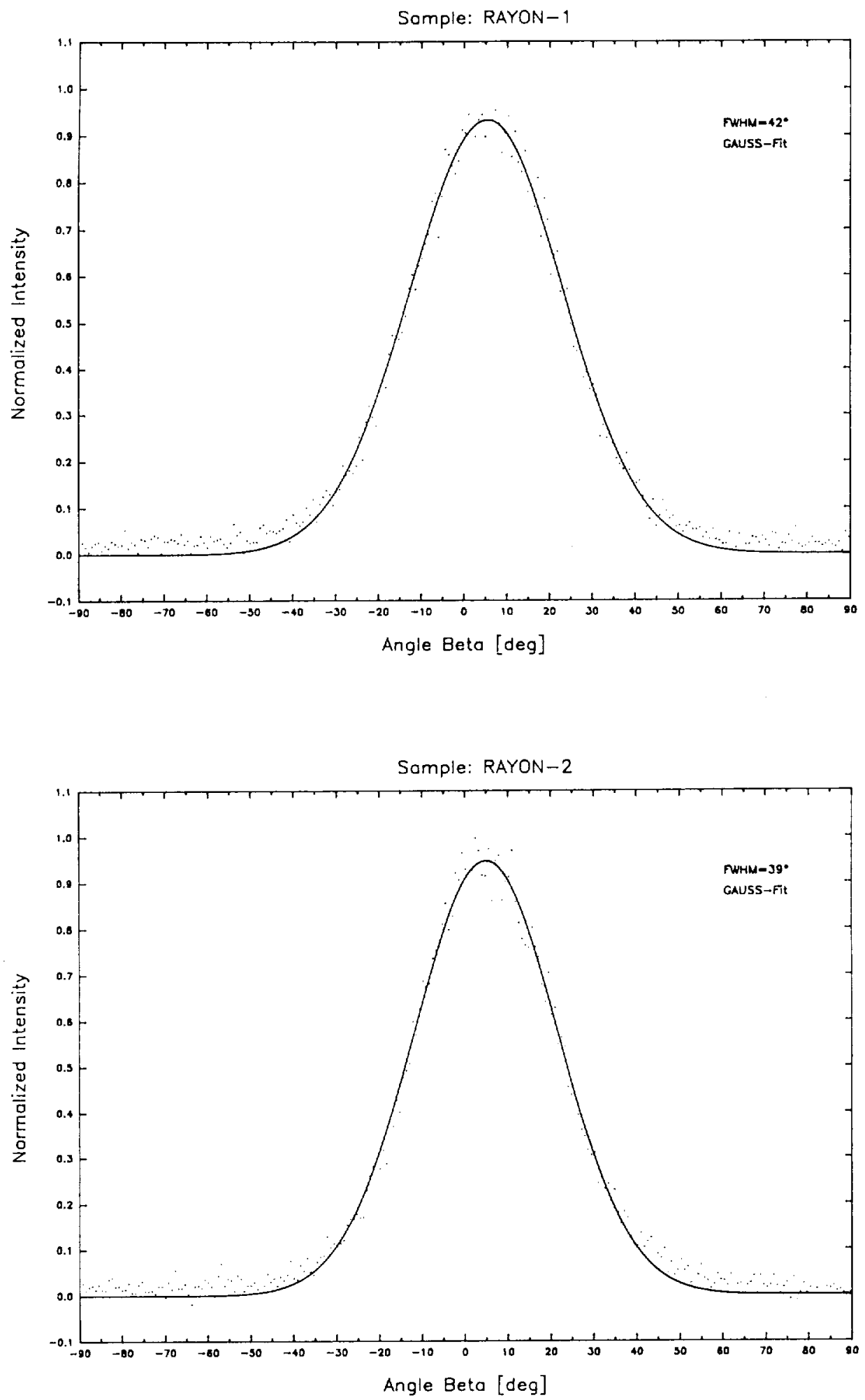
Plot of fiber orientation angle $(\beta)$ vs. intensity of $\{002\}$ reflection for Amoco 23 and 25 fibers.
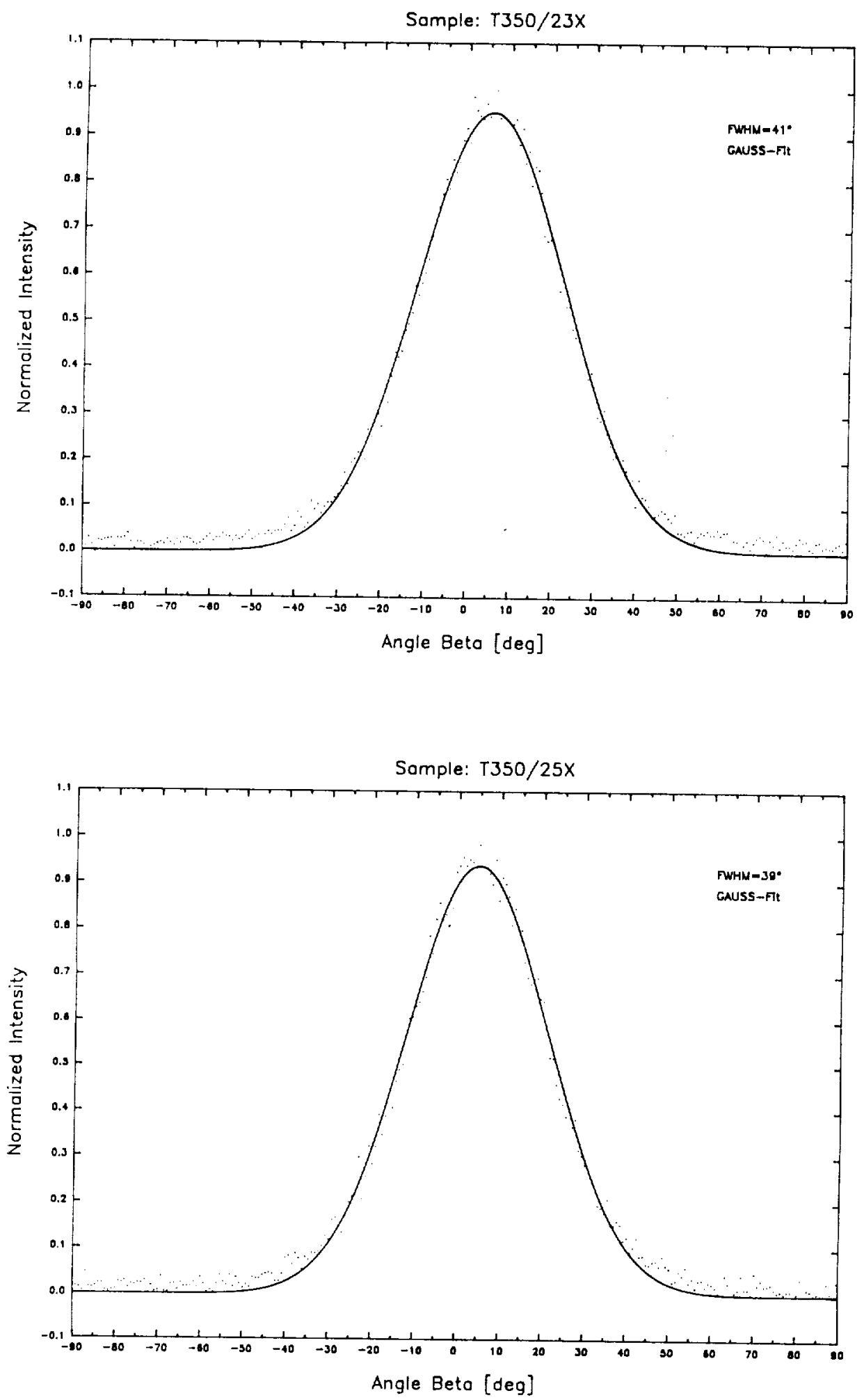
Plot of fiber orientation angle ( $\beta$ ) vs. intensity of 1002 reflection for $A V C A R B$ B2 and $G$ fibers.
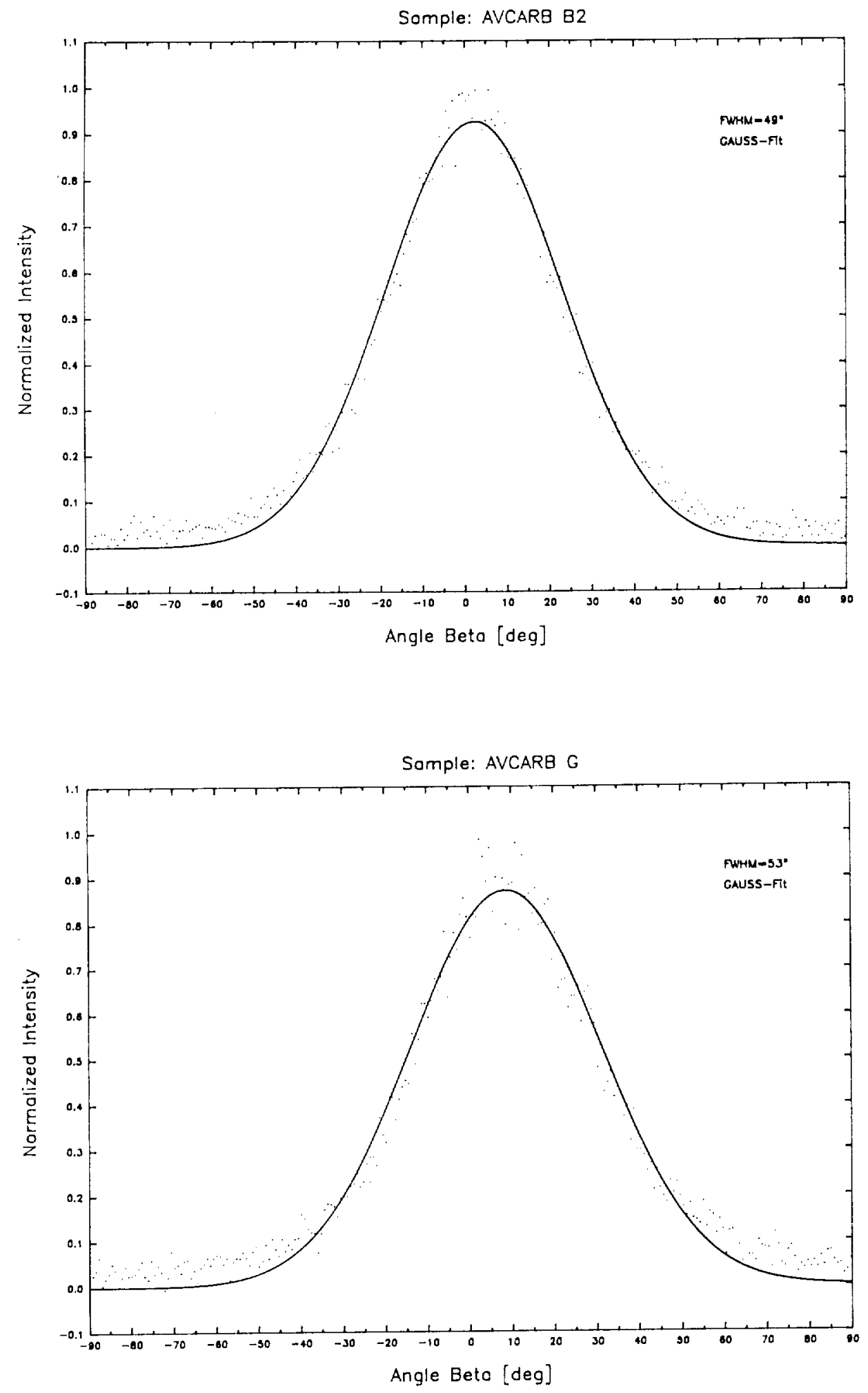


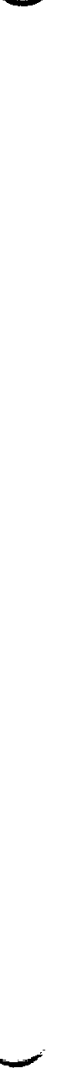

$-$ 
APPENDIX C

SMALL-ANGLE X-RAY SCATTERING PLOTS 


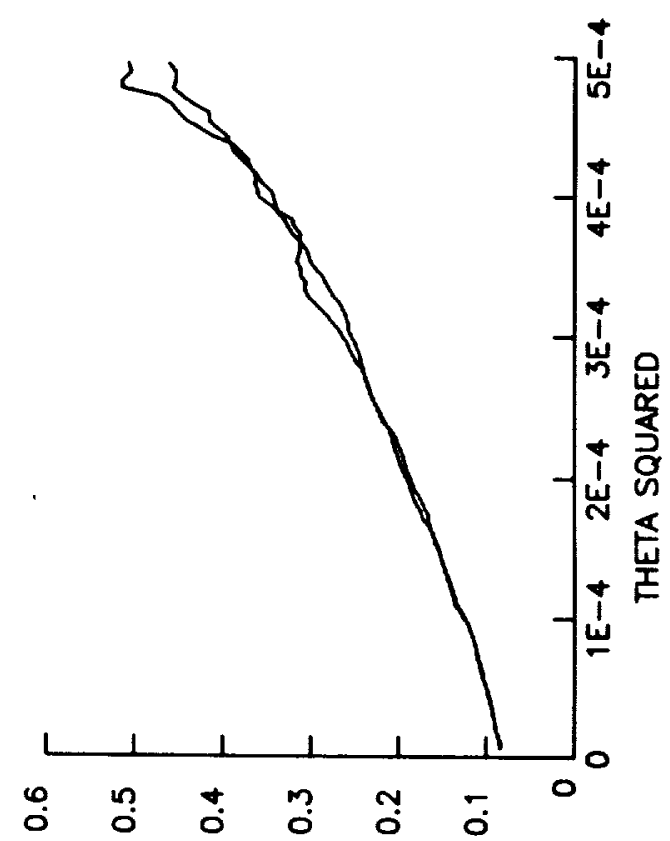

Xł!sue\}u ubs/l

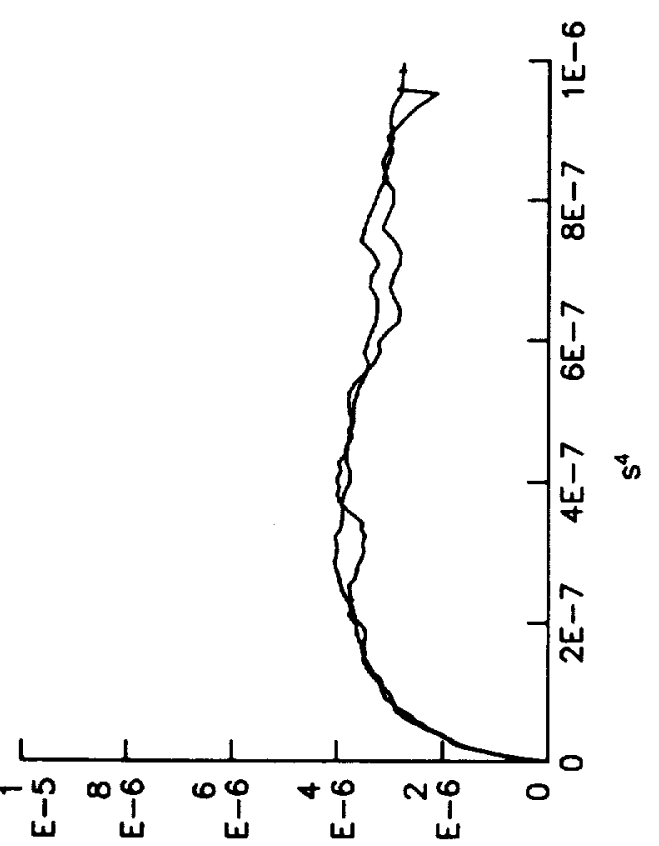

S $X$ LLISNZINI

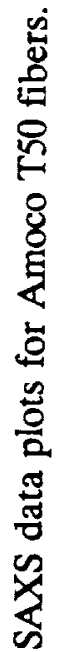

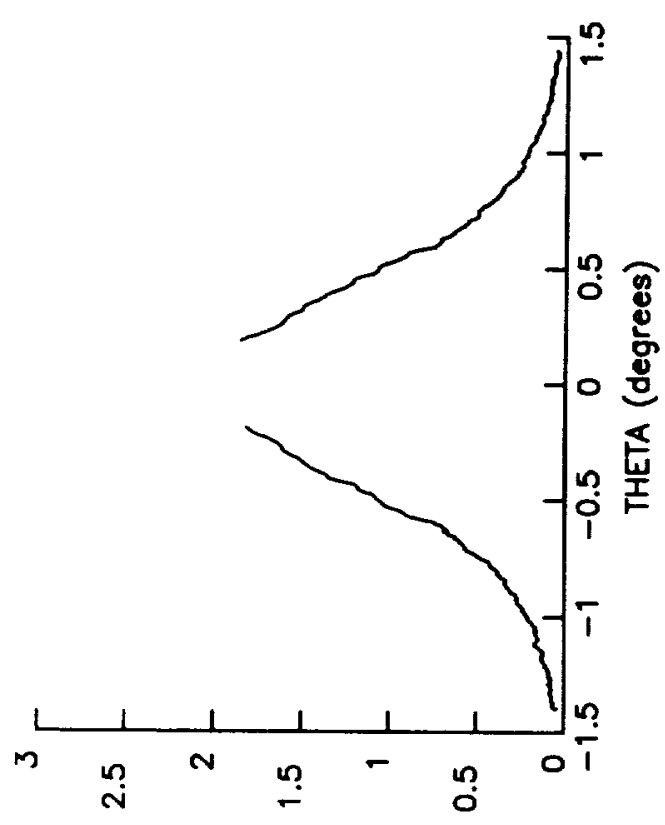

UISNGO ר

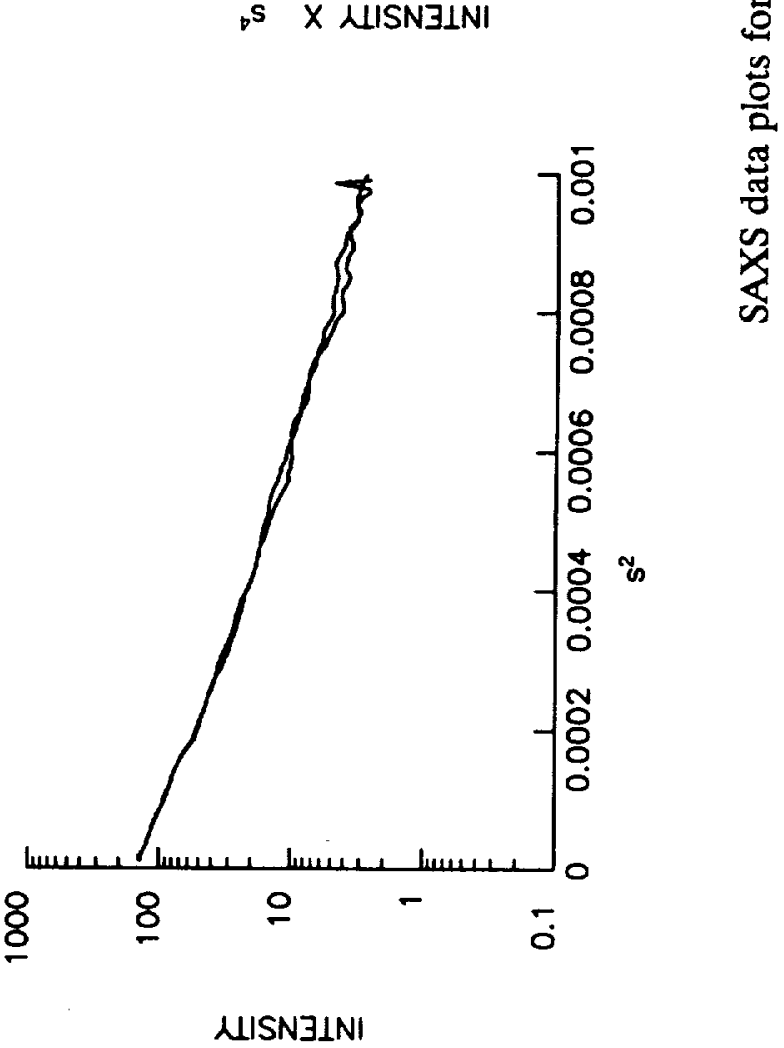




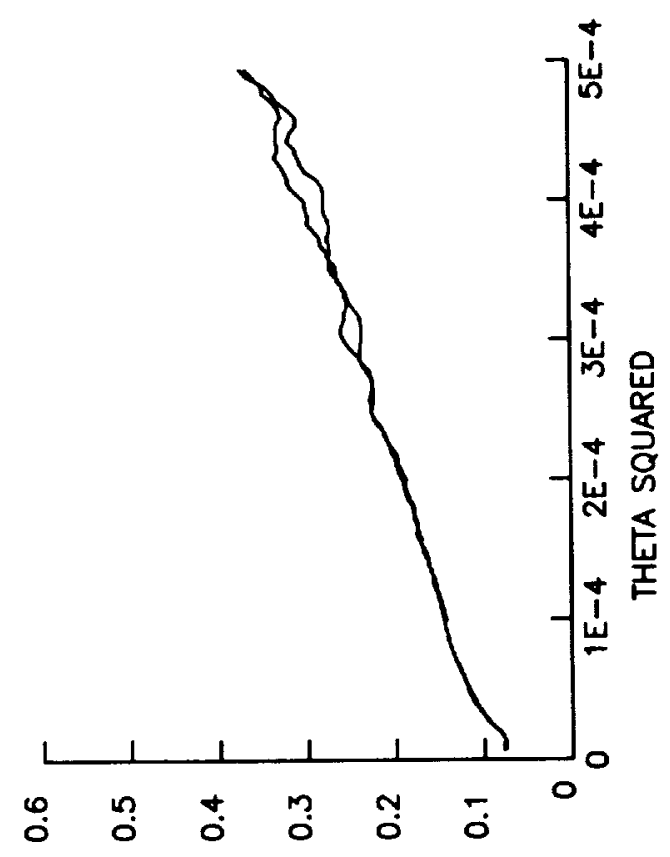

Kł!suąul ubs $/ 1$
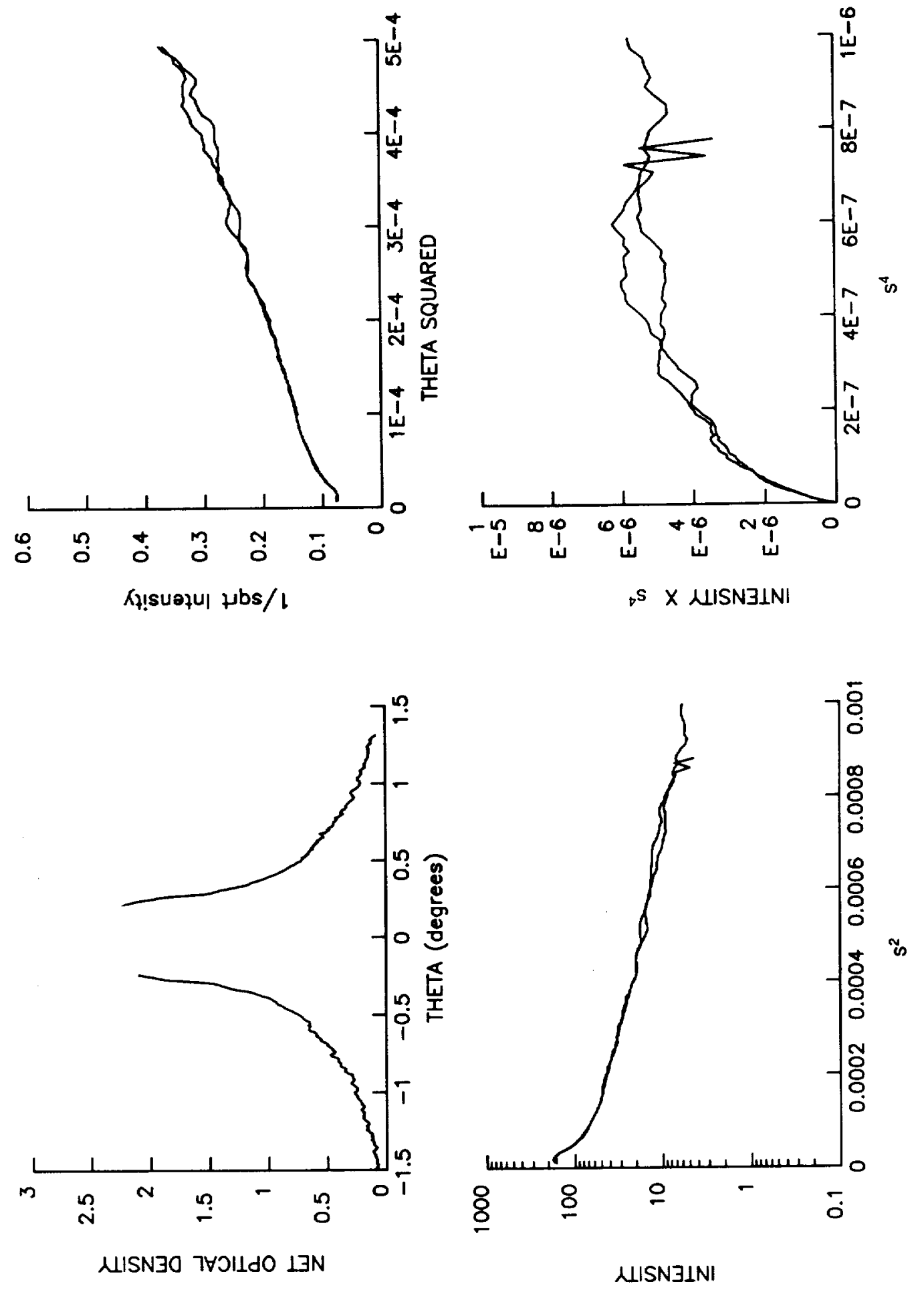

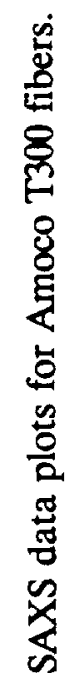



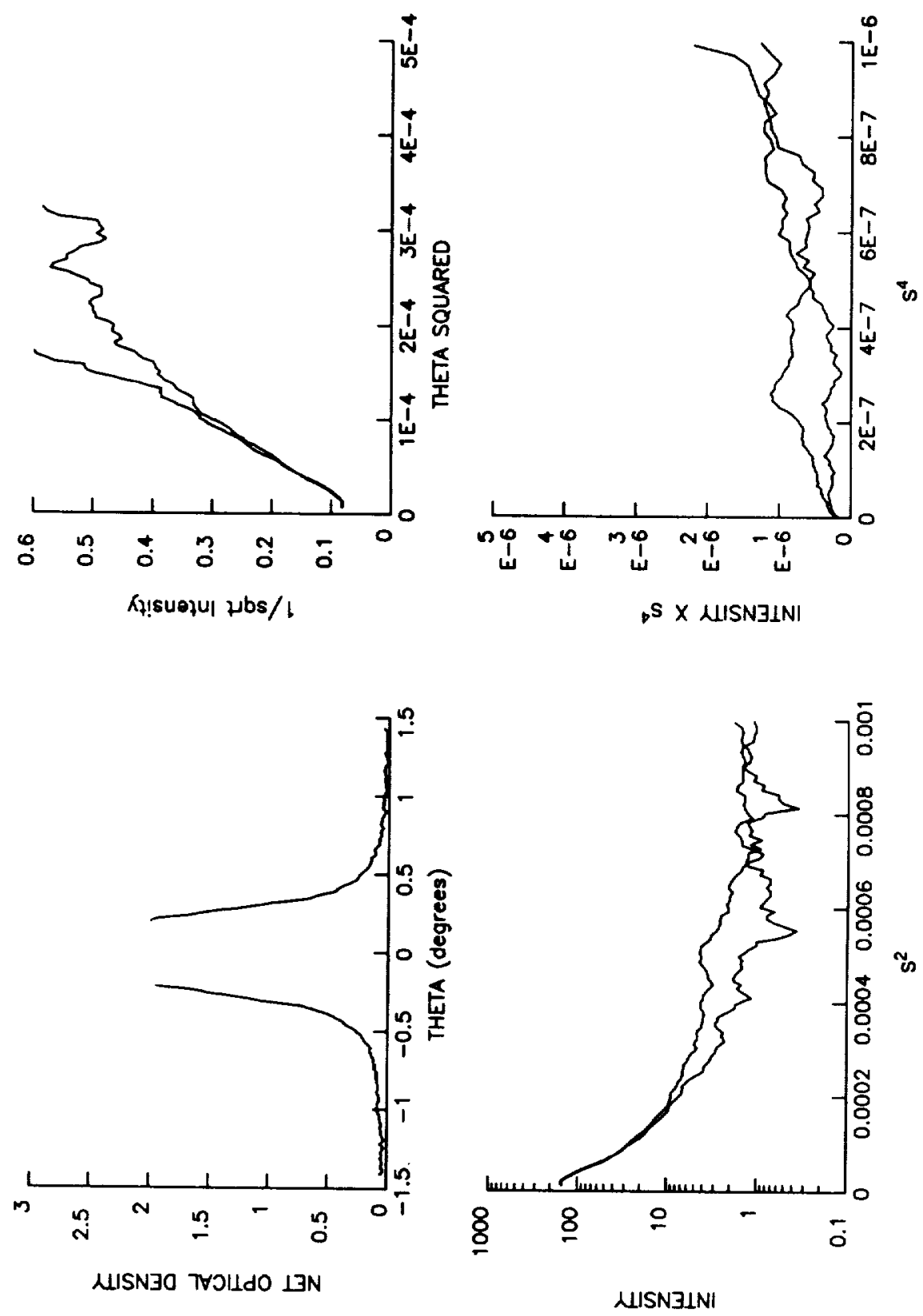

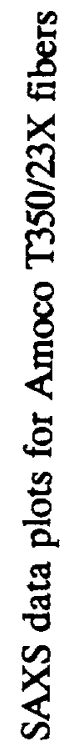



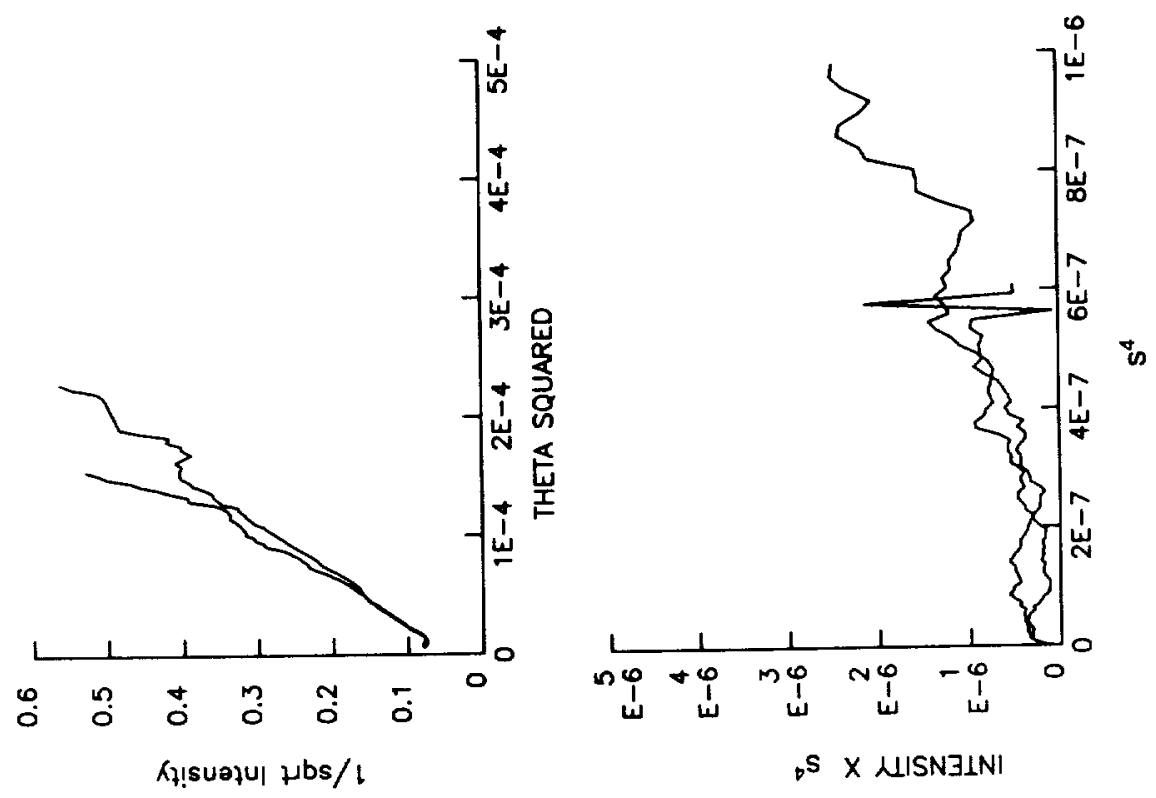

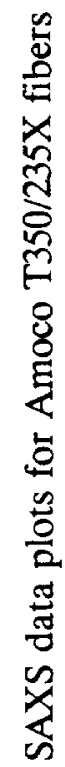
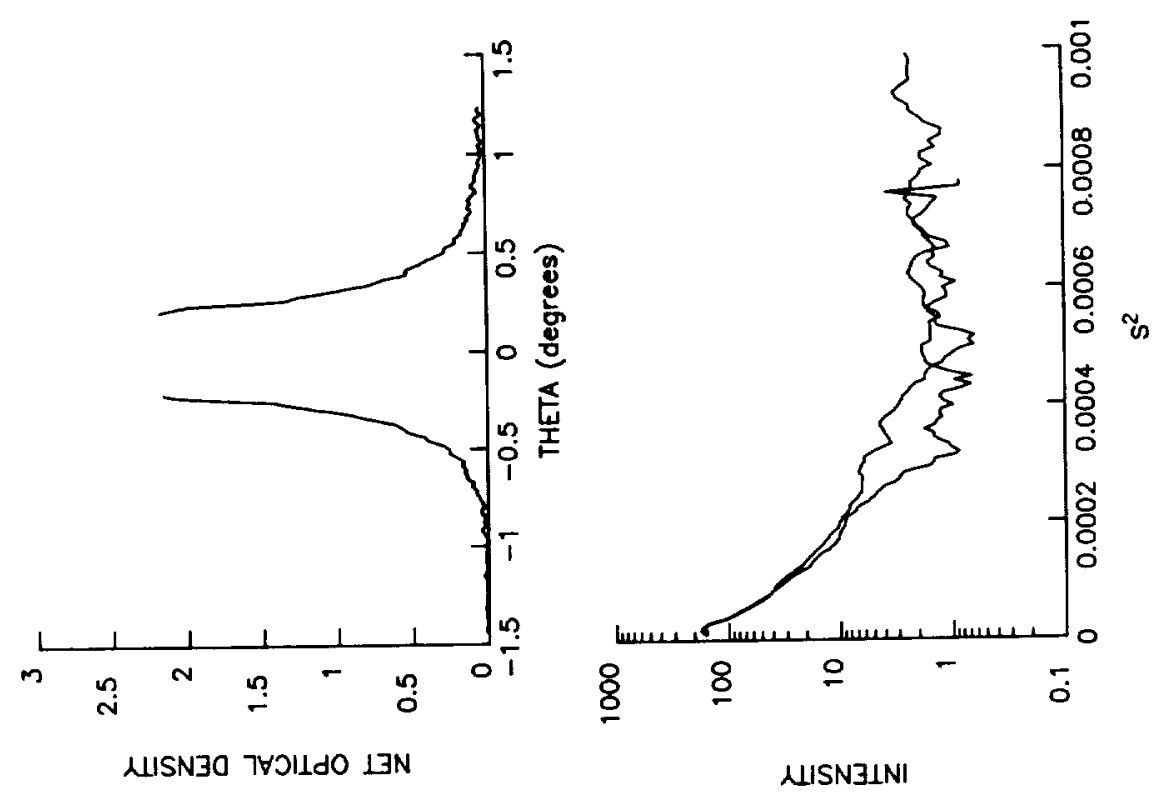

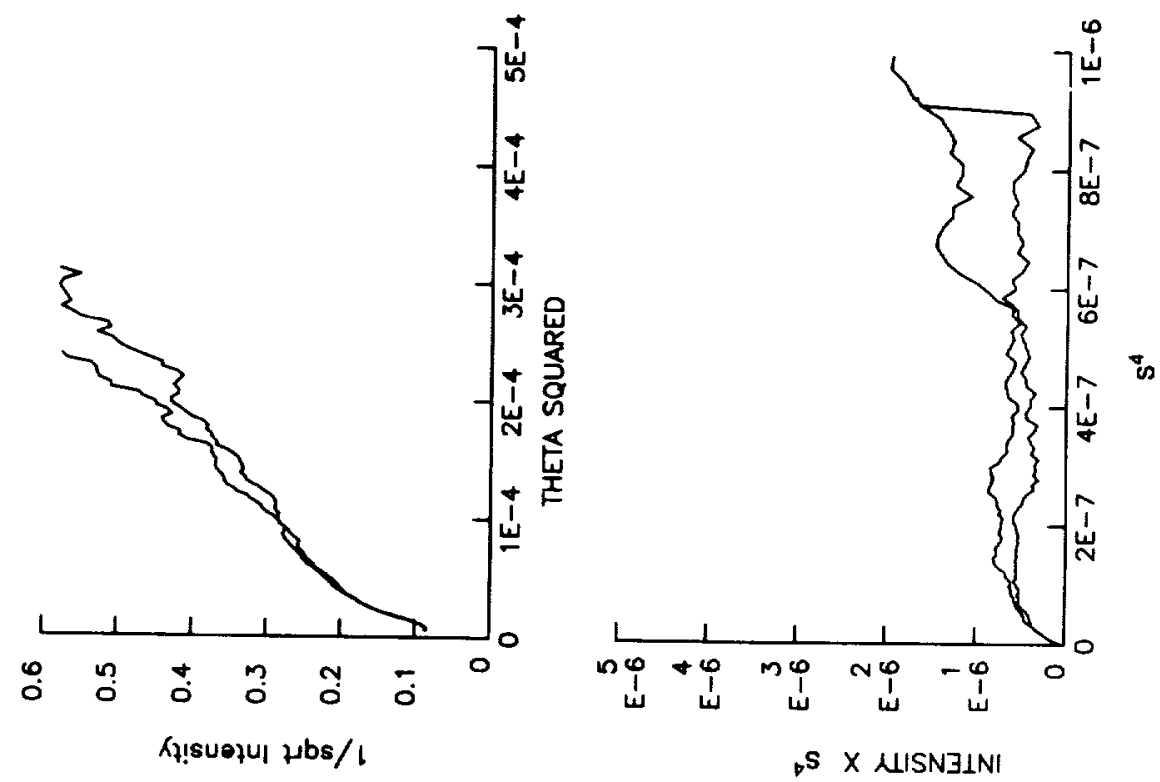

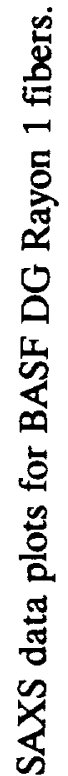
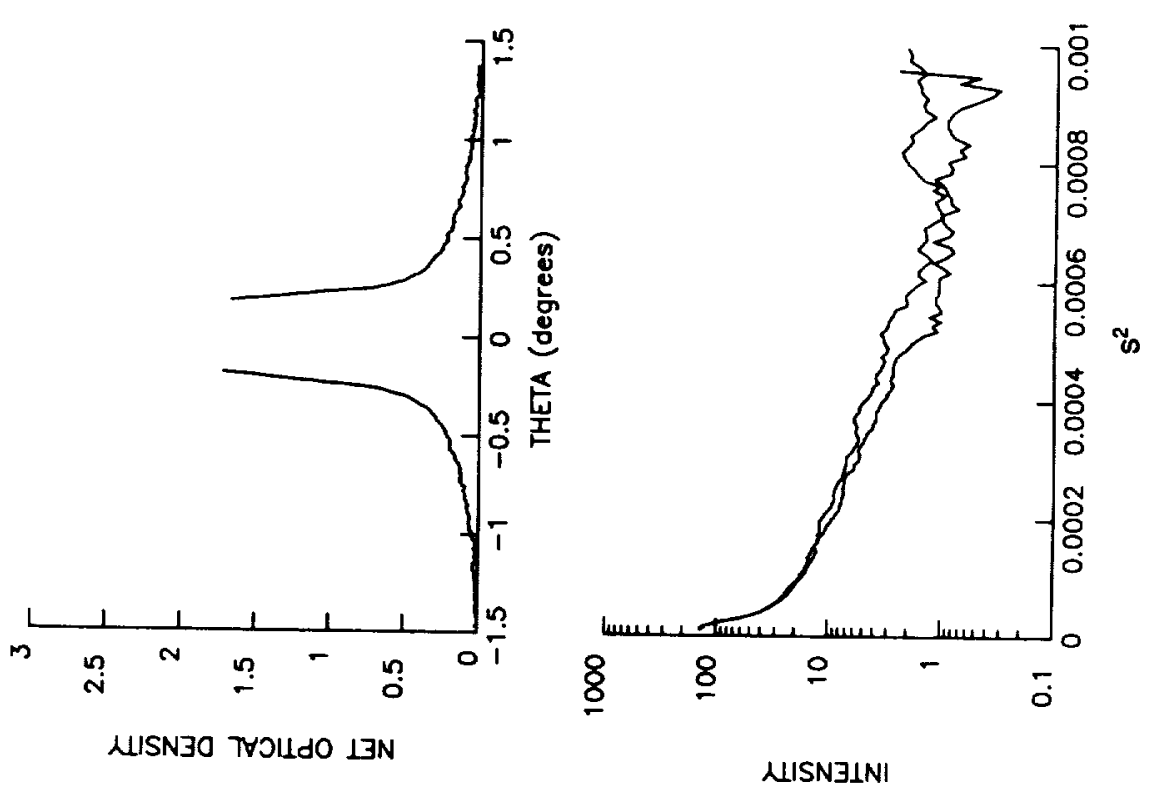


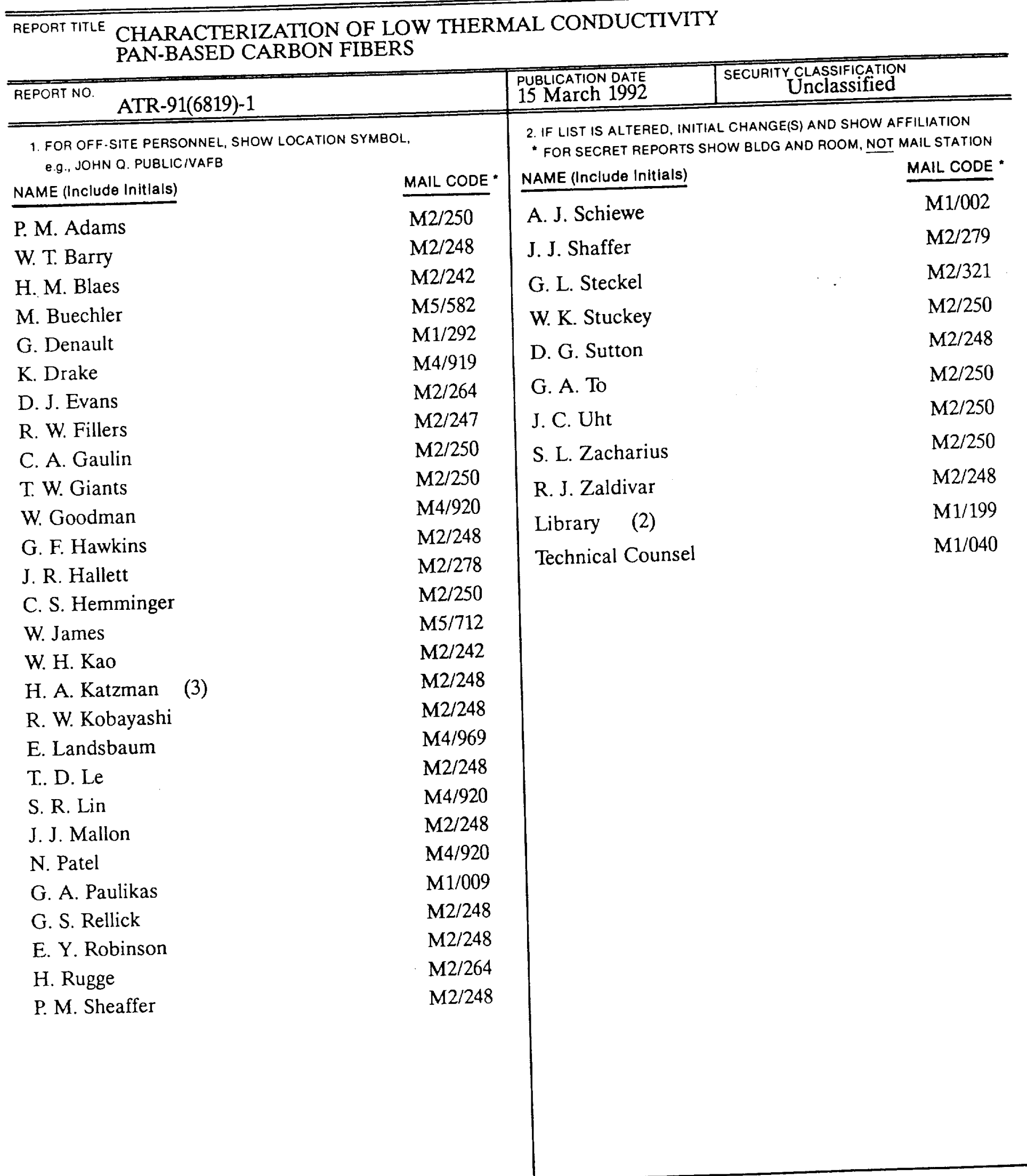


$\sim$

$\sim$ 
EXTERNAL DISTRIBUTION LIST

REPORT TITLE CHARACTERIZATION OF LOW THERMAL CONDUCTIVITY PAN-BASED CARBON FIBERS

\begin{tabular}{|c|c|c|}
\hline $\begin{array}{ll}\text { AEPORT NO. } & \text { ATR-91(6819)-1 } \\
\end{array}$ & $\begin{array}{l}\text { PUBLICATION DATE } \\
15 \text { March } 1992 \\
\end{array}$ & $\begin{array}{r}\text { SECUAITY CLASSIFICATION } \\
\text { Unclassified }\end{array}$ \\
\hline MILITARY AND GOVERNMENT OFFICES & \multicolumn{2}{|c|}{ ASSOCIATE CONTRACTORS AND OTHERS } \\
\hline
\end{tabular}

AF BMO/MYET

Norton Air Force Base, CA 92409-6468

Attn: Lt. R. Einhorn

Phillips Laboratory

Edwards AFB, CA 93533

Attn: J. Wanchek
L. Tepe
J. Buch
B. Wells
PL/RKS
PL/RK

Defense Technical Information Center

Cameron Station (12 unc)

Alexandria, VA 22314

Attn: DTIC-TC

Institute for Defense Analyses

1801 N. Beauregard St.

Alexandria, VA 22311-1772

Attn: Library

J. Hovey

\section{AF/SSD}

Attn: Col. Randma

Jet Propulsion Laboratory

4800 Oak Grove Drive

Pasadena, CA 91103

Attn: W. Phillips

Library

Naval Surface Warfare Center

10901 New Hampshire Ave.

Silver Spring, MD 20903-5000

Attn: A. L. Bertram R32
Acurex Corp.

PO Box 7040

Mountain View, CA 94039

Attn: B. Laub

Aerojet Strategic Propulsion Co.

PO Box 15699C

Sacramento, CA 95813

Attn: S. C. Brown

KETEMA<smiles>C1=CCCCC1</smiles>

3611 S. Harbor Blvd. Suite 225

Santa Ana, CA 92704-6928

Attn: J. Garibotti

T. Lascarus

AMOCO Performance Products, Inc.

4500 McGinnis Ferry Road

Alpharetta, GA 30202

Attn: R. Bacon

M. Towne

C. McGuire

AMOCO Performance Products, Inc.

375 Northridge Road Suite 600

Atlanta, GA 30350-3297

Attn: L. Matthews

Atlantic Research Corporation

5390 Cherokee Avenue

Alexandria, VA 22312

Attn: J. Baetz

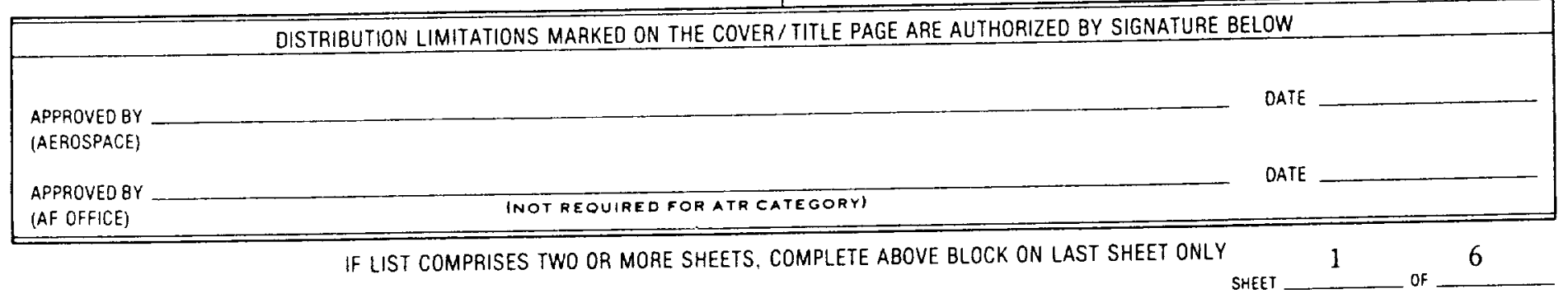


EXTERNAL DISTRIBUTION LIST

REPORT TITLE CHARACTERIZATION OF LOW THERMAL CONDUCTIVITY PAN-BASED CARBON FIBERS

\begin{tabular}{|c|c|c|c|}
\hline REPORTNO & ATR-91(6819)-1 & $\begin{array}{l}\text { PUBLICATION DATE } \\
15 \text { March } 1992\end{array}$ & $\begin{array}{r}\text { SECURITY CLASSIFICATION } \\
\text { Unclassified }\end{array}$ \\
\hline & MILITARY AND GOVERNMENT OFFICES & \multicolumn{2}{|c|}{ ASSOCIATE CONTRACTORS AND OTHERS } \\
\hline
\end{tabular}

NASA

Ames Research Center

Moffett Field, CA 94035

Attn: Library

NASA

Marshal Space Flight Center

Huntsville, AL 35812

Attn: R. G. Clinton, Code EH 34 Library

A. Puckett, Code EH 34

R. Nichols, Code ER 41

M. Stucker, Code ER 41

B. Neighbors

NASA Scientific \& Technical Information Facility

PO Box 8757

Baltimore-Washington International Airport

MD 21240

Attn: SAK/DL

Office of Naval Technology

800 N. Quincy St.

Arlington, VA 22217-5000

Attn: W. Messick
BF Goodrich Research \& Development Center

9921 Brecksville Road

Brecksville, OH 44141

Attn: E. R. Stover

BF Goodrich

11120 Norwalk Blvd.

Santa Fe Springs, CA 90670

Attn: W. H. Pfeifer

G. B. Engle

W. Terasen

General Electric

3198 Chestnut St.

Philadelphia, PA 19101

Attn: R. Randolph

Hercules Aerospace Co.

PO Box 98

Magna, UT 84044-0098

Attn: J. P. George

S. Lewis

C. M. Heyborne, M/S B2

K. H. Hill, M/S B2

J. Larson, M/S B2

F. P. Magin, M/S X11T1

H. M. Pressley, Jr., M/S B2

G. M. Wendel, M/S N1EQ1

Lockheed Palo Alto Research Laboratory

3251 Hanover St.

Palo Alto, CA 94304-1191

Attn: P. C. Pinoli, Org 93-30, Bldg 204

F. C. Weiler, Org 93-30, Bldg 251

Materials Sciences Corporation

930 Harvest Drive, Suite 300

Union Meeting Corporate Center

Blue Bell, PA 19477

Attn: J. J. Kibler

B. J. Sullivan

DATE

DATE 
EXTERNAL DISTRIBUTION LIST

REPORT TITLE CHARACTERIZATION OF LOW THERMAL CONDUCTIVITY

PAN-BASED CARBON FIBERS

\begin{tabular}{|c|c|c|c|}
\hline REPORT NO. & ATR-91(6819)-1 & $\begin{array}{l}\text { PUBLICATION DATE } \\
15 \text { March } 1992\end{array}$ & $\begin{array}{r}\text { SECURITY CLASSIFICATION } \\
\text { Unclassified }\end{array}$ \\
\hline & MILITARY AND GOVERNMENT DFFICES & \multicolumn{2}{|c|}{ ASSOCIATE CONTRACTORS AND OTHERS } \\
\hline
\end{tabular}

Office of Director of Defense for Research \&

Engineering

The Pentagon

Washington, DC 20301

Attn: J. Persh

Staff Specialist for Materials \& Structures

Room 3D1089

Office of Naval Research

800 N. Quincy St.

Arlington, VA 22217-5000

Attn: S. Fishman, Code 1131

SSD/AFWAL

Attn: P. Propp

U.S. Army Materials Technology Laboratory

Watertown, MA 02172

Attn: J. Dignam

S. Wentworth

Wright Laboratory

Wright-Patterson AFB

Dayton, $\mathrm{OH} 45433$

Attn: D. Schmidt

AFIT

Wright-Patterson AFB, OH 45433

Attn: Technical Library

U.S. Army Ballistic Missile Agency

Technical Documents Library

Redstone Arsenal, AL 35809

Attn: Commander

Prototype Development Assoc., Inc.

2975 Redhill Ave.

Costa Mesa, CA 92626

Attn: J. G. Crose

Southern Research Institute

PO Box 55305

Birmingham, AL 35255-5305

Attn: J. Koenig

C. Pears

W. Lundblad

Science Applications Intl. Corp.

18872 Bardeen Ave.

Irvine, CA 92715

Attn: W. C. Loomis

F. I. Clayton

TRW/EDC

PO Box 1310

San Bernardino, CA 92402

Attn: B. Balachandra

T. Serafini

Union Carbide Corporation

Parma Technical Center

PO Box 6116

Cleveland, OH 44101

Attn: S. Strong

United Technologies Corporation

Chemical Systems Division

PO Box 49028

San Jose, CA 95161-9028

Attn: E. R. Mills

AFSC (DLF)

Andrews AFB, DC 20331

DATE

(AEROSPACE)

INOT REOUIAEO FOR ATR CATEGORY

DATE 
EXTERNAL DISTRIBUTION LIST

CEPORT TITLE CHARACTERIZATION OF LOW THERMAL CONDUCTIVITY
PAN-BASED CARBON FIBERS

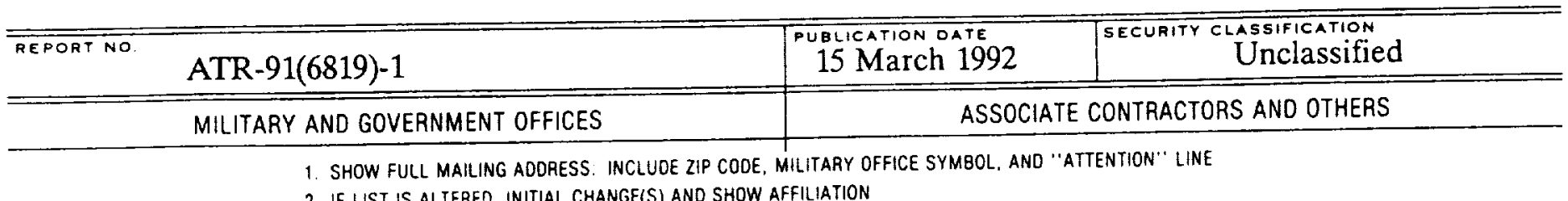

1. SHOW FULL MAILING AOORESS. INCLUDE ZIP CODE, MILITARY OFFI
2. IF LIST IS ALTEREO. INITIAL CHANGE(S) AND SHOW AFFILIATION

BASF Structural Materials, Inc.

Celion Carbon Fibers

11501 Steele Creek Rd.

PO Box 7687

Charlotte, NC 28241

Attn: K. Bloomer

Aerojet Corp

1 NASA Drive

Iuka, MS 38852-8998

Attn: W. Armour

US Polymeric

700 East Dyer Rd.

Santa Ana, CA 92702

Attn: D. Beckley

Thiokol Corp.

MSFC, AL 35812

Attn: R. Bunker, Bldg 4708, Room 254

Thiokol Corp. Wasatch Division

Advanced Technology

PO Box 707

Brigham City, UT 84302-0707

Attn: A. Canfield

Kaiser Aerotech

880 Doolittle Drive

San Leandro, CA 94577

Attn: H. O. Davis

Thiokol Corp.

6767 Old Madison Pike, Suite 490

Huntsville, AL 35806

Attn: T. Day

ICI Fiberite

4500 South 575 East, Suite B-100

Murray, UT 84107

Attn: N. DiMeo

DISTRIBUTION LIMITATIONS MARKED ON THE COVER/TITLE PAGE ARE AUTHORIZEO BY SIGNATURE BELOW

DATE

(AEROSPACE)

DATE

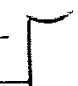


EXTERNAL DISTRIBUTION LIST

CEAPOR TITLE
PAN-BASED CARBON FIBERS

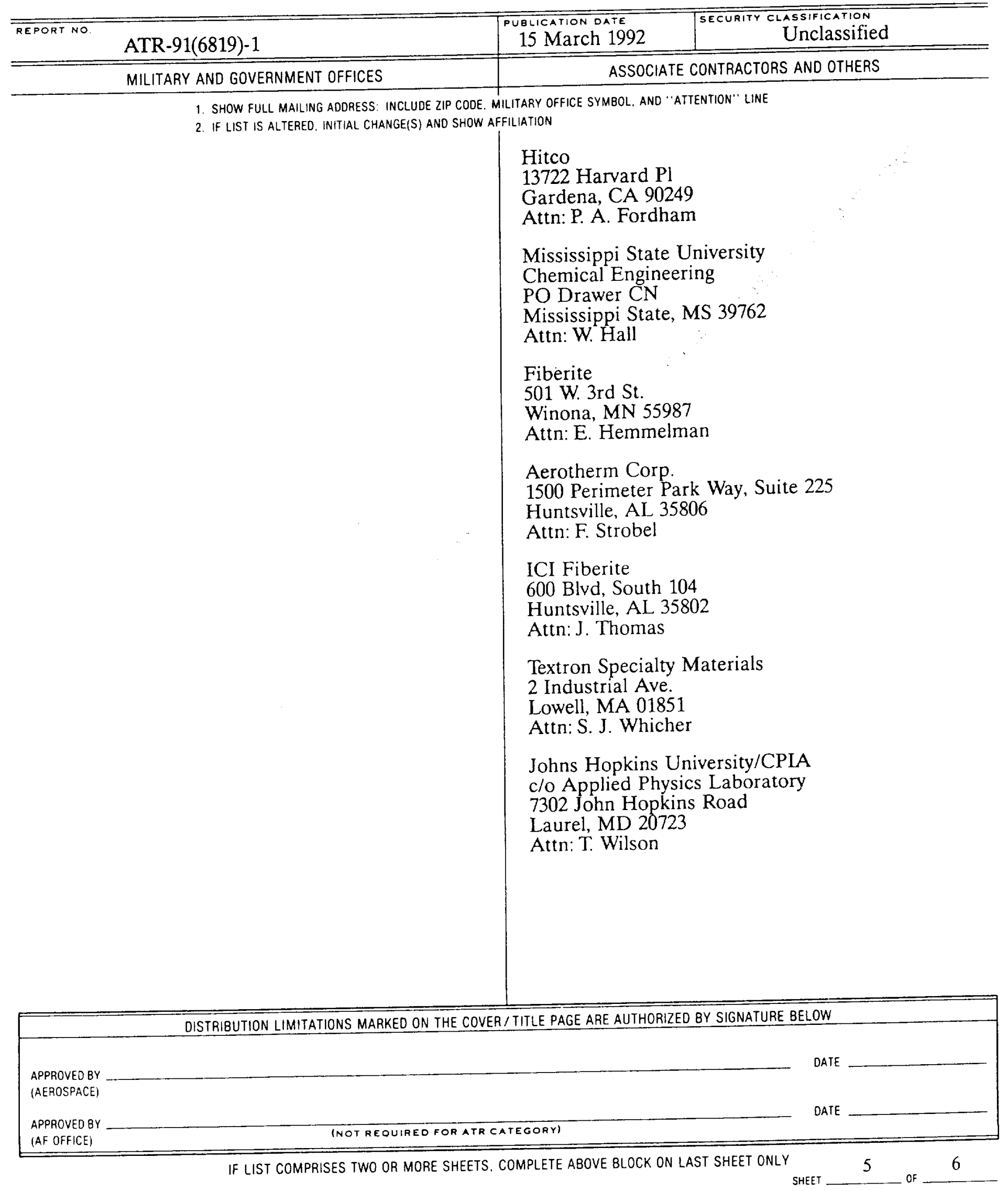


EXTERNAL DISTRIBUTION LIST

REPORT TITLE CHARACTERIZATION OF LOW THERMAL CONDUCTIVITY

PAN-BASED CARBON FIBERS

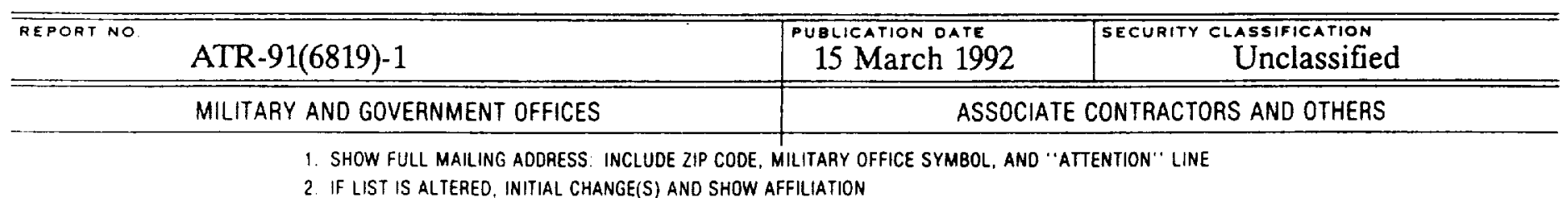

Reinhold Industries

12827 E. Imperial Highway

Santa Fe Springs, CA 90670

Attn: R. Pegg

OISTRIBUTION LIMITATIONS MARKED ON THE COVER/TITLE PAGE ARE AUTHORIZED BY SIGNATURE BELOW

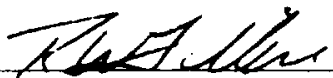

DATE

DATE 

